\title{
SWEET SIXTEEN AND NEVER BEEN DRUNK?
}

ADOLESCENT ALCOHOL USE, PREDICTORS AND CONSEQUENCES

Joris J. van Hoof 
Thesis, University of Twente

ISBN: 978-90-365-3092-7

Van Hoof, J. J. (2010). Sweet Sixteen and Never Been Drunk? Adolescent Alcohol Use, Predictors and Consequences. Enschede, The Netherlands: University of Twente.

Cover design: Marleen Mulder-Wieske

Printed by: Gildeprint B.V., Enschede 


\section{SWEET SIXTEEN AND NEVER BEEN DRUNK?}

ADOLESCENT ALCOHOL USE, PREDICTORS AND CONSEQUENCES

\section{PROEFSCHRIFT}

ter verkrijging van

de graad van doctor aan de Universiteit Twente,

op gezag van de rector magnificus,

prof. dr. H. Brinksma,

volgens besluit van het College voor Promoties

in het openbaar te verdedigen

op vrijdag 12 november 2010 om 13.15 uur

door

Joris Jasper van Hoof

geboren op 1 november 1979

te Geldrop 
Dit proefschrift is goedgekeurd door de promotor: prof. dr. M. D. T. de Jong 


\section{Contents}

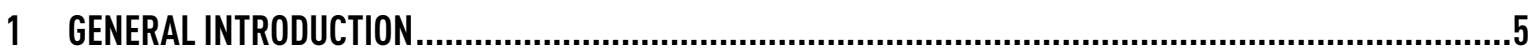

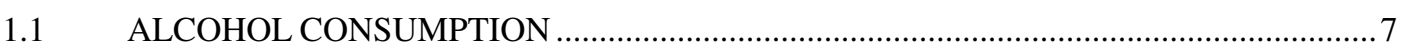

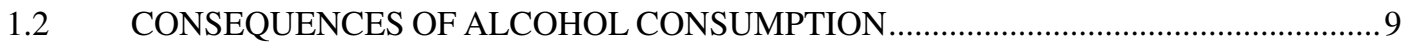

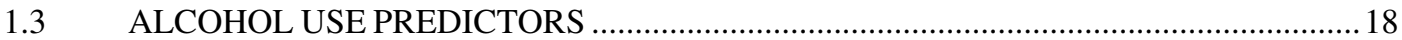

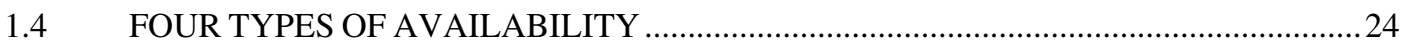

1.5 CONCEPTUAL MODEL AND OUTLINE OF THE STUDIES ……………......................2.

2 ADOLESCENT ALCOHOL INTOXICATION IN THE DUTCH HOSPITAL DEPARTMENTS OF PEDIATRICS. .33

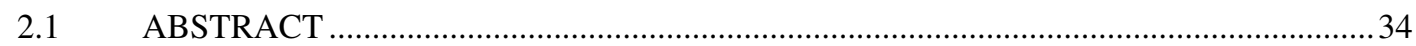

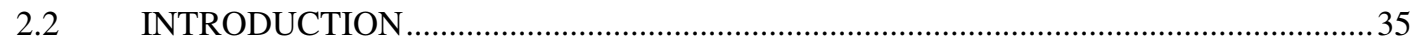

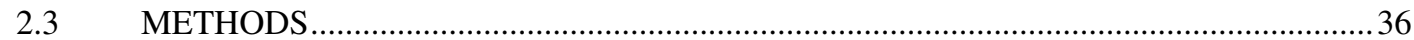

$2.4 \quad$ RESULTS

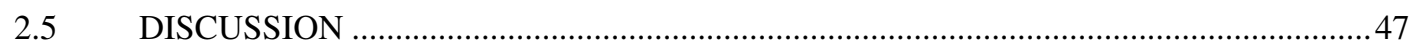

3 ADOLESCENT ALCOHOL INTOXICATION IN THE DUTCH HOSPITAL DEPARTMENTS OF PEDIATRICS; A TWO-YEAR COMPARISON STUDY.

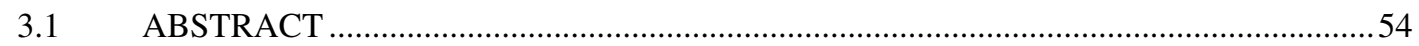

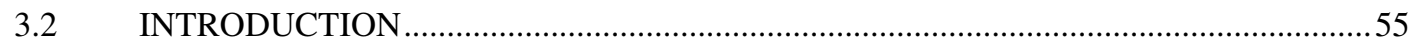

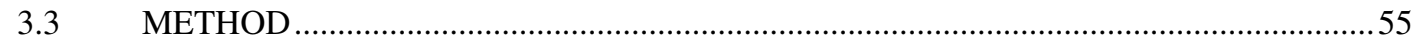

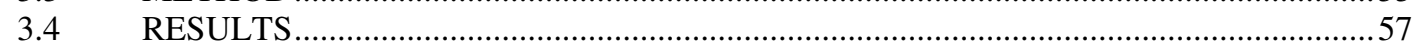

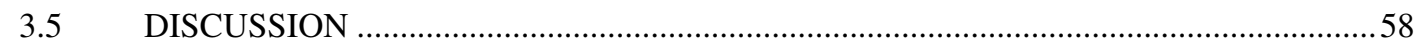

4 MAKING SENSE OF ALCOHOL EXPERIENCES. YOUNG ADOLESCENTS' ACCOUNTS OF ALCOHOL-

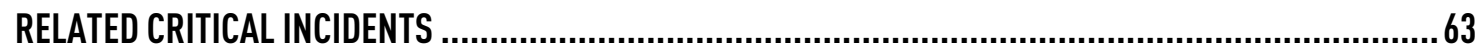

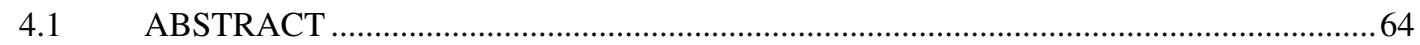

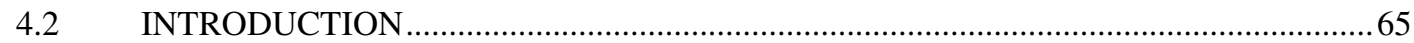

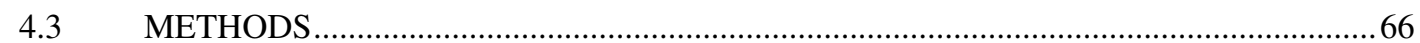

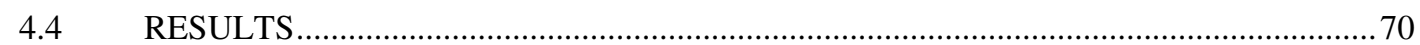

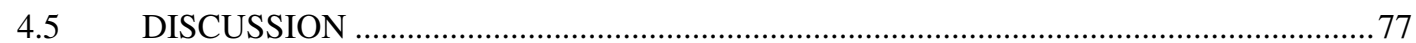

5 DETERMINANTS OF PARENTAL SUPPORT FOR GOVERNMENTAL ALCOHOL CONTROL POLICIES..

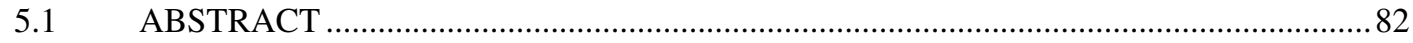

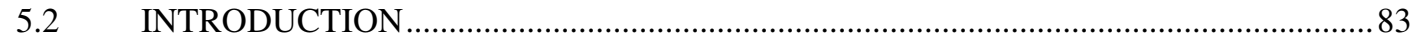

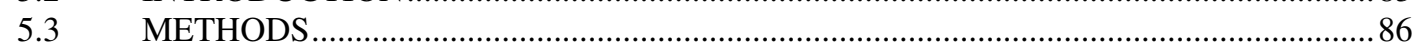

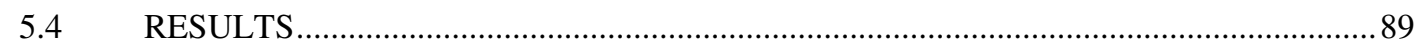

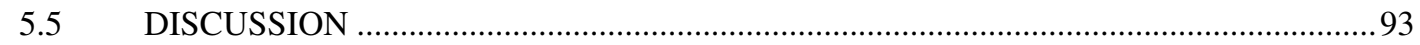

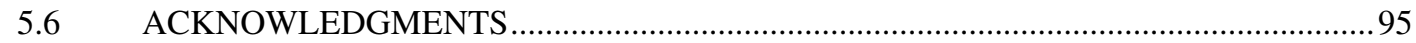


6 THERE'S ALCOHOL IN MY SOAP: PORTRAYAL AND EFFECTS OF ALCOHOL USE IN A POPULAR

TELEVISION SERIES

99

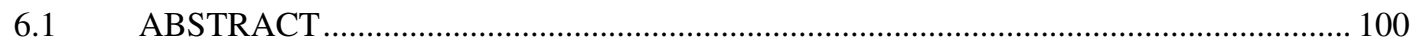

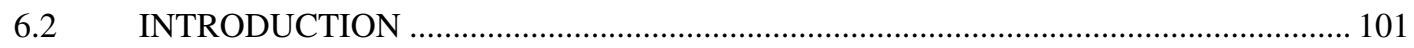

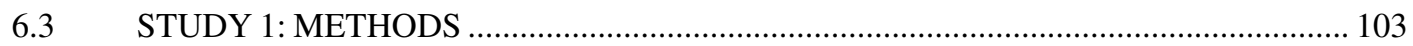

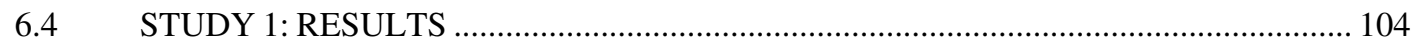

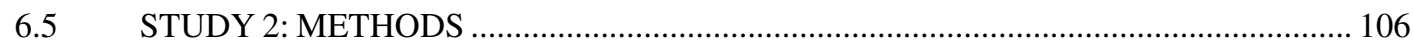

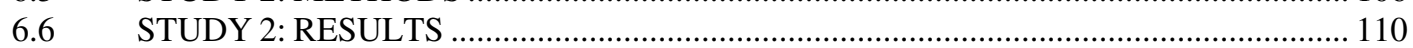

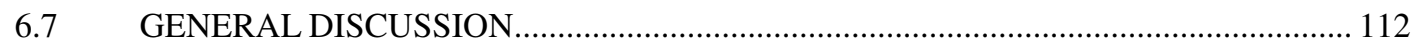

7 HAPPY HOURS AND OTHER ALCOHOL DISCOUNTS IN CAFÉS: PREVALENCE AND EFFECTS ON UNDERAGE ADOLESCENTS .

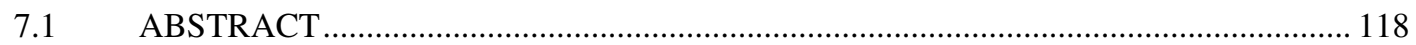

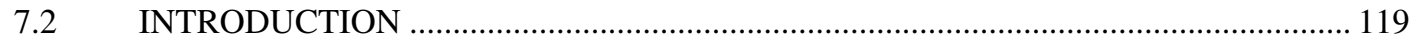

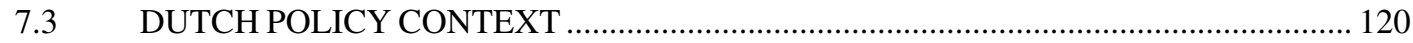

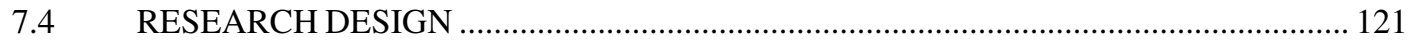

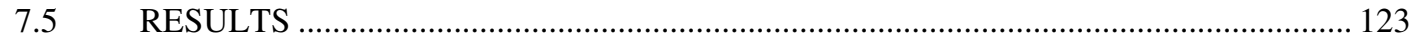

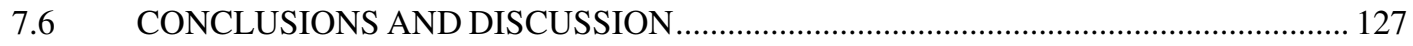

8 ADOLESCENT PRIVATE DRINKING PLACES: PREVALENCE, ALCOHOL CONSUMPTION, AND OTHER RISK BEHAVIOURS.

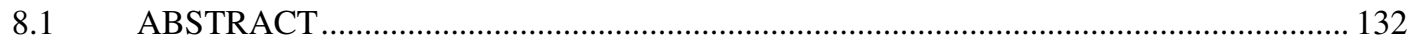

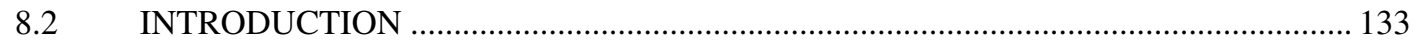

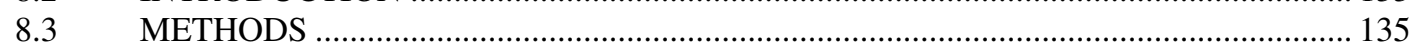

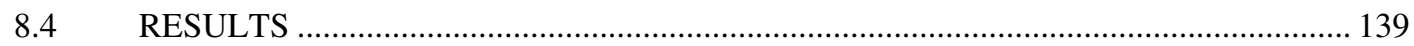

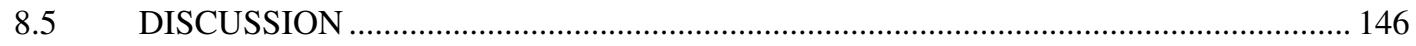

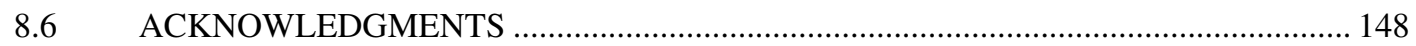

9 MYSTERY SHOPPING AND ALCOHOL SALES: DO SUPERMARKETS AND LIQUOR STORES SELL ALCOHOL TO UNDERAGE CUSTOMERS?

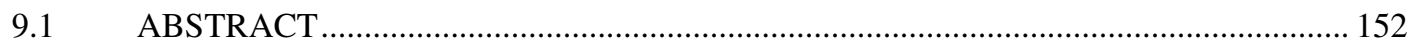

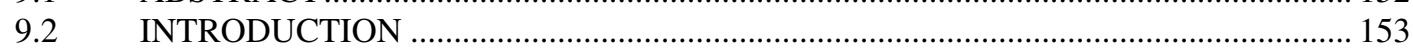

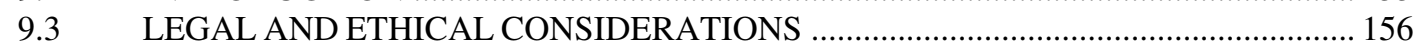

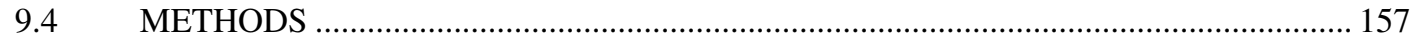

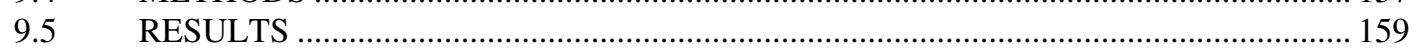

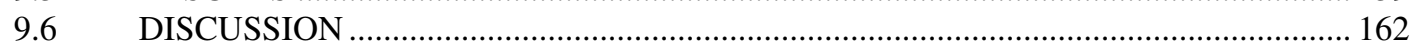


10 IMPROVING SHOP FLOOR COMPLIANCE WITH AGE RESTRICTIONS FOR ALCOHOL SALES: THE EFFECTIVENESS OF A FEEDBACK LETTER INTERVENTION. ........................................................ 167

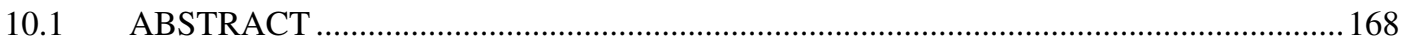

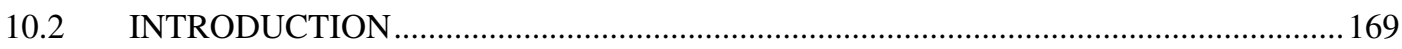

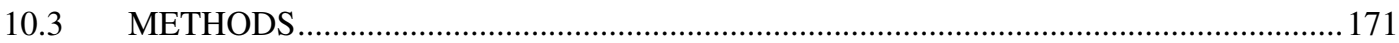

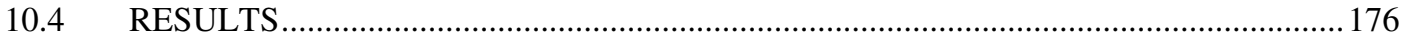

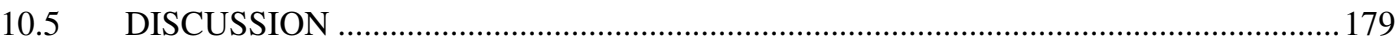

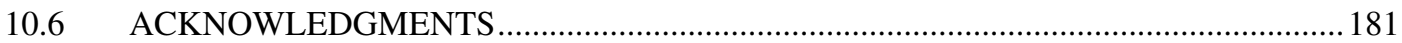

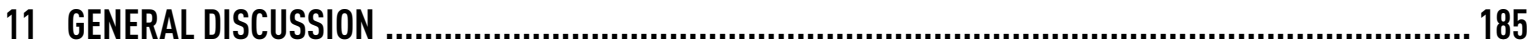

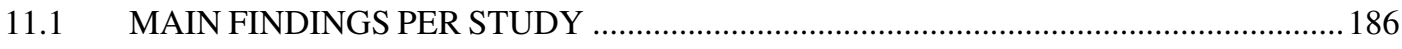

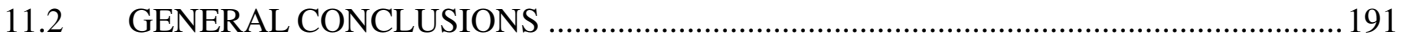

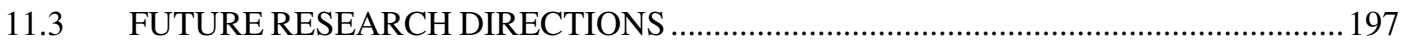

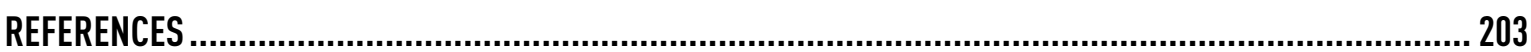

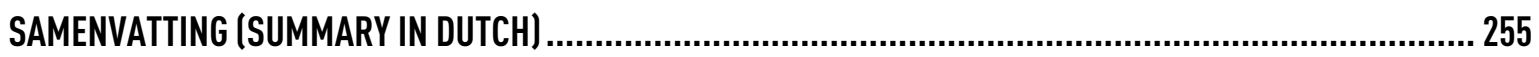


"I'll never feel comfortable taking a strong drink, and I'll never feel easy smoking a cigarette. I just don't think those things are right for me"

Elvis Aaron Presley (1935 - 1977) - Singer 
General Introduction

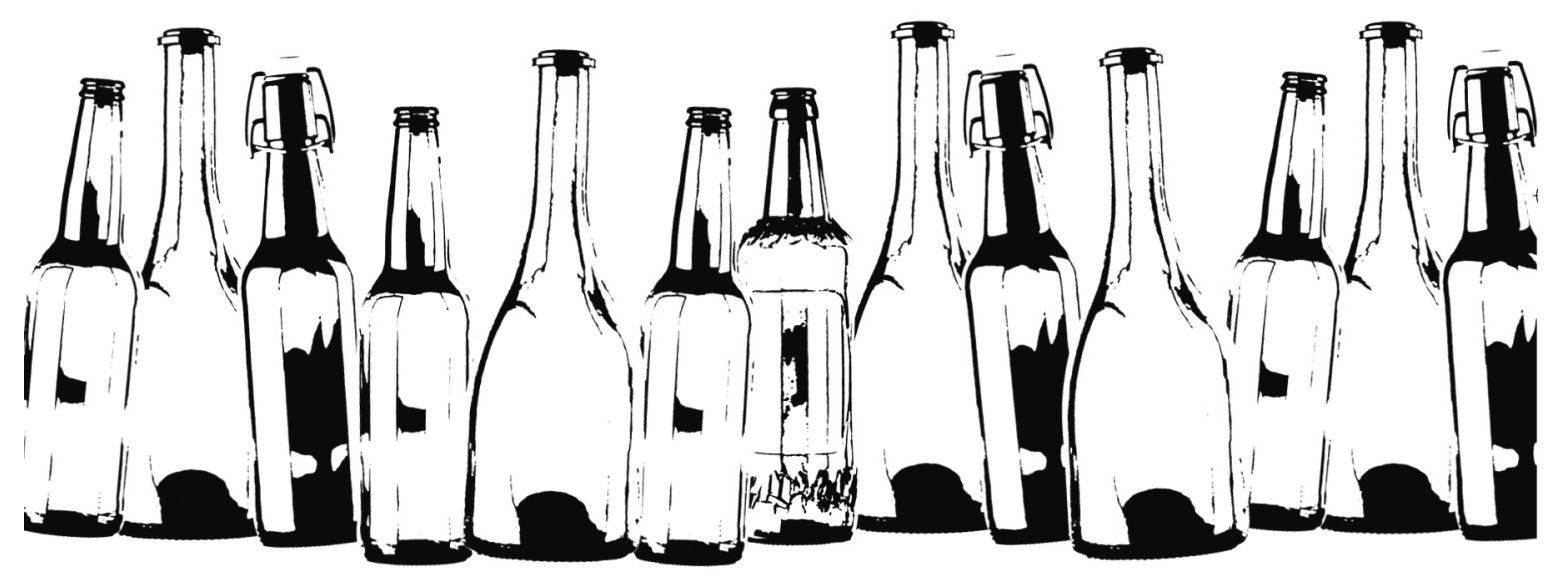


After coffee and tea, alcohol is the most consumed drug in most countries, including in the Netherlands. Alcohol is produced by fermentation of fruit or grain mixtures (e.g. wines and beers). These alcohol-containing beverages have alcohol percentages up to about $15 \%$. To make stronger drinks, fermented fruit or grain mixtures can be distilled, resulting in stronger spirits (e.g. whiskeys, cognacs, rums, gins and vodkas). These drinks carry alcohol percentages from about $30-45 \%$, but some rums contain up to $80 \%$ alcohol. The molecule for alcohol is ethyl alcohol (ethanol), which contains carbon, hydrogen, and oxygen $\left(\mathrm{C}_{2} \mathrm{H}_{5} \mathrm{OH}\right)$ (Wikipedia, 2010a).

Alcohol producers may add flavours to beers, wines and distilled spirits. To improve the tasting pallet of wines, different batches from various types of grapes are often mixed. Over the last few decades, many sweetened alcoholic drinks have been introduced into the market. These so-called 'mixed drinks' contain distilled alcohol mixed with soft drinks or energy drinks.

When consumed, about $20 \%$ of the alcohol is absorbed in the stomach and about $80 \%$ is absorbed in the small intestine. The speed of alcohol absorption depends on the concentration of alcohol in the consumed beverage (i.e. the more alcohol in the drink, the faster the absorption), the type of drink (i.e. carbonated beverages tend to speed up the absorption of alcohol), and the content of the stomach (i.e. the fuller the stomach, the slower alcohol is absorbed). After absorption, alcohol enters the bloodstream and dissolves in the water of the blood. In the blood, the alcohol is carried throughout the body. The alcohol from the blood then enters and dissolves in the water inside each tissue of the body (except fat tissue, as alcohol cannot dissolve in fat). Inside the body tissues, alcohol exerts its effects on the body. The extent of these effects depends on the blood alcohol concentration (BAC), which is related to the amount of alcohol consumed. The BAC differs by person and depends on the amount of liquid in the body (taller individuals have a slower BAC increase), gender (females have smaller amounts of liquid per kilo), physical condition and drug use of the drinker.

Alcohol influences the human body. Different stages occur with increasing BAC. First, drinkers reach the euphoric stage (BAC $=0.03-0.12 \%)$ accompanied by an increase in selfconfidence and daring behaviour, flushed look, decreased attention span, decreased 
judgment and trouble with fine movements. The lethargy stage is next (BAC $=0.09$ $0.25 \%$ ) and includes sleepiness and decreased comprehension, memory (even of recent events), balance and reaction to situations, as well as uncoordinated body movements, blurry vision and delayed reactions. The confusion stage is then reached at BAC levels between 0.18 and $0.30 \%$. This stage typically includes confusion, dizziness, staggering, getting highly emotional (including aggression), blurred vision, the inability to speak clearly, uncoordinated movement and a reduced feeling of pain. The stupor stage follows the confusion stage $(\mathrm{BAC}=0.25-0.4 \%)$ and includes a significant reduction in the ability to move, the inability to respond to stimuli, the inability to walk or even stand, vomiting, and reduced levels of consciousness. The last stage is the coma stage (BAC $=0.35-0.50 \%)$, which includes complete loss of consciousness, depressed reflexes (pupils), a decrease in body temperature, breathing rate, and heart rate, and sometimes death (often with a BAC greater than 0.50\%) (Discover Health, 2010; Wikipedia, 2010b).

This is just the technical story of alcohol and alcohol use. However, many of the problems alcohol causes can be seen as both personal and societal problems, in particular when minors are involved. This dissertation focuses on the problem of alcohol use by adolescents in the Netherlands. I will first discuss the prevalence of alcohol consumption (1.1) and the consequences alcohol use may have (1.2). After that, I will describe the predictors of alcohol use (1.3), with special attention to issues of availability (1.4). The chapter ends with a conceptual model and an outline of the studies reported in this dissertation (1.5).

\subsection{ALCOHOL CONSUMPTION}

\section{Worldwide consumption}

Alcohol has been consumed for centuries. In fact, beer brewing recipes older than 5,000 years have been found. In old paintings (even those before Christ), people are shown drinking wine. Today, approximately 2 billion people worldwide regularly consume alcoholic drinks. The global alcohol consumption has increased in recent decades, with all or most of that increase in developing countries. Worldwide, 76.3 million individuals are 
currently affected by alcohol-related disorders such as alcohol dependence and alcohol abuse.

The amount of alcohol consumed worldwide is difficult to establish because in many countries alcohol sales are not recorded. This is because alcohol is not always produced and sold through official channels; there is home production in many countries, which can be either licit (wine and beer in some countries) or illicit (spirits). Furthermore, alcohol crosses borders through smuggling and lawful shopping. In addition, not all alcoholcontaining beverages are labelled as such in some countries. Some beverages with an alcohol content below the legal definition of alcohol are not included in statistics (World Health Organization, 2004).

\section{Alcohol consumption in the Netherlands}

In 2008 , about $81 \%$ of the inhabitants in the Netherlands consumed alcohol. This pattern is quite similar to that of previous years. The total recorded alcohol consumption per capita (16 years of age and older) in litres of pure alcohol was 9.47 in 2004, making the Netherlands one of the top 30 countries in alcohol consumption worldwide. Almost $10 \%$ of Dutch people, or approximately 1.4 million individuals, are heavy drinkers (consuming six drinks or more at one occasion at least once a week). Dutch men are more frequently heavy drinkers $(17 \%)$ compared to women $(4 \%)$. Heavy drinking is not equally divided with respect to age. In those aged 18 to 24 years, about $37 \%$ of the male population and $12 \%$ of women are heavy drinkers.

Between 2003 and 2007, alcohol use decreased in the youngest age group (12-14 years of age) after years of increased use (more often and younger). In 2003, about $47 \%$ of this age group was a regular drinker, which decreased to $32 \%$ in 2007 . Within this age group, 'binge drinking' behaviour decreased within the same timeframe. In 2003, about $28 \%$ of this group drank five or more drinks at a single occasion at least once in a month; in 2007, this value decreased to $19 \%$. This decrease, however, still means that about one in five children drink a large amount of alcohol once a month or more.

The drinking patterns of those between the ages of 15 and 18 years did not change between 2003 and 2007. In 2003, about 76\% drank regularly, and this value decreased to only $75 \%$ 
in 2007. Within this group, binge drinking statistics also did not change (56\% in 2003 vs. $57 \%$ in 2007).

Compared to other countries, the Dutch youth is still drinking heavily. They drink large quantities and also start consuming alcohol at a young age (Van Laar, Cruts, Van OoyenHouben, Meijer, \& Brunt, 2010).

\subsection{CONSEQUENCES OF ALCOHOL CONSUMPTION}

In this section, the consequences of alcohol consumption will be elaborated. Within the large body of literature, I attempted to include as many relevant studies as possible. When multiple studies report on the same topic, I cite all of them. I did not exclude specific research designs; therefore, the studies referenced involved questionnaires, (laboratory) experiments, longitudinal designs, interviews, focus groups, observational studies, metaanalyses, literature reviews, and/or combinations of these study designs. Given that the background of this dissertation is behavioural (psychology, sociology and communication science), clinical/medical and biological experiments investigating, for instance, the effects of alcohol on human cell structures have been excluded. Studies involving animals (mice, rats and monkeys), for which extrapolation of the results to human populations is disputable or unclear, have also been excluded.

First, I will describe the negative consequences of adult alcohol use on two levels; personal and societal. I will then closely evaluate adolescent alcohol use and its consequences. Finally, I will report on the health benefits related to (moderate) alcohol use.

\section{Consequences of alcohol consumption in adults}

The use of alcohol is not without short- and long-term negative and positive consequences, most of which are largely reported in scientific studies and published in peer-reviewed journals. Although this dissertation focuses on adolescent alcohol use, most studies explore the consequences of alcohol use general, which typically involves all drinkers (i.e. both adults and adolescents). 
The first type of consequences are consequences on the personal level, which involve both the individual drinker and often others. First, alcohol use is undoubtedly related to and causes a broad range of diseases (Anderson \& Baumberg 2006; Babor et al., 2003). It is well known that alcohol can cause diseases everywhere in the human body that the alcohol comes across after consumption. The most demonstrated example of this occurrence is the causal relationship between alcohol consumption and liver diseases such as liver cirrhoses and liver cancer (Arico, Galatola, Tabone, \& Corrao, 1994; Corrao, Aricò, Zambon, Torchio, \& Di Orio, 1997; Corrao, Bagnardi, Zambon, \& Arico, 1999; Corrao, Bagnardi, Zambon, \& La Vecchia, 2004; Corrao, Bagnardi, Zambon, \& Torchio, 1998; Doll, Peto, Hall, Wheatley, \& Gray, 1994; Holman, English, Milne, \& Winter, 1996; Longnecker \& Enger, 1996; Lieber, 1994; Mathews, 1976; Ramstedt, 2001; Rehm et al., 2003a; Thun et al., 1997).

Alcohol can also cause oral cavity cancers (e.g. cancer of the lips, the inside lining of the lips and cheeks, the teeth, the gums, the front two-thirds of the tongue, the floor of the mouth below the tongue, the hard palate, and the area behind the wisdom teeth), oropharyngeal cancers (base of the tongue, the soft palate, the tonsils, and the side and back wall of the throat), pharyngeal cancers (hollow tube inside the neck that starts behind the nose and ends at the top of the windpipe and oesophagus), hypopharyngeal cancers (uppermost portion of the oesophagus), laryngeal cancers, and oesophageal cancers (the tube through which food travels to the stomach) (Bagnardi, Blangiardo, Vecchia, \& Corrao, 2001; Corrao et al., 2004; Cheng et al., 1995; Franceschi et al., 2000; Grønbæk et al., 1999; Holman et al., 1996; Kato, Nomura, Stemmermann, \& Chyou, 1992; Launoy et al., 1997; Rehm et al., 2003a; Salaspuro, 2003; Thygesen, Keiding, Johansen, \& Grønbæk, 2007).

In addition, at the end of the human digestive tract, alcohol can cause cancers in the colorectal area, which includes the colon (the longest part of the large intestine), the rectum (the last several inches of the large intestine closest to the anus), the appendix (blind-ended tube connected to the cecum) and the anus (Akhter et al., 2007; Bardou et al., 2002; Bongaerts, Van Den Brandt, Goldbohm, De Goeij, \& Weijenberg, 2008; Cho et al., 2004; Corrao et al., 1999; Ferrari et al., 2007; Glynn et al., 1996; Hong et al., 2005; Ji et al., 
2002; Kim, 2007; Kim et al., 2004; Lin, 2009; Longnecker, Orza, Adams, Vioque, \& Chalmers, 1990; Maekawa et al., 2004; Moskal, Norat, Ferrari, \& Riboli, 2007; Muñoz et al., 1998; Otani et al., 2003; Pedersen, Johansen, \& Grønbæk, 2003; Sharpe, Siemiatycki, \& Rachet, 2002; Shimizu et al., 2003; Su \& Arab, 2004; Thygesen et al., 2008; Toriola, Kurl, Laukanen, Mazengo, \& Kauhanen, 2008; Tsong et al., 2007; Yamada et al., 1997).

Furthermore, although alcohol does not come into direct contact with the heart, it does reach the heart via the blood stream. Alcohol consumption has been reported to have both positive and negative consequences on the heart and veins (the positive studies will be discussed later in this section). Many studies have shown that alcohol use increases the risk for coronary disease, also called coronary heart disease or coronary artery disease (Ahlawat \& Siwach, 1994; Corrao, Rubbiati, Bagnardi, Zambon, \& Poikolainen, 2000; Friedman \& Kimball, 1986; Kittner, Garcia Palmieri, \& Costas Jr., 1983; Mathews, 1976; Rehm et al., 2003a; Rehm, Sempos, \& Trevisan, 2003b; Shaper \& Wannamethee, 2000; Yano, Rhoads, \& Kagan, 1977).

Alcohol consumption is also related to other blood-related diseases, including hypertension or high blood pressure (Athyros et al., 2008; Corrao et al., 1999; Corrao et al., 2004; Mathews, 1976; Klatsky, 1996; Rehm et al., 2003a) and cerebrovascular incidents or stroke (Corrao et al., 1999; Hansagi, Romelsjo, De Verdier, Andreasson, \& Leifman, 1995; Ikehara et al., 2008; Rehm et al., 2003a; Reynolds et al., 2003).

Undoubtedly, alcohol consumption is related to obesity and higher body mass index (BMI or Quetelet Index), which calculates a body weight index based on a statistical measure using an individual's weight and height $\left(\mathrm{BMI}=\right.$ weight $\left.[\mathrm{kg}] /(\text { height }[\mathrm{m}])^{2}\right)($ Athyros et al., 2008; Bell, Ge, \& Popkin, 2001; Gordon \& Doyle, 1986; Gruchow, Sobocinski, Barboriak, \& Scheller, 1985; Istvan, Murray, \& Voelker, 1995; Rissanen, Heliovaara, Knekt, Reunanen, \& Aromaa, 1991; Suter, Häsler, \& Vetter, 1997; Wannamethee, Field, Colditz, \& Rimm, 2004; Wannamethee \& Shaper, 2003).

Alcohol use has also been related to breast cancer in females (Corrao et al., 1999; Holman et al., 1996; Longnecker, 1994; Rehm et al., 2003a; Schatzkin \& Longnecker, 1994; SmithWarner et al., 1998; Singletary \& Gapstur, 2001; Thun et al., 1997), major depressive 
disorder (clinical depression, major depression, unipolar depression, or unipolar disorder) (Deykin, Levy, \& Wells, 1987; Gilman \& Abraham, 2001; Grant \& Harford, 1995; Rehm et al., 2003a), and, to a lesser extent, chronic pancreatitis (Corrao et al., 1999; Corrao et al., 2004). Moreover, alcohol use has been shown to be the major cause of non-ischaemic cardiomyopathy in Western society (Papadakis, Ganotakis, \& Mikhailidis, 2000). In some high-risk populations such as epileptics, alcohol use is more harmful because it might increase the risk of sudden unexpected death in epilepsy (SUDEP) (Ghaeni, 2008; Gordon \& Devinsky, 2001; Hauser, Ng, \& Brust, 1988; Rehm et al., 2003a; Scorza et al., 2009).

Alcohol use is also related to other risk behaviours, such as tobacco use and the use of other illicit drugs (Jackson, Sher, Cooper, \& Wood, 2002; Fillmore et al., 1998).

Holistic research also shows that, in general, alcohol use is related to injuries and deaths (Corrao et al., 2004; Doll et al., 1994; Hingson, Heeren, Jamanka, \& Howland, 2000; Hingson \& Howland, 1987; Jones-Webb, Fabian, Harwood, Toomey, \& Wagenaar, 2004; McGinnis \& Foege, 1993; Wechsler, Davenport, Dowdall, Moeykens, \& Castillo, 1994), that alcohol use can cause intoxication or poisoning (Doll et al., 1994; Measham \& Brain, 2005; Peterson, Rothfleisch, Zelazo, \& Pihl, 1990) and that alcohol consumption might cause higher mortality risk (Bloss, 2006; Doll et al., 1994; Fillmore et al., 1998; Klatsky, Armstrong, \& Friedman, 1992; Leino et al., 1998; Single, Robson, Rehm, \& Xi, 1999; Theobald, Johansson, Bygren, \& Engfeldt, 2001; Thun et al., 1997).

Alcohol is estimated to cause about $20 \%$ to $30 \%$ of oesophageal cancer, liver cancer, cirrhosis of the liver, homicide, epilepsy, and motor vehicle accidents worldwide (World Health Organization, n.d.). It is well known that (impaired) drinking and driving is causally related to car crashes, which causes injuries and deaths of drivers, passengers, and (nondrinking) victims (Bako, Mackenzie, \& Smith, 1976; Brewer et al., 1994; Hingson, Heeren, Zakocs, Kopstein, \& Wechsler, 2002; Hingson, Heeren, Zakocs, Winter, \& Wechsler, 2003a; Hingson \& Winter, 2003; Jones-Webb et al., 2004; Lewis, Lapham, \& Skipper, 1998; Shults et al., 2001; Sise et al., 2009; Wagenaar, Murray, \& Toomey, 2000; Whitehead et al., 1975; Zador \& Krawchuk, 2000; Williams, Rich, Zador, \& Robertson, 1975; Lang \& Stockwell, 1991; Lee, Jones-Webb, Short, \& Wagenaar, 1997; O'Donnell, 1985; Stockwell, Lang, \& Rydon, 1993). 
When alcohol is involved, people may practice unprotected sexual behaviour, which increases the risk of sexually transmittable diseases (STDs) such as human immunodeficiency virus (HIV), leading to acquired immune deficiency syndrome (AIDS), chlamydia, gonorrhoea, and syphilis. This involves adult heterosexual (Hingson, Strunin, Berlin, \& Heeren, 1990; McEwan, McCallum, Bhopal, \& Madhok, 1992; Robertson \& Plant, 1988; Sen, 2002; Stall, McKusick, Wiley, Coates, \& Ostrow, 1986) and adult homosexual behaviour (Leigh, 1990; Vanable et al., 2004). Research has also shown that a higher proportion of rapes tends to occur when women are intoxicated (Mohler-Kuo, Dowdall, Koss, \& Wechsler, 2004).

Alcohol use has also been related to criminal and violent behaviour (Corrao et al., 2004; Ellickson, Tucker, \& Klein, 2003; Fergusson, Lynskey, \& Horwood, 1996), and alcohol use increases aggression and the occurrence of fights (Hingson, Heeren, \& Zakocs, 2001; Lau, Pihl, \& Peterson, 1995; Rossow, 1996; Rossow, Pape, \& Wichstrøm, 1999). In addition, alcohol use is an important factor in domestic violence (Rodriguez, Lasch, Chandra, \& Lee, 2001a; Rodriguez, Lasch, Chandra, \& Lee, 2001b).

In addition to the previous described consequences on the personal level, (excessive) alcohol use might also have societal effects. Alcohol use and misuse is related to employment problems. Research shows a positive correlation between alcohol use at a young age and unemployment (Ellickson et al., 2003), and between drinking problems in adults and unemployment (De Cuyper, Kiran, De Witte, \& Aygoglu, 2008; Mullahy \& Sindelar, 1996; Terza, 2002).

Economists have calculated the costs of alcohol use for several countries as well as some American states to gain insight into the economic burden of alcohol on society. In most studies, both direct and indirect costs are included. These costs on society include medical treatment (hospital admissions, doctor treatments, accident and emergency attendances), unemployment, less production, premature death, mortality, morbidity, imprisonment, property loss, and administration costs. 
In high-income and middle-income countries, the costs associated with alcohol are estimated to be more than $1 \%$ of the gross national product (Rehm et al., 2009). In the United States, the economic costs for society as a result of alcohol abuse and alcoholism were about $\$ 85.8$ billion in 1988 and \$148 billion in 1992 (Harwood, Fountain, \& Livermore, 1998; Rice, Kelmand, \& Miller, 1991). Miller and Blincoe (1994) have estimated that the comprehensive cost of alcohol-involved crashes was $\$ 148$ billion in 1990 ( $\$ 46$ billion in monetary costs and $\$ 102$ billion in loss of quality of life) and that the total costs related to alcohol misuse are higher. Alcohol-related costs have also been calculated in the US state of Minnesota for 1983. In Minnesota, alcohol abuse was estimated to contribute to $12 \%(33,909)$ of all of the years of potential life lost, of which two-thirds were derived from injury. The estimated cost of alcohol abuse ranged from $\$ 1.4$ billion to $\$ 2.1$ billion, representing $2.8-4.3 \%$ of all personal income of Minnesota inhabitants. Alcohol-related medical care costs were estimated to be at least $\$ 216$ million, which was $3.8 \%$ of Minnesota's medical costs for that year. Costs of reduced job productivity and short-term absenteeism related to alcohol abuse were estimated to be between $\$ 630$ million and $\$ 1.2$ billion (Parker, Shultz, \& Gertz, 1987).

In New Zealand and Canada, economists have estimated alcohol costs for society. An overall calculation in New Zealand estimates that the total alcohol-related loss in productivity among the working population was about $\$ 57$ million per year (Jones, Casswell, \& Zhang, 1995). In the year 1991, more detailed calculations were conducted for New Zealand. The total sum of societal costs ranged from $\$ 1,045$ million to $\$ 4,005$ million in that year (Devlin, Scuffham, \& Bunt, 1997). In Canada, the costs of alcohol at the societal level are also very substantial. In 1981, the estimated alcohol-related societal costs of excess health care, reduced labour productivity, law enforcement activities, social welfare, fire-related losses and traffic accidents were estimated conservatively to exceed $\$ 5.7$ billion (Adrian, 1988). In addition, new calculations in 1992 estimated $\$ 7.52$ billion in alcohol-related costs (Single, Robson, Xie, \& Rehm, 1998). For the Province of Ontario, Canada the direct and indirect economic costs of alcohol abuse in 1992 were estimated to be over \$2,261 million (Xie, Rehm, Single, Robson, \& Paul, 1998).

In Japan, estimations of alcohol costs for society were calculated for 1987 . These costs were $6.9 \%$ of the total national medical balance (a total of 1,095.7 billion Yen). When 
taking the sum of the societal cost of all components, the total cost of alcohol abuse was estimated to be $6,637.5$ billion Yen, which represents $1.9 \%$ of the gross national product of Japan in 1987 (Nakamura, Tanaka, \& Takano, 1993). In Korea, the annual alcohol costs to society are $2.86 \%$ of the gross national product, which is estimated to be 149,352 hundred million Won (Chung, Chun, \& Lee, 2006).

In Europe, calculations of alcohol-related costs to society are available for England and Wales, Scotland, France, and Germany. In England, a conservative estimation of the total cost to society regarding alcohol misuse was about $£ 1,500$ million in 1983 (McDonnell \& Maynard, 1985). In Scotland, the annual healthcare cost with regard to only management of alcohol misuse was estimated to be $£ 95.6$ million. Social work services were estimated to cost $£ 85.9$ million, and the costs related to the criminal justice system were estimated to be $£ 267.9$ million. Indirect costs were estimated to account for $£ 404.5$ million, and the human cost of premature mortality among the non-working population was estimated to be $£ 216.7$ million (Varney \& Guest, 2002). In France, 1.42\% of the gross national product was spent on alcohol-related costs in 1997, which represented 115,420.91 million FRF. The greatest share of the societal cost of alcohol came from the loss of productivity (57,555.66 million FRF) due to premature death (53,168.60 million FRF), morbidity (3,884.0 million FRF) and imprisonment (503.06 million FRF) (Fenoglio, Parel, \& Kopp, 2003). In Germany (a neighbour country of the Netherlands), the society cost of alcoholrelated incidents was $€ 24,398$ million ( $1.16 \%$ of Germany's gross national product) (Konnopka \& König, 2007).

In 2001, the accounting firm KPMG estimated the societal costs derived from alcohol use and abuse in the Netherlands to be $€ 2.6$ billion a year; $€ 115$ million for direct health care (hospital treatment), €68 million health aftercare (addiction treatment centres), €1,554 million from the loss of productivity and unemployment, and $€ 841$ million related to crimes and offences (loss of property, traffic accidents, and legal costs) (KPMG, 2001). With a gross national product of about $€ 447.7$ billion in 2001 , the alcohol costs counted for $0.58 \%$ of the Dutch gross national product. 


\section{Consequences of alcohol consumption in adolescents}

Most diseases related to alcohol use discussed in the previous section occur after a long period of excessive alcohol consumption and are, for that reason, studied in adult populations. Clearly, if one begins consuming alcohol at a young age, the risk that one or more of these diseases may occur increases. In general, with respect to the abovementioned diseases and disorders, alcohol consumption is more harmful when one starts to drink earlier in life.

Several studies, both in animal and human populations, have shown that alcohol consumption at a young age is harmful for the adolescent brain. The human brain does not reach full development until the mid-twenties. Moreover, the adolescent brain is changing in organisation and function, and during the adolescent period, the frontal lobes (including the frontal cortex) and other regions are undergoing a "rewiring". Adolescent alcohol consumption influences this brain development, and research shows that alcohol use during adolescence might have permanent consequences for the brain, including incomplete brain development (De Bellis et al., 2000; Medina, Schweinsburg, Cohen-Zion, Nagel, \& Tapert, 2007; Tapert, Caldwell, \& Burke, 2005), suboptimal functioning of the hippocampus (Hiller-Sturmhöfel \& Scott Swartzwelder, 2005; White \& Swartzwelder, 2005), lower blood supply to certain brain areas (Tapert et al., 2005), reduced electrical brain activity (Tapert, 2005), and reduced memory formation (Hiller-Sturmhöfel \& Scott Swartzwelder, 2005; White \& Swartzwelder, 2005).

In addition to brain damage, research has shown that adolescent alcohol use is a strong predictor for adult alcohol use (Grant et al., 2006; Kandel, Yamaguchi, \& Chen, 1992; Pedersen \& Skrondal, 1998), alcohol abuse or addiction (Chou \& Pickering, 1992; Clapper, Buka, Goldfield, Lipsitt, \& Tsuang, 1995; DeWit, Adlaf, Offord, \& Ogborne, 2000; Ellickson, Tucker, Klein, \& McGuigan, 2001; Fergusson, Horwood, \& Lynskey, 1995; Grant \& Dawson, 1997; Grant et al., 2006; Grant, Stinson, \& Harford, 2001; Hingson et al., 2003a; Kandel et al., 1992; Pedersen \& Skrondal, 1998). Moreover, early starters (i.e. those who begin drinking before age 14) are at a significantly higher risk of alcohol dependence and/or problematic drinking in adulthood (Bonomo, Bowes, Coffey, Carlin, \& Patton, 2004; Ellickson et al., 2003; Grant \& Dawson, 1997; Hingson, Heeren, \& Winter, 2006; Wells, Horwood, \& Fergusson, 2004). 
The so-called "gateway theory of drug use" states that the use of entry drugs (alcohol and cigarettes; sometimes marijuana is also included as an entry drug) causes more severe illicit drug use (e.g. marijuana, ecstasy, and cocaine). This has also be found in research, studies show that adolescent alcohol consumption is related to tobacco use and the (ab)use of marijuana and other illicit drugs in adolescence (Ginzler, Cochran, DomenechRodríguez, Cauce, \& Whitbeck, 2003; Golub, Labouvie, \& Johnson, 2000; Grant et al., 2006; Johnson, Boles, \& Kleber, 2000; Kandel et al., 1992; Peele \& Brodsky, 1997; Sutherland \& Willner, 1998; Welte \& Barnes, 1985; Yamada, Kendix, \& Yamada, 1996; Yu \& Williford, 1992).

Consistent with adults, alcohol consumption during adolescence is related to risky sexual behaviour (Hingson, Heeren, Winter, \& Wechsler, 2003; Tapert, Aarons, Sedlar, \& Brown, 2001) and getting involved in unplanned sex (Wechsler et al., 1994).

Adolescent alcohol use in adolescents is also related to school drop-out rates and a decrease in school performance (Cook, 1993; De Micheli \& Formigoni, 2004; Townsend, Flisher, \& King, 2007; Wichstrøm, 1998; Wolaver, 2002; Yamada et al., 1996).

\section{Health benefits}

As described above, adolescent and adult alcohol consumption increases the risk of a variety of diseases and risk behaviours, resulting in negative consequences. These negative consequences can be observed at the personal and societal level. There are, however, studies that have shown alcohol use to have health benefits. In this section, we will describe these reported benefits.

The most reported health benefit is that moderate or light alcohol consumption has a protective effect against coronary heart disease and/or other cardio-related diseases (Ahlawat \& Siwach, 1994; Bagnardi, Zatonski, Scotti, La Vecchia, \& Corrao, 2008; Cleophas, 1999; Doll et al., 1994; Ebbert, Janney, Sellers, Folsom, \& Cerhan, 2005; Gigleux et al., 2006; Gronbaek, 2004; Gronbaek et al., 2000; Hennekens, Rosner, \& Cole, 1978; Ikehara et al., 2008; Jackson, Scragg, \& Beaglehole, 1991; Kannel \& Ellison, 1996; Keil, Chambless, Döring, Filipiak, \& Stieber, 1997; Kitamura et al., 1998; Langer, Criqui, 
\& Reed, 1992; Lindeman et al., 1999; Mäkelä, Valkonen, \& Poikolainen, 1997; Mann \& Folts, 2004; Marmota, 2001; Meister, Whelan, \& Kava, 2000; Miller, Beckles, Maude, \& Carson, 1990; Moore \& Pearson, 1986; Mukamal, Chiuve, \& Rimm, 2006; Mukamal et al., 2006; Rehm, Bondy, Sempos, \& Vuong, 1997; Rigaud, 2000; Rimm et al., 1991; Rimm, Klatsky, Grobbee, \& Stampfer, 1996; Rimm \& Moats, 2007; Rimm, Williams, Fosher, Criqui, \& Stampfer, 1999; Sacco et al., 1999; Shaper, Wannamethee, \& Walker, 1994; Shaper \& Wannamethee, 2000; Suh, Shaten, Cutler, \& Kuller, 1992; Tolstrup et al., 2006; Valmadrid, Klein, Moss, Klein, \& Cruickshanks, 1999; Vogel, 2002; Younis, Cooper, Miller, Humphries, \& Talmud, 2005), and this effect might be especially applicable to diabetic patients (Ajani et al., 2000; Koppes, Dekker, Hendriks, Bouter, \& Heine, 2006; Solomon et al., 2000; Tanasescu, Hu, Willett, Stampfer, \& Rimm, 2001).

Moderate alcohol consumption has also been reported to lower the risk of type 2 diabetes (Koppes, Dekker, Hendriks, Bouter, \& Heine, 2005; Sakuta, Suzuki, Ito, \& Yasuda, 2007). In addition, there is some evidence of a modest protective association between alcohol consumption and hearing loss (Popelka et al., 2000).

\subsection{ALCOHOL USE PREDICTORS}

To understand and explain human behaviours (including risky behaviours such as alcohol use), researchers often use behavioural models such as the Theory of Reasoned Action (Fishbein \& Ajzen, 1975) or the more elaborated Theory of Planned Behaviour (Ajzen, 1991). The basic assumption of the Theory of Planned Behaviour is that an individual's behavioural intentions lead to the specific human behaviour, which is restrained by practical barriers. Behavioural intentions are influenced by attitudes towards the specific behaviour, the subjective norms, and the perceived behavioural control.

The studies presented in this dissertation were designed to investigate varying predictors and barriers of adolescent alcohol use in the context of Dutch adolescents. In addition, a study was added that addressed the consequence of alcohol intoxication in the Netherlands (as data in the Netherlands are lacking on this specific point). The theoretical starting 
points of the studies were external (societal) influences regarding the intentions of adolescent alcohol use and the barriers adolescents might experience when they want to transform intention into behaviour. I did not focus on psychological, internal aspects of adolescents, which may also influence the intentions underlying alcohol use. Nonetheless, the most important aspects will be briefly discussed in this section.

An important physical aspect in adolescents that is related to alcohol use and other risky behaviours is the level of novelty and sensation seeking, also referred to as impulsivity or venturesomeness. Adolescents with high levels of sensation seeking turn out to be more likely to experiment in risky behaviours, including alcohol use (Caspi, Moffitt, Newman, \& Silva, 1996; Cherpitel, Meyers, \& Perrine, 1998; Donohew et al., 1999; Kalichman, Cain, Zweben, \& Swain, 2003; Kalichman, Weinhardt, DiFonzo, Austin, \& Luke, 2002; Martin et al., 2002; Nagoshi, Wilson, \& Rodriguez, 1991). Not only is sensation seeking in adolescents related to alcohol use, the sensation seeking of peers also influences an adolescent's own use of alcohol (Donohew et al., 1999).

Also, children and adolescents suffering from mood and anxiety disorders tend to have a higher risk to develop alcohol use disorders, which in some studies has been found to be correlated (Comeau, Stewart, \& Loba, 2001; Conway, Compton, Stinson, \& Grant, 2006; Degenhardt, Hall, \& Lynskey, 2001; Grant et al., 2004; Kushner, Abrams, \& Borchardt, 2000; Kushner, Sher, \& Beitman, 1990; Schuckit \& Hesselbrock, 1994). Therefore, some addiction treatment personnel in the field focus on decreasing substance use while also attempting to treat mood and anxiety disorders.

In addition to this type of treatment, more temporary beliefs might also influence adolescent alcohol use. Alcohol expectations, sometimes referred to as perceived consequences derived from alcohol use, and perceived behavioural control, are predictors for alcohol use (Reis \& Riley, 2000; Wood, Sher, \& Strathman, 1996). Moreover, cultural norms regarding alcohol predict alcohol use (Larimer, Turner, Mallett, \& Geisner, 2004; Rimal, 2008; Trockel, Williams, \& Reis, 2003). Cultural norms, knowledge and outcome beliefs regarding alcohol use are influenced by external factors in the private and public domain. First, I will discuss alcohol visibility in the public domain, including media 
influences, advertising, and product placement, followed by alcohol education; counterbalanced health messages and warnings.

\section{Visibility}

Consistent with other commercial products, most alcohol-producing companies want to sell as much of their product as possible. A tool to inform consumers and persuade them toward a specific product or brand is, of course, commercials. These advertisements attempt to make the customer feel positive about a specific product or brand. When advertising for alcohol, not only adults are persuaded but teens and adolescents also start feeling more positive about the specific product (Grube \& Wallack, 1994). This can be seen as a positive side effect; however, when selling a dangerous product (especially dangerous when used in excess or at too young of an age), the process of advertising is rather complex in terms of ethics. Therefore, supported by research on the behavioural effects of advertising, legislation in many countries is actively guiding commercial alcohol advertisements. The primary aim of this legislation is to attempt to avoid having at-risk populations be in contact with these communication messages, while allowing the possibility of advertising towards a responsible target audience. Examples of such legislation are the restriction on outdoor alcohol advertisements near schools, the banning of television commercials on channels primarily watched by youths, only allowing television commercials late in the evening, not allowing the use of popular figures among youths in such commercials, and only allowing advertisements to inform about the product and not about the consumption moment.

Despite these measures and the fact that adolescents are not the official target audience, research shows that alcohol advertising still reaches youths through various media outlets and that this exposure increases alcohol consumption in this age group (Adlaf \& Kohn, 1989; Atkin, 1990; Aitken, Eadie, Leathar, McNeill, \& Scott, 1988a; Austin, Chen, \& Grube, 2006; Casswell \& Zhang, 1998; Collins, Ellickson, McCaffrey, \& Hambarsoomians, 2007; Connolly, Casswell, Zhang, \& Silva, 1994; Ellickson, Collins, Hambarsoomians, \& McCaffrey, 2005; Garfield, Chung, \& Rathouz, 2003; Grube \& Wallack, 1994; Hastings, Anderson, Cooke, \& Gordon, 2005; King III et al., 2009; Saffer, 2002; Smart, 1988; Smith \& Foxcroft, 2009; Smith \& Geller, 2009; Snyder, Milici, Slater, Sun, \& Strizhakova, 2006; Stacy, Zogg, Unger, \& Dent, 2004; Strasburger, 2002; Villani, 
2001; Wyllie, Zhang, \& Casswell, 1998a; Wyllie, Zhang, \& Casswell, 1998b). Some research has shown that alcohol advertisements reaching youths are related to drunk driving and accidents (Atkin, 1990; Smith \& Geller, 2009).

One could say that the alcohol producing and selling industry has taken its responsibility and transformed it into a more socially responsible entrepreneurship. However, some studies have shown that the intentions of the alcohol producing and selling industry are disputable, as youths are not less exposed to alcohol advertisements but are instead increasingly exposed (Jernigan, Ostroff, Ross, \& O'Hara III, 2004). Moreover, research from the United States has shown that instead of avoiding the youth audience, alcohol companies have placed significant amounts of advertising where youths are more likely to be exposed to than adults (Garfield et al., 2003; Jernigan, Ostroff, \& Ross, 2005).

In addition to the direct relationship between exposure to alcohol advertisements and adolescent alcohol consumption and accidents, the underlying factors have also been analysed. As stated previously, alcohol advertisements are targeted towards adults, but research shows that underage adolescents like alcohol advertisements even though they are not the target audience (Aitken et al., 1988a; Aitken, Leathar, \& Scott, 1988b). Studies have also shown that adolescents like alcohol advertisements related to alcohol consumption (Aitken et al., 1988a; Casswell \& Zhang, 1998; Wyllie et al., 1998a; Wyllie et al., 1998b) and that young people tend to own and use numerous commercial promotional items related to alcohol, which appear to encourage underage alcohol consumption and binge drinking (Fisher, Miles, Austin, Camargo Jr., \& Colditz, 2007).

Young people are influenced through these media portrayals, partly through 'modelling'. Seeing people consume alcohol in certain situations (e.g. a party) makes drinking alcohol at parties more common. Although people know that commercials have a certain aim (i.e. influencing the viewer), these commercials still shape a certain reality. Perhaps more confusing and complex to process rationally are the so-called 'product placements', which are hidden commercials in television shows and movies to which young people are extensively exposed (Dal Cin, Worth, Dalton, \& Sargent, 2008). People watching television shows and movies identify themselves with certain characters, and this fictitious identity will create reality, at least to a certain extent. For example, research has shown that 
96\% of the top 10 films from 1985 to 1995 had positively referenced alcohol use and that the negative consequences of alcohol use were never exposed (Everett, Schnuth, \& Tribble, 1998). Other recent research supports the previous findings, showing that people who consume alcohol in movies do not suffer from any negative consequences, including both short-term (hangover, sickness) or long-term consequences (addiction). Characters were rarely shown refusing offers to drink or regretting their substance usage (Stern, 2005). In television shows, alcohol portrayals are mainly positive (Russell \& Russell, 2008). In addition to the theory of modelling, research also shows direct relationships between exposure to alcohol use in the movies and early-onset teen drinking (Sargent, Wills, Stoolmiller, Gibson, \& Gibbons, 2006) and drinking without parental knowledge (Hanewinkel, Tanski, \& Sargent, 2007), and a direct relationship between exposure to drinking models and alcohol commercials on acute alcohol consumption has also been demonstrated (Engels, Hermans, Van Baaren, Hollenstein, \& Bot, 2009).

Given that alcohol advertisements and product placements are related to increased alcohol consumption, it is plausible that alcohol advertising bans might have an influence on lowering alcohol consumption. This idea has also been supported by research (Pinsky \& El Jundi, 2008; Saffer, 1991; Saffer \& Dave, 2002; Saffer \& Dave, 2006). Alcohol consumption might decrease when alcohol advertising bans are active, and such a ban will likely reduce motor vehicle fatalities in the range of 2000 to 3000 lives saved per year (Saffer, 1997).

\section{Alcohol education}

In addition to the affective alcohol depictions that promote alcohol brands and alcohol in general, counterbalancing health programmes exist in the public domain. These health interventions consist of government campaigns in the mass media or smaller programmes in educational and/or campus environments. On national levels, these programmes have not been evaluated very often. In fact, I only found a single study that states that mass media health interventions did not influence alcohol consumption (Flynn et al., 2006). More frequently, the so-called alcohol education programmes (AEPs) are designed such that schools, governmental organisations, and sometimes media work together to inform youths about alcohol use and health-related consequences with the aim of decreasing alcohol consumption. These programmes have been studied quite extensively. 
The effects of these types of interventions on knowledge, attitude and behaviour outcomes, however, are not without dispute. About half of the studies evaluating AEPs do find effects on these outcomes. In fact, some studies have stated that knowledge of alcohol (the effects in the body), health consequences and legal issues with respect to alcohol (use) increased after AEPs (Arthur, 2001; Bagnall, 1990; Collins \& Cellucci, 1991; Duryea, Mohr, Newman, Martin, \& Egwaoje, 1984; Goodstadt, Sheppard, \& Chan, 1982; Newman, Anderson, \& Farrell, 1992; Reis, Riley, Lokman, \& Baer, 2000; Shope, Copeland, Maharg, \& Dielman, 1996).

Furthermore, it is possible that AEPs influenced attitudes towards alcohol use, as others have shown (Arthur, 2001; Goodstadt et al., 1982). The biggest and most hoped for outcome of AEPs is a change in drinking-related behaviour, and numerous studies have shown that AEPs indeed have a positive behavioural impact (DiCicco, Biron, \& Carifio, 1984; Fromme, Alan Marlatt, Baer, \& Kivlahan, 1994; Goodstadt et al., 1982; Mauss, Hopkins, Weisheit, \& Kearney, 1988; Sheehan et al., 1996; Shope et al., 1996; Shope, Copeland, Marcoux, \& Kamp, 1996; Werch et al., 2000).

It is plausible and stated in research that AEP effects disappear over time (Duryea \& Okwumabua, 1988; Ellickson \& Bell, 1990; Licciardone, 2003). Besides studies which do prove effects of AED's, other studies do show no effects on attitudes towards alcohol (Collins \& Cellucci, 1991) or alcohol related behaviour (Collins \& Cellucci, 1991; Newman et al., 1992). Furthermore, a lot of alcohol education programs which have been evaluated, turn out to be non-effective on all aspects (Chatterji, 2006; Hopkins, Mauss, Kearney, \& Weisheit, 1988; Foxcroft, Lister-Sharp, \& Lowe, 1997; Foxcroft, Ireland, Lister-Sharp, Lowe, \& Breen, 2003; Rowland \& Maynard, 1993; Sharmer, 2001)

Some reviews exist on AEPs (e.g. Foxcroft et al., 2003); however, the content of the different programmes was not related to the (lack of) effects. 


\subsection{FOUR TYPES OF AVAILABILITY}

In this section, I will discuss four external predictors of adolescent alcohol use intention separately, which are the four types of alcohol availability. These four types of availability are predictors of alcohol use and (three in particular) may also function as barriers.

In general, alcohol availability is a very (perhaps the most) important predictor of adolescent alcohol consumption, drinking patterns and alcohol-related health issues. (Norström, 1987; Ólafsdóttir, 1997; Paschall, Grube, \& Kypri, 2009; Popova, Giesbrecht, Bekmuradov, \& Patra, 2009; Schechter, 1986; Wald, Morawski, \& Moskalewicz, 1986). The term 'availability' is not persistently used in common language or in scientific literature. Strictly, availability refers to the degree to which something is at hand when needed. In literature related to alcohol use, however, availability mainly refers to the economic and physical (although this term is not common) availability and thus to the degree to which alcohol (outlets) is present and what the prices are. I distinguish between four types of availability: (1) economic availability, (2) physical availability, (3) legal availability and (4) social availability. With respect to these four types of availability, I used the following definitions and inclusion criteria:

- $\quad$ Economic availability: all research on the relationship between alcohol use and the prices of alcohol, which involves structural and incidental increases and decreases in the price of alcoholic beverages and/or government taxes.

Physical availability: all research about outlet density (number of outlets) and opening hours of on-premise (e.g. bars) and off-premise (e.g. supermarkets) alcohol outlets related to alcohol use.

- Legal availability: all research regarding official legislation measures and laws related to alcohol use, including legislation and compliance of age limits on buying, selling and consuming alcohol.

Social availability: research on the social context of adolescent alcohol consumption, which also includes peer influences and parenting styles. 


\section{Economic availability}

Alcohol prices are negatively correlated to alcohol consumption. The most used governmental tool in society is taxes on alcoholic beverages, and research has shown that higher alcohol prices are related to lower alcohol consumption (Chaloupka \& Wechsler, 1996; Edwards et al., 1994; Farrell, Manning, \& Finch, 2003; Grossman, Chaloupka, Saffer, \& Laixuthai, 1994; Kenkel, 1993; Osterberg, 1995; Yamada et al., 1996) and that lower prices (e.g. in special promotions) increase alcohol consumption (Kuo, Wechsler, Greenberg, \& Lee, 2003; Wechsler, Kuo, Lee, \& Dowdall, 2000).

Not only do alcohol prices influence drinking behaviour, research has also shown that increasing alcohol prices or taxes reduces alcohol-related problems, including drinking and driving and alcohol-related crime (Chaloupka, Saffer, \& Grossman, 1993; Cook \& Tauchen, 1982: Markowitz \& Grossman, 1998; Markowitz \& Grossman, 2000). Research with a broader perspective on healthcare costs and health consequences for drinkers has also shown that an alcohol tax increase is a cost-effective policy (Van den Berg et al., 2008).

\section{Physical availability}

Research covering physical factors of availability mainly focus on outlet density and opening hours. It is known that both outlet density and opening hours negatively correlate with alcohol consumption. Clearly, higher alcohol outlet density is related to higher availability in general (Chen, Gruenewald, \& Remer, 2009). Fewer alcohol outlets therefore cause a reduction in alcohol consumption (Gruenewald, Ponicki, \& Holder, 1993; Treno, Parker, \& Holder, 1993), and higher alcohol outlet density (near educational institutions) is related to higher alcohol consumption (Kuntsche, Kuendig, \& Gmel, 2008; Scribner, Cohen, \& Fisher, 2000; Wechsler, Lee, Hall, Wagenaar, \& Lee, 2002). In addition, research has shown that higher alcohol outlet density is not only related to higher alcohol consumption but also to more violence (Zhu, Gorman, \& Horel, 2004).

With respect to opening hours, the same patterns are found in the literature. Restrictions on opening hours are related to a decrease in alcohol consumption, whereas longer opening hours are related to more alcohol consumption (Baker, Johnson, Voas, \& Lange, 2000; Chikritzhs \& Stockwell, 2002; Ligon, Thyer, \& Lund, 1996; Norström \& Skog, 2001; 
Smith, 1998). Finally, a study by Duailibi and colleagues investigating an introduction of restrictions on opening hours showed a significant decrease in murders (Duailibi et al., 2007).

\section{Legal availability}

Age limits are an interesting and effective governmental tool to influence alcohol consumption and related consequences. Underage sales are related to more alcohol consumption (Dent, Grube, \& Biglan, 2005; Paschall, Grube, Black, \& Ringwalt, 2007b) and more binge drinking, drinking at school and drinking and driving (Dent et al., 2005). In general, higher legal drinking ages are related to a decrease in alcohol consumption (Wagenaar \& Toomey, 2002; Yamada et al., 1996).

Research on age limits has also shown that implementation of stricter (higher) legal age limits is related to a decrease of alcohol-related car crashes (Bako et al., 1976; Jones, Pieper, \& Robertson, 1992; Shults et al., 2001; Wagenaar \& Toomey, 2002; Wagenaar et al., 2000b; Whitehead et al., 1975; Williams et al., 1975) and other injuries (Jones et al., 1992).

In today's society, legislations alone (of course) do not create a system without flaws. Age limits on alcohol consumption and alcohol purchases [but also on other products with age limits, including tobacco, gambling products, financial products, and within the Netherlands, soft drugs (e.g. marijuana)] set a formal and normal boundary, but compliance of these age limits is not $100 \%$.

Research in several countries outside the Netherlands has shown that underage adolescents are able to buy alcohol in commercial places despite legal age limits (Britt, Toomey, Dunsmuir, \& Wagenaar, 2006; Grube, 1997; Paschall et al., 2007a; Perry et al., 2002; Romano, Duailibi, Pinsky, \& Laranjeira, 2007; Rossow, Storvoll, \& Pape, 2007; Storvoll, Pape, \& Rossow, 2008; Wagenaar et al., 1996; Wagenaar et al., 2000a; Williams \& Mulhall, 2005; Willner, Hart, Binmore, Cavendish, \& Dunphy, 2000). In the Netherlands, the compliance levels with respect to alcohol sales to underage youths are unknown, especially because those who sell alcohol state that they rarely sell to underage individuals. Nonetheless, adolescents state that it is very easy to buy alcohol. 
Other research related to the abovementioned legislation on age limits has shown the same pattern. In some countries, legislation does not allow the serving of alcohol to intoxicated customers (i.e. over-serving). Nevertheless, intoxicated people are still able to buy alcohol (Toomey, Erickson, Patrek, Fletcher, \& Wagenaar, 2005; Toomey et al., 2004).

When age limits are implied, however, some adolescents try to find other ways to obtain alcoholic beverages. Some adolescents and underage teens falsify identification cards and use fake IDs to purchase alcohol (Fabian, Toomey, Lenk, \& Erickson, 2008; Schwartz, Farrow, Banks, \& Giesel, 1998). Moreover, ownership of a fake ID has been found to correlate with heavy drinking (Martinez, Rutledge, \& Sher, 2007).

Underage adolescents and teens might also have older friends who purchase alcohol for them. In addition, underage adolescents have also asked unknown people to buy them alcohol (so-called "shoulder tapping”) (Fabian et al., 2008; Hemphill, Munro, \& Oh, 2007; Rossow, Pape, \& Storvoll, 2005; Wagenaar et al., 1996; Wagenaar et al., 2000a).

\section{Social availability}

The fourth type of availability is social availability in which the social context of drinking is incorporated. Drinking company plays a significant role in alcohol consumption. Drunk adult drivers often consume their last beverages in a social context, which means that the company they were with implicitly approved of drunk driving (Lang \& Stockwell, 1991; Lee et al., 1985; Stockwell, Lang, \& Rydon, 1993). Teens and adolescents, starting at young ages, also drink alcohol in the company of friends (Mayer, Forster, Murray, \& Wagenaar, 1998; Wechsler, Kuo, Lee, \& Dowdall, 2000), and the drinking behaviour of those peers is related to adolescent alcohol use; drinking peers cause drinking adolescents, the so-called modelling theory) (Barnes \& Welte, 1986; Dishion \& Loeber, 1985; Graham, Marks, \& Hansen, 1991; Kuntsche et al., 2008; Mays et al., 2010; Poelen, Scholte, Willemsen, Boomsma, \& Engels, 2007; Reifman, Barnes, Dintcheff, Farrell, \& Uhteg, 1998; Wood, Read, Palfai, \& Stevenson, 2001; Wood, Mitchell, Read, \& Brand, 2004).

With respect to the drinking environment of teens and adolescents, research has shown that underage individuals have easy access to alcohol in the homes of their parents (Hearst, 
Fulkerson, Maldonado-Molina, Perry, \& Komro, 2007; Hemphill et al., 2007; Jones-Webb et al., 1997; Komro, Maldonado-Molina, Tobler, Bonds, \& Muller, 2007; Komro et al., 1998; Rossow et al., 2005; Storvoll et al., 2008; Swahn, Hammig, \& Ikeda, 2002; Williams \& Mulhall, 2005) and that easy accessibility to alcohol is related to higher alcohol consumption (Komro et al., 2007; Wechsler, Kuo, Lee, \& Dowdall, 2000). Not only do adolescents have easy access to alcohol at home, some parents actively supply alcohol to their underage children (Friese \& Grube, 2008), and some parents let children consume alcohol within their company (Mayer et al., 1998).

Parental alcohol consumption is another aspect of social availability. When parents consume a lot of alcohol, their children also drink more alcohol (Dishion \& Loeber, 1985; Ellickson et al., 2001; Poelen et al., 2007). However, parents are also able to decrease their children's alcohol use by good parenting patterns such as open communication about alcohol (mis)use, creating a safe environment, and by setting clear rules (Barnes, Hoffman, Welte, Farrell, \& Dintcheff, 2006; Barnes, Reifman, Farrell, \& Dintcheff, 2000; DeVore \& Ginsburg, 2005; LaBrie, Hummer, Neighbors, \& Larimer, 2010; Reifman et al., 1998; Van der Vorst, Engels, Deković, Meeus, \& Vermulst, 2007; Van der Vorst, Engels, Meeus, \& Deković, 2006; Van Zundert, Van der Vorst, Vermulst, \& Engels, 2006; Velleman, Templeton, \& Copello, 2005). If parents do so in early youth, the effects of this responsible parenting style remain when teens go to college later in life (Abar \& Turrisi, 2008; Deakin $\&$ Cohen, 1986). In addition, more parental influence also decreases peer influence (Wood et al., 2004).

\subsection{CONCEPTUAL MODEL AND OUTLINE OF THE STUDIES}

In Figure I, I have combined all the consequences and predictors described above in a conceptual model of adolescent alcohol use. As described, adolescent alcohol use may have consequences in adolescence and in adulthood. Prior to adolescent alcohol use, an intention to consume alcohol is formed. That intention is influenced by alcohol visibility (advertising), alcohol education (counterbalancing) and the four types of alcohol availability. 
Figure I: Adolescent alcohol use, predictors, and consequences

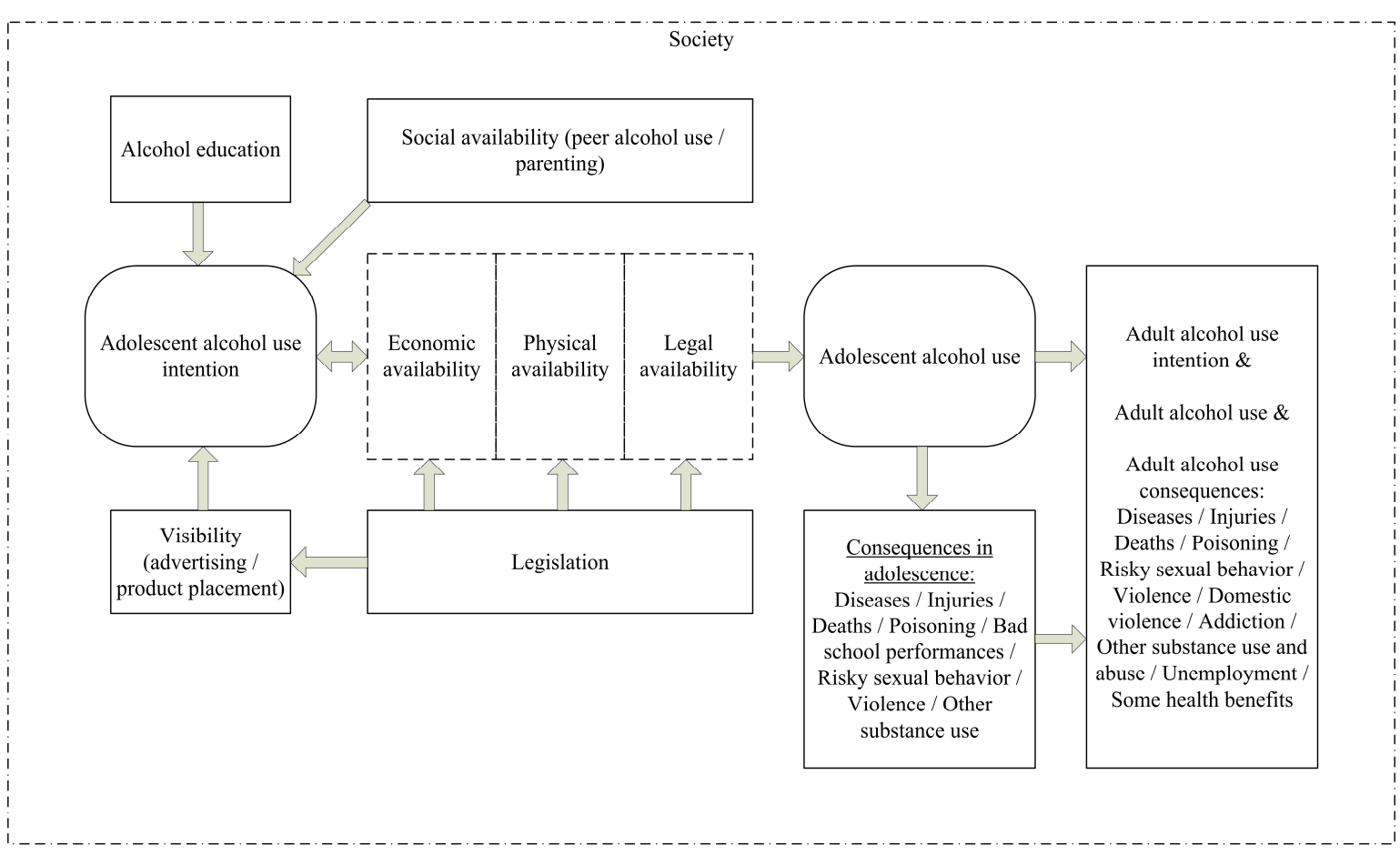

Three types of availability may also function as barriers: economic availability (alcohol price versus money available), physical availability (number of alcohol outlets open versus time available), and legal availability (legislation versus personal situation). By legislation, the government can shape these three forms of legislation (e.g. alcohol tax levels, rules on opening hours and age limits), and the government can also influence visibility (e.g. by placing rules on alcohol advertisements).

In the next nine chapters of this dissertation, I will present studies on the consequences of adolescent alcohol use (chapters 2 and 3) and studies on the predictors and barriers of adolescent alcohol use (chapters 4 to 10). In chapter 11 I will discuss general conclusions and future research directions.

The study presented in chapters 2 and 3 was designed to explore the number and characteristics of adolescents suffering from alcohol intoxication that have been treated in a hospital. 
Chapter 4 presents a study that focused on the aspect of the social availability of alcohol. In interview sessions, we explored the alcohol experiences adolescents have had and the meaning of these experiences for young people. The next study presented in chapter 5 is a quantitative questionnaire study in which we questioned parents about their support of the government's alcohol control policies.

Chapter 6 describes a study in which we explored the effects of alcohol commercials and alcohol product placement in a soap series on the intention of alcohol use in adolescents.

Figure II: Outline of the studies in this dissertation

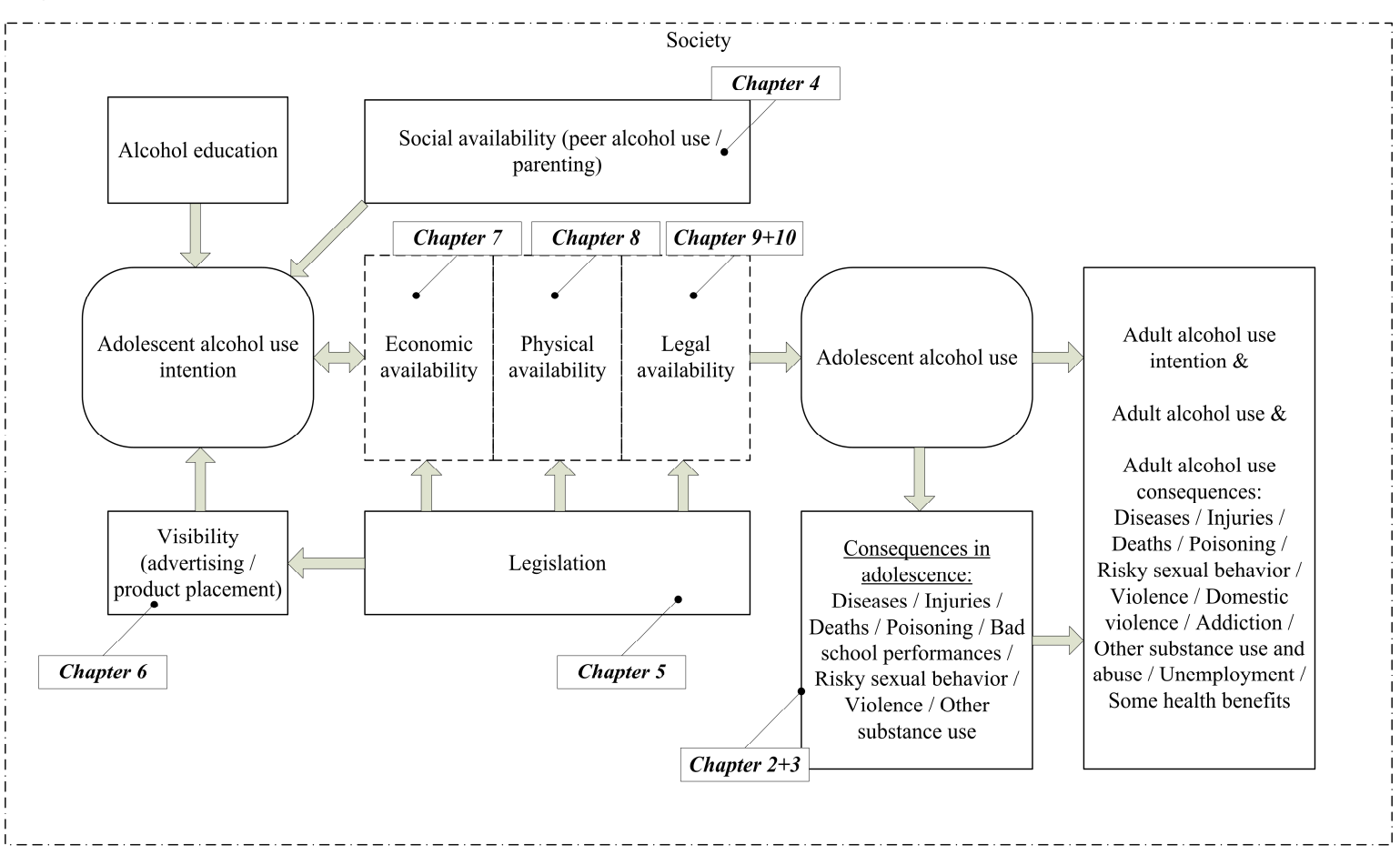

The last four chapters describe studies regarding the three barriers of alcohol availability. The first study in this part focuses on the impact of happy hours and other price discounts on the reported intention of alcohol use in adolescents (chapter 7). We next present a study exploring a trend in the Netherlands with respect to places for alcohol consumption, e.g. drinking in the 'barracks' (chapter 8). In the last two chapters, we first explore the level of compliance with respect to underage alcohol sales in supermarkets and liquor stores (chapter 9). Finally, we describe a field experiment in which we investigated an intervention meant to improve compliance (chapter 10). 
"Once, during Prohibition, I was forced to live for days on nothing but food and water.

W. C. Fields (1879 - 1946) - American actor 


\section{Adolescent alcohol intoxication in the Dutch hospital Departments of Pediatrics}

Joris J. van Hoof

Nico van der Lely

Rob Rodrigues Pereira

Wim E. van Dalen

Journal of Studies on Alcohol and Drugs, 2010, 71, 366-372.

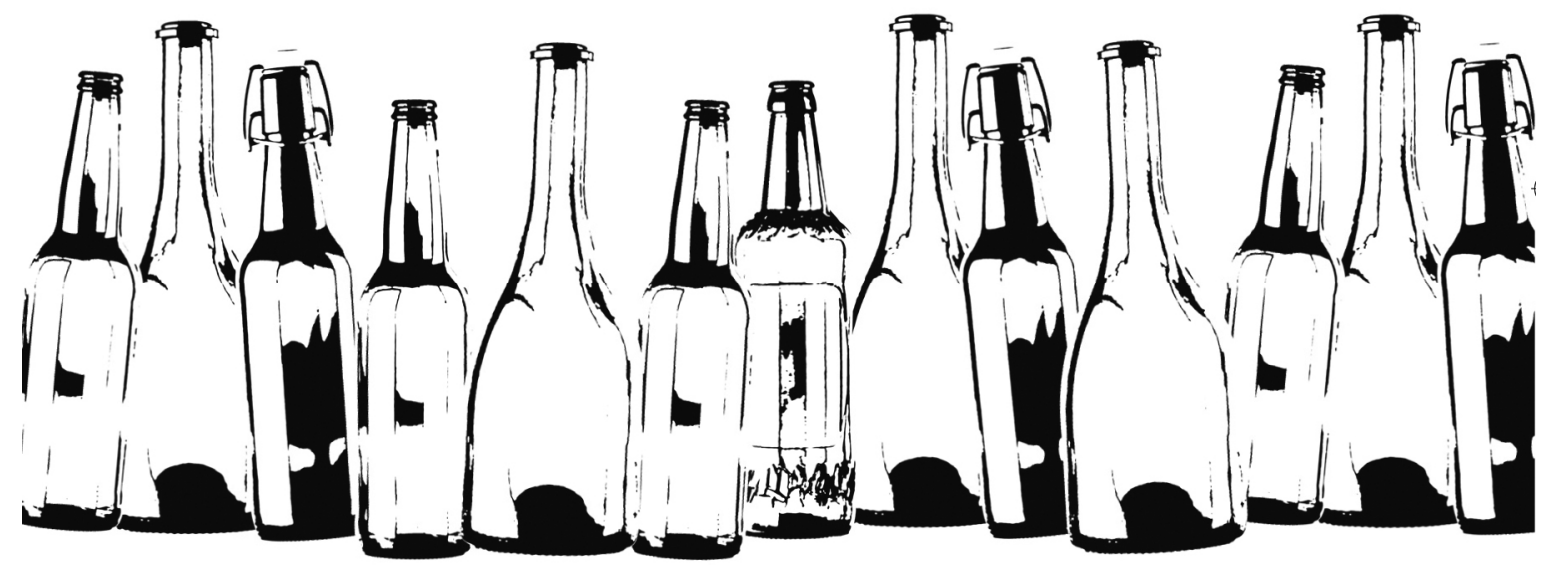




\subsection{ABSTRACT}

Objective: This study was conducted to investigate the number and characteristics of adolescent alcohol intoxication cases in hospital departments of Pediatrics. The study also analyzes drinking patterns and intoxication characteristics.

Method: Data were collected using the Dutch Pediatric Surveillance System (NSCK), in which about $92 \%$ of general pediatricians and $83 \%$ of academic pediatricians participate. In 2007, questionnaires were collected every month within 56 hospitals. A total of 297 adolescent alcohol intoxications were reported, and 231 cases are analyzed.

Results: Hospital-admitted adolescents in this study are 12 to 18 years old, with an average age of 15.3. On all background variables (gender, educational level, family structure), intoxicated adolescents appear to be a representative sample of the Dutch population.

Conclusion: This study shows the serious nature of adolescent intoxication and may indicate that more strict governmental alcohol control policies are required. 


\subsection{INTRODUCTION}

Alcohol consumption is a common element in today's society. It is associated with positive effects, but it also results in many negatives consequences. On the one hand, consuming alcohol might contribute to social well-being on an individual and societal level. On the other hand, alcohol use is correlated with many negative effects on individual health, such as liver disease, heart disease, stroke, intoxication, and mental health issues, as well as with societal issues such as crime, rape, (traffic) accidents, and fighting (Brown, Tapert, Granholm, \& Delis, 2000; Ellickson, Tucker, \& Klein, 2003; Macdonald et al., 2005; Sindelar, Barnett, \& Spirito, 2004; Tapert et al., 2003; Warner \& White, 2003).

Alcohol consumption in adolescents is an increasing health concern. In the Netherlands, alcohol is the most prevalent abused substance among early and late adolescent youths (Hibell et al., 2004; Johnston, O’Malley, Bachman, \& Schulenberg, 2006; Van der Laar, Cruts, Verdurmen, Van Ooyen-Houben, \& Meijer, 2008). Alcohol consumption is even more harmful for one's health at a younger age. The immediate effects of alcohol consumption by adolescents are increased risks of traffic accidents (Sindelar et al., 2004), involvement in fights (Macdonald et al., 2005), falling incidents (Harnett, Herring, Thom, \& Kelly, 1999), unprotected sex (Miller, Naimi, Brewer, \& Jones, 2007; Sen, 2002), and alcohol poisoning (Wilsterman, Dors, Sprij, \& Wit, 2004). Over the long term, the risks are various diseases and even addiction at an older age (National Center for Chronic Disease Prevention and Health Promotion, Division of Adult and Community Health, n.d.). Furthermore, research has shown that alcohol consumption by adolescents has permanent consequences on the brain and that the adolescent brain does not fully develop when children start drinking before the age of 15 (Ellickson et al., 2003). Also, adolescents who drink alcohol score poor results on memory tests compared with adolescents who do not drink alcohol (Tapert et al., 2003). Consuming alcohol, therefore, also negatively influences school performance (Miller et al., 2007).

Parents strongly underestimate their children's alcohol consumption (Verdurmen, Smit, Van Dorsselaer, \& Schulten, 2008), and parents are not completely informed about their children's excessive alcohol consumption (Van Hoof, De Jong, \& Van Noordenburg 
2008). A direct indicator of excessive youth alcohol consumption is alcohol intoxication. In 2006, the Department of Pediatrics in one Dutch hospital (Reinier de Graaf Gasthuis) identified an increase in the number of adolescents who were admitted with alcohol-related infirmities, especially among underage girls. Influenced in part by debates in the media on this topic, we initiated a systematic national study to investigate cases of adolescent alcohol intoxication in Departments of Pediatrics, with a special interest for characteristics of the admitted adolescents, intoxication and related hospital treatment, and established drinking patterns.

Previous studies with data on alcohol intoxication are mainly registered in hospital emergency departments (e.g., Cherpitel, 1993; Marchi et al., 2003; Meropol, Moscati, Lillis, Ballow, \& Janicke, 1995; Vitale, 2007; Weinberg and Wyatt, 2006). The metaanalyses done by Cherpitel (1993) show that the intoxicated populations in emergency departments are 15 years of age and older. As a result of circumstances surrounding the emergency department (such as an ongoing entrance of patients demanding immediate care and a limited number of doctors), only basic information on characteristics of the admitted adolescents is registered, such as blood alcohol concentration, age, and gender (Amdur, 1975; Radenkova-Saeva, 2007; Vitale, 2007; Weinberg \& Wyatt, 2006), and on the alcohol consumption situation, such as the type of alcohol consumed, the time frame of the hospital treatment, and the type of visit (Marchi et al., 2003; Vitale, 2007). Most previous studies have investigated hospital emergency department documentation on alcohol intoxication retrospectively (Cherpitel, 1993), and therefore the data on adolescent characteristics, intoxication characteristics, and drinking patterns are limited. In this study, we developed an extended questionnaire to explore these topics.

\subsection{METHODS}

\section{Procedure}

Data were collected with the use of the Dutch Pediatric Surveillance System, a system with a response rate of about $92 \%$ of the general Departments of Pediatrics and $83 \%$ of the pediatricians in academic hospitals. Every month, the Dutch Pediatric Surveillance System 
sends questionnaires to all Dutch pediatricians in general, and to academic hospitals or representatives of a group of pediatricians. These questionnaires concern 10 to 12 varying predetermined diseases, disorders, or syndromes. At notification of a case, a questionnaire is sent to the responding pediatrician, who fills it in and returns it to the research group. Since 2007, "alcohol intoxication" has been one of the 12 topics in the system.

\section{Materials}

To explore alcohol intoxication prevalence in Dutch Departments of Pediatrics, characteristics of intoxicated adolescents, and drinking situations causing intoxication, we developed a questionnaire containing four parts.

General and demographic information about the adolescent. We collected the following general and demographic information: patient code (control variable consisting of initials of the adolescent, confidential), date of birth ( $\mathrm{dd} / \mathrm{mm} / \mathrm{yyyy})$, gender, living region (first two numbers of postal code), daily occupation (educational level, work), school performance (normal, staying down a class, dropout), family situation (traditional, foster parents, living alone), siblings (none, brother[s], sister[s], both), position to siblings (oldest, middle, youngest), cultural background (Dutch, Moroccan, Turkish, Surinamese, Antillean, other), religious background (none, Roman Catholic, Protestant Christian, Jewish, Muslim, Hindu, Buddhist, other), and adolescent registration to medical or aid agencies (none, pediatrician, psychologist, other professional, mental health care institution, The Netherlands Youth Institute, other).

Patterns of alcohol use and other substance use. We recorded the following data regarding alcohol and substance use: alcohol use in previous months (average number of glasses per week day [Monday-Thursday] and average number of glasses per weekend day [Friday-Sunday]), regular drinking places (parents' home, adolescents' own home, friends' home, on the street, working place, at [a] school [party], public place [sports bar/canteen], commercial place [hotel and catering industry/bar/pub/discotheque], holiday, other), regular (illicit) substance use (none, cannabis, cocaine, amphetamines/speed, magic mushrooms, Ecstasy [3,4- methylenedioxymethamphetamine, or MDMA], other), regular tobacco use (no, yes; if possible, estimated number of cigarettes per week), prescribed medication use (no, yes; if yes, what type of medications/name], and parental knowledge of alcohol use (parents know exactly, parents know approximately, parents believe their adolescent child consumes more or less). 
Intoxication and characteristics of hospital treatment. The following information was assessed regarding intoxication and hospital treatment: time frame of intoxication (morning [6 A.M.-noon], afternoon [noon-6 P.M.], evening [6 P.M.-midnight], night [midnight-6 A.M.]), reason for hospitalization (traffic accident, other accident, aggression/violence, suicide attempt, reduced consciousness-if yes, time of unconsciousness in hours), blood alcohol concentration (grams of alcohol per liter blood), type of alcohol consumed (beer, wine, distilled spirits, premixed drinks, postmixed drinks [home or commercial mixed drinks], other), alcohol-obtaining practice (at home, from friends, supermarket, liquor store, hotel and catering industry, other), alcohol-consuming location (parents' home, adolescents' own home, friends' home, on the street, working place, at [a] school [party], public place [sports bar/canteen], commercial place [hotel and catering industry/bar/pub/discotheque], holiday, other), alcohol-consuming company (nobody, friends, parents, other relatives, unknown people, other), and other (illicit) substances used (none, cannabis, cocaine, amphetamines/speed, magic mushrooms, Ecstasy, other). If respondents answered "yes" to any of the previous questions, the following information was ascertained: how it was determined (adolescents' own acknowledgment, other testimony, judgment of the pediatric doctor, laboratory values/urine, other), total time of hospitalization (days), hospital intensive care use (days), intravenous fluids (yes/no), and hospitalization aftercare (patient forwarded to any medical or aid agency).

Control variables. Finally, some questions were embedded on the date of the intoxication, the date of filling in the questionnaire, pediatrician code number, and the hospital involved.

\section{Response}

In 2007, 297 questionnaires were sent to Departments of Pediatrics in hospitals because of reported alcohol intoxication hospitalizations at those locations. Of these 297 questionnaires, 235 were returned to the researchers and were used in the analyses. Four questionnaires were not used in the analyses (two duplicate copies of an admission were sent by a hospital, and two questionnaires were incomplete). We analyzed a total of 231 adolescent hospital admissions (for a total response rate of $78 \%$ ). 


\section{$2.4 \quad$ RESULTS}

In this section, we report on the analyses of the 231 hospitalized adolescents with respect to alcohol intoxication in 2007. These adolescents were admitted to 56 different Departments of Pediatrics (of the existing 98 Dutch hospitals). A total of 129 pediatricians participated by filling in questionnaires. We will first describe the general demographics of the 231 adolescents and compare that data with national (Dutch) statistics. Second, we will focus on adolescent alcohol-use and other (illicit) drug-use patterns. Finally, we will further investigate the details of alcohol intoxication (both physical as well as contextual) and hospital treatment characteristics.

All 231 reported cases were derived from individual adolescents (analyzing patient code and date of birth). Not all questionnaires were completely filled in, which may be because not all subjects were discussed with the specific adolescents (e.g., drinking patterns). This may also be because doctors are confronted with lack of time, and research, unfortunately, is not the first priority in the hectic daily operations of a hospital. We therefore provide as much as information as possible for the number of cases per question.

\section{General and demographic information about the adolescent}

Of the 231 adolescents hospitalized in Departments of Pediatrics, 52\% were male (Table I). The educational level of the hospitalized adolescents seems similar to national figures regarding educational levels. As can also be seen in Table 1, 44\% of the adolescents in our sample were attending prevocational secondary education (in Dutch, VMBO), $20 \%$ of the sample were attending senior general secondary education (HAVO), 16\% of the sample were attending pre-university education (VWO), and another $20 \%$ of the sample were attending other forms of education or were working (in the Netherlands, there is compulsory education until age 16). These educational levels, to a great extent, are representative of those of Dutch youths. In 2007, about 201,000 students attended the third year of the secondary school system, in which most students have chosen their level. Of these students, approximately $55 \%$ are in the prevocational secondary education level, $20 \%$ are in the senior general secondary education level, $21 \%$ are in the pre-university education level, and another $4 \%$ attend other education types (mostly the combined classes). 
Table I: Demographic information about the adolescents

\begin{tabular}{|c|c|c|c|}
\hline Respondent demographics & $n$ & $\%$ & Age \\
\hline Gender & 231 & & \\
\hline Male & & 52 & \\
\hline Female & & 48 & \\
\hline Educational level & 178 & & \\
\hline VMBO & & 44 & \\
\hline HAVO & & 20 & \\
\hline VWO & & 16 & \\
\hline Other & & 20 & \\
\hline School performance & 163 & & \\
\hline Normal & & 80 & \\
\hline Repeater & & 16 & \\
\hline Drop out & & 4 & \\
\hline Family structure & 207 & & \\
\hline Traditional & & 71 & \\
\hline Other & & 29 & \\
\hline Cultural background & 210 & & \\
\hline Dutch & & 80 & \\
\hline Other & & 20 & \\
\hline Siblings & 168 & & \\
\hline None & & 7 & \\
\hline Brother(s) & & 35 & \\
\hline Sister(s) & & 37 & \\
\hline Both & & 21 & \\
\hline Sibs position & 150 & & \\
\hline Youngest & & 44 & \\
\hline Middle & & 24 & \\
\hline Oldest & & 32 & \\
\hline Age while intoxicated & 230 & & \\
\hline Youngest & & & 12 \\
\hline Oldest & & & 18 \\
\hline$M(S D)$ & & & $15.3(1.2)$ \\
\hline Patient regular treatment by & 205 & & \\
\hline None & & 63 & \\
\hline Pediatric doctor & & 11 & \\
\hline TNYI & & 8 & \\
\hline Other & & 18 & \\
\hline
\end{tabular}

* $\mathrm{VMBO}=$ pre-vocational secondary education, $\mathrm{HAVO}=$ senior general secondary education, $\mathrm{VWO}=$ preuniversity education

* The Netherlands Youth Institute 
Depending on educational level and study year, between $2 \%$ and $17 \%$ of all Dutch students per year repeat a study year (Statistics Netherlands, 2007c). In our sample, 16\% of the students had repeated a study year at least once during their education. This is only a holistic comparison, of course, but even here our sample appears to reflect the Dutch adolescent population.

In the Netherlands, there are 2,472,739 households with children. Of these households, 2,012,375 (81\%) are "traditional families" (married couples) and 19\% are "other families," consisting of 99,610 households with nonmarried couples with children and 360,745 households with divorced parents (Statistics Netherlands, 2007b). In 2007, the total population of the Netherlands was 16,357,992, of which 13,187,586 (80.6\%) inhabitants were native Dutch, and 3,170,406 had other foreign backgrounds (Statistics Netherlands, 2007a). As also can be seen in Table 1, the family structures and cultural backgrounds of the adolescents in the sample represent these national statistics. With respect to siblings, about $40 \%$ of children in the Netherlands do not have any brothers or sisters, whereas in our sample only $7 \%$ of the hospitalized adolescents did not have any siblings. In addition, the adolescents in our sample are more often (44\%) the youngest child in the family (compared with $32 \%$ who are the oldest child).

Another indicator for problem youths was included, namely, whether the adolescents in the sample were familiar with or registered for medical or aid agencies. The Netherlands Youth Institute runs the Dutch system of national youth care, with 15 offices spread throughout the country and 7,144 full-time personnel (MOgroep, 2008). In 2007, the Netherlands Youth Institute served 136,999 youths younger than age 18, which is $7.6 \%$ of all youths in that age group in the Netherlands (National Public Health Compass, 2007). In the sample, $8 \%$ of the adolescents were registered with the Netherlands Youth Institute.

Finally, regarding adolescent age during hospitalization, we found that the youngest child in the sample who was hospitalized related to alcohol intoxication was 12 years old at that time, and the oldest adolescent treated by a pediatrician was 18 years old. The average age of the adolescents was 15.3 years of age. 


\section{Patterns of alcohol use and other substance use}

As can be seen in Table II, the adolescents admitted to hospitals were not heavy alcohol drinkers; weekday consumption (Monday-Thursday) varied from 0 to 5 glasses per day, with a mean of 0.13 glasses per day $(S D=0.64)$. Weekend consumption (Friday-Sunday) varied from 0 to 15 glasses per day, with a mean of 3.00 glasses per day ( $S D=3.54$ ). For $30 \%$ of the sample, the current alcohol consumption event was the first time alcohol was consumed in their lifetime. For favourite drinks (more than one type was allowed to be selected), beer accounted for $59 \%$ of the sample, followed by distilled spirits (21\%), premixed drinks (12\%), wine (11\%), and post-mixed drinks (5\%). The most popular regular drinking locations were a friend's home (54\%), the commercial catering industry, mainly bars (35\%), and their own parents' home (30\%).

In the sample, about $13 \%$ of respondents indicated that they have used cannabis in their lifetime, which is less than lifetime cannabis use in the general Netherlands population (where cannabis use is legal at age 18 and older); 19\% of the adolescents between 12 and 18 used cannabis in their lifetime and $9 \%$ of that age group used cannabis at least once a month (Van der Laar et al., 2008). With respect to tobacco use, about $19 \%$ of the sample smoked cigarettes on a regular basis, which is similar to national Dutch statistics on youth smoking (20\%) (Van der Laar et al., 2008). Furthermore, 19\% of the adolescents in the sample used prescription drugs, which were mostly contraception drugs (for birth control), methylphenidate (Ritalin and others for attention-deficit/hyperactivity disorder), and albuterol (Ventolin HFA and others for asthma). On all three aforementioned topics, the admitted population did not differ significantly from the Dutch population.

Adolescents indicated that their parents "to some extent know" (41\%) how much alcohol they drink or think "they drink less" (39\%). A smaller group (16\%) stated that their parents "exactly know" how much alcohol they consume, and about $4 \%$ of the sample said that their parents think "they drink more" than they actually do. 
Table II: Alcohol use and other substance-use patterns

\begin{tabular}{|c|c|c|c|}
\hline Variable & $n$ & $M(S D)$ & $\%$ \\
\hline \multicolumn{4}{|l|}{ Alcohol consumption } \\
\hline Weekday (range: 0-5 drinks) & 83 & $0.13(0.64)$ & \\
\hline Weekend day (range: 0-15 drinks) & 94 & $3.00(3.54)$ & \\
\hline Abstainers & & & 30 \\
\hline Other (illicit) substance use & 190 & & \\
\hline None & & & 82 \\
\hline Cannabis & & & 13 \\
\hline Ecstasy & & & 1 \\
\hline Cocaine & & & 0 \\
\hline Amphetamines/speed & & & 0 \\
\hline Magic mushrooms & & & 0 \\
\hline Other & & & 4 \\
\hline Cigarette use & 171 & & \\
\hline No & & & 81 \\
\hline Yes & & & 19 \\
\hline Drug use & 91 & & \\
\hline No & & & 81 \\
\hline Yes & & & 19 \\
\hline \multicolumn{4}{|l|}{ Favorite alcoholic beverages } \\
\hline (more than one possible) & 140 & & \\
\hline Beer & & & 59 \\
\hline Wine & & & 11 \\
\hline Distilled spirits & & & 21 \\
\hline Premix & & & 12 \\
\hline Postmix & & & 5 \\
\hline Other & & & 1 \\
\hline \multicolumn{4}{|l|}{ Regular drinking places } \\
\hline (more possible) & 133 & & \\
\hline Parents' home & & & 30 \\
\hline Own home & & & 3 \\
\hline Friend's home & & & 54 \\
\hline Street & & & 15 \\
\hline Work & & & 0 \\
\hline School (party) & & & 17 \\
\hline Public place & & & 8 \\
\hline Commercial catering industry & & & 35 \\
\hline Holiday & & & 9 \\
\hline Other & & & 8 \\
\hline \multicolumn{4}{|l|}{ Parental knowledge about alcohol } \\
\hline consumption & 167 & & \\
\hline Exactly & & & 16 \\
\hline To some extent & & & 41 \\
\hline Think less & & & 39 \\
\hline Think more & & & 4 \\
\hline
\end{tabular}




\section{Intoxication and hospital treatment characteristics}

The characteristics of the hospitalization include information on the alcohol consumption before the hospitalization and treatment. As can be seen in Table III, most hospitalizations occurred during the evening (42\%) and at night (51\%). The reason for hospitalization, by far, turned out to be reduced consciousness (92\%), whereas about 3\% came to the hospital because of a traffic accident, $2 \%$ because of aggression and/or violence, and $1 \%$ because of a suicide attempt (all these events were connected to alcohol consumption). About $2 \%$ had multiple reasons, which always included reduced consciousness.

Alcohol consumption had occurred before the hospital admission in all cases. As shown in Table 3, a considerable number of the admitted adolescents (39\%) consumed two or more different types of alcoholic drinks on the occasion that led to hospital admission. When consuming one type of alcoholic beverage led to hospitalization, distilled spirits (36\%) and beer $(11 \%)$ were the most types reported. Alcohol consumption occurred primarily in the company of friends $(85 \%)$, who also were involved in obtaining alcoholic beverages in $42 \%$ of the reported cases. Other ways in which adolescents stated they obtained alcohol beverages were through the commercial catering industry $(17 \%)$, supermarkets $(11 \%)$, and liquor stores (5\%), all of which are forbidden to sell alcohol to minors. For beer, wine, and premixed drinks, the age restriction in the Netherlands is 16 years old, and for distilled spirits (and postmixed drinks), alcohol sales are permitted only to persons 18 years of age or older. Also, $12 \%$ of the adolescents said they obtained alcohol in their parents' home.

Table III: Intoxication characteristics of the hospitalization

\begin{tabular}{lll}
\hline Intoxication characteristics & $n$ & $M(S D)$ \\
\hline Time frame of hospitalization & 208 & $\%$ \\
Morning & & 5 \\
Afternoon & & 42 \\
Evening & 218 & 51 \\
Night & & 3 \\
Main reason of hospitalization & & 2 \\
Traffic accident & & 1 \\
Aggression/violence & & 92 \\
Suicide attempt & &
\end{tabular}


Multiple reasons

Reduced consciousness $(n=102)$

(range: 10 minutes-16 hours), hours

$2.19(2.24)$

Type of alcohol

217

Beer only

Wine only

Distilled spirits only

Premix only

Postmix only

Other only

Two types of alcohol consumed

Three types of alcohol consumed

Four types of alcohol consumed

Five types of alcohol consumed

Alcohol obtained

215

Parents' home

Friend's home

Supermarket

Liquor store

Commercial catering industry

Other

11

2

36

3

5

4

31

6

1

1

12

42

11

5

17

14

Alcohol consuming location

216

Parents' home

Own home

Friend's home

Street

Work

School (party)

Public place

Commercial catering industry

Holiday

Other

Alcohol consuming company

Nobody

Friends

Parents

Other relatives

Unknown people

Other

BAC (range: 0.05-4.30) $\mathrm{g}$ of alcohol/L blood

Time of hospitalization

$<1$ day

1 day

$>1$ day

Intensive care

No
185

$1.84(0.58)$

$1.08(0.48)$

222

2

85

1

4

3

4

7

1

29

30

0

6

3

16

1

8

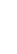
3 
Yes

Other (illicit) substance use

None

Cannabis

Ecstasy

Cocaine

Amphetamines/speed

Magic mushrooms

Other

IV fluids

No

Yes

Notes: $\mathrm{BAC}=$ blood alcohol concentration; $\mathrm{IV}=$ intravenous.
190

Alcohol consumption leading to hospital admission primarily takes place on the streets (30\%) and at friends' homes (29\%). Also, $16 \%$ of alcohol consumption took place in the commercial catering industry, where the same legal restrictions on alcohol sales to minors should be in effect.

Additionally, only a relatively small percentage of the admitted adolescents turned out to have used other (sometimes illicit) substances: $4 \%$ of the youngsters used cannabis, and $2 \%$ used Ecstasy.

The length of reduced consciousness, which was reported to have occurred 200 times, varied from a couple of minutes up to 16 hours, with an average of 2 hours and 11 minutes. Most hospitalized adolescents (77\%) stayed in the hospital for 1 day, about $15 \%$ needed to stay longer, and about $8 \%$ left the hospital on the same day they were admitted. For $11 \%$ of the sample, admission to the hospital's intensive care section was needed. Also, $92 \%$ of the patients were treated with intravenous fluids.

Of the 231 hospitalized adolescents, 106 were reported to have received aftercare; about 20 intoxicated patients received psychological care in the specific hospital in which they were originally admitted, about 20 patients were forwarded to The Netherlands Youth Institute, and about 10 patients were forwarded to their own general practitioner's office. A small number of patients were forwarded to other medical or aid agencies (such as a rehab centre). 


\subsection{DISCUSSION}

This study reported on 231 registered cases of the 297 adolescents who were admitted to hospitals in the Netherlands in 2007 because of alcohol consumption. The real number of underage alcohol victims is naturally far higher because (a) not all hospitals participated in the data collection procedure; (b) not all underage adolescents in hospitals see a pediatrician (they may see an emergency department doctor or another specialist instead) and, therefore, these cases are not registered in the data collection system; (c) not all alcohol-related incidents might be diagnosed as alcohol related; and (d) not all adolescents with an alcohol-related injury or intoxication visit a hospital. However, our data on 231 alcohol-related hospital admissions do give useful insight into the characteristics and drinking patterns of hospitalized adolescents, in the alcohol consumption leading to hospital admission, and in hospital treatment.

The sample of 231 admitted adolescents ranged from 12 to 18 years old. Not all of these adolescents were frequent alcohol consumers; for $30 \%$ of the sample, the alcohol consumption event that led to the current hospitalization was their first alcohol consumption. The other $70 \%$ of the sample had previously consumed alcoholic beverages, but the current occasion apparently got out of hand. That current occasion almost always involved drinking together with friends while drinking more types of alcoholic beverages. Alcohol was obtained through those specific friends, in the commercial catering industry, at home, or in the supermarket. The alcohol was primarily consumed at home, on the streets, and in the commercial catering industry (sometimes more than one different location was involved).

Hospital admission deriving from (excessive) alcohol consumption is quite serious. More than 9 of 10 adolescents (92\%) suffered from reduced consciousness as a result of intoxication, varying from a few minutes up to 16 hours. These types of events are damaging to a young brain. Underage drinking constitutes a public health problem with serious social and personal consequences. Several decades of research have shown that chronic heavy drinking is associated with adverse effects on the central nervous system 
and have revealed some of the processes that give rise to these effects (Tapert, 2005). Pervasive drinking and the highly prevalent emergence of problem drinking and dependence in late adolescence were seen as being inextricably connected to development processes (Windle et al., 2008). As a result of this long period of research, family-based interventions as well as multisystem therapy were designed, developed, modified, and reviewed (Kaminer, Burleson, \& Goldberger, 2002).

Our findings emphasize the need for adequate alcohol policy legislation and for professional patient aftercare. Of the adolescents admitted to Dutch hospitals who were suffering from alcohol intoxication, only $46 \%$ received professional aftercare. More and more hospitals are now starting so-called Policlinic for Youth and Alcohol, in which pediatric screening is performed 3 weeks after admission as well as 4-8 months after admission on a special outpatient clinic. At the end of the admission, prevention starts by means of participation of the child, with help of teaching assistants, using a Dutch interactive Web site. Questionnaires are used by the pediatric psychologists and are distributed to the child, his or her parents, and his or her mentor at school to detect internalizing problems, such as depression, and externalizing problems, such as aggression or attention and/or hyperactivity syndromes. If a problem is detected, children are referred for specialized treatment. Intellectual damage of the alcohol abuse is detected by means of neuropsychological investigations on an "examination day."

This study provides insight into the lack of functioning of the Dutch law with respect to underage youths being able to obtain alcohol. About 33\% of the youths admitted to the hospitals with alcohol intoxication obtained alcoholic beverages directly from places where professional and trained staff sells alcohol (supermarkets, liquor stores, or the commercial catering industry). Further analyses of our data show that about half the adolescents who were younger than age 16 obtained alcohol from those places, which is against the Licensing and Catering Act. However, these findings are in line with previous research in the Netherlands, which made clear that underage youths were able to purchase alcohol in $80 \%-90 \%$ of the purchase attempts (Gosselt, Van Hoof, De Jong, \& Prinsen, 2007). Furthermore, $16 \%$ of the sample not only obtained but also consumed alcohol in the catering industry. In the Netherlands, it is forbidden to sell any alcohol to a youth younger than age 16 (further analyses show that $8 \%$ of the youths younger than age 16 obtained 
alcohol in the catering industry). It is also forbidden to sell alcohol to intoxicated customers. It is plausible that a certain part of the sample got (further) intoxicated in the catering industry (and not only started off their evening there). It is striking that commercial and professional adult stakeholders, whose primary task is to sell a potentially toxic product, do not always seem to take this job seriously and sell alcohol to underage and even intoxicated adolescents. The Dutch authorities such as the Ministry of Agriculture and Nature and Food Quality might consider increasing the power of the Food and Consumer Product Safety Authority, which could raise the legal fines to further inhibit the ability of youths to purchase alcoholic beverages in commercial places. 
"First you take a drink, then the drink takes a drink, then the drink takes you" Francis Scott Key Fitzgerald (1896 - 1940) - American author 


\title{
Adolescent alcohol intoxication in the
}

\author{
Dutch hospital Departments of
}

\section{Pediatrics; a two-year comparison study}

Joris J. van Hoof

Nico van der Lely

Selma H. Bouthoorn

Rob Rodrigues Pereira

Wim E. van Dalen

Journal of Adolescent Health, in press.

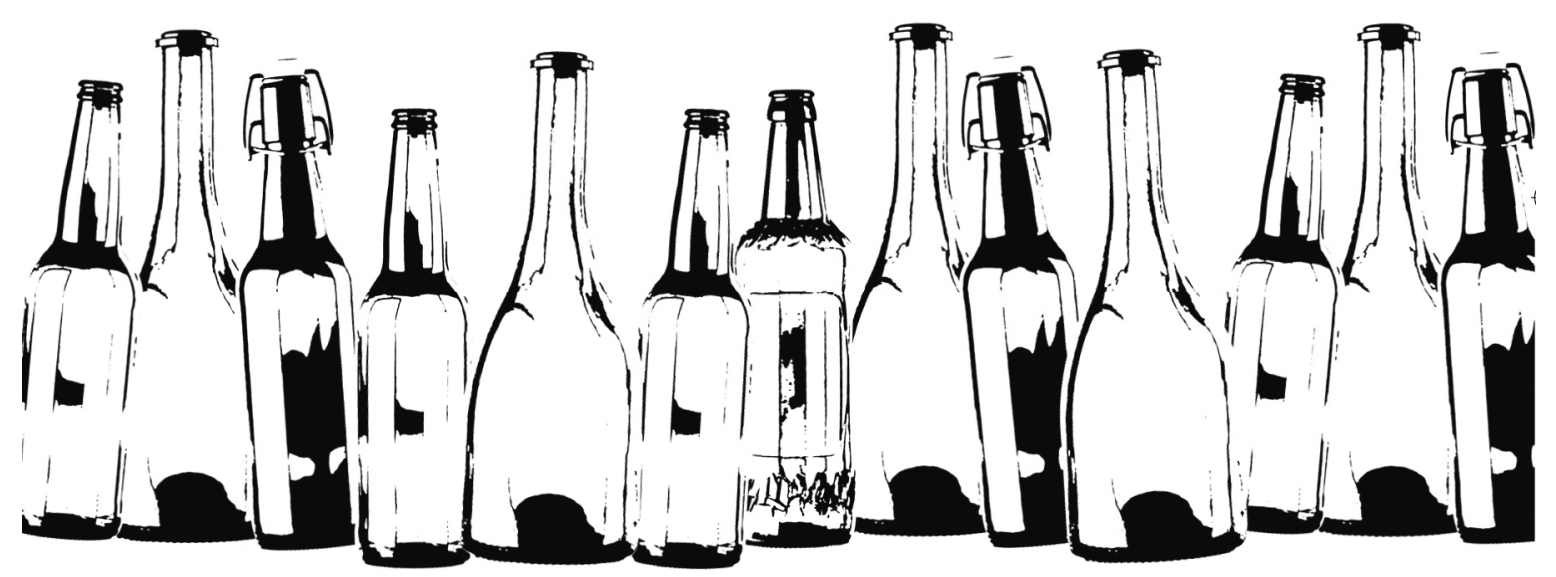




\subsection{ABSTRACT}

Purpose: to monitor the prevalence of, and circumstances leading to, adolescent alcohol intoxication admissions in Dutch hospital departments of pediatrics.

Methods: data were collected in 2007 and 2008, using the Dutch Pediatric Surveillance System (NSCK), in which pediatricians receive questionnaires on varying issues, including adolescent alcohol intoxication admissions.

Results: the adolescents treated in 2008, as in 2007, were average youth across proportion of gender, educational level, school performances, family structure, siblings, familiarity with medical or aid agencies, alcohol use, and other (illicit) drug use. In 2008, $13 \%$ more adolescents were treated. These adolescents showed trends having a younger average age, higher blood alcohol concentrations, and longer durations of mental impairment. About $45 \%$ of the adolescents who were treated suffering alcohol intoxication purchased alcohol in a commercial place, despite 51 times the specific adolescent had not reached the legal age of 16 years old. About a third of the youngsters consumed alcohol at home or at a friend's home.

Conclusions: the number of adolescents suffering alcohol intoxication increased in 2008 compared to 2007. Parental (lack of) involvement and responsibilities of commercial sales personnel are discussed. 


\subsection{INTRODUCTION}

Alcohol consumption by adolescents is a highly important health concern, since alcohol is the most commonly abused substance among early and late adolescent youth, also in the Netherlands (Hibell et al., 2004; Johnston, O’Malley, Bachman, \& Schulenberg, 2006; Sindelar, Barnett, \& Spirito, 2004). Consuming alcohol in adolescence has negative consequences on one's health in both the short term (for example violence, traffic accidents, sexual behaviours, and alcohol intoxication), and the long term (for example various diseases, permanent brain damage, and addiction) (Centers for Disease Control and Prevention, n.d.; Macdonald et al., 2005; Miller, Naimi, Brewer, \& Jones, 2007; Wilsterman, Dors, Sprij, \& Wit, 2004).

Adolescents admitted to hospitals due to alcohol intoxication are an indication of excessive alcohol use by the youth. In 2007, to monitor and explore adolescent alcohol intoxication, a registration system in Dutch hospital departments of pediatrics was developed (Van Hoof, Van der Lely, Van Dalen, \& Rodrigues Pereira, 2010). This system involves information not only about the admitted adolescent, but also on the specific hospital treatment and underlying patterns in adolescent health. Data are supplied by "the first line," which means that the pediatric doctor is the source.

In this Adolescent Health Brief, we present the most important 2008 data and compare the admitted adolescents with the 2007 cases (on key statistics).

\subsection{METHOD}

Data were collected through the Dutch Pediatric Surveillance System (NSCK), in which $83 \%$ of pediatricians in Dutch general hospitals and $92 \%$ in academic hospitals participate. On about ten varying predetermined diseases, disorders, or syndromes, pediatricians fill in monthly questionnaires. Adolescent (0 to 18 years old) alcohol intoxication (BAC $>0$ grams of alcohol / litre blood) has been included in the NSCK system since 2007. The 
Ethical Commission of the Faculty of Behavioural Sciences of the University of Twente approved the study.

\section{Questionnaire}

We administered a questionnaire consisting of four parts; (1) General and demographic information about the adolescent, including gender, age, family structure, patient code, and date of birth, (2) Alcohol use and other substance use patterns, including regular alcohol use patterns, and other (illicit) drug, (3) Intoxication and hospital treatment characteristics, including alcohol purchase location, location of alcohol consumption, time of hospital admission, blood alcohol concentration (BAC), duration of reduced conscience, and hospitalization, and (4) Hospital information, including pediatrician, and hospital name.

\section{Response}

In 2007, within the participating 84 (out of 98) hospitals, a total number of 297 admissions was reported. After a notification within the NSCK system, a questionnaire was send to the specific pediatrician. 233 questionnaires were returned, of which 231 questionnaires were useful for further analyses (a response rate of 78\%). In 2008, 337 cases were reported, of which 288 questionnaires were analyzed (a response rate of 85\%). The number of adolescents admitted to hospitals with alcohol intoxication increased by $13 \%$ between 2007 and 2008. With about 1,400,000 adolescents in the age category 11 to 18 years old, the number of reported intoxicated adolescents increased approximately significant $\left(\chi^{2}[1, \mathrm{~N}=2,800,634]=2.53, \mathrm{p}=.06\right)$. All reported cases were derived from individual adolescents (analyzing patient code and date of birth). 


\subsection{RESULTS}

Besides the $13 \%$ increase in admitted adolescents, adolescents admitted in both years show a similar proportion of gender $\left(\chi^{2}[2, \mathrm{~N}=518]=1.03, \mathrm{p}=.60\right)$, educational level $\left(\chi^{2}[9, \mathrm{~N}=406]=5.37, \mathrm{p}=.80\right), \quad$ school performances $\quad\left(\chi^{2}[3, \mathrm{~N}=369]=0.09, \mathrm{p}=.99\right)$, family structure $\left(\chi^{2}[3, \mathrm{~N}=471]=0.59, \mathrm{p}=.90\right)$, siblings $\left(\chi^{2}[4, \mathrm{~N}=386]=4.57, \mathrm{p}=.33\right)$, familiarity with medical or aid agencies $\left(\chi^{2}[7, \mathrm{~N}=467]=11.75, \mathrm{p}=.11\right)$ alcohol use $\left(\chi^{2}[4, \mathrm{~N}=238]=2.81, \mathrm{p}=.59\right)$, and other (illicit) drug use $\left(\chi^{2}[6, \mathrm{~N}=485]=9.91, \mathrm{p}=.13\right)$. In 2008, equal to 2007, the distribution of the above mentioned characteristics appear proportional to nation-wide statistics (Van Hoof et al., 2010).

The alcohol use behaviour that led to the intoxication incident took place while drinking with friends (in 2007 in $85 \%$ of the intoxications, and in $90 \%$ of the cases in 2008). In both years, about a third of the adolescents were drinking at a friend's home, while another third drank on the streets. About $15 \%$ of the adolescents consumed alcohol in a bar or discotheque, despite the fact that they were under-aged. About $45 \%$ of the adolescents purchased alcoholic beverages in a supermarket or liquor store (though they consumed these off the premises), despite the fact 51 times an adolescent had not reached the legal age to purchase such beverages (in the Netherlands, the legal age limit for purchasing beverages with a low alcohol content, including fortified wines, is 16 years old, and it is 18 years old for spirits containing $15 \%$ alcohol or more).

Despite the modifications of the three key indicators (age while intoxicated, duration of reduced conscience, and BAC) are not statistically significant, the tendencies over 2008 are worrisome (see Table I). 
Table 1: Intoxication characteristics

\begin{tabular}{llll}
\hline & & 2007 & 2008 \\
& & $\mathrm{~N}=231$ & $\mathrm{~N}=288$ \\
\hline Age while intoxicated & Youngest & 12 years-old & 11 years-old \\
& Oldest & 18 years-old & 17 years-old \\
& Average (SD) & $15.3(1.2)$ years-old & $15.0(1.2)$ years-old \\
\hline Duration of & Minimum & couple of minutes & couple of minutes \\
reduced conscience & Maximum & 16.0 hours & 24.0 hours \\
& Average (SD) & $2.2(2.2)$ hours & $2.9(3.2)$ hours \\
\hline BAC (grams alcohol / & Minimum & 0.05 & 0.03 \\
liter blood) & Maximum & 4.30 & 5.50 \\
& Average (SD) & $1.84(0.58)$ & $1.88(0.65)$ \\
\hline
\end{tabular}

In 2007, the youngest adolescent admitted to a hospital with alcohol intoxication was 12 years of age, and in 2008, the youngest adolescent treated was 11. The mean age of all admitted adolescents decreased from 15.3 in 2007 to 15.0 in 2008 ( $t[513]=-1.46, p=.145)$. The duration of mental impairment increased from 2.2 hours on average in 2007 (with a maximum of 16 hours) to 2.9 hours (with a maximum of 24 hours) $(t[199]=-1.82, p=.070$ ). Finally, the blood alcohol concentrations (BAC was determined by laboratory blood tests, obtained at diagnostic assessment) also increased from 1.84 in 2007 to 1.88 in 2008 $(t[448]=-0.79, p=.428)$.

\subsection{DISCUSSION}

Despite ongoing national health promotion campaigns, in-service compliance campaigns, and local initiatives to enforce alcohol laws, the number of adolescents suffering from alcohol intoxication increased by $13 \%$ in 2008 (compared to 2007). A remark should be made that this raise might also be influenced by an increased attention of the Dutch Pediatric Surveillance System within the group of participating pediatricians. In both years, other characteristics demonstrate that these adolescents are average youngsters, who, possibly accidently, drink an amount of alcohol that causes intoxication.

About a third of the adolescents suffering alcohol intoxication consumed alcohol at a friend's home; therefore the role of parents needs further attention. Apparently, alcohol is 
easily available, and parental supervision is lacking. In addition to this 'social availability' in both years, a large proportion (about 45\%) of the admitted adolescents obtained, or consumed (about 15\%), alcohol in a commercial setting. Unfortunately, violating the Dutch Licensing and Catering Act, sales personnel in supermarkets and liquor stores sell alcohol to youth who are too young to buy alcohol. More worrisome are sales in bars and discotheques, where $15 \%$ of the intoxicated youth finished their evenings (and were transported to a hospital). We found, in line with previous research, that 51 times an adolescent who obtained alcohol commercially was under-aged (Gosselt, Van Hoof, De Jong, \& Prinsen, 2007). This means that almost $15 \%$ of the alcohol intoxications would not have happened if commercial sales personnel complied with the legal age limits. Clearly, much remains to be desired when it comes to preventing the illegal sale of alcohol to minors. 
"I like liquor - its taste and its effects - and that is just the reason why I never drink it" Thomas Jonathan Jackson (1824 - 1863) - American teacher and soldier 


\section{Making Sense of Alcohol Experiences.}

\section{Young Adolescents' Accounts of}

\section{Alcohol-Related Critical Incidents}

Joris J. van Hoof

Saskia G.M. van den Boom

Menno D.T. de Jong

Submitted.

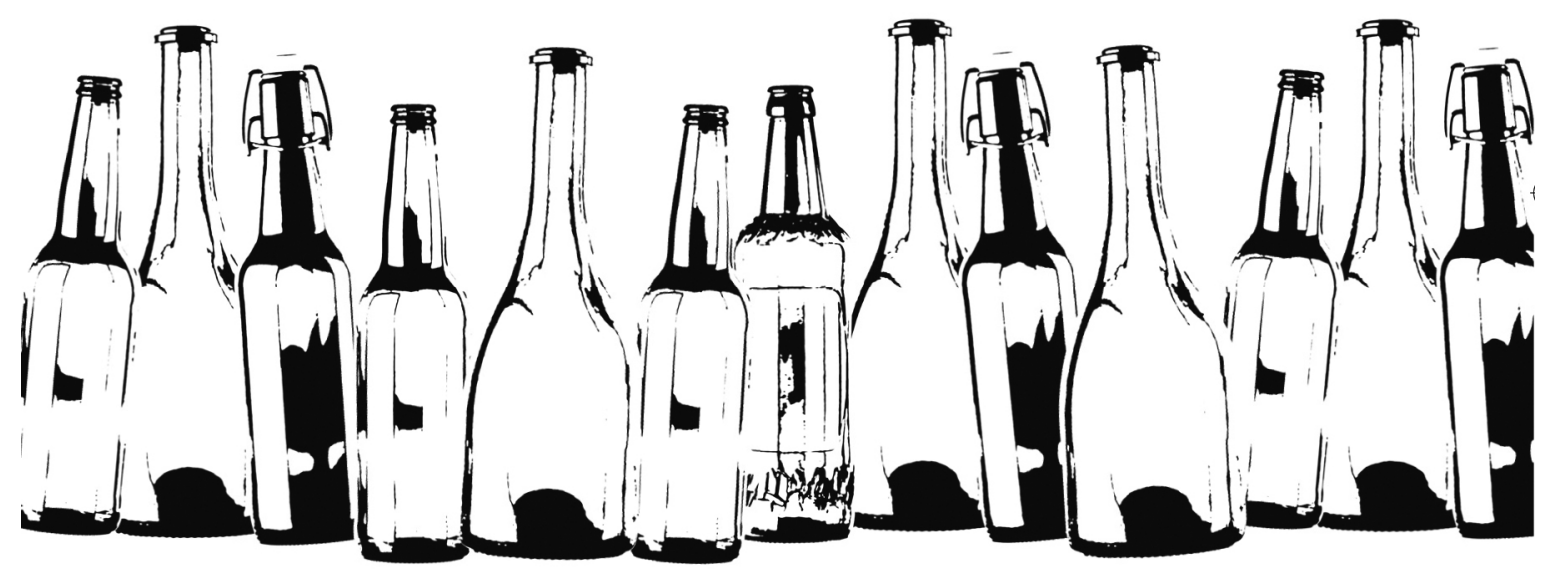




\subsection{ABSTRACT}

Objective: This study explores how alcohol use is incorporated in the lives of young adolescents in the Netherlands. To this end, critical incidents involving alcohol use situations are analyzed. Special attention is paid to the consequences associated with alcohol use, the role of the parents, and the way adolescents evaluate incidents and link them to behavioural intentions.

Method: Data were collected in 45 interviews using the critical incident technique. Participants were asked to mention salient alcohol-related incidents, which they had either experienced or observed. Participants were 45 adolescents, aged 15 and 16, who were recruited at high schools.

Results: A total of 145 incidents were described. Many different, mostly adverse, consequences were associated with the incidents. Parents only played a minor role: they were not always aware of incidents, and if they were, they often did not take them seriously. Two tendencies were found in adolescents' sense making of incidents: the tendency to link adverse consequences to positive overall experiences, and the tendency to not translate negative overall experiences into lower drinking intentions.

Conclusion: The study shows that alcohol is already deeply rooted in the lives of adolescents. The role of parents appears to be problematic. Furthermore, the study underlines the complexity of the problem of adolescent alcohol use. If their own experiences and first-hand observations do not substantially lead to lower drinking intentions, it does not seem plausible that alcohol information and education materials focusing on consequences will. 


\subsection{INTRODUCTION}

Alcohol is considered to be the most used and most harmful drug, also in the Netherlands (Van der Laar, Cruts, Verdurmen, Van OoyenHouben, \& Meijer, 2008). Both in the short and the long term, the negative consequences associated with alcohol consumption are numerous. For example, traffic accidents, intoxication, and various diseases are univocally related to alcohol use (e.g., Babor et al., 2003; Corrao, Bagnardi, Zambon, \& Arico, 1999; KWF, 2004; Longnecker, Orza, Adams, Vioque, \& Chalmers, 1990; Rehm et al., 2003; Tapert, Aarons, Sedlar, \& Brown, 2001).

Adolescent alcohol use is a risk factor of extra concern. In addition to the drawbacks mentioned above, adolescent alcohol use is found to be related to experimenting with other drugs (the so-called 'gateway theory'), alcohol addiction at higher ages, bad school performance, severe alcohol intoxication, and brain damage (Babor et al., 2003; Grant et al., 2006; Kandel, Yamaguchi, \& Chen, 1992; Townsend, Flisher, \& King 2007; Van Hoof, Van der Lely, Rodrigues Pereira, \& Van Dalen, 2010).

Prior drinking experiences may be an important source of information when individuals make decisions about the quantity of alcohol to consume (Mallet, Lee, Neighbors, Larimer, $\&$ Turrisi, 2006). Previous studies mainly assessed the types of consequences associated with (excessive) drinking behaviours (e.g. Hauge \& Irgens-Jensen, 1986; Mäkelä \& Mustonen, 2002; Nyström, 1992). Research shows that consequences of excessive alcohol use are injuries (Presley, Meilman, \& Cashin, 1996), behavioural problems (Montgomery \& Haemmerlie, 1993; Wood, Sher, \& McGowan, 2000), physical aggression (Giancola, 2002; Marcus \& Reio Jr., 2002), and risky sexual behaviour (Abbey, McAuslan, \& Ross 1998; Wechsler, Lee, Kuo, \& Lee, 2000).

Few studies have focused on the way people interpret alcohol experiences, and use them for their future drinking intentions. In a large-scale study involving 2,800 respondents between 15 and 69 years old, Mustonen and Mäkelä (1999) found that public and largegroup drinking situations are relatively often connected to negative experiences, and that private and intimate situations are often linked to positive experiences. Other studies have 
demonstrated that health-related experiences-such as hospitalization and medical problems-may affect subsequent drinking behaviour among adults (e.g., Dunn et al., 2003; Perreira \& Sloan, 2001). Barnett et al. (2003) found, for instance, that adult emergency-room patients were likely to have an intention to reduce excessive drinking after being treated for an alcohol-related incident.

In this study, we will focus on the way young adolescents make sense of alcohol experiences in their lives. First, we investigate in detail to what extent and how alcohol use is embedded in the lives of adolescents. Second-and this is obviously different than in the research among adults-we aimed to find out how parents are involved in the alcoholrelated incidents of their children: do they know, and how do they react? Third, we explored whether the straightforward reactions to adverse consequences that were found in the aforementioned studies among adults also apply to adolescents: does experiencing negative effects of alcohol use indeed lead to lower drinking intentions?

\subsection{METHODS}

\section{Procedure}

Data were collected using semi-structured interviews, based on the critical incident technique (CIT; Flanagan, 1954), among adolescent high school students. Confidentiality was assured to all participants. The research design was approved by the high school boards concerned and the ethical commission of the Faculty of Behavioural Sciences of the University of Twente. Informed consent was given by all participants, as well as by their parents (by letter). No compensation was offered for participation.

Before the actual data collection, four test interviews were held with two male and two female participants, with different levels of education. The test interviews served to evaluate whether the CIT would work in this context and to identify specific questions that would cause problems for participants. In the test interviews, the interview protocol was complemented with questions about the participants' interpretation of questions (e.g., 'Can you state in your own words what I asked you to answer?') and their experiences 
answering questions (e.g., 'Did you have problems answering this question?'). All test participants appeared to be able to discuss salient alcohol experiences. They all mentioned two or three alcohol-related incidents, including both positive and negative ones. Furthermore, the test interviews showed that the interview protocol worked well; only few minor changes had to be made to further optimize the protocol.

The interviews were held on different weekdays in designated offices of the participating high schools. On average, the interviews lasted 35 minutes (range: 10-60 minutes). All interviews were conducted by the same interviewer (the second author).

\section{Interview protocol}

The interview protocol was based on the CIT. 'Critical incidents' (either positive or negative) serve as 'triggers' or 'entrances' for the participants to retrospectively describe and assess issues in life-in our study: alcohol use. The technique gives participants complete freedom in describing any kind of experience, stressing those incidents that are salient to the participants themselves. The technique allows us to focus on specific events instead of generalized attitudes, and to explore these events in detail.

The interviews started with a question about participants' first alcohol experience. The participants were asked to describe their first alcohol consumption. When participants indicated that their first drinking experience got out of hand, this experience was treated as a first incident.

The participants were then asked to describe situations of alcohol use they had either experienced or observed, which they considered to be memorable in a positive or negative sense. For each incident, one at a time, the participants were asked to describe in detail what happened. The interviewer checked a list with topics-who were involved, when and where did it happen, how much alcohol was consumed, what kind(s) of beverages were consumed, what did their parents know and how did they react—and asked about topics not mentioned.

After participants had given a complete account of an incident, they were asked to indicate on a five-point scale whether they perceived the incident to be positive or negative, and 
whether it had affected their drinking behaviours. The following options were offered: $1=$ intention to drink more, 2 = no change in drinking intentions, $3=$ intention to drink less, but fall back to pre-incident consumption, 4 = intention to drink less, and actually do so, 5 = complete alcohol abstinence.

This procedure was repeated until no more salient alcohol experiences were given. When participants only mentioned either positive or negative incidents, the interviewer asked for incidents highlighting the other side of the coin. When participants only mentioned incidents they had observed, the interviewer asked for incidents reflecting their own experiences, and vice versa. At the end of the interview, participants filled out a short questionnaire about their background characteristics.

\section{Participants}

Our initial sample consisted of 55 15- or 16-year-old adolescents who attended four high schools in the Netherlands. Two schools were in the northeast region, and two were in the south. Participants were randomly selected, and were informed in advance about the topic of the interview. In the initial sample, ten participants indicated that they did not have any experience with alcohol. They were excluded from the interviews. Interviews were held with 45 adolescents. Their mean age was $15.4(\mathrm{SD}=.7)$, which indicates that the majority of the participants had not reached the legal drinking age in the Netherlands (which is 16 for lower-percentage beverages, and 18 for beverages with higher alcohol percentages). Table I gives an overview of the participants' background characteristics. 
Table I: Participants’ background characteristics.

\begin{tabular}{lll}
\hline & & Number of respondents (\%) \\
\hline \multirow{3}{*}{ Education } & Male & $26(58)$ \\
& Female & $19(42)$ \\
\multirow{4}{*}{ Region } & Lower education & $22(49)$ \\
& Higher education & $23(51)$ \\
\multirow{3}{*}{ Home situation } & Northeast & $23(51)$ \\
& South & $22(49)$ \\
& Married or cohabiting parents & $39(87)$ \\
\hline
\end{tabular}

\section{Data analysis}

All interviews were audio recorded and transcribed verbatim. Only incidents experienced or observed by the participants themselves were included in the analysis; alcohol-related stories participants had heard from someone else were excluded. Two other inclusion criteria were that the incident was indeed a demarcated event, and not a longer-lasting situation, and that the incident was entirely and clearly described. In all, four incidents were excluded because they did not meet these criteria.

The critical incidents were coded on the following aspects:

- $\quad$ Type of incident: experience, first-hand observation, or a combination of both;

- $\quad$ Type(s) of alcohol consumed;

- $\quad$ Amount of alcohol consumed;

- Consequences: physical consequences, social consequences, behavioural consequences, practical consequences, and (self-)criticism;

- $\quad$ Parents' awareness of the incident (and, if so, how they found out); and

- $\quad$ Parents' reaction to the incident.

For each incident, one main consequence was coded. However, since incidents may have multiple consequences, one or more additional consequences could also be given.

To test the coding scheme, 50 incidents (from 15 participants), including first experiences, were independently analyzed by two coders. The inter-coder reliability (Cohen's kappa) varied from 0.72 to 1.00 . 


\subsection{RESULTS}

\section{Critical incidents described}

The 45 participants came up with as many as 145 alcohol incidents. On average, 3.2 incidents per participant were mentioned $(\mathrm{SD}=1.4)$ with a maximum of 6 incidents.

More than half of the incidents (53\%) involved experiences of the participants themselves, $40 \%$ were first-hand observations of other people's drinking behaviours, and $7 \%$ were combinations of experiences and first-hand observations. Incidents that were first mentioned predominantly concerned the participants themselves (73\%).

The amount of alcohol consumed in the incidents was generally high. For 126 of the incidents, participants were able to estimate the amount of alcohol consumed. In $61 \%$ of these incidents, binge drinking was involved (six or more glasses of alcohol). In another $25 \%$, binge drinking may have been involved: although the participants talked about one to five glasses of alcohol, the state of intoxication they described suggests that more glasses of alcohol may have been consumed. In only $14 \%$ of the incidents, fewer than six glasses had been consumed.

Many different consequences were associated with the incidents. Table II gives an overview of the types of consequences mentioned. For each of the 145 incidents, one main consequence was coded. 'Becoming ill' was the most prevalent main consequence (19\%), followed by 'doing strange things' (16\%), 'interpersonal conflicts' (12\%), 'accidents or injury' (11\%), and 'making contact more easily' (10\%). Furthermore, 'becoming ill' was mentioned in $22 \%$ of the incidents as an additional consequence, followed by 'doing strange things' (21\%), 'accidents or injury' (12\%), and 'memory loss' (10\%). With the exception of social consequences, all consequences mentioned had negative connotations, varying from temporary nuisances to severe problems. 
Table II: Consequences of alcohol use in the 145 critical incidents.

\begin{tabular}{|c|c|c|c|c|}
\hline Category & Consequence & Main* & Add.** & Example \\
\hline \multirow[t]{9}{*}{ Physical } & Feeling ill & $19 \%$ & $22 \%$ & 'I threw up in my bed.' \\
\hline & & & & 'He was suffering from a hangover the next day.' \\
\hline & Accidents/injury & $11 \%$ & $12 \%$ & 'I fell from my bike when I went home.' \\
\hline & & & & 'Boyfriend had an injury because he climbed on car.' \\
\hline & Blacking out & $6 \%$ & $1 \%$ & 'She passed out after she drank the bottle on her own.' \\
\hline & Memory loss & $4 \%$ & $10 \%$ & 'I didn't know anymore what happened the next day.' \\
\hline & & & & 'I heard afterwards that I did some stupid things. \\
\hline & Hospital adm. & $0 \%$ & $5 \%$ & 'The ambulance took my sister to the hospital.' \\
\hline & & & & 'I had to go to the hospital because alcohol poisoning.' \\
\hline \multirow[t]{6}{*}{ Social } & Doing strange & $16 \%$ & $21 \%$ & 'I did some reckless things I normally wouldn't do.' \\
\hline & & & & 'I danced on a stage. I was totally crazy.' \\
\hline & Contact easily & $10 \%$ & $4 \%$ & 'I kissed a girl, which I wouldn't do if I were sober.' \\
\hline & & & & 'I got closer to a boy I just met.' \\
\hline & Have good time & $7 \%$ & $7 \%$ & 'We had a drink. It was a nice evening, nothing more.' \\
\hline & & & & 'Everybody was just having a good time.' \\
\hline \multirow[t]{4}{*}{ Behavioural } & Interpers. Confl & $12 \%$ & $4 \%$ & 'I got involved in a fight with some guys in the disco.' \\
\hline & & & & 'I wounded another guy.' \\
\hline & Robbery or theft & $0 \%$ & $1 \%$ & 'My wallet was stolen by somebody who was drunk.' \\
\hline & Dam./vandalism & $2 \%$ & $3 \%$ & 'The boy smashed a shop window.' \\
\hline \multirow[t]{7}{*}{ Practical } & Problems sleep. & $3 \%$ & $3 \%$ & 'I couldn't find a place to sleep.' \\
\hline & & & & 'I woke up and saw that I slept outside in the grass.' \\
\hline & Work/school & $3 \%$ & $1 \%$ & 'They failed an exam because of drinking.' \\
\hline & & & & 'I drank during school time.' \\
\hline & & & & 'I had a hangover when I had to go to work.' \\
\hline & Problem police & $1 \%$ & $6 \%$ & 'I was arrested because I was a little drunk.' \\
\hline & & & & 'He got a fine because he was drunk.' \\
\hline \multirow[t]{2}{*}{ (Self-) criticism } & Worries/self-crit. & $3 \%$ & $7 \%$ & $\begin{array}{l}\text { 'I had to take care of an intoxicated friend and was } \\
\text { really worried.' }\end{array}$ \\
\hline & Criticism others & $2 \%$ & $3 \%$ & 'My father gave hard time because I drank too much.' \\
\hline
\end{tabular}

Percentage of incidents in which consequences was mentioned as main consequences* or additional consequence**

\section{Role of the parents}

The role of the parents with respect to the reported incidents is summarized in Table III. In most cases (55\%), participants indicated that their parents knew about the incident. However, in a substantial number of cases, the parents only knew the tip of the iceberg $(22 \%)$ or nothing at all $(22 \%)$. The following example illustrates the participants' reluctance to share alcohol-related experiences with their parents, which was sometimes justified by participants' low expectations of their parents' interest in such experiences: 
'I didn't tell anything about it to my parents. What should they have to do with that kind of information? I never tell things like that. They also don't ask about these issues.'

Table III: Knowledge and reaction of the parents about the alcohol incidents.

\begin{tabular}{lll}
\hline Parental awareness of the incident & Fully aware & $55 \%$ \\
& More or less aware & $22 \%$ \\
& Not aware & $22 \%$ \\
If aware: How did parents find out? & They were part of the incident & $38 \%$ \\
& They found out themselves & $36 \%$ \\
& Participant told them & $26 \%$ \\
If aware: How did parents react? & Approval, laughter, no reaction & $60 \%$ \\
& Advising against & $29 \%$ \\
& Forbidding & $10 \%$ \\
\hline
\end{tabular}

Parents became aware of the incidents in various ways. First of all, in many incidents, they were part of the scenery: they were present at the time of the incident (38\%). Second, they found out about the incident themselves, for instance because their child came back home sick or had a hangover the next day, or because they heard about the incident from others $(36 \%)$. Less often, participants had told their parents themselves what happened (26\%).

If parents were aware of the incident, the majority reacted very mildly: they approved, laughed or did not react at all $(60 \%)$. Only in $39 \%$ of the incidents, the parents appeared to have taken the incident seriously, either by advising against such behaviours or by forbidding them in the future. The following examples illustrate the mild reactions of parents:

'My parents found out that I suffered from a hangover because we were having breakfast and I had to throw up everything. They laughed about it.'

'Then my parents discovered scratches on my face. They asked me what happened. I told them that I fell of my bike because I was not able to ride my bike anymore. They started to laugh at me. That was funny.' 
In many cases, participants suggested that their parents did not seem to feel responsible about their alcohol use. Instead, they seemed to have the opinion that their children should learn about the drawbacks of alcohol themselves. For example:

'I think my parents think it's okay. They always say that I have to decide for myself how much I drink. "You know how we think about it", they always say, but in fact I don't. They only say something like "You know what's good for you and what you can handle”.'

'I puked in the toilet. My mom and dad said that this showed my maximum on alcohol consumption. I think they thought it was good for me that I experienced myself how it felt to be sick of alcohol. They think I can learn from it.'

'I think my parents don't care if I'm drunk. When I am nauseous, they say that it's my own responsibility. My father always says that it's my own fault.'

In all, the combination of not knowing (44\%) and not caring (60\%) severely limits the role of parents in the prevention of alcohol-related incidents. In only $22 \%$ of all incidents, parents did know about them and expressed their concerns to their children.

\section{Participants' evaluation of the incidents}

Participants evaluated each incident on a five-point scale (from entirely negative to entirely positive). Table IV gives an overview of these ratings. The table shows that participants were inclined to interpret the incidents in a positive way, even though the majority of the consequences were negative. Overall, 55\% of the incidents were considered to be (mainly or entirely) positive; only $25 \%$ of the incidents were seen as (mainly or entirely) negative. This is remarkable because the CIT often triggers more negative than positive incidents (Downs \& Adrian, 2004).

Table IV also displays the participants' evaluation of the six most prevalent consequences (mentioned ten times or more as main consequence). Not surprisingly, the incidents with positive main consequences 'having a good time' and 'making contact more easily' were evaluated positively. 
Table IV: Participants' overall evaluation of incidents.

\begin{tabular}{llllll}
\hline Category & $\begin{array}{l}\text { Entirely } \\
\text { negative (1) }\end{array}$ & $\begin{array}{l}\text { Mainly } \\
\text { negative (2) }\end{array}$ & $\begin{array}{l}\text { Neutral } \\
\mathbf{( 3 )}\end{array}$ & $\begin{array}{l}\text { Mainly } \\
\text { positive (4) }\end{array}$ & $\begin{array}{l}\text { Entirely } \\
\text { positive (5) }\end{array}$ \\
\hline Total & $10 \%$ & $15 \%$ & $19 \%$ & $15 \%$ & $40 \%$ \\
\hline Feeling ill & $7 \%$ & $22 \%$ & $26 \%$ & $19 \%$ & $26 \%$ \\
Accidents or injury & $6 \%$ & $0 \%$ & $6 \%$ & $19 \%$ & $69 \%$ \\
Doing strange things & $4 \%$ & $9 \%$ & $9 \%$ & $13 \%$ & $65 \%$ \\
Contact more easily & $7 \%$ & $0 \%$ & $33 \%$ & $13 \%$ & $47 \%$ \\
Having a good time & $0 \%$ & $0 \%$ & $0 \%$ & $0 \%$ & $100 \%$ \\
Interpers. conflicts & $11 \%$ & $33 \%$ & $28 \%$ & $22 \%$ & $6 \%$ \\
\hline
\end{tabular}

Note: Only consequences mentioned ten times or more as main consequence are included

However, also incidents with more negative main consequences ('feeling ill', 'accidents or injury', 'doing strange things', and 'interpersonal conflicts') received substantial numbers of positive evaluations. For example, incidents involving accidents or injury were evaluated mainly positive in $19 \%$ of the cases and entirely positive in $69 \%$. Adolescents often had the tendency of turning adverse consequences of alcohol use into positive overall evaluations. Negative consequences were counterbalanced by other aspects of the incident. For instance:

'There's nothing you can do about it. If I have such a nice evening beforehand, then I accept that I'm ill for two days.'

'The fight was negative. That sucked. But the rest of the evening was very nice. I was drunk, so that was really positive.'

In some cases, however, the negative consequences were even considered to be "part of the fun.' For example:

'We drank a lot. Our sports coach was also there and he was drunk. We caused an accident with his car. We drove really hard against a pole. (...). It was very cool. We really liked it. We were sitting in his car, with loud music, and racing all over the car park. We laughed a lot. That was a great experience' 
'My boyfriend was drunk. He had a bet and climbed on the car while his friend drove. He fell off the car. We had to go to the hospital to have his head stitched.. But it was a really funny evening. Maybe it was stupid that he had an accident, but it was a very nice evening. I have very positive memories of that evening.'

Alcohol-related incidents were often experienced as 'funny' or 'cool'. Negative consequences were accepted because the entire context of the alcohol experience was positive. This resulted in overall positive evaluations of events with negative side effects.

\section{Effects on drinking intentions and behaviour}

Participants also indicated whether the incidents they described had effects on their own drinking behaviour. In the majority of the cases (65\%), participants stated that the particular incident did not affect their drinking intentions and behaviour ('Not at all, I'll keep on drinking anyway'). In 5\% of the cases, participants indicated that they had the intention to drink more, and sometimes even did so ('It makes me want to drink more often', 'I discovered that it's actually quite normal to drink', and 'I felt good, so... Therefore yes... next year I will be drunk more often').

The remaining $30 \%$ of the incidents were associated with intentions to drink less. Only $2 \%$ of the incidents resulted in complete alcohol abstinence ('I never want to drink again. That was the last time that I drank alcohol', and 'That is once and never again. Each time I smell alcohol now I think: leave it. I don't want to drink anymore because I am frightened that the same will happen again'). In $15 \%$ of the cases, the incidents led to lower drinking intentions and lower consumption ('That was terrible. I just don't want to experience it again so I drink less now'). In another $13 \%$ of the cases, lower drinking intentions only led to a temporary decrease in alcohol consumption:

'The first couple of months I didn't drink at all, but now I drink the same as before. I don't think about the time I was vomiting anymore.

'Almost every week I tell myself that I want to drink less because my brain is getting worse. I don't remember things clearly anymore (...).That's what I think in the morning, when I wake up. But that feeling disappears on Saturday', 
'Now I drink less (...) I don't know if it's a permanent situation. Once you end up in a drinking situation you don't know what you're going to do'.

Table V combines the self-reported effects on drinking intentions and behaviour with (1) the participants' evaluation of the incidents, and (2) the most prevalent main consequences (mentioned ten times or more). Although, positively evaluated incidents generally led to a reinforcement of the participants' drinking behaviour, and negatively evaluated incidents often had the effect of (temporarily) reducing their alcohol consumption, a second remarkable tendency in the participants' interpretations of alcohol-related incidents may be seen. Even in the case of entirely negative or mainly negative evaluations, alcohol-related incidents often did not result in lower drinking intentions (53 and 41\%, respectively).

Table V: Self-reported effects of the incidents on drinking intentions and behaviour

\begin{tabular}{llllll}
\hline & $\begin{array}{l}\text { Alcohol } \\
\text { Abstinence }\end{array}$ & $\begin{array}{l}\text { Lower alcohol } \\
\text { consumption }\end{array}$ & $\begin{array}{l}\text { Lower intent. } \\
\text { old behaviour }\end{array}$ & $\begin{array}{l}\text { No } \\
\text { influence }\end{array}$ & $\begin{array}{l}\text { Higher alc } \\
\text { consumption }\end{array}$ \\
\hline (1) Incident evaluation & & & & & \\
Entirely negative & $7 \%$ & $33 \%$ & $7 \%$ & $53 \%$ & $0 \%$ \\
Mainly negative & $9 \%$ & $27 \%$ & $23 \%$ & $41 \%$ & $0 \%$ \\
Neutral & $0 \%$ & $14 \%$ & $18 \%$ & $64 \%$ & $4 \%$ \\
Mainly positive & $0 \%$ & $14 \%$ & $5 \%$ & $81 \%$ & $0 \%$ \\
Entirely positive & $0 \%$ & $5 \%$ & $12 \%$ & $72 \%$ & $10 \%$ \\
(2) Main consequences & & & & & \\
Feeling ill & $4 \%$ & $29 \%$ & $29 \%$ & $36 \%$ & $4 \%$ \\
Accidents or injury & $0 \%$ & $6 \%$ & $0 \%$ & $88 \%$ & $6 \%$ \\
Doing strange things & $0 \%$ & $22 \%$ & $9 \%$ & $61 \%$ & $9 \%$ \\
Make contact more easily & $0 \%$ & $7 \%$ & $13 \%$ & $80 \%$ & $0 \%$ \\
Having a good time & $0 \%$ & $0 \%$ & $10 \%$ & $70 \%$ & $20 \%$ \\
Interpersonal conflicts & $0 \%$ & $0 \%$ & $0 \%$ & $100 \%$ & $0 \%$ \\
\hline
\end{tabular}

Note: Only consequences mentioned ten times or more as main consequence are included.

When zooming in on the main consequences, the same unexpected tendency can be seen: Again, negative consequences did not unambiguously lead to lower alcohol consumption. 'Feeling ill' was associated with an alcohol reduction pattern in about $60 \%$ of the incidents, but the other $40 \%$ of the incidents led to unchanged or even higher alcohol consumption. When an 'accident or injury' was the main consequence of an incident, only $6 \%$ of the participants wanted to reduce their alcohol consumption. When interpersonal conflicts' were involved, none of the participants had lower drinking intentions. 


\subsection{DISCUSSION}

This study provides a broader insight in the prevalence, characteristics and self-reported effects of salient alcohol incidents 15- and 16-year-old adolescents have experienced in their lives. Despite their young age, participants turned out to have experienced quite a few alcohol-related incidents. Of course, it should be kept in mind that ten adolescents in the original sample (18\%) were excluded because they had no experience with alcohol. However, among the adolescents who did participate in our study (82\% of the initial sample), alcohol use was already deeply rooted in their lives.

The results of our study raise serious questions about the role parents play in the alcoholrelated education of their children. Only in slightly more than half of the cases, parents were aware of the incidents that had occurred. Adolescents often did not feel the need to inform their parents about the incidents they had experienced or witnessed, and sometimes explicitly questioned whether their parents would be interested in such information. If parents were aware of the incidents, they tended to react very mildly: in $60 \%$ of the cases, parents did not consider the incident important enough to start a serious discussion about it. If we combine the lack of awareness with the weak responses, we can infer that only in $22 \%$ of the incidents parents were able and willing to provide appropriate feedback to their children. This seems to be an important direction for future interventions. Research has shown that parents are the most direct source of influence for adolescents (Beck \& Treiman, 1996). Parental attitudes and practices toward underage drinking have been shown to be an important influence (Ary, Tildesley, Hops, \& Andrews, 1993; Deakin \& Cohen, 1986; Harford \& Grand, 1987; Wilks \& Callan, 1984). Setting clear rules and communicating seriously with adolescents are considered to be important factors in protecting youth against alcohol abuse (Barnes, Hoffman, Welte, Farrell, \& Dintcheff, 2006; Reifman, Barnes, Dintcheff, Farrell, \& Uhteg, 1998; Van der Vorst, Engels, Deković, Meeus, \& Vermulst, 2007; LaBrie, Hummer, Neighbors, \& Larimer, 2010).

Another important finding in this study involves the way adolescents make sense of the alcohol incidents they experience and/or witness. A first remarkable finding is that 
adolescents have the tendency to turn incidents with adverse consequences into positive overall experiences. Two main strategies are used: either the overall experience is considered to outweigh the adverse effects of alcohol use, or the adverse effects are considered to be part of the fun. A second remarkable finding is that even if adolescents judge an incident to be negative overall, they are often still not inclined to change their drinking intentions. As such, the results of our study underline the complexity of the problem of underage alcohol use.

Our findings raise questions about the effectiveness of alcohol prevention programs that stress the negative consequences of alcohol use. In situations where adolescents' own experiences or first-hand observed incidents do not substantially affect their drinking intentions, it does not seem plausible that warning and second-hand accounts will be influential. Health care workers targeting youth with 'scary stories' about alcohol (mis)use (sometimes told by former addicts) — a widespread intervention tool in many countries including the Netherlands-must not be expected to straightforwardly lead to lower alcohol consumption patterns among adolescents. Contrary to rational expectations, they might even increase drinking intentions and actual alcohol consumption.

Instead, it seems more fruitful to address the problem from the angle of availability. First, it is important that parents become more aware of their responsibilities regarding the alcohol-related behaviours of their children (social availability). Second, it seems to be crucial to reduce the number of experiences adolescents have. Examples of effective strategies are: increasing taxes on alcoholic beverages (Grossman, Chaloupka, Saffer, \& Laixuthai, 1994), decreasing the number of outlets (Kuntsche, Kuendig, \& Gmel, 2008), regulating opening hours (Duailibi et al., 2007), enforcing the age restrictions for underage alcohol sales (Gosselt, Van Hoof, De Jong, \& Prinsen, 2007), or even increasing age restrictions (Wagenaar \& Toomey, 2002). In addition, it seems worthwhile to consider interventions aimed at the image of adolescent alcohol consumption. 
"In 1969 I gave up women and alcohol - it was the worst 20 minutes of my life"

George Best (1945 - 2005) - soccer player 


\section{Determinants of Parental Support for}

Governmental Alcohol Control

\section{Policies}

Joris J. van Hoof

Jordy F. Gosselt

Menno D.T. de Jong

Health Policy, 2010, 97, 195-201.

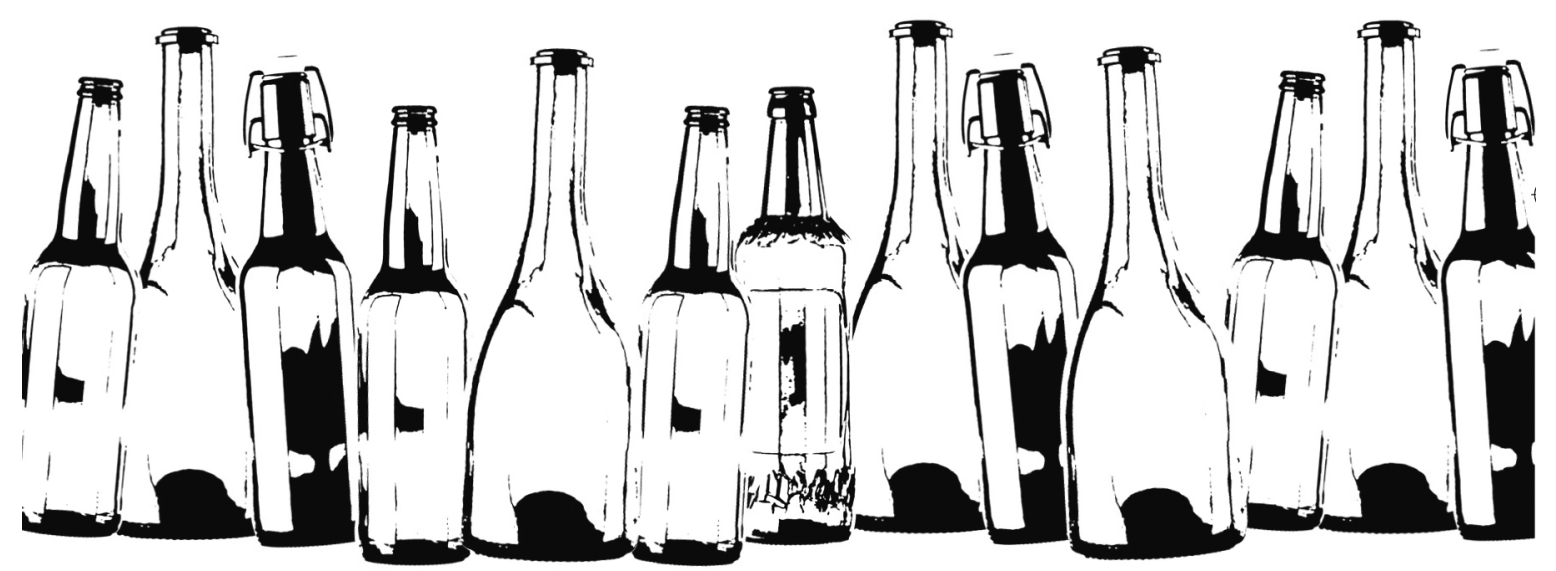




\subsection{ABSTRACT}

Aim: to explore determinants that predict parental support for governmental alcohol control policies in the Netherlands.

Method: a questionnaire was administered among 1,550 parents, containing six possible predictors to explain support for alcohol control policies.

Results: parental support can be explained by five partly normative predictors $(\mathrm{R} 2=.503)$. Parents with lower drinking frequencies are stricter and more supportive than parents who consume more alcohol. Higher-educated parents are stricter than lower-educated parents.

Conclusion: in general, parents do support governmental alcohol control policies. Communication of the fact that youth alcohol consumption is problematic tends to increase parental support. Also, if policy makers are able to influence parents' opinions on the consequences of alcohol consumption, as well as the norm of not consuming alcohol before 16 years of age, then parental support increases. Parents' experiences with drunken youths also explain support. Factual knowledge does not influence support, so information campaigns alone do not increase parental support. 


\section{$5.2 \quad$ INTRODUCTION}

Alcohol is the drug of choice among youth (Monshouwer, Van Dorsselaer, Gorter, Verdurmen, \& Vollebergh, 2008). To regulate alcohol consumption in society and to protect underage youth, governments have implemented a variety of alcohol control policies in the last few decades (such as campaigns, restrictions, taxes, and fines). Public support for these measures is indispensable for their success.

Despite currently implemented measures, adolescent alcohol consumption is still increasing, and adolescents now start drinking at much younger ages than in the past (Monshouwer et al., 2008; Van de Pol \& Duijser, 2003). The situation in the Netherlands is one of growing concern, since research shows that $90 \%$ of Dutch 15-year olds have consumed at least one glass of alcohol, and $52 \%$ of adolescents within this age group drink alcohol every week. About $20 \%$ of males and $10 \%$ of females in this group report drinking more than 10 glasses of alcoholic beverages on a weekend day, whereas $63 \%$ of 15 -year olds have experiences with getting drunk. Alcohol use is ingrained in the daily lives of adolescents (Wagenaar \& Perry, 1994), and alcohol promotion is highly visible, even for young adolescents (Collins, Ellickson, McCaffrey, \& Hambarsoomians, 2005).

Underage drinking may lead to serious problems, such as risky behaviours (Austin \& Knaus, 2000; National Highway Traffic Safety Administration, 2003), suboptimal school performance (López-Frías et al., 2001; Mullahy \& Sindelar, 1989), aggression (Exum, 2006), and intoxicated adolescents who need to be treated in hospitals (Van Hoof, Van der Lely, Van Dalen, \& Rodrigues Pereira, 2010). In addition, early alcohol use has been shown to have detrimental effects on adolescent brain development (Brown, Tapert, Granholm, \& Delis, 2000; Tapert, Brown, Kindermann, \& Cheung, 2001). Early drinking is also associated with alcohol dependence and problem drinking during adulthood (Grant, Stinson, \& Harford, 2001; Pitkänen, Lyyra, \& Pulkkinen, 2005), and the use of entry drugs (alcohol, cigarettes, marijuana) causes deeper and more severe illicit drug involvements (ecstasy, cocaine), the so called 'gateway theory' (Ginzler, Cochran, DomenechRodríguez, Cauce, \& Whitbeck, 2003; Kandel, Yamaguchi, \& Chen, 1992). 
Several strategies may be used to prevent underage drinking (Komro \& Toomey, 2002). Public information campaigns and school curricula may contain elements that try to counterbalance the effects of alcohol marketing (Casswell, 2004). However, the effectiveness of such health education approaches is often limited. A recent study shows that logic-based health campaigns and curricula will never completely refute the effects of commercial alcohol advertising, as logic-based skepticism turns out to be weaker than effect-based processing (Weintraub Austin, Chen, \& Grube, 2006). In addition to public information campaigns and school curricula about risks involved in alcohol consumption, the implementation of governmental alcohol control policies may also be considered. These policies provide legal justification to intervene in various stages of the adolescent alcohol consumption chain; examples include restrictions on alcohol promotion, alcohol sales tax increases, and higher fines for selling alcohol to underage customers. All of these policies are intended to decrease youth alcohol consumption and to reduce alcohol-related problems.

After developing control policies and/or legislation by policy makers, the general public gets involved when the implementation phase begins. New governmental control policies, which can regulate different topics in society, can only succeed when the general public supports such measures (Applegate et al., 1995; Cullen et al., 1998; De Lint \& Schmidt, 1971; Edwards, 1997; Lamble, Rajalin, \& Summala, 2002; Mignogna, Fedele, Lo Russo, \& Lo Muzio, 2001).

When alcohol control policies are implemented, several target groups may be identified. While children or adolescents might be the direct target group of a certain control policy (e.g., fines for buying alcohol when under the legal age), other target groups are also involved (e.g., parents, peers, and teachers). With respect to alcohol control policies aimed at adolescents, previous studies mainly focused on the general public and compared differences based on background variables, such as gender, religious background, income, educational level, and alcohol consumption (Giesbrecht \& Greenfield, 1999; Richter, Vaughnan, \& Foster, 2004; Schmid et al., 1990). When focusing on specific target groups, retailers (Kotecki, Fowler, German, Stephenson, \& Warnick, 2000; Kotecki, Torabi, \& Elenijan, 1997) or abstainers (Greenfield, 1993) were involved. Remarkably enough, however, the opinions of parents with respect to their support of alcohol control policies 
has not yet been systematically studied. Especially since we know that parents are an important factor in youth alcohol use (DeVore \& Ginsburg, 2005; Van der Vorst, Engels, Deković, Meeus, \& Vermulst, 2007).

Furthermore, current alcohol opinion research focuses primarily on attitudes towards specific measures aimed at reducing underage drinking, such as limiting alcohol sales to adolescents (Giesbrecht \& Greenfield, 1999; Kotecki et al., 1997; Kotecki et al., 2000), reducing alcohol promotion and/or banning alcohol advertising (Bongers, Van de Goor, \& Garretsen, 1998; Giesbrecht \& Greenfield, 1999; Pendleton, Smith, \& Roberts, 1990; Richter et al., 2004; Schmid et al., 1990; Van Hoof, Van Noordenburg, \& De Jong, 2007), increasing alcohol taxes (Giesbrecht \& Greenfield, 1999; Pendleton et al., 1990; Richter et al., 2004; Van Hoof et al., 2007) and increasing penalties for people (parents and sale points) who provide alcohol to underage adolescents (Richter et al., 2004).

When predicting the level of governmental alcohol control policy support, previous studies found that only individual and socio-demographic factors (e.g., individual drinking patterns, age, education, and ethnicity) were correlated with public support (Hilton \& Kaskutas, 1991; Latimer, Harwood, Newcomb, \& Wagenaar, 2001). More 'normative factors,' such as drinking norms, perceived seriousness of adolescent alcohol problems, alcohol consumption consequences, and responsible alcohol consumption starting ages, were rarely mentioned or measured in relation to public support for alcohol control policies, despite rich discussions on the topic in mainstream newspapers (Jones-Webb, Wagenaar, \& Finnegan, 1997). In this study, therefore, the researchers questioned parents (raising at least one adolescent child between 10 and 18 years of age) as a target population, and used six possible predictors (four normative components, combined with alcohol nuisances caused by adolescents, and alcohol knowledge) in order to explain their support for governmental alcohol control policies. 


\subsection{METHODS}

\section{Sampling and Survey Procedures}

Data were collected (in November 2006) by conducting a questionnaire among 1,550 parents in a southern region of Netherlands. The region consists of 21 rural and urban municipalities (including one of the nation's five largest cities) covering an area of 1370 $\mathrm{km}^{2}$, representing $3.3 \%$ of the total area of the Netherlands. The region has 725,000 inhabitants and 32,000 businesses. Using the region's Public Health Service (GGD), a random stratified sample from 3,040 families with children younger than 18 was drawn. Each municipality was represented proportionally in the sample. The questionnaire (and an introduction letter) was sent by mail to the home address of the families. Half of the questionnaires were sent to families with children between 10 and 15 years old (this was the most important age group for this project), and the remaining questionnaires were split between families with children under 10 and those with children between 16 and 18 years. In total, 1,585 questionnaires were returned (a 52\% response rate). After removing 35 respondents (incomplete questionnaires and questionnaires filled out by children) a total of 1,550 questionnaires were analyzed. The response rate per municipality varied from $43 \%$ up to $84 \%$, with an average of $51 \%$.

\section{Measures}

Questions in the questionnaire were derived from prior research and adjusted or constructed for the typical Dutch context. The first part of the questionnaire consisted of six possible predictive elements for policy support: (1) the extent to which parents consider adolescents' alcohol use to be problematic, (2) the perceived negative consequences of adolescent alcohol consumption, (3) parents' support of the norm to not drink alcohol before the age of 16, (4) what parents consider to be a responsible starting age for adolescent alcohol consumption, (5) parents' own experiences with problems caused by drunken youth, and (6) knowledge about alcohol-related diseases. The second part of the questionnaire was designed to measure parents' policy support on several governmental alcohol control policies that could be implemented to reduce underage drinking and related problems. Finally, questions were asked about background variables. 


\section{Predictors:}

(1) Adolescent problematic alcohol use (10-item scale, Cronbach's alpha $=.69)$. Using a five-point Likert scale (1=strongly disagree; 2=disagree; 3=neutral; 4=agree; 5=strongly agree), 10 questions conceptualized the perceived degree to which the Dutch youth's alcohol use can be considered problematically. This scale was formed using six positively formulated questions (e.g., "Adolescents start consuming alcohol too young") and four negatively formulated questions (e.g., "Adolescents do not consume too much alcohol").

(2) Perceived negative alcohol consequences (6-item scale, Cronbach's alpha $=.87$ ). This scale contained six questions, both positively formulated (e.g., "Adolescents consuming alcohol cause damage to public properties, such as street lighting and public transport") and negatively formulated (e.g., "Adolescents consuming alcohol do not cause any trouble") questions, again using a five-point Likert scale.

(3) Support for the norm not to consume alcohol below 16 years of age (11-item scale, Cronbach's alpha $=.84$ ). Eleven questions (both positively and negatively formulated on a five-point Likert scale) evaluated parents' attitudes towards the norm that adolescents should not drink alcohol when they are younger than 16. In the Netherlands, the legal age limit for alcohol sales is 16 years for soft alcoholic beverages (drinks containing up to $14.9 \%$ alcohol and some stronger wine products, such as sherry), and 18 years for strong alcoholic beverages (15\% alcoholic content or higher). However, these legal age limits are not aimed towards youths consuming alcohol, and the 16-year-old selling age restriction has evolved into a more general 'rule.' Questions involve both adolescents' own responsibilities (e.g., "Adolescents under 16 should not try alcohol”) and parents' responsibilities (e.g., "Parents should not supply alcohol to their underage children at home").

(4) Responsible starting age. Three questions were used to investigate the starting ages that parents consider responsible for adolescents in general (not specific their own children) for alcohol consumption. The researchers asked about responsible ages for consuming a first sip of an alcoholic beverage, a first glass of an alcoholic beverage, and for independent alcohol use.

(5) Experiences with problems caused by drunken youth. The researchers asked parents the number of times (never; 1-3 times a year; monthly; weekly; or more times a week) they suffered from eight types of annoyances and/or nuisances in the last 12 months. In cases where parents did have a certain extent of experience, the researchers also asked whether 
or not they called the police in that matter. Types of annoyances and/or nuisances included drinking and drunken adolescents in the streets, vandalism of public and personal property (such as cars and gardens), urinating in public, other indecent behaviours, noise nuisances, and feelings of danger in public.

(6) Knowledge of alcohol-related diseases. To determine parents' knowledge regarding alcohol, the researchers asked respondents whether greater than average alcohol consumption could cause 10 physical related drawbacks, of which 7 are correlated to alcohol consumption (addiction, reduced school functioning, obesity, heart complaints, reduced brain functioning, learning difficulties, and stomach aches) and 3 are not related to alcohol use (lung cancer, rheumatism, and vision loss).

Policy support: (12-item scale, Cronbach's alpha $=.82$ ). Based on prior research (Giesbrecht \& Greenfield, 1999; Jones-Webb et al., 1997; Richter et al., 2004) 12 questions were posed on possible governmental policy measures (such as limiting youth access to alcohol establishments, restricting public access to alcohol, imposing penalties on illegal alcohol sales, and stronger police actions against drunken youth on the streets) intended to reduce underage drinking and alcohol-related problems. A five-point Likert scale ( $1=$ strongly disagree, $2=$ disagree, $3=$ neutral, $4=$ agree, $5=$ strongly agree) was also used here.

Background variables: for a description of the respondents, and to verify their repetitiveness the following background variables were asked: number of children, age of children, age, gender, and family situation. In addition, questions were asked about the expected (Hilton \& Kaskutas, 1991; Latimer et al., 2001) differences between different types of parents, their alcohol consumption (drinking frequency), and education level.

\section{Respondents}

A total of 1,550 questionnaires from parents (actually taking care of at least one child aged under the age of 18) were analyzed. Parents ranged in age from 19 to 67 years old (mean age $=42.3$ ). The average number of children per family in the sample was 2.24 , which corresponds to the Dutch average of 2.27 (CBS, 2005a). In most cases, the mother of the family (77\%) filled out the questionnaire. Furthermore, most parents in this research were married and living together (82\%), compared to $7 \%$ of unmarried cohabiting parents, and 
$6 \%$ divorced (which differs to some extent from the Netherlands population, where $73 \%$ of parents are married, $10 \%$ are not married, and 17\% are divorced) (CBS, 2005b).

\subsection{RESULTS}

First, the researchers will present outcomes on the six predictors for governmental policy support, as well as parental support for the governmental control policies themselves. Then the researchers will explore differences between types of parents (gender, drinking frequency, and education level). Finally, the authors show which predictors contribute to parental support for governmental alcohol control policies.

In Table I, the results are presented on the predictors adolescent problematic alcohol use, alcohol consequences, and the norm of not drinking alcohol before 16 years. The parents consider Dutch adolescent alcohol use to be problematic (more specifically, the early starting age for drinking and the amount of alcohol consumed by Dutch adolescents). Also, parents agree that youth alcohol consumption causes problems (e.g., vandalism and feelings of public danger); furthermore, parents strongly support the norm that youth should not consume alcohol before they reach the legal age of 16 .

Table I: Parental support on normative aspects of adolescent alcohol use. Scale scores and most typical questions

(scales are five-point Likert-scales; 1=strongly disagree, 2=disagree, 3=neutral, 4=agree, 5=strongly agree / dichotomy question with 10 items correct and incorrect).

\begin{tabular}{llll}
\hline Construct & Question type & $N$ & Mean (SD) \\
\hline Adolescent problematic alcohol use & 10-item scale & 1550 & $3.65(.43)$ \\
Alcohol consequences & 6-item scale & 1548 & $3.70(.62)$ \\
No alcohol < 16 year norm & 11-item scale & 1550 & $3.87(.64)$ \\
Responsible starting age (mean) & 3-item open & 1515 & $16.5(1.4)$ \\
$\quad$ Sip & & 1491 & $15.2(1.8)$ \\
$\quad$ Glass & & 1509 & $16.3(1.4)$ \\
$\quad$ Regular & & 1478 & $18.0(1.7)$ \\
Knowledge & 10-item dichotomy & 1524 & $6.9(1.8)$ \\
Policy support & 13-item scale & 1541 & $3.73(.52)$ \\
\hline
\end{tabular}


In addition to the norm of support that adolescents should not drink alcohol under 16 years of age, the researchers asked open-ended questions about what parents consider to be a responsible age for consuming alcohol beverages. Parents report the starting age for a first sip of an alcoholic beverage between 2 and 25 years of age, with an average of 15.2 years old, and that a first glass of an alcoholic beverage could be consumed responsibly at the age of 16.3 years old (between 12 and 28 years of age). Independent and regular alcohol use is considered to be responsible at the age of 18 years old (varying between 14 and 30 years old).

Another section of the questionnaire concerned knowledge of alcohol-related diseases and other drawbacks. On average, 6.9 consequences are correctly labelled as alcohol-related or not alcohol-related. Most known consequences turn out to be 'reduced school functioning' and 'reduced brain functioning' (95\% of the parents selected both consequences as alcohol-related issues), followed by 'learning difficulties' (91\%), 'addiction' (88\%), 'stomach aches' (72\%), 'obesities' (70\%), and 'heart complaints' (56\%). The diseases not related to alcohol consumption were less frequently correctly labelled as such; 'lung cancer' (55\%), 'rheumatism' (39\%) and 'bad eyes' (29\%).

Table II: Parents' own experiences with drunken youth previous 12 months (never, 1-3 times a year, monthly, weekly, more times a week, in percentages) and percentage who called the police.

\begin{tabular}{lllllll}
\hline & Never & $1-3 \mathrm{Y}$ & Mon & Wee & More & Call Police \\
\hline Drinking adolescents & 26.3 & 53.2 & 11.1 & 7.6 & 1.7 & 0.7 \\
Drunk adolescents & 23.5 & 54.7 & 12.4 & 8.1 & 1.4 & 0.5 \\
Vandalism (public) & 57.8 & 30.9 & 8.3 & 2.5 & 0.5 & 3.1 \\
Vandalism (personal) & 67.6 & 25.8 & 4.8 & 1.4 & 0.4 & 4.7 \\
Peeing in public & 42.4 & 43.7 & 8.9 & 4.1 & 0.9 & 0.1 \\
Indecent behaviour & 81.7 & 14.8 & 2.5 & 0.8 & 0.2 & 0.2 \\
Noise nuisance & 29.6 & 50.1 & 11.7 & 7.6 & 1.0 & 2.5 \\
Feelings of unsafely & 59.9 & 33.2 & 4.1 & 2.1 & 0.7 & 0.8 \\
\hline
\end{tabular}

As can also be seen in Table II, almost $10 \%$ of parents have been confronted with drinking and/or drunken youth in the streets on at least a weekly basis. Almost $9 \%$ of parents report suffering from noise nuisances caused by drunken youth at least once a week. Parents do not call the police very often; even when personal belongings (such as gardens or cars) are damaged, less than $5 \%$ of parents call the police. 
The parents questioned did support the 13 proposed governmental alcohol control policies; with an average score of 3.7 (see Table I). Scores on individual questions varied from 3.4 to 4.0. The least support was given to a total ban on alcohol at school parties is a bad idea $(M=3.25, S D=1.07, t[1535]=9.15, p=.000)$, which was significantly higher than the neutral score of 3 .

On the two predictors for parental support were support of the norm not to consume alcohol before 16 years of age, and the responses to three open-ended questions on responsible ages for alcohol consumption (sip, glass, and regular), correlation are significant with parents' opinions on adolescent alcohol consumption $(r(1550)=.523, p=$ .000 , and $r(1515)=.269, p=.000)$.

\section{Different opinions between various types of parents}

As shown in Table III, there are no differences between females (mothers) and males (fathers) with respect to the implementation of governmental alcohol control policies. Fathers turn out to be stricter than mothers with respect to a responsible starting age for drinking $(F[1,17]=4.90, p=.027)$.

In comparison with parents with higher drinking frequencies, those with lower drinking frequencies (< once a month) are more in favor of implementing governmental alcohol control policies $(F[2,17]=12.85, p=.000)$, more convinced that adolescent alcohol consumption is worrisome $(F[2,17]=9.42, p=.000)$, believe alcohol drinking youth causes problems $(F[2,17]=9.63, p=.000)$, and support the norm not to drink alcohol prior to the age of $16(F[2,17]=14.87, p=.000)$, more than parents with high drinking frequencies $(>$ once a week). Parents who are low drinkers also state higher responsible starting ages compared to moderate and high alcohol consuming parents $(F[2,17]=9.63, p=.000)$. 
Table III: Parent's opinions and parental support for governmental alcohol control policies. Means (Standard Deviations), also related to background characteristics; gender (Male - Female), drinking frequency (Low DF = less than once a month, Mid DF = between once a month and once a week, High DF = more times a week) and educational level (Low EL = no school, elementary school, preparatory middle-level applied education, Mid EL = middle-level applied education, High EL = higher general continued education, higher applied education, university).

\begin{tabular}{|c|c|c|c|c|c|c|c|}
\hline \multicolumn{8}{|c|}{ Construct } \\
\hline \multicolumn{2}{|c|}{$\begin{array}{ll}\text { Male } & \text { Female } \\
(\mathrm{n}=330) & (\mathrm{n}=1118)\end{array}$} & \multicolumn{3}{|c|}{$\begin{array}{l}\text { Low DF Mid DF High DF } \\
(n=472) \quad(n=335) \quad(n=641)\end{array}$} & \multicolumn{3}{|c|}{$\begin{array}{l}\text { Low EL Mid EL High EL } \\
(\mathrm{n}=238)(\mathrm{n}=543)(\mathrm{n}=667)\end{array}$} \\
\hline \multicolumn{8}{|c|}{ Adolescent problematic alcohol use } \\
\hline 3.62 & 3.64 & $3.73_{\mathrm{b}}$ & $3.58_{\mathrm{a}}$ & $3.57 \mathrm{a}$ & $3.53 \mathrm{a}$ & $3.61_{\mathrm{a}}$ & $3.74_{b}$ \\
\hline \multicolumn{8}{|c|}{ Alcohol consequences } \\
\hline 3.67 & 3.72 & $3.85_{b}$ & $3.60_{\mathrm{a}}$ & $3.64_{a}$ & 3.69 & 3.70 & 3.70 \\
\hline \multicolumn{8}{|c|}{ No alcohol $<16$ year norm } \\
\hline 3.82 & 3.85 & $3.98_{\mathrm{c}}$ & $3.85_{b}$ & $3.68 \mathrm{a}$ & $3.70_{\mathrm{a}}$ & $3.85_{b}$ & $3.96_{c}$ \\
\hline \multicolumn{8}{|c|}{ Responsible starting age } \\
\hline $16.8_{\mathrm{b}}$ & $16.5_{\mathrm{a}}$ & $17.3_{\mathrm{c}}$ & $16.5_{\mathrm{b}}$ & $16.2_{\mathrm{a}}$ & 16.8 & 16.7 & 16.5 \\
\hline \multicolumn{8}{|c|}{ Policy support } \\
\hline 3.73 & 3.73 & $3.88_{\mathrm{a}}$ & $3.67_{b}$ & $3.64_{b}$ & 3.68 & 3.74 & 3.77 \\
\hline \multicolumn{8}{|c|}{ Knowledge } \\
\hline 6.6 & 6.8 & 6.6 & 6.6 & 6.8 & 6.2 & 6.6 & 7.3 \\
\hline
\end{tabular}

MANOVA: Means in the same row that do not share subscripts differ at $p<.05$ on post-hoc Bonferroni

Higher-educated parents showed stronger support (compared to mid- and lower-educated parents) of the norm not to consume alcohol under the age of $16(F[2,17]=8.88, p=.000)$. Higher-educated parents are also more convinced that adolescent alcohol use nowadays is problematic $(F[2,17]=14.92, p=.000)$. No differences were found between education groups regarding responsible starting ages and policy support.

\section{Determinants explaining parental support}

To predict parental support on governmental alcohol control policies, a linear regression analysis was conducted using the six predictors. The mean score was included for three constructs: experiences with drunken youth and responsible starting age were recorded as an average, and the average number of correctly labelled alcohol consequences per respondent regarding knowledge was included in regression analyses (Table IV).

The six predictors accounted for over half of the parental support on governmental alcohol control policies (adjusted $\mathrm{R}^{2}=.501$ ), which is highly significant $(F(6,1452)=245.1$, $p=.000$ ). Five normative measures demonstrate significant effects on parental policy 
support: 'adolescent problematic alcohol use' $(\beta=.309, p=.000)$; 'alcohol causing problems' $(\beta=.109, p=.000)$; 'no alcohol < 16 year norm' $(\beta=.275, p=.000)$; 'experiences with drunken youth' $(\beta=.116, p=.000)$, and 'responsible starting age' $(\beta=.171, p=.000)$. Only the factor 'knowledge of alcohol-related diseases and drawbacks' did not predict parental support of alcohol policy $(\beta=.013, p=n s)$.

Table IV: Results of linear regression analysis for parental support on governmental alcohol control policies $(\mathrm{N}=1458)$

\begin{tabular}{llllll}
\hline Predictor & $B$ & $S E(B)$ & $\beta$ & $t$ & Sig. $(p)$ \\
\hline Adolescent problematic alcohol use & .372 & .028 & .309 & 13.210 & .000 \\
Alcohol consequences & .093 & .018 & .109 & 5.008 & .000 \\
No alcohol < 16 year norm & .224 & .021 & .275 & 10.869 & .000 \\
Experiences with drunken youth & .108 & .018 & .116 & 5.910 & .000 \\
Responsible starting age & .064 & .009 & .171 & 7.510 & .000 \\
Knowledge about alcohol & .004 & .005 & .013 & .690 & .490 \\
\hline
\end{tabular}

$\mathrm{R}^{2}=.503$ / Adjusted $\mathrm{R}^{2}=.501$

\subsection{DISCUSSION}

In line with prior research in which general public opinions on a variety of governmental alcohol control policies were explored, our findings within highly involved civilians are the same; parents with adolescent children also supported such measures (Bongers et al., 1998; Hilton et al., 1991; Latimer et al., 2001; Pendleton et al., 1990; Richter et al., 2004; Schmid et al., 1990).

The researchers only found one significant difference between fathers and mothers regarding responsible starting age, despite prior research showing that mothers were stricter (Bongers et al., 1998; Hilton et al., 1991; Latimer et al., 2001; Richter et al., 2004; Schmid et al., 1990). When focusing on differences between parents with lower drinking frequencies, these parents are generally stricter and more in favour of governmental alcohol control policies. This is the same pattern shown in the general public (not parents in particular) from prior research (Hilton et al., 1991; Latimer et al., 2001; Pendleton et al., 1990; Richter et al., 2004); drinking frequency is negatively correlated with control 
policies support and opinions of responsible drinking starting ages. For public youth health policy, therefore, prevention should not only be aimed at youth and adolescents themselves, but the alcohol consumption of parents is also a point of concern. When parental alcohol consumption decreases, support for governmental alcohol control policies increases, and parents become less tolerant of young alcohol consuming starting ages. Parental educational levels seem unrelated to support for alcohol control policies and responsible starting ages, but the researchers did find higher-educated parents to be more convinced regarding norms, which is consistent with prior research (Bongers et al., 1998; Richter et al., 2004).

More than $50 \%$ of the variance in parental support on governmental alcohol control policies can be attributed to five (out of six) mainly normative predictors. The most important factor is the degree to which parents actually believe that current youth/adolescent alcohol consumption patterns are worrisome. In that respect, the involvement of parents, increased support, trends, and information on adolescent alcohol consumption and youth culture need to continually reach the public eye. Public health organizations and researchers should work together and carry out a strategic media policy (which is not the case in the Netherlands), together with policy makers when new health policies are implemented. Alcohol consumption data and other related 'issues' (e.g., hospital intoxication admissions, alcohol-related accidents) might be portrayed more purposefully. In addition, cooperation with television and documentary filmmakers should be used to inform the public (including parents) about trends in youth culture (e.g., drinking in hidden places in the country, flat rate alcohol parties).

Two other predictors for parental support were support of the norm not to consume alcohol before 16 years of age, and the responses to three open-ended questions on responsible ages for alcohol consumption (sip, glass, and regular). Both of these predictors are correlated with parents' opinions on adolescent alcohol consumption. This correlation is a second reason for the cooperative strategy in the (Dutch) public health sector, discussed above. Finally, the researchers also found that alcohol-attributed consequences and actual experienced consequences with respect to adolescent alcohol use could predict parental support on governmental alcohol policies. However, factual knowledge of alcohol-related diseases and drawbacks were not predictive for policy support. This implies the need for 
reconstruction of structure and the focus of health care institutions, which sometimes tend to focus on factual knowledge of alcohol (and other risk products) instead of focusing on broader societal and cultural concerns.

Overall, our data support governmental alcohol control policies, and supports limiting youth access to alcohol and to alcohol establishments. Parental support on this point may be attributed to the fact that adolescents in the Netherlands have easy access to alcohol in supermarkets, in sports canteens, and the catering industry (Gosselt, Van Hoof, De Jong, \& Prinsen, 2007). This can be considered a clear signal for Dutch policy makers, who are clearly supported to make new health policies. From the results in this study specific fields for policy can be selected for health or policy interventions.

\subsection{ACKNOWLEDGMENTS}

The authors would like to thank The Province of Noord-Brabant, SRE (Cityregion Eindhoven, representing the 21 municipalities), STAP (Dutch Foundation for Alcohol Prevention), GGD Eindhoven, and GGD Zuidoost-Brabant (Public Health Services) for facilitating this research. 
"Life with fools consists in drinking; with the wise man, thinking"

Benjamin Franklin (1706 - 1790) - American Statesman 


\section{There's Alcohol in My Soap: Portrayal and Effects of Alcohol Use in a Popular Television Series}

Joris J. van Hoof

Menno D.T. de Jong

Bob M. Fennis

Jordy F. Gosselt

Health Education Research, 2009, 24, 421-429.

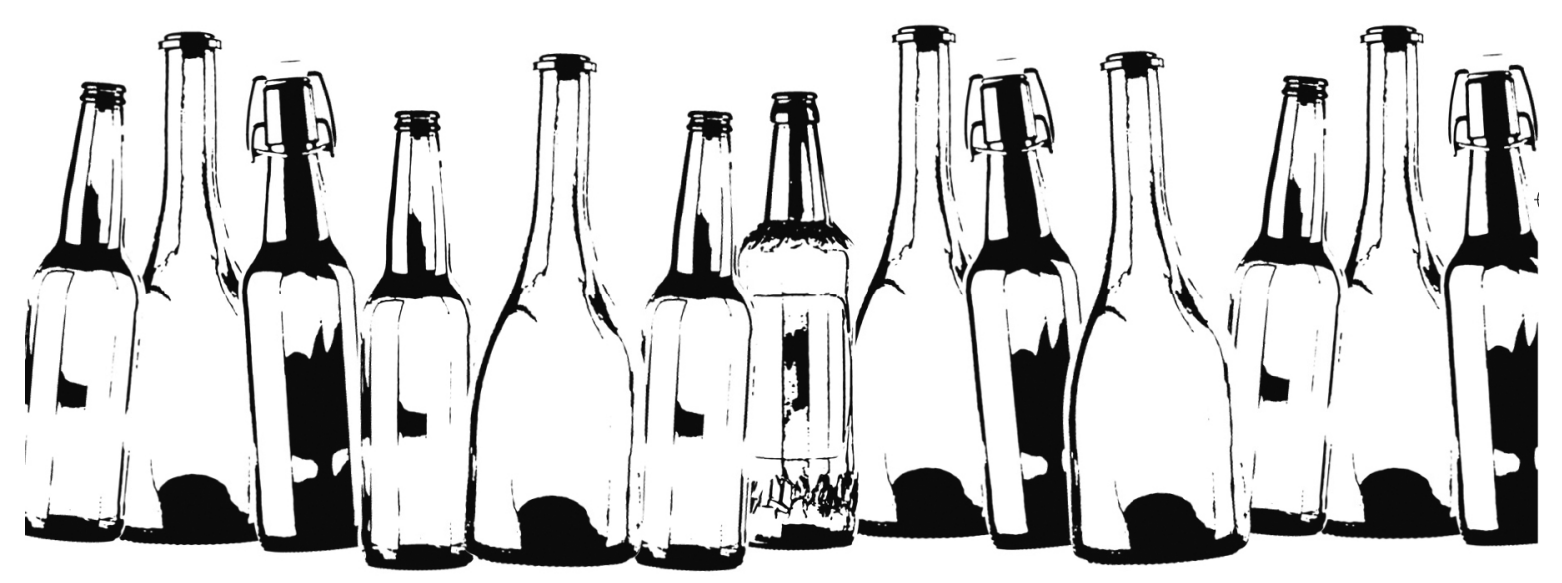




\subsection{ABSTRACT}

Two studies are reported addressing the media influences on adolescents' alcohol-related attitudes and behaviours. A content analysis was conducted to investigate the prevalence of alcohol portrayal in a Dutch soap series. The coding scheme covered the alcohol consumption per soap character, drinking situations and drinking times. Inter-coder reliability was satisfactory. The results showed that alcohol portrayal was prominent and that many instances of alcohol use reflected undesirable behaviours. To assess the influence of such alcohol cues on adolescents, a 2x2 experiment was conducted focusing on the separate and combined effects of alcohol portrayal in the soap series and surrounding alcohol commercials. Whereas the alcohol commercials had the expected effects on adolescents' attitudes, the alcohol-related soap content only appeared to have adverse effects. Adolescents who were exposed to the alcohol portrayal in the soap series, had a less positive attitude towards alcohol and lower drinking intentions. Implications of these findings for health policy and future research are discussed. 


\subsection{INTRODUCTION}

Television has much impact on our daily life. Fictional television programmes can give viewers a skewed image of reality, despite their knowing that it is only fiction. People who often watch violent television series have stronger feelings of insecurity and are overly afraid of crime and serial killers (Busselle, 2001). Adolescents who see smokers in movies are more inclined to try cigarettes (Sargent et al., 2001a). Teenagers consider entertainment media to be their most important source of information concerning sexuality (Kaiser Family Foundation and Children Now, 1997). Overviews of media effects on healthrelated behaviours of children and adolescents show that media exposure often has strong effects on attitudes and behaviours (Bar-on, 2000; Brown \& Witherspoon, 2002; Villani, 2001). A theoretical underpinning is cultivation theory, which assumes that people use what they see on television to make inferences about everyday reality and eventually adopt certain behaviours (Gerbner, Gross, Morgan, \& Signoreilli, 1986). The basic tenet of cultivation theory is that this reliance on television as a basis of social inferences may result in a biased worldview. That is, a worldview that reflects television's portrayal of reality, rather than reality itself. In cultivation research, discrepancies between television and real-life data are assumed to indicate a biased television world, and significant correlations between indicators of this television world and audience beliefs and attitudes are assumed to indicate biasing effects of television content on people's perceptions. In addition, the concept of modelling describes how such effects may occur, namely by imitating behaviours of role models on television (Grube \& Waiters, 2005; Singer, 1985).

Given the potential risks of media exposure to problematic content, it seems important to monitor the health-related messages adolescents are exposed to in the media. This article focuses on alcohol portrayal on television. Research shows that alcohol advertisements may positively affect adolescents' drinking intentions and behaviours (Atkin, Hocking, \& Block, 1984; Wyllie, Zhang, \& Casswell, 1998b). Besides 'regular' alcohol advertisements, however, adolescents may also be exposed to more implicit alcohol-related cues, in music videos (Gruber, Thau, Hill, Fisher, \& Grube, 2005), movies (Everett, Schnuth, \& Tribble, 1998; Thompson \& Yokota, 2001), and television programmes like soaps (Furnham, Ingle, Gunter, \& McClelland, 1997; Long, O’Connor, Gerbner, \& 
Concato, 2002; Mathios, Avery, Bisogni, \& Shanahan, 1998; Wallack, Grube, Madden, \& Breed, 1990). There is reason to assume that these indirect cues may have stronger effects on audience perceptions and behaviour than commercial messages, whose persuasive intentions can be more easily inferred and resisted (Signorielli, 1990).

One of the ways to present alcohol-related cues in fictional programming is through product placement, which refers to a marketing strategy whereby actors more or less ostensibly use commercial products. In its most common form, product placement entails the promotion of brands, but product placement techniques can also be used to promote a product category or a specific class of behaviour. Star Trek, for instance, promoted safe sex without advertising for specific condom brands (Tannen, 2003). Furthermore, 85\% of the movies portray smoking behaviour, of which only $28 \%$ refers to specific cigarette brands (Sargent et al., 2001b).

Many countries have issued regulations to limit the exposure of underage viewers to alcohol-promotion. In the Netherlands, for instance, no alcohol commercials are allowed on channels aimed at young audiences. The regulations, however, mainly apply to explicit alcohol advertisements. There are fewer limitations for more implicit ways of portraying alcohol: it is not allowed to repeatedly show one particular alcohol brand in a programme, but there are no restrictions regarding alcohol or alcohol-related behaviours in general.

In this article, we will explore the effects of the exposure of adolescents to alcohol-related television content. In a first study, we analysed the alcohol portrayal in the most popular Dutch soap (“Goede Tijden, Slechte Tijden”). The show is broadcast 5 days a week on prime-time (between 8 and 8.30 p.m.) and attracts $\sim 1.7$ million viewers daily, of whom > 200,000 are 6- to 19-year old. In a second study, we experimentally investigated the effects of alcohol cues on adolescents. Participants were exposed to alcohol-related soap content or not and to alcohol or non-alcohol advertisements in the surrounding commercial blocks to establish the combined and separate effects of direct and indirect alcohol messages. 


\section{STUDY 1: ALCOHOL PORTRAYAL IN THE SOAP SERIES}

To investigate the role of alcohol in the soap series we conducted a content analysis. Most of the available studies into alcohol portrayal in the media focused only on the prevalence of alcohol consumption (Everett et al., 1998; Furnham et al., 1997; Gruber et al., 2005; Long et al., 2002; Mathios et al., 1998; Thompson \& Yokota, 2001; Wallack et al., 1990) without systematically addressing the hedonic and social contexts in which it occurs. Like two earlier studies (Christenson, Henriksen, \& Roberts, 2000; Hansen, 2003), we tried to extend the existing research by examining the specific contexts of alcohol use.

\subsection{STUDY 1: METHODS}

We systematically analysed a random sample of 40 episodes, broadcast between 2 March and 26 April 2004. Each episode lasted 22 minutes (excluding commercial breaks).

\section{Coding scheme}

A coding scheme was developed, focusing on four aspects of alcohol portrayal: (i) amount of alcohol consumed, (ii) types of alcohol, (iii) time of day, and (iv) drinking situations.

Regarding the amount of alcohol consumed, we recorded the drinking behaviour of the 20 protagonists in the series. Both visual and verbal cues were used as signs of alcohol consumption. Visual cues were scenes in which characters drank alcohol or had the apparent intention to drink. Verbal cues involved audible mentions of alcohol consumption (e.g. ordering a drink at the bar). This resulted in indications of the total amount of explicit alcohol consumption in the series, and the alcohol-related behaviours of the protagonists.

The types of alcoholic beverage were recorded for all alcohol consumptions. Four categories were distinguished: (i) beer, (ii) wine (including port, sherry, vermouth, sake and champagne), (iii) distilled spirits (e.g. whisky or brandy), and (iv) mixed drinks and cocktails. 
For the time of the day at which alcohol consumption took place, we distinguished: (i) morning (between 6 a.m. and noon), (ii) afternoon (between noon and 5 p.m.), (iii) dinnertime (between 5 and 8 p.m.), (iv) evening/night (between 8 p.m. and 6 a.m.), and (v) unknown time.

Regarding the situations in which the soap characters consumed alcohol, we used five categories: (i) alcohol use in regular social settings (e.g. going to a bar), (ii) alcohol use in culinary situations (e.g. drinking wine during dinner), (iii) alcohol use to suppress problems, conflicts or fears, (iv) alcohol use immediately before or during work, and (v) other situations. The first two categories refer to situations of alcohol use that are often deemed tolerable; the third and fourth category correspond to generally acknowledged forms of alcohol misuse. We also recorded whether the negative consequences of (excessive) alcohol use were depicted (e.g. hangovers, sickness, or addiction).

\section{Procedure}

After the coding scheme was developed, it was pre-tested and three coders were trained. To evaluate the coding scheme, $10 \%$ of the episodes were analysed by three coders. Intercoder reliability ranged from .87 to 1.00 (Cohen's kappa) and was considered satisfactory. The remaining episodes were analysed by the first author.

\subsection{STUDY 1: RESULTS}

\section{Amount of alcohol consumed}

Alcohol proved to be omnipresent in the series. In $98 \%$ of all broadcasts (39 of the 40 episodes), alcohol was consumed by at least one character. In total, 177 alcoholic consumptions were counted in the 40 episodes, amounting to 4.4 alcoholic drinks per episode (or one drink every $5 \mathrm{~min}$ ). The 20 protagonists consumed on average 0.39 glasses of alcohol per episode (ranging from 0 to 1.2 drinks per episode). Only two of the characters never drank alcohol. The percentage of non-drinkers in the series $(10 \%)$ is 
considerably lower than in the Dutch adult population (19.4\%) (Centraal Bureau voor de Statistiek, 2006).

\section{Types of alcoholic beverages}

Table I presents the types of alcoholic beverages consumed. Wine was by far the most popular drink, distilled spirits and beer trailed far behind, and mixed drinks and cocktails were consumed the least frequently. This pattern of alcohol consumption does not mirror the real pattern of alcohol consumption. Beer is the most popular alcoholic drink in the Netherlands (75\%), and mixed drinks are increasingly popular, particularly among young people (Commission for Distilled Spirits, n.d.).

Table I: Results of the content analysis

\begin{tabular}{lll}
\hline & Frequency & Percentage \\
\hline Types of alcohol consumed & & \\
Wine & 102 & $58 \%$ \\
Distilled & 39 & $22 \%$ \\
Beer & 26 & $15 \%$ \\
Cocktails / Mixed & 10 & $6 \%$ \\
Time of alcohol consumption & & \\
6.00 a.m. to noon & 7 & $4 \%$ \\
noon - to5.00 p.m. & 28 & $16 \%$ \\
5.00 p.m. to 8.00 p.m. & 50 & $28 \%$ \\
8.00 p.m. to 6.00 a.m. & 84 & $47 \%$ \\
Unknown & 8 & $5 \%$ \\
Situations of alcohol consumption & & \\
Social settings & 68 & $38 \%$ \\
Culinary situations & 19 & $11 \%$ \\
To suppress problems & 45 & $25 \%$ \\
Before/during work & 21 & $12 \%$ \\
Other & 24 & $14 \%$ \\
\hline
\end{tabular}

${ }^{\mathrm{a}}$ For example: explicit alcohol consumption by minor characters and walk-ons.

Time of the day

Almost half of the alcohol consumption took place in the evening or at night (Table I). About a quarter was at dinnertime. Almost $20 \%$ took place before 5 p.m., $16 \%$ in the afternoon and $4 \%$ in the morning. 
Situations of alcohol consumption.

About half of the drinking situations in the series refer to normal, non-problematic alcoholrelated behaviours (Table I). Characters consumed alcohol in regular social settings or in combination with a meal. Over $35 \%$ of the drinking situations, however, were generally acknowledged forms of alcohol misuse. Characters drank to suppress problems, conflicts or fears, or used alcohol immediately before or during work. For example, a businessman drank a double brandy to drown his sorrows after noticing that an expensive painting had been stolen. Later, he poured another drink when watching a blackmail video. When romantic relationships ended, the characters involved often grabbed the bottle to ease their pain. Regarding alcohol use before or during work, a senior entrepreneur tended to drink wine while reading business reports or using the computer in her office, and a business deal was celebrated with champagne. Half of the protagonists consumed alcohol before or during work. This does not reflect reality: only $4 \%$ of the Dutch working population occasionally consumes alcohol before or during work (Schutten, Van den Eijnden, \& Knibbe, 2003). No negative consequences (such as hangovers, sickness or addiction) or health-promoting messages occurred in the series.

\section{STUDY 2: EFFECTS OF ALCOHOL PRODUCT PLACEMENT}

To investigate the effects of alcohol-related cues on adolescent viewers, we conducted an experiment. In a $2 \times 2$ post-test design, adolescents were randomly assigned to four experimental conditions, based on two treatments: a soap episode containing alcohol cues versus a non-alcoholic episode, surrounded by commercials for either alcoholic or nonalcoholic beverages. After exposure, participants had to fill out a questionnaire. Six weeks after the experiments, debriefing sessions were held to collect additional qualitative data.

\subsection{STUDY 2: METHODS}

\section{Pilot study}

Prior to the experiment, we held a focus group with 16 adolescents to pre-test the materials and generate relevant questionnaire items. Regarding the materials, the main issue was the 
percentage of alcohol-related scenes to be included in the alcoholic episode. It is generally assumed that at least 20 to $30 \%$ of the experimental cues must be prime items (Chaiken \& Bargh, 1993; Scrull \& Wyer, 1979). As higher percentages of prime items may lead to stronger effects (Bargh, Chen, \& Burrows, 1996; Scrull \& Wyer, 1979; Wyer \& Scrull, 1981), an episode with about $50 \%$ of alcohol-related cues was developed. After watching the experimental episode, participants filled out a questionnaire about the credibility of the episode and the purpose of the study. All participants considered the episode to be a normal version of the soap series, and not one of them guessed that alcohol was the scope of the research.

To inventory salient opinions about alcohol, we asked the adolescents about the positive and negative aspects they associated with alcohol use. Participants had to mention positive and negative consequences of drinking and rank their relevance. Postive consequences were: (i) drinking is enjoyable, (ii) it is social, (iii) it is relaxing, (iv) it makes you cheerful, (v) it feels good, (vi) it boosts your self-confidence, and (vii) it makes you sociable. Negative consequences were: (i) alcohol is bad for your brain, (ii) it makes you feel tired, (iii) it makes you lose control, (iv) it makes you sombre, and (v) it breaks down your selfconfidence. These attributes were used for the post-exposure questionnaire.

\section{Materials}

The materials for the four conditions were compiled from the episodes used in the content analysis. To do so, we selected suitable scenes from the original broadcasts and combined them to two plausible episodes. In the alcoholic soap episode, $50 \%$ of the scenes were alcohol-related; in the non-alcoholic episode, none of the scenes contained alcohol-related cues. Since episodes usually consist of three or four different storylines, it was relatively easy to assemble the two episodes. We included four storylines per episode: two storylines differed on the variable of interest (alcohol versus non-alcohol), and two were the same in both versions. All selected scenes involved younger soap characters, so that both versions would be particularly appealing to an adolescent target audience. All selected scenes contained drinking in social settings. The editing resulted in two episodes of about the same length as a real episode (22 min). 
To also investigate the effects of alcohol commercials, the episodes were embedded in two commercial blocks, one before and one after the episode. Each block consisted of six commercials, three of which differed (alcohol versus lemonade commercials). The six alcohol commercials advertised beer, spirits and mixed drinks (two for each type of drink). All commercials focused on young consumers. The alcohol and lemonade commercials had the same length.

\section{Sample}

Participants were recruited in a secondary school in the eastern part of the Netherlands. The school's headmaster helped us select 12 groups of pupils (three times four similar study tracks and years). Two hundred and forty-eight pupils were randomly assigned to the four conditions. The participants ranged in age from 12 to 18 (mean 14.9). The male:female ratio was 40:60. The four conditions, each containing 61-63 pupils, were similar regarding age, study track, and gender. After eliminating incomplete forms and extreme outliers (using standardized residuals), 223 questionnaires were usable for further analysis.

\section{Post-exposure questionnaire}

The questionnaire focused on three types of effects: (i) supraliminal alcohol priming, (ii) perceived consequences of alcohol use, and (iii) drinking intentions. To investigate supraliminal alcohol priming effects, we used a word completion task (Krishnan \& Chakravarti, 1999). Participants had to complete a list of words of which only the first two or three letters were given (e.g. al..., bee... and spi...). The underlying assumption is that exposure to alcohol cues may lead to a larger proportion of completed words referring to alcohol (e.g. 'alcohol', 'beer' and 'spirits' versus 'alarm', 'beef' and 'spider'). To ensure that the word completion task would not reveal our research interest, we only used letter combinations that could be completed in at least ten different ways and we complemented the six target words with twelve other words, which could not be associated with alcohol.

The perceived consequences of alcohol use were measured with a set of 11 items based on the pilot study and the literature (the two items about self-confidence were combined). The questions were asked using five-point Likert scales. To hide our research interest, the questionnaire also contained questions on general consumption patterns and lifestyle (e.g. 
eating habits and sports). The six positive and five (recoded) negative items about the consequences of alcohol use formed a reliable scale (Cronbach's alpha $=0.81)$. The perceived consequences measured by this scale appeared to correlate significantly with participants' behavioural intentions regarding the amount of alcohol they would consume in the next weekend $(r=0.56, P<0.001)$.

Alcohol consumption intentions were measured in two ways. Immediately after the word completion task, participants were asked what kind of beverage they would like to consume; they could choose from a list of 5 alcoholic and 10 non-alcoholic beverages (immediate intention). To conceal the research purpose, they also had to choose a favourite snack. It was clear to the participants that this task was fictitious: we did not give them drinks or snacks. At the end of the questionnaire, the participants were asked to estimate how many glasses of alcohol they would consume in the next weekend (postponed intention). Again, other lifestyle-related questions were asked as well (e.g. sporting hours and fruit consumption).

\section{Procedure}

Participants watched the soap episode and commercials in groups of $\sim 20$. After exposure, they had to individually complete the questionnaire. All sessions took place in school, between 11.00 a.m. and 3.00 p.m. The scope of the research remained undisclosed until the end of all experimental sessions.

\section{Debriefing sessions}

Six weeks after the research, ten debriefing focus group sessions were organized. These sessions were held (i) to check whether or not participants had guessed the research topic (in none of the ten sessions, participants mentioned alcohol content as possible research topic), (ii) to present the main outcomes of the research and (iii) to further explore some of the results. All participants attended one of the debriefing sessions. 


\subsection{STUDY 2: RESULTS}

The main results are presented in Table II. The word completion task, the perceived consequences, and the postponed intentions were analysed using analysis of variance, with the two experimental conditions as independent variables and the participants' gender as an additional independent variable. The participants' age group was used as a covariate. The immediate intentions were analysed with a chi-square test.

Table II: Effects of alcohol content in soap series and commercials

\begin{tabular}{|c|c|c|c|c|}
\hline & \multicolumn{2}{|l|}{ Soap series } & \multicolumn{2}{|c|}{ Commercials } \\
\hline & Alcohol & Non-alcohol & Alcohol & Non-alcohol \\
\hline Word completion ${ }^{\mathrm{a}}$ & $1.35(.87)$ & $1.49(.89)$ & $1.41(.91)$ & $1.42(.86)$ \\
\hline Perceived consequences ${ }^{\mathrm{b}}$ & $3.05(.51)^{*}$ & $3.20(.60)^{*}$ & $3.20(.55)^{*}$ & $3.05(.55)^{*}$ \\
\hline Immediate intention $^{c}$ & $13 \%$ & $11 \%$ & $9 \%$ & $16 \%$ \\
\hline Postponed intention $^{\mathrm{d}}$ & \multicolumn{2}{|c|}{$4.15(5.87)^{* * 7.31}(9.19)^{* *}$} & $6.05(7.94)$ & $5.38(7.74)$ \\
\hline
\end{tabular}

Indepent sample t-tests: $* P<0.05 / * * P<0.01$

${ }^{a}$ Mean number of alcohol references in six target words (SD).

${ }^{\mathrm{b}}$ Mean score on five-point scale $(1=$ negative and $5=$ positive $)(\mathrm{SD})$.

${ }^{\mathrm{c}}$ Percentage of participants choosing an alcoholic beverage.

${ }^{\mathrm{d}}$ Mean estimated number of glasses of alcohol in the next weekend (SD).

Concerning the word completion task, no significant differences were found due to alcohol exposure, both in the soap episode and in the commercial blocks. On average, only $25 \%$ of the six target words referred to alcohol, irrespective of the experimental condition. There was only a significant difference between the genders: female participants referred more to alcohol than male participants $[F(1214)=7.260, P<0.01]$.

Regarding the perceived consequences of alcohol use, significant differences were found between the two soap versions $[F(1214)=4.812, P<0.05]$ and between the two sets of commercial blocks $[F(1214)=5.224, P<0.05]$. As expected, participants who were exposed to alcohol commercials had more positive scores on the perceived consequences scale than participants who watched non-alcoholic commercials. The alcohol portrayal in the soap episode, however, appeared to have a negative effect on the perceived consequences of alcohol use: participants who watched the alcoholic soap episode judged less positively about the consequences of alcohol use than participants in the non-alcoholic 
soap condition. There was also a significant difference between the genders: male participants were more positive about alcohol than female participants $[F(1214)=6.218, P$ $<0.05]$. No interaction effects were found.

Participants' immediate alcohol consumption intentions did not differ significantly due to their exposure to alchol-related cues. Given the fact that one-third of the alternatives offered were alcoholic beverages, the percentage of participants choosing alcohol was rather low (9-16\%), which may be due to the time and context of the sessions (at daytime and in a school setting).

Regarding participants' postponed alcohol consumption intentions, we did find one significant difference which reinforces our findings on the perceived consequences. Exposure to alcohol portrayal in the soap episode resulted in significantly lower drinking intentions $[F(1214)=17.250, P<0.001]$. There was an interaction effect with gender: the effect of the soap series only occurred among male participants $[F(1214)=10.112, P<$ 0.005], who generally intended to drink considerably more alcohol than female participants $[F(1214)=59.987, P<0.001)$. The alcoholic soap content only seemed to reduce the drinking intentions of participants who intended to consume a lot of alcohol. Exposure to the alcohol commercials did not have a significant effect on the partipants' behavioural intentions.

In the focus group debriefing sessions, we further explored the difference in effects between alcohol commercials and alcohol portrayal in the soap series. Participants generally concurred with the finding that alcohol commercials positively affected their attitudes toward alcohol, explaining that the alcohol commercials triggered their attention to alcohol and made drinks more appealing. Although it is not allowed in the Netherlands to aim alcohol commercials at young audiences, the commercials did have a positive effect on adolescents. Participants mentioned two possible explanations for the unexpected finding that the alcoholic soap episode had negative effects on their attitude towards alcohol and drinking intentions. First, they found it hard to fully identify with the characters drinking in the episode. This is partly due to an age difference; although we only included younger soap characters, there was still an age difference with the adolescents. It also had to do with the personality of the characters, whom they characterized as "bullies" 
or "jerks." Second, the alcohol scenes in the episode were considered to be exaggerated, and also focused their attention on the annoying behaviour of drinking characters, rather than on the alcohol consumption per se.

\subsection{GENERAL DISCUSSION}

Earlier research has shown that the media may have significant influence on the attitudes, intentions and behaviour of adolescents. Television soap series, in particular, have several ingredients that may strongly affect their audience's opinion: viewers are absorbed in the series' reality; characters become imaginary friends who undergo many emotional experiences; and viewers are expected to expose themselves to the series on a daily basis.

The results of our studies confirm the effects of television programming on adolescents. However, these effects appear to be unpredictable and strongly related to the exact content of the primes offered. The alcohol commercials worked largely as expected, but it appears to be considerably harder to predict the effects of alcohol portrayal in the soap series. Despite the soap series' appeal to adolescents and our attempts to select appealing alcoholrelated scenes, participants reacted negatively to the alcohol-related soap content. Exposure to alcohol cues in the soap series had negative effects on the participants' attitudes and behavioural intentions. In the debriefing sessions, we found that the level of identification with the characters and the specific drinking situations may be crucial variables.

The results problematize the relationship between media portrayal of alcohol (and other risk behaviours) and the attitudes and behaviours of (adolescent) viewers. Our content analysis underlines the importance of more in-depth investigations of the way alcohol is portrayed on television. Many earlier studies have focused primarily on the intensity of alcohol portrayal in television programmes (Furnham et al., 1997; Long et al., 2002; Mathios et al., 1998; Wallack et al., 1990), implicitly assuming a positive relationship between exposure and attitudes or behaviours. In addition to the amount of alcohol consumption portrayed, it seems important to investigate the "lessons" adolescents may learn from the specific ways in which alcohol is portrayed. 
From the theoretical perspective of cultivation, which assumes that viewers' image of reality may be skewed by the things they see on television, it must be noted that the soap series exaggerates the prevalence of alcohol in daily life. Of course, the mean number of glasses explicitly consumed per character ( 0.39 per episode) is lower than most statistics on daily alcohol consumption, but these consumptions take place in only $22 \mathrm{~min}$. Another indication of the prominence of alcohol is that only $10 \%$ of the main characters were nondrinkers, which is half of the actual percentage of non-drinkers in the Netherlands. In all, cultivation theory predicts that adolescent viewers will learn from the series that alcohol consumption is a normal and almost necessary part of people's daily life.

From the perspective of modelling, which assumes that viewers imitate the behaviour of important characters, the portrayal of times of drinking and drinking situations must be labelled as potential risk factors. Adolescents may get the impression that alcohol consumption in the morning and early afternoon is a normal thing to do. They may also learn that drinking is a normal reaction to problems, that it may help to drown or solve them, that excessive alcohol use is a valid excuse for irresponsible behaviour, and that it is possible to drink before or during working hours without malfunctioning. Not only are the main characters frequently involved in such problematic alcohol-related situations, but the series also fails to portray the negative consequences of such behaviour.

Our experimental results further complicate the assumed relationship between alcohol exposure and viewers' attitudes and behaviour, based on the theoretical notions of cultivation and modelling. The results of the experiment did not straightforwardly confirm any cultivation or modelling effects. Instead, messages may be interpreted in different ways, depending on the characteristics of scenes and actors (Borzekowski, 1996; Borzekowski \& Poussaint, 1999). The advertisements used were all positive by nature (attention, interest, excitement), and univocally interpreted that way. The scenes in the soap series were selected to represent positive scenes depicting young characters drinking alcohol in social settings, but were predominantly interpreted rather negatively. More research is needed into the way adolescent viewers interpret the messages contained in television programmes. Our debriefing sessions suggest that identification may be a crucial variable in need of more systematic exploration. To estimate the attitudinal and 
behavioural effects of the media, it is important to understand how identification moderates or mediates the effects of positive and negative media portrayal, and to consider the factors that facilitate or impede viewers' identification with characters and scenes. These issues are not only important for predicting adolescents' risk behaviours due to media exposure, but also to help design entertainment-education programmes which are increasingly used to promote a healthy lifestyle among adolescents (Slater \& Rouner, 2002; Sood, 2002).

It is important to realize that our experiment is limited to the immediate effects of a single exposure to alcohol cues. In real life, such effects will probably diminish over time. On the other hand, our study did not address the cumulative effects of repeated exposure to alcohol-related content in the series. Soap viewers may be receptive to such cumulative effects as they watch episodes on a daily basis and strongly empathize with the characters. Another limitation is that the exposure to the soap series and commercials was not ecologically valid: the viewing situation in our study differed from a normal home situation, and not all participants were necessarily interested in this particular soap. Moreover, our participants did not represent the entire adolescent viewing population of the soap series either as they all lived in the eastern part of the Netherlands. Finally, it is important to realize that we did not collect baseline data about alcohol-related attitudes and intentions, and that we did not include actual behaviours in this study. It would be interesting to see whether the findings of our study also apply to more natural viewing situations and to viewers' actual behaviours. 
"Abstaining is favorable both to the head and the pocket"

Horace Greeley (1811 - 1872) - American newspaper editor 


\section{Happy Hours and Other Alcohol}

\section{Discounts in Cafés: Prevalence and \\ Effects on Underage Adolescents}

Joris J. van Hoof

Marieke van Noordenburg

Menno D.T. de Jong

Journal of Public Health Policy, 2008, 29, 340-352.

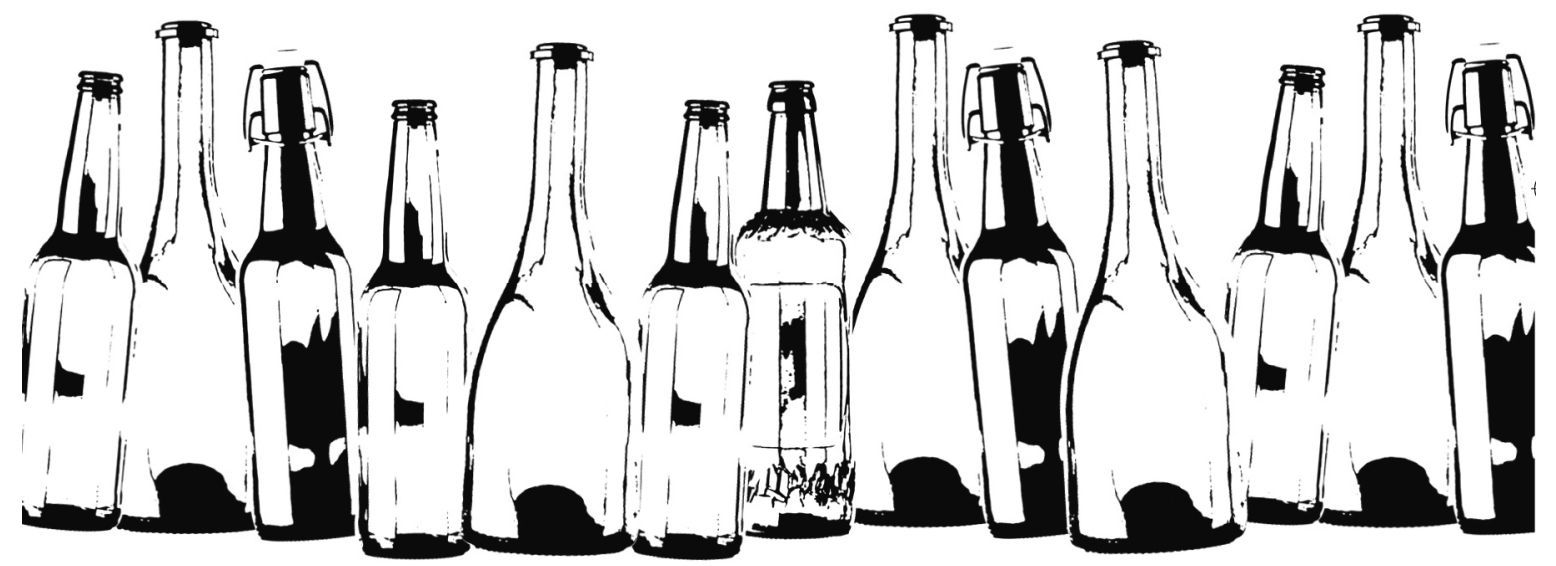




\subsection{ABSTRACT}

Adolescents' alcohol-related attitudes and behaviours may be affected by marketing efforts of the alcohol industry, retailers and the catering industry. Most research has focused on the effects of commercials and media exposure. This article investigates another aspect of alcohol marketing in the Netherlands: the use of alcohol discounts by cafés. The prevalence of alcohol discounts was studied using unobtrusive café observations and website content analysis. It is estimated that $39 \%$ of the cafés offer some kind of cash discount for alcoholic beverages. The effects of alcohol discounts were investigated in a survey among adolescents (14-17 years old, N=409). Adolescents reported to use alcohol discounts eight times a year, and to consume more alcohol when discounts are offered. Alcohol discounts, however, do not attract adolescents to visit certain cafés and/or to spend more money when going out. No differences were found between minors (16-17 years) and underage adolescents (14-15 years). 


\subsection{INTRODUCTION}

Policy makers are confronted with alarming facts about youth and alcohol. First, there is a growing body of evidence for the detrimental effects of early alcohol use among adolescents, which particularly focuses on the physiological and developmental effects of teenage alcohol consumption (NIAAA, 2004-2005a; NIAAA, 2004-2005b) and the way teenage drinking evolves into adulthood problem drinking (Bonomo, Bowes, Coffey, Carlin, \& Patton, 2004; Wells, Horwood, \& Fergusson, 2004). Second, teenagers tend to start drinking earlier and also drink more than ever before. In the Netherlands, $90 \%$ of the 15 year old adolescents have experience with alcohol, and 52\% drink every week (Monshouwer, Van Dorsselaer, Gorter, Verdurmen, \& Vollebergh, 2004; Van de Pol \& Duijser 2003). About $20 \%$ of the male and $10 \%$ of the female 15 year olds drink more than ten glasses of alcohol on a weekend day, and $63 \%$ have been intoxicated at least once (Monshouwer et al., 2004). A third trend is that alcohol marketers increasingly seem to focus on younger target audiences, not only in their advertisements but also in the alcoholic products they offer (Casswell, 2004; Hastings, Anderson, Cooke, \& Gordon, 2005; Jackson, Hastings, Wheeler, Eadiel, \& Mackintosh, 2000).

Given these developments, traditional and restricted public health approaches focusing on education and public information will not suffice. Surveys in the United States and the Netherlands show that people strongly support more rigorous government measures to reduce alcohol consumption among minors (Gosselt, Van Hoof, \& De Jong, 2007; Richter, Vaughan, \& Foster, 2004). In addition to informing adolescents about the risks of alcohol use, it is important to limit the availability of alcohol to adolescents-which proves to be a major problem in the Netherlands (Gosselt et al., 2007; Gosselt, Van Hoof, De Jong, \& Prinsen, 2007)—and to thoroughly scrutinize and regulate the alcohol marketing activities to which adolescents are exposed (Casswell \& Maxwell, 2005; Hastings et al., 2005; Jackson et al, 2000; Jernigan, Ostroff, \& Ross, 2005; Toomey \& Wagenaar, 1999).

Many studies have focused on the effects alcohol marketing efforts have on adolescents, most of which address adolescents' exposure to and the effects of alcohol advertising in the mass media (Hastings et al., 2005). Less attention has been paid to the marketing activities 
at the points of sale. In this article, we will investigate the prevalence of happy hours and alcohol discounts in Dutch cafés, as well as their effects on (underage) adolescent drinkers.

Research has shown that the price of alcohol affects adolescents' alcohol use: the higher the price, the lower the consumption (Grossman, Chaloupka, Saffer, \& Laixuthai, 1994). Two earlier studies have specifically addressed the effects discounts and promotions have on college students. Christie et al. (2001) did this in a laboratory setting. Students were given advertisements of a fictitious bar, two of which mentioned alcohol discounts, whereas the control condition offered reduced prices on appetizers. The alcohol discounts appeared to positively affect the students' intentions to visit the bar and their estimated alcohol consumption. Kuo, Wechsler, Greenberg, and Lee (2003) took a macro-approach and correlated survey data collected from students at 118 American colleges with observational data about alcohol promotions (and prices) in the vicinity of the colleges concerned. They found a positive relation between alcohol discounts and binge-drinking. In our study, we take a middle position between the artificial data reported by Christie et al. (2001) and the coarse-grained correlations reported by Kuo et al. (2003). We investigated the prevalence of alcohol discounts in Dutch cafés, and asked underage (14-15 years old) and minor (16-17 years old) adolescents about their experiences with and the effects of alcohol discounts.

\subsection{DUTCH POLICY CONTEXT}

In the current Dutch situation, happy hours and other alcohol discounts in the catering industry are only subject to self regulation. The Dutch Foundation for the Responsible Use of Alcohol (STIVA), an organization of alcohol industries representatives, has formulated an Advertising Code with regulations for alcohol promotions (STIVA, 2006). According to the Advertising Code, alcohol promotions are not allowed in premises where $25 \%$ or more of the visitors are minors. It is also not permitted to offer alcoholic beverages for free or to sell them for less than half of the normal price, to offer more than one drink with discount per customer, or to combine alcohol discounts with extra free gifts. 
The Royal Dutch Catering Industry (Koninklijke Horeca Nederland) has issued a number of self regulation guidelines as well. Cash discounts must: (a) not be aimed at adolescents under 18, (b) not take place shortly before closing time, (c) also include sodas and/or snacks, and (d) not be higher than half of the original selling price. The Royal Dutch Catering Industry supports a ban on alcohol discounts, not only because excessive alcohol use causes nuisance and violence, but also because discounts are only profitable for individual cafés but eventually cost the catering industry a lot of money. In politics, attempts have been made to forbid alcohol discounts in cafés, but they did not succeed, partly because of the assumption that the phenomenon of alcohol discounts in cafés is already on the decrease.

\subsection{RESEARCH DESIGN}

To investigate the prevalence of alcohol discounts in cafés, we collected two types of data: undercover observations in cafés and a content analysis of café websites. We had two reasons for this combination. First, it is imaginable that some of the promotions are only offered on specific times of the day, or days of the week. Observational research will possibly overlook such promotions, when cafés are visited at the wrong times. The website content analysis serves as a safety net for these situations. Second, the combination of methods allows us to see whether cafés used the alcohol discounts for promotional purposes. If the discounts are considered important for the attraction of guests, they will be mentioned prominently on the website. To investigate the effects of alcohol discounts, we conducted a written survey among adolescents. The research was conducted in five cities in different regions of the Netherlands.

\section{Observational research}

In each of the five cities, at least 40 cafés (in the downtown area) were observed in September 2006. To limit the chance of overlooking alcohol discounts and the influence of observer bias, all cafés were observed twice, at random times on different nights, by teams consisting of two research assistants. There was $86 \%$ agreement between the observations of two teams. 
Shortly before the research took place, the research assistants received training and written instructions. The teams observed about 20 cafés per evening, recording all alcohol discounts they encountered on a checklist. If possible, they wrote down verbatim the texts announcing discounts, collected advertising materials on discounts, and/or took photographs of announcements. They also wrote down the normal price of the beverage(s) concerned, and the design and place of the announcement(s). Each visit, the following information was recorded: (a) name of the café, (b) city, (c) date and time, and (d) the café's closing time.

\section{Content analysis of websites}

For all five cities, a list of approximately 120 cafés was compiled (645 in total). An up-todate website was found for 256 of the cafés (40\%). All these websites were analyzed for the announcements of alcohol discounts. A print screen was made of the announcements. The following characteristics of the alcohol discounts were recorded: (a) type of discount, (b) type of drink(s) involved, (c) days and times when the discount was offered, (d) frequency, (e) duration, and (f) prominence of the announcement on the website.

\section{Written survey among adolescents}

The survey focused on 14-17 year old adolescents (underage and minors). In each of the five cities, secondary schools were asked to participate. A questionnaire was designed, which students could fill out anonymously. The survey was administered in a class setting. A total of 409 adolescents participated, representing all three educational levels in the Netherlands: "vmbo" (low), "havo" (middle), and "vwo" (high).

The questionnaire consisted of four parts. First, respondents were asked whether they went out, and if yes, where, when, and how often. Second, they were asked about their drinking behaviour when going out. After that, the questionnaire focused on adolescents' experiences with alcohol discounts. They were asked how often they encountered alcohol discounts when going out, how they learned about them, and how often they made use of discounts. Two scales were used to investigate the consequences of alcohol discounts, focusing on alcohol consumption (five items on five-point Likert scales, Cronbach's alpha .74) and café attractiveness (three items on five-point Likert scales, Cronbach's alpha .67). 
One question involved the effects of alcohol discounts on the amount of money adolescents spent when going out. The last part of the questionnaire consisted of background variables.

\subsection{RESULTS}

\section{Prevalence of alcohol discounts}

We found a total of 122 alcohol discounts, available at 65 of the 209 cafés observed (31\%). The $95 \%$ confidence interval for this percentage ranges from $25 \%$ to $37 \%$. Most often, cafés offered one type of alcohol discount (59\%). In extreme cases, single cafés offered up to ten different types of alcohol discounts. Table I gives an overview of the types of alcohol discounts encountered. The most frequently observed type of discount were cash discounts for beer, followed by happy hours and cash discounts for cocktails. Less common were cash discounts for wine, mixed drinks, shooters and strong alcoholic beverages, unlimited drinking, student nights or student prices, and ladies nights.

Table I: Frequency of various types of cash discounts observed in cafes

\begin{tabular}{lll}
\hline & Frequency & Percentage \\
\hline Cash discount for beer & 58 & 48 \\
Happy hour & 13 & 11 \\
Cash discount for cocktails & 12 & 10 \\
Cash discount for shots/shooters & 8 & 7 \\
Cash discount for mixed drinks & 7 & 6 \\
Cash discount for strong alcoholic beverages & 7 & 6 \\
Student night/ student prices & 6 & 5 \\
Cash discount for wine & 5 & 4 \\
Ladies night & 2 & 1 \\
Unlimited drinking & 1 & 1 \\
Other & 3 & 2 \\
Total & $\mathbf{1 2 2}$ & $\mathbf{1 0 0}$ \\
\hline
\end{tabular}

Nearly half of the alcohol discounts (45\%) were offered every week, usually on the same day of the week. Some of the discounts, particularly happy hours, were offered several times a week $(13 \%)$ or even on a daily basis $(5 \%)$. Other discounts were incidental or were offered only once per month. Most of the discounts amounted less than half of the original 
price (67\%); $25 \%$ were exactly half of the original price, and in $8 \%$ the discount was more than half of the original price.

The website content analysis yielded similar results. The total number of alcohol discounts observed was 133, found on 63 of the 256 websites (25\%). The 95\% confidence interval for this percentage ranged from $20 \%$ to $30 \%$. Nearly half of these websites mentioned only one type of alcohol discount (48\%). On one of the websites, ten different alcohol discounts were mentioned. Table II gives an overview of the types of alcohol discounts found. Compared to the observational data, two striking differences were found. First, student night or student prices were more prominent on the websites than in the café observations. This may reflect underlying assumptions about higher internet use by students. Second, relatively many alcohol discounts ended up in the "other" category, which included, for example, free champagne on the guest's birthday, and combinations of drinks and snacks.

Table II: Frequency of various types of cash discounts found on the cafe' websites

\begin{tabular}{lll}
\hline & Frequency & Percentage \\
\hline Cash discount for beer & 36 & 27 \\
Happy hour & 16 & 12 \\
Student night/student prices & 13 & 10 \\
Cash discount for shots/shooters & 12 & 9 \\
Cash discount for mixed drinks & 9 & 7 \\
Cash discount for cocktails & 8 & 6 \\
Ladies night & 5 & 4 \\
Cash discount for wine & 5 & 4 \\
Cash discount for strong alcoholic beverages & 4 & 3 \\
Unlimited drinking & 0 & 0 \\
Other & 25 & 18 \\
Total & $\mathbf{1 3 3}$ & $\mathbf{1 0 0}$ \\
\hline
\end{tabular}

More than half of the discounts (58\%) were offered weekly. Some discounts were offered several times per week $(17 \%)$ or even daily $(7 \%)$. The remaining discounts were offered less frequently or were incidental. Most alcohol discounts were presented rather prominently on the café websites: $25 \%$ were placed directly on the homepage and were immediately visible, $43 \%$ were placed on the homepage, but only visible after scrolling, or immediately visible on a relevant second-level page (e.g., "Agenda," or "Upcoming Events"), and $23 \%$ were placed on a relevant second-level page but only visible after scrolling). Relatively few alcohol discounts were harder to find (9\%). 
Comparisons of the observational data and the website analysis were only possible for 122 cafés; 87 of the cafés that were visited did not have a website. Regarding the question whether or not cafés offered alcohol discounts, a $71 \%$ agreement was found between the observational data and the website analysis. In $10 \%$ of the cases, the website analysis revealed discounts that were unnoticed in the observations; in 19\% of the cases, observed discounts were not present on the website.

The agreement between the observational data and the website analysis underlines the validity of our findings. At the same time, however, the two sources of information also appear to complement each other. The observational research may have overlooked a substantial number of discounts, because of the days on which the cafes were visited: discounts that are only offered on other days of the week may easily go unnoticed. The website analysis is not only restricted to cafés with a website but may also overlook discounts that are not advertised. If the added value of the website analysis is extrapolated to the 209 cafés included in the observations, the overall percentage of cafés offering discounts would rise to $39 \%$ ( $95 \%$ confidence interval $=30 \%-48 \%)$.

\section{Effects of alcohol discounts}

Table III gives an overview of the background characteristics of the survey respondents. Most respondents were 15 and 16 year old, male and female respondents were almost in balance.

Of the 409 adolescents surveyed, 161 students did not go out at all (39\%). The remaining 248 students visited discotheques (68\%), cafés (60\%), private semi-commercial places (23\%), and other places (19\%), such as playgrounds, public outdoor benches and/or cinemas. Of these adolescents, $76 \%$ reported to drink alcohol. The remaining analyses focus on this group of 172 adolescents who reported to both go out and drink alcohol. As can be seen in Table III, adolescents who went out and drank alcohol were generally somewhat older than the rest of the sample (under 16 it is not allowed to buy and/or consume alcohol in commercial places or even to enter cafés). Male-female ratio and educational level were roughly the same for the total sample and the sub-sample of adolescents who both went out and drank alcohol. 
Table III: Background characteristics of the survey respondents

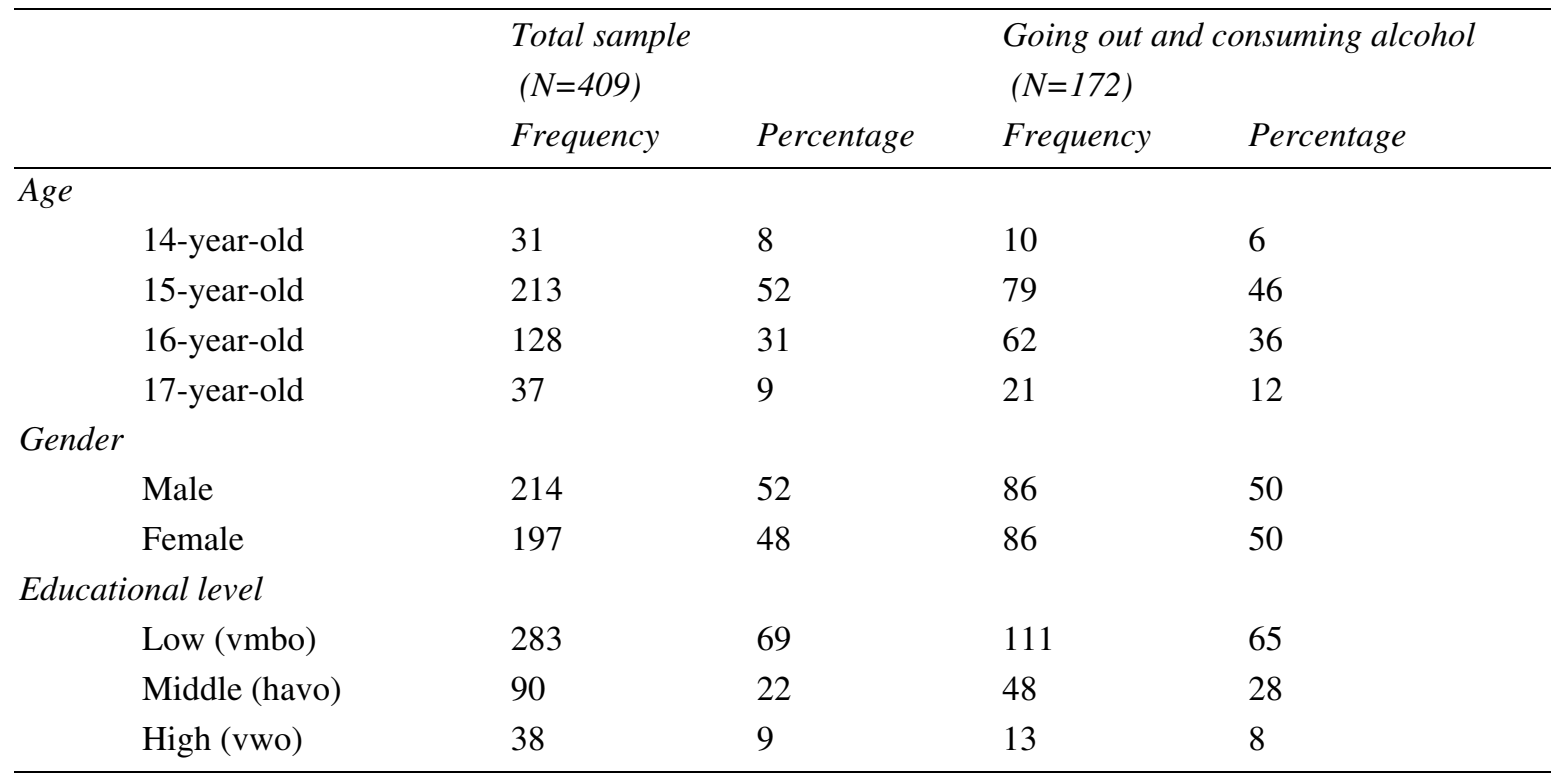

When asked about their use of alcohol discounts, adolescents reported to visit, on average, eight cafés with alcohol discounts a year (the maximum was 54 a year). The most important sources of information about alcohol discounts was word-of-mouth by friends (75\%), followed by advertisements (39\%), café personnel (29\%), and the internet (20\%).

The presence or absence of alcohol discounts appeared to affect adolescents' alcohol consumption. On the 5-point Likert scale ( $1=$ totally disagree, $5=$ totally agree), adolescents indicated that alcohol discounts had a significant effect on their alcohol consumption $(M=3.39, S D=.76, t[149]=6.25, p=.000)$. Although adolescents reported to consume more alcohol when visiting cafés with alcohol discounts, they reported that alcohol discounts did not affect their choice of cafés when going out $(M=3.04, S D=.84,(t[149]=.59, p=.559)$. Alcohol discounts also did not influence the amount of money adolescents spent when going out $(M=2.99, S D=1.08, t[147]=-.08, p=.940)$.

We finally compared the scores of underage (14-15) and minor (16-17) adolescents on alcohol discount use, and the effects of alcohol discounts on alcohol consumption, café attractiveness, and amount of money spent. Although cafés are not allowed to serve alcohol to underage adolescents, the use of alcohol discounts among underage adolescents did not differ from that among minors ( 8.3 vs. 7.7 times a year, $t[104]=.01, p=.788)$. The 
effects of alcohol discounts on alcohol consumption also did not differ between underage adolescents and minors $(t[138,54]=.91, p=.367)$. The same applies to the effects of alcohol discounts on café attractiveness $(t[148]=1.55, p=.122)$ and money spent when going out $(t[146]=.68, p=.498)$. In all, alcohol discounts have similar effects on underage adolescents, who are legally not allowed to buy and/or consume alcohol in commercial places, as on minors.

\subsection{CONCLUSIONS AND DISCUSSION}

Two main conclusions may be drawn from the research reported in this article. First, happy hours and alcohol discounts are still very common in cafés in the Netherlands. Based upon the observational data, we would conservatively conclude that $31 \%$ of the cafés offer alcohol discounts occasionally. Given the two-day limitation of the observational study, it seems likely that this percentage is an underestimation of the prevalence of alcohol discounts in cafes. We used the website analysis to estimate a more comprehensive percentage: within the sample of cafés included in both types of data collection, we calculated the number of extra cafés with alcohol discounts identified by the website analysis, and extrapolated this to the original sample of 209 cafés. The percentage of cafés offering alcohol discounts would then be $39 \%$.

A limitation of the prevalence study was that the data collection was limited to the downtown areas of five cities. While the data were geographically spread over the country, we did not make observations in the more rural parts of the country or in the suburbs. It can be maintained, however, that many adolescents in the villages and suburbs go out in the downtown area of nearby cities. In all, the conclusion seems justified that happy hours and other alcohol discounts are still a common phenomenon in Dutch cafés.

The second main conclusion involves the effects of alcohol discounts on underage and minor adolescents. In agreement with the findings of the two earlier studies involving college students in the United States, we found that alcohol discounts do affect the drinking behaviour of adolescents; respondents indicated to be aware of discounts offered, 
to use discounts on a regular basis, and to drink more alcohol when discounts were offered. Despite legal age restrictions for buying and/or consuming alcohol beverages, more than half of our sample under 16 reported to go out and consume alcohol. Underage adolescents visited about eight cafés with alcohol discounts a year and, when doing so, consumed more alcohol than they regularly did. These findings are worrisome, and this group should be protected against alcohol misuse. The cafés involved fail to act responsibly regarding alcohol and youth twice, first by allowing underage adolescents to buy alcoholic beverages (which is against the law), and second by tempting them to drink more for less money.

Considering the relative prominence of alcohol discount announcements on café websites, the conclusion may also be drawn that cafés see discounts as an important marketing tool to attract guests. However, the assumed contribution of alcohol discounts for the attraction of guests is not confirmed by our survey data. Both underage and minor adolescents are not attracted by alcohol discounts when selecting places to go out, and do not spend more money when visiting alcohol discount evenings. The one and only effect on adolescents is that they drink more alcohol (for the same amount of money normally spent).

The question arises why cafés continue to offer alcohol discount evenings. From a marketing perspective, alcohol discounts may serve to attract new visitors (especially among adolescents) and increase sales. These strategies are not supported by our findings. Alcohol discounts do not attract young visitors to cafés and only seem to increase the amount of alcohol sold (and consumed), not the amount of money earned (and spent).

Individual cafés may also not want to 'endanger' their market position by stopping to offer alcohol discounts, while competitors in the market continue to offer them. Alcohol discounts are a widespread phenomenon in Dutch cafés and it may be a risky strategy for cafés to change these habits. This is a classical example of a social dilemma: what is best in the long run for all parties involved may not seem to be the most favorable option for all individual cafés on the short term. Even when cafés are willing to take their social responsibility they must be able to trust that their competitors also decline the use of alcohol discounts. This calls for local or national government policy, aimed at eliminating alcohol discounts from the marketing mix cafés use to attract guests, with special attention to compliance by all cafés. 
"I have taken more out of alcohol than alcohol has taken out of me"

Sir Winston Churchill (1874 - 1965) - British politician 


\section{Adolescent Private Drinking Places:}

\section{Prevalence, Alcohol Consumption, and other Risk Behaviours}

Joris J. van Hoof

Joost Mulder

Jojanneke Korte

Marloes G. Postel

Marcel E. Pieterse

Submitted.

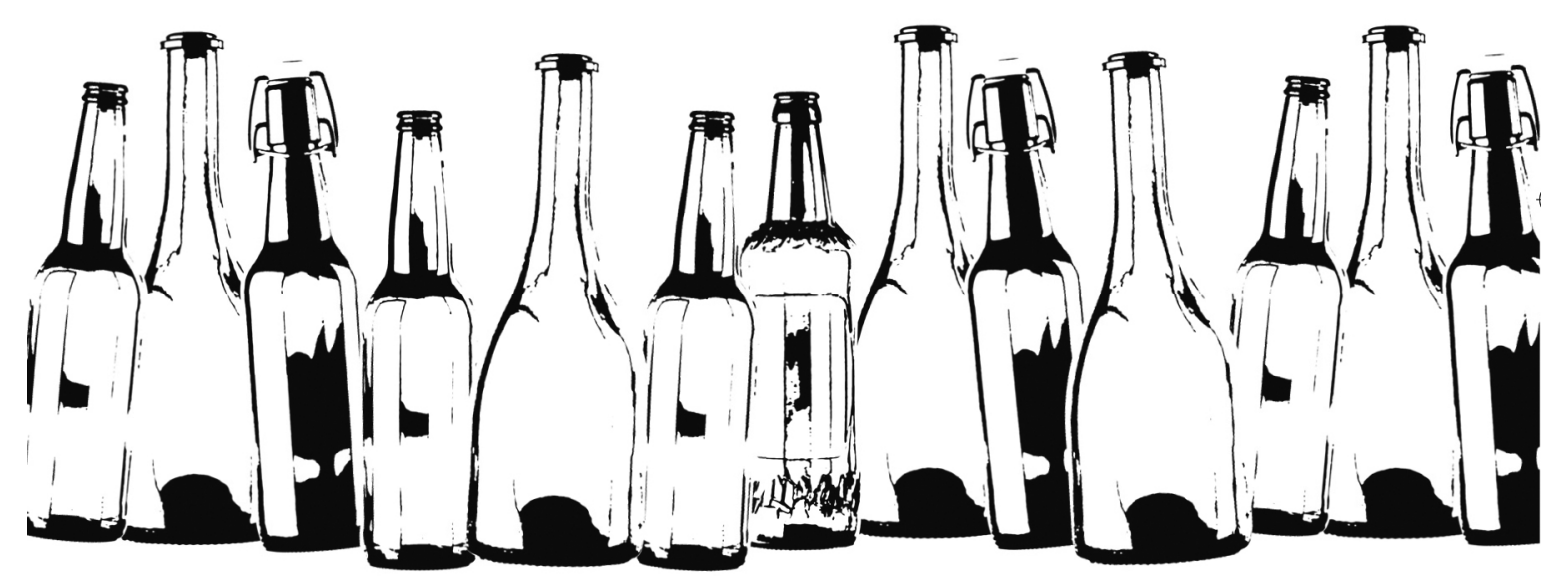




\subsection{ABSTRACT}

Aim. To explore the increasingly popular community health phenomenon of 'gathering in private drinking places (barracks)', with a focus on the prevalence and characteristics of barracks and the (risk) behaviours of their visitors.

Method. Three studies were conducted. The first consisted of field research, including interviews and observations at a sample of 51 barracks. The second consisted of an internet study in which 442 barracks' websites were analyzed using a content analysis. The third consisted of a questionnaire completed by 1,457 adolescents, aged 15-17, in order to explore differences in behaviour between barracks visitors and non-visitors.

Results. There was wide variation in barracks' characteristics and culture (from small 'innocent' gathering places to professional 'illegal' pubs). Barracks' members and visitors also organize diverse activities (e.g., game evenings, holidays, parties) that are publicly shown on the websites. A common characteristic of barracks is the social function that they fulfill in areas that have few activities for adolescents (i.e., rural parts of the country). On the other hand, barracks suffer various legal issues, such as alcohol sales to minors, lack of parental supervision, and easily available alcohol and illicit drugs. Barracks' visitors drink alcohol more frequently, drink more alcohol per location (up to fifteen bottles of beer a night), and have been drunk more frequently than non-visitors.

Conclusion. National and local policymakers must be aware of the barracks phenomenon and use their powers in adjacent political and legal areas (such as in binge drinking, illicit drug use, and public safety) to intervene and create solid, responsible, and tailor-made policies for dealing with this phenomenon. 


\subsection{INTRODUCTION}

Despite almost a century of governmental health messages and prevention efforts, alcohol consumption is still an important societal risk. Consuming alcohol contributes to a wide range of diseases, including various cancers, liver cirrhosis and cardiovascular disease (Anderson \& Baumberg, 2006; Babor et al., 2003; Corrao, Bagnardi, Zambon, \& Arico, 1999). Also, alcohol use contributes to injuries and deaths (e.g., from falls) (Hingson \& Howland; 1987), and especially injuries and deaths from driving by young inexperienced drivers who drink and drive (Zador, Krawchuk, \& Voas, 2000). Furthermore, a higher proportion of rapes tend to occur when women are intoxicated (Mohler-Kuo, Dowdall, Koss, \& Wechsler, 2004).

In the Netherlands, adolescent alcohol consumption has increased greatly over the past two decades. Adolescents (15-16 years old) in the Netherlands drink more frequently than their peers in other European countries (Hibell et al., 2004). At the age of twelve, 36\% have imbibed alcohol, a rate that increases to $89 \%$ for 15 year olds. By age 16, almost half of these adolescents (48\%) drink more than 5 glasses of alcohol per occasion (binge drinking) (Monshouwer et al., 2008). The prevalence of problem drinking among Dutch 16- and 17year-old boys and girls is $26 \%$ and 19\%, respectively (Dijck \& Knibbe, 2005).

Adolescents are more vulnerable to alcohol than adults. The body of a teenager is not yet fully grown. Vital body parts like the brain are still developing, and serious damage can be caused by drinking alcohol at such a young age (Brown, Tapert, Granholm, \& Delis, 2000; Spear, 2002; Tapert et al., 2001). Early starters (i.e., those who begin before age 14) also significantly increase their chances of alcohol dependence (Grant \& Dawson, 1997; Hingson, Heeren, \& Winter, 2006).

Researchers often use behavioural models such as the Theory of Reasoned Action (Fishbein \& Ajzen, 1975) or Theory of Planned Behaviour (Ajzen, 1991) to investigate and explain risky human behaviours. These models' basic assumptions are that behaviour is caused by behavioural intention (actual behaviour depends on practical barriers), and that intention is predicted by attitudes, subjective norms, and perceived behavioural control. 
There is abundant (fundamental, empirical, and experimental) scientific research on (causal) relationships between one or more of the abovementioned factors and (youth) risk behaviours, like the use of tobacco (McMillan \& Connor, 2003), cannabis (Conner \& McMillan, 1999), ecstasy (Umeh \& Patel, 2004), and alcohol (Conner, Graham, \& Moore, 1999; McMillan \& Connor, 2003).

With respect to social influences, these theories consider alcohol consumption a rational decision on the micro-level (i.e., at the level of the individual adolescent). However, more than $3 / 4$ of adolescent alcohol consumption takes place in the context of 'going out' with friends, and drinking behaviour is mostly influenced by other (social) primes (Engels, Knibbe, De Vries, Drop, \& Van Breukelen, 2006; Holder, 1998; Knibbe, Oostveen, \& Van de Goor, 1991; Oostveen, Knibbe, \& De Vries, 1996). It is common for a group of friends to start their evening drinking at a private location before going to pubs and discos to continue their drinking (Bot, Engels, Knibbe, \& Meeus, 2007). Therefore, private places must not be overlooked. Private places range from parents' couches to professionally created illegal pubs.

In this article, we describe three studies on a rather new national community phenomenon, 'drinking in (the) barracks'. A barracks (Dutch: 'hok' or 'keet') is a privately owned youth gathering place, located in rural areas, created in an old trailer, caravan, container, shed, barn, basement or factory building. Since the beginning of the 21 st century, barracks have been a well-known phenomenon in the Netherlands. Eleven percent of Dutch adolescents (aged 13-17) occasionally visit some type of barracks (Van Laar, Cruts, Verdurmen, Van Ooyen-Houben, \& Meijer, 2007). Almost a quarter of the 443 Dutch municipalities is confronted with barracks (varying from just a few to over a hundred), and are facing problems related to their presence (interacting with a lack of effective regulation policy).

Among barracks, there is wide variety in terms of physical size, interior and exterior facilities, looks and decorations, number of members and visitors, activities organized, hierarchical structures, culture, professionalization, and grade of commercialization. For example, there are primitive 'innocent' barracks', which may be a backyard shed where several friends gather every Friday night, play darts and foosball, and drink sodas. A more problematic barracks could be an old grain silo building (owned by an adolescent's father, 
for example), located on factory property, in which a changing group of adolescents gather, drink beer and liquor (that they bring themselves), use marijuana (legal in The Netherlands) and illicit drugs, watch television, and carry out motorcycle and car street races. Finally, there are barracks that look like 'illegal pubs', i.e., an old cattle barn, open every day of the week, equipped with a professional bar, including taps, refrigerators, seats, and snacks, and using commercial payment systems for drinks and snacks (though of course at cheaper prices than in licensed bars).

In this article, we report the results of three studies that we conducted to explore this phenomenon. First, we visited 51 barracks and conducted group interviews and questionnaires to further explore barracks' and visitors' characteristics. Then, in order to get an idea of the number of barracks, we carried out an internet study (including a content analysis) to approximate barracks' prevalence and their superficial characteristics. Finally, we selected one region in The Netherlands (with a high prevalence of barracks) and administered questionnaires to 1,457 adolescents (aged 15 to 17) in order to investigate more of the barracks' characteristics and the (risk) behaviours of their visitors.

\subsection{METHODS}

In this section, we describe the methods used in the field research, the internet study, and the questionnaire study. For each research component, we discuss our procedure, measures, and respondents (if any).

\section{Field research}

\section{Procedure}

To explore the Dutch barracks phenomenon, we visited 51 barracks spread across the country. We combined a face-to-face group interview, brief questionnaire, and observation techniques to assess barracks' characteristics, as well as the characteristics and behaviour of their visitors. To select barracks for the study, we collected barracks information from 
three 'barracks homepages' (www.jongeren-startpagina.nl/vriendensites, www.keten.boom.nl, and 0174-hokken.startpagina.nl/). From there, based on the provided contact information (e-mail addresses and/or telephone numbers), we arranged one-hour appointments with barracks located in three of the main rural areas (West, South and North-east) of the Netherlands. We explained to barracks visitors that we were only interested in the Dutch barracks phenomenon and that we would not provide information to governmental organizations and / or police. During open hours (evenings and weekend days only), two researchers visited the barracks. First (after a short introduction), a 45minute group interview was conducted (in which all present visitors were asked to participate). Second, a questionnaire was administered to individual visitors. During the visit, researchers also observed several characteristics of the barracks and their visitors. At the end of the session, we asked the barracks visitors to introduce us to other associated barracks (i.e., through a 'snowballing' method).

\section{Measures}

In this study, we collected data on Characteristics (opening hours, ownership and organization, safety measures, payment systems, sponsorships) of the barracks (through interviews and observations) and Characteristics and opinions (age, education level, alcohol, tobacco and illicit drug use, and opinions on risk behaviours) of barracks visitors (through the supplemental questionnaire).

\section{Respondents}

A total of 51 barracks were included in the sample, and an equal number of interviews were conducted at each. None of the appointments were canceled, and all attempts to recruit other barracks through the snowballing method were successful. In total, 204 barracks visitors completed the questionnaire (187 male and 17 female). The average age of visitors was 18 , ranging from 12 to 41 years old. 


\section{Internet study}

\section{Procedure}

After the field research, we conducted an Internet study to investigate the prevalence of private drinking places on the internet, along with their geographical dispersal. We searched the web in three ways. First, we collected barracks' websites by screening three major homepages (www.jongeren-startpagina.nl/vriendensites, www.keten.boom.nl, and 0174-hokken.startpagina.nl/). Second, we used search engines (Google, Alta Vista, and Yahoo!) by combining the (Dutch translations of the) words 'barracks, shed, caravan, trailer, youth, beer, binge, drinking, alcohol, booze, and friends.' Finally, we analyzed the barracks' websites, which often contained a 'links' section, redirecting to friend sites.

\section{Measures}

A total of 442 websites were analyzed, using a coding scheme, for the following three variables (for each variable we describe which parts of the websites, if available, were used): Characteristics (number, age, gender) of barracks' visitors (by analyzing barracks 'history', 'photographs', 'public guest books', 'party invitations', 'members sections' aka 'who are we', or 'introducing ourselves'), Activities (opening hours, regular activities, alcohol consumption, parties) in the barracks (by analyzing barracks 'photographs', 'agenda', 'activities'), and Other (geographical information, organization, paying systems, sponsorships) barracks' characteristics (by analyzing 'contact information', 'activities', 'mission statements'). Because the websites vary widely in terms of size, complexity, graphics, and content, coding took place in an inductive and explorative way.

\section{Questionnaire study}

\section{Procedure}

To explore differences in the attitudes and behaviours between barracks visitors (including members) and non-visitors, we developed a questionnaire for use in one region that had a high number of barracks (the Eastern region). To reach as many adolescents as possible, we contacted (through a letter and then phone calls) all 35 secondary schools in the region. 
A total of 31 schools were willing to join the study, which resulted in an $88.6 \%$ response rate at the school level. Based on national statistics on education levels $(50 \%$ prevocational secondary education, $29 \%$ senior general secondary education, and $21 \%$ preuniversity education), we randomly selected two pre-vocational secondary education classes, one senior general secondary education, and one pre-university education class per school (all fourth graders (comparable to $10^{\text {th }}$ grade in American school system); average ages between 15 and 17 years old). A total of 1,516 students filled out the questionnaire, and after cleaning the dataset (removing outliers, incomplete questionnaires, students younger than 15 and older than 17), analyses were based on 1,457 respondents.

\section{Measures}

The questionnaire began with four questions on Barracks characteristics (barracks age and characteristics, number of members, opening hours, and safety features), followed by three questions on Member behaviours (time as a barracks member, visiting frequency, and visiting days).

The questionnaire also contained five measures of alcohol consumption: 'drinking prevalence' (dichotomized, yes/no), 'weekly drinking prevalence' (average number of weekdays respondents consume alcohol (nominal scale, 0 - 4), weekend drinking prevalence' (average number of weekend days respondents consume alcohol (nominal scale, $0-3$ [Friday was considered a weekend day]), 'life-time consumption' (ordinal scale, 1 - 5 times, 6 - 10 times, 11 - 20 times, 21 - 39 times, 40 - 79 times, more than 80 times), and 'life-time drunkenness' (ordinal scale, 1 - 5 times, 6 - 10 times, 11 - 20 times, 21 - 39 times, more than 40 times).

\section{Respondents}

A total of 1,457 questionnaires were used in our analyses. A little less than half (47\%) of the respondents were male, and 53\% were female. Respondents were 15 years of age (36\%), 16 years of age (53\%), and 17 years of age (12\%), with an average of 15.8 years. Most respondents studied pre-vocational secondary education (58\%), followed by senior general secondary education (20\%), and pre-university education (22\%). 
Table I: Respondent characteristics

\begin{tabular}{lll}
\hline Total $(N=1457)$ & $\begin{array}{l}\text { Barracks visitors } \\
439(30 \%)\end{array}$ & $\begin{array}{l}\text { Non-visitors } \\
1018(70 \%)\end{array}$ \\
\hline $\begin{array}{l}\text { Male** }(\mathrm{n}=683) 47 \% \\
\text { Female** }(\mathrm{n}=774) 53 \%\end{array}$ & $257(59 \%)$ & $426(42 \%)$ \\
& $182(42 \%)$ & $592(58 \%)$ \\
15 -year-olds $(\mathrm{n}=517) 36 \%$ & $155(35 \%)$ & $362(36 \%)$ \\
16 -year-olds $(\mathrm{n}=766) 53 \%$ & $230(52 \%)$ & $536(53 \%)$ \\
17 -year-olds $(\mathrm{n}=174) 12 \%$ & $54(12 \%)$ & $120(12 \%)$ \\
& & $544(53 \%)$ \\
Pre-voc Sec Ed** $(\mathrm{n}=845) 58 \%$ & $301(69 \%)$ & $216(21 \%)$ \\
Senior Gen Sec Ed** $(\mathrm{n}=277) 20 \%$ & $73(17 \%)$ & $258(25 \%)$ \\
Pre-university Ed** $(\mathrm{n}=314) 22 \%$ & $65(15 \%)$ &
\end{tabular}

Significance Levels Chi Square Test: $* \mathrm{p}<.05 / * * \mathrm{p}<.01$

As can be seen in Table I, 30\% of respondents were barracks visitors (including members), as compared to $70 \%$ who do not visit barracks. Barracks visitors and non-visitors were both 15.8 years of age on average $(t(1455)=.207, p=.836)$. The percentage of adolescents who visit barracks did differ by gender $\left(\chi^{2}(1, N=1457)=34.33, p<.05\right)$; about $59 \%$ of barracks' visitors were male, as compared to $42 \%$ of non-visitors. Also, the educational level of barracks visitors was lower $\left(\chi^{2}(1, N=1457)=30.72, p<.05\right)$ as compared to the educational level of non-visitors (see Table I).

\subsection{RESULTS}

\section{Field research}

Characteristics (opening hours, visitors, ownership and organization, safety, payment systems, sponsorships) of barracks: privately owned barracks do not have official opening hours like commercial bars or discotheques. Opening hours vary, and the first member to arrive opens up. On average, members gather around $7-8 \mathrm{PM}$, with a non-fixed closing time (between 11 PM and 6 AM). About half of the barracks we visited opened on Friday and Saturday only, while the other half had expanded opening hours. Almost all barracks were located on private property (only two were situated on public property), and they 
were mostly located in a shed or (used) trailer. The lifetime of the visited barracks varied from 2-16 years, with an average of approximately 5 years.

Most barracks had a group of 'members', who were usually also the founders of the barracks. Organizational structures ranged from very explicit and elaborated barracks with a fixed number of members who come together every time to more unstructured groups combining some members various groups of invited visitors. All barracks were owned by the parents of a barracks member. These parents also paid regular costs, such as electricity and water, but did not supervise what happened in the barracks. On average, a barracks was visited by 17 adolescents on a given weekend evening. The total number of visitors (from here, we label all members and visitors as visitors) can range up to 50, as two barracks reported to us. Regarding safety, most barracks were not well equipped. Only three (out of 51) barracks had an emergency exit and a fire extinguisher, while another 15 had a fire extinguisher only, and 24 had neither safety measure.

Characteristics and opinions (age, education level, alcohol, tobacco and illicit drug use, and opinions on risk behaviours) of barracks' visitors: about half of the barracks were visited by males only. Just two barracks were exclusively visited by females, and the remaining locations had mixed populations. Most visitors (53\%) had a low-level education (primary school or pre-vocational secondary education), about a quarter had mid-level education (senior general secondary education), and the remaining quarter had high-level education (pre-university education or High School). Alcohol and alcohol use were inextricably connected with barracks. Alcohol was predominately visible in terms of promotional items, beer bottles and crates, alcohol consumption during the research, and comments from barracks visitors (e.g., "a barracks without beer ain't no barracks"). Respondents reported consuming 10 to 15 bottles $(30-50$ centiliters / $11-16$ fl. oz per bottle) of beer per night (with an average of 12). Favorite drinks were beer (for both males and females) and pre-mixed drinks (for females only). Hard liquor was only consumed at parties. Almost all barracks allowed smoking, despite the serious fire hazards inherent in their wooden building construction, fabric decorations, and limited escape possibilities (e.g., a small single stairwell). Regarding other (illicit) drug use, barracks visitors claimed to be less tolerant than they were of alcohol. 


\section{Internet study}

From the internet, we discovered 442 barracks' websites, of which 88 percent appeared accessible and properly functional. The remaining $52(12 \%)$ websites turned out to be shut down for maintenance or barracks closure or were otherwise temporarily unavailable (possibly because of recent rumors in the media regarding police actions against 'illegal' barracks). For most barracks, the barracks' name appears to have been assimilated in its URL. Furthermore, most barracks used the internet extension .tk, which is available for free in the Netherlands.

Characteristics (number, age, gender) of barracks visitors: Specific regulations were hard to assess from websites only. Analyzing public guest books, it became clear that some barracks have special 'girlfriend evenings' (often organized once a month). On such evenings, the male visitors invite their girlfriends (or girlfriends-to-be) for a barracks evening. When parties are organized, a larger group of guests is also invited.

Activities (opening hours, regular activities, alcohol consumption, parties) in the barracks: about half of the barracks were open on weekend days, about one quarter were open only on Fridays, and the last quarter of had activities during the weekend and one or more weekdays. Regular activities included playing games together (often computer games, fuss ball, and darts), watching television and movies, gathering and consuming alcohol before going out, throwing parties, and organizing trips for the holiday season (often to popular coastal places, such as the Dutch islands and Lloret de Mar, in Spain). Most barracks organized a big party once a year. The photos sections and public guest books made clear that it was a common rule for members of associated barracks in the neighborhood to visit each others' parties (although we did not do a network analysis of this topic). Only on two websites was a party invitation found (for a party in the near future). Both invitations were 'open' and aimed at all 'cool party youth' in the neighborhood. An entry fee of 10 euros (about 13 US dollars at that time) was charged, with (alcoholic) drinks served for free. None of the party pictures show adult supervisors attending the party, though some party 
pictures and/or guest book stories indicated police interventions (mostly because neighbors called the police for noise nuisances).

Other (geographical information, organization, paying systems, and sponsorships) barracks' characteristics: almost all barracks were located in the rural parts of the Netherlands, and never in cities. All barracks were privately owned, often by the parents of one of its members. Most barracks have an organization committee, often including the owners' child. Out of the 442 barracks, we qualified 60 barracks as 'big' (over 18 members). These barracks had several characteristics indicating that they were more of an 'illegal pub' than an 'innocent private gathering place'. These characteristics included weekly pictures with continually varying visitors, invitations to drop by when in the neighborhood (on $23 \%$ of the big barracks' websites), a professional payment system for drinks (three types: with coins, a personal account to be paid once a month, and a fixed price for one evening of 'as much you can drink'), professional bars (including beer taps and upside down hanging bottles), and commercial sponsorships. Alcohol and alcoholrelated issues were prominent in the barracks. On almost 50 websites, alcohol brand logos and/or other alcohol promotional materials were dominant and visible. Finally, some alcohol-related statements were made in the sites' running texts (mainly on the home page). We found these comments worrisome, however, on only six websites (i.e., statistics on the number of times barracks members 'puked' because of alcohol, or a barracks introducing itself as 'the best place to drink yourself unconscious').

\section{Questionnaire study}

Most barracks had existed between one and five years, with only $6 \%$ existing for six years or longer. About $16 \%$ of barracks were funded in the last year (see also table II), which indicates an increase in the prevalence of barracks. The average number of members was reported as approximately 14, with an estimated average number of male and female members of 10 and 5 , respectively. 
Table II: Barracks characteristics (based on barracks visitors, $n=439$ )

\begin{tabular}{lll}
\hline Barracks age $(\mathrm{n}=425)$ & $<1$ year & $16.2 \%$ \\
& 1 year -2 years & $43.3 \%$ \\
& 3 years -5 years & $31.8 \%$ \\
& 6 years -9 years & $4.7 \%$ \\
& $>10$ years & $1.2 \%$ \\
Members $(\mathrm{n}=338)$ & From 0 to 80 & Average: 14.2 \\
Male members $(\mathrm{n}=338)$ & From 0 to 70 & Average: 10.1 \\
Female member $(\mathrm{n}=338)$ & From 0 to 50 & Average: 5.2 \\
& & $72.3 \%$ \\
Opening hours $(\mathrm{n}=422)$ & Only weekend days & $2.6 \%$ \\
& Only week days & $25.1 \%$ \\
Fire extinguisher $(\mathrm{n}=408)$ & Both weekend and week & \\
& & $50.9 \%$ \\
& Yes & $49.1 \%$ \\
Emergency exit $(\mathrm{s})(\mathrm{n}=208)$ & Yes & $43.6 \%$ \\
& No & $56.3 \%$
\end{tabular}

Most barracks opened on weekend days only, while approximately a quarter opened on weekends and week days, and only $3 \%$ closed for the weekend but opened during weekday evenings. With respect to safety issues, only half of the barracks were equipped with a fire extinguisher, and less than half of the barracks had one or more emergency exits.

As can be seen in Table III, approximately $40 \%$ of all barracks visitors started visiting a barracks in the past year. Another $40 \%$ had been visiting a barracks for more than one year but less than two years. Just a small percentage were long-time members. In terms of opening hours, weekend days were of course the most popular visiting days, followed by both weekend and weekdays. Although almost a quarter of all barracks were open on weekend and weekdays, only $12 \%$ of the barracks' members have that visiting pattern. This indicates a smaller group of regular members. 
Table III: Member behaviours (based on barracks visitors, $\mathrm{n}=439$ )

\begin{tabular}{lll}
\hline Time membership $(\mathrm{n}=420)$ & $20.9 \%$ \\
& $1 / 2$ year -1 year & $20.9 \%$ \\
& 1 year -2 years & $38.7 \%$ \\
& 3 years - 4 years & $15.9 \%$ \\
& $>5$ years & $3.3 \%$ \\
& & \\
Visiting days $(\mathrm{n}=423)$ & Only weekend & $84.4 \%$ \\
& Only week days & $3.3 \%$ \\
& Both weekend and week & $12.3 \%$ \\
& & \\
Visiting frequency $(\mathrm{n}=338)$ & $<1 /$ month & $33.3 \%$ \\
& 1 - 3 / month & $25.8 \%$ \\
& $1 /$ week & $21.0 \%$ \\
& $2 /$ week & $10.2 \%$ \\
& $3 /$ week & $4.5 \%$ \\
& 4 - 6/ week & $3.5 \%$ \\
\hline
\end{tabular}

Finally, we explored some alcohol consumption measures between barracks visitors and non-visitors. To correct for possible differences attributable to respondents' sex, education level, and/or age, we ran ANCOVA analyses to estimate main effects on alcohol attitudes and consumption of barracks visiting behaviour. As expected (and also shown in the Chi Square analyses presented in the Respondents section), we found that the covariates 'sex' and 'education level' were significantly related to all three dependent variables.

Regarding alcohol consumption, as can be seen in Table IV, barracks visitors, on average, consumed alcohol .46 times per week, which is significantly more frequent than the .23 times per week for non-visitors $(F[3,1340]=19.94, \mathrm{p}<.05)$. When consuming alcohol during weekdays, barracks visitors consumed, on average, 1.49 glasses, which is marginally more $(F[3,313]=3.78, \mathrm{p}=.05)$ then non-visitors' consumption (1.29). For weekend days, the same pattern was found (significant $F(3,1356)=105.19, \mathrm{p}<.01$ ); on average, barracks visitors drank 1.89 times per weekend, versus 1.38 times for adolescents who did not visit a barracks. When drinking on weekend days, barracks visitors consumed, on average, 1.89 glasses, significantly more $(F[3,1249]=81.57, \mathrm{p}<.01)$ than the average for non-visitors (1.38). 
Table IV: Alcohol consumption behaviour and attitudes about alcohol use

\begin{tabular}{|c|c|c|c|c|c|c|}
\hline \multirow[b]{2}{*}{ Non-drinkers** } & \multirow[b]{2}{*}{$(n=81)$} & \multirow[b]{2}{*}{$6 \%$} & \multicolumn{2}{|c|}{$\begin{array}{l}\text { Barracks visitors } \\
(n=439)\end{array}$} & \multicolumn{2}{|c|}{$\begin{array}{l}\text { Non-visitors } \\
(n=1018)\end{array}$} \\
\hline & & & 8 & $2 \%$ & 73 & $7 \%$ \\
\hline Drinkers** & $(n=1376)$ & $94 \%$ & 431 & $98 \%$ & 945 & $93 \%$ \\
\hline
\end{tabular}

Lifetime alcohol consumption**

$\begin{array}{lllllll}1-5 \text { times } & (\mathrm{n}=80) & 6 \% & 9 & 2 \% & 71 & 8 \% \\ 6-10 \text { times } & (\mathrm{n}=88) & 7 \% & 10 & 3 \% & 78 & 9 \% \\ 11-20 \text { times } & (\mathrm{n}=187) & 14 \% & 39 & 10 \% & 148 & 16 \% \\ 21-39 \text { times } & (\mathrm{n}=205) & 16 \% & 46 & 11 \% & 159 & 18 \% \\ 40-79 \text { times } & (\mathrm{n}=281) & 21 \% & 80 & 20 \% & 201 & 22 \% \\ >80 \text { times } & (\mathrm{n}=474) & 36 \% & 224 & 55 \% & 250 & 28 \% \\ \text { Total } & (\mathrm{n}=1315) & 100 \% & 408 & 100 \% & 907 & 100 \%\end{array}$

Lifetime drunkenness $* *$

$\begin{array}{lllllll}0 \text { times } & (\mathrm{n}=714) & 53 \% & 164 & 39 \% & 550 & 59 \% \\ 1-5 \text { times } & (\mathrm{n}=465) & 34 \% & 165 & 39 \% & 300 & 32 \% \\ 6-10 \text { times } & (\mathrm{n}=79) & 6 \% & 42 & 10 \% & 37 & 4 \% \\ 11-20 \text { times } & (\mathrm{n}=46) & 3 \% & 27 & 6 \% & 19 & 2 \% \\ 21-39 \text { times } & (\mathrm{n}=21) & 2 \% & 8 & 2 \% & 13 & 1 \% \\ >40 \text { times } & (\mathrm{n}=27) & 2 \% & 17 & 4 \% & 10 & 1 \% \\ \text { Total } & (\mathrm{n}=1352) & 100 \% & 408 & 100 \% & 907 & 100 \%\end{array}$

\begin{tabular}{lll}
\hline Mean (SD) & Mean (SD) & \\
\hline${ }^{\mathrm{a}}$ Average week days cons** & $.46(.79)$ & $.23(.59)$ \\
${ }^{\mathrm{b}}$ Average drinks on week days & $1.49(.72)$ & $1.29(.64)$ \\
${ }^{\mathrm{c}}$ Average weekend days cons** & $1.89(.70)$ & $1.38(.75)$ \\
${ }^{\mathrm{d}}$ Average drinks on weekend days** & $2.86(.95)$ & $2.25(.98)$ \\
\hline
\end{tabular}

Significance Levels on ANCOVA (sex, age and education used as covariates / barracks visiting as fixed factor): $* \mathrm{p}<.05 / * * \mathrm{p}<.01$

a average number of weekdays (Monday, Tuesday, Wednesday, Thursday) respondents drink one or more alcoholic beverages

${ }^{\mathrm{b}}$ average number of drinks consumed on weekdays (when drinking)

${ }^{c}$ average number of weekend days (Friday, Saturday, Sunday) respondents drink one or more alcoholic beverages

d average number of drinks consumed on weekend days (when drinking)

Furthermore, adolescents who visited barracks had drunk more alcohol in their lives $(F[3$, $1310]=73.95, \mathrm{p}<.01)$ and also had been drunk more often $(F[3,1347]=41.33, \mathrm{p}<.01)$ than had adolescents who do not visit a barracks. More results related to alcohol consumption, other risk behaviours, and differences between barracks visitors and nonvisitors can be found in the study of De Korte, Postel, Van Hoof and Pieterse (n.d). 


\subsection{DISCUSSION}

Barracks are a growing Dutch phenomenon, and more research on this topic is necessary. Research is first necessary to get more insight into the size of the phenomenon, but more importantly, to help construct tailor-made and suitable policies and then evaluate their effectiveness. Our studies give a first look at the prevalence and characteristics of these private drinking places, and on the alcohol consumption that occurs therein. In terms of both prevalence and characteristics, however, these studies may only be the tip of the iceberg'. Barracks are more prevalent in rural areas, which might be related to leisure possibilities (in cities, of course, there are more facilities for youngsters), lifestyle, and more suitable places for building barracks. In the (partially) rural region where we conducted our questionnaire study, 30\% of adolescents between 15 and 17 had visited a barracks. Compared to the total population questioned, barracks visitors were more likely to be boys and to be slightly less educated.

One common characteristic of all barracks is that they are essentially 'autonomous islands' from four perspectives. The first perspective, on which more research is necessary, is the legal perspective. Although our studies did not focus on legal questions, two interesting issues occurred during the course of our studies. First, almost all barracks were located on private property, on which authorities (e.g., police, fire fighters) can only intervene (aside from emergencies) with the permission of the owner. Second, another legal issue arising in our studies was the semi- or para-commercial aspect of some barracks. In the Netherlands, one can, of course, throw a party, invite friends over, and serve drinks. One cannot, however, start a pub without a license. Although some barracks can indisputably be labeled 'illegal pubs' (and other barracks have some characteristics of illegal pubs, such as professional bar equipment and elaborate payment systems), governmental organizations seem to suffer difficulties in regulating this semi- or para-commercial activity (also because there are as yet no legal structures or policies for doing so).

A second perspective from which barracks constitute 'autonomous islands' is that of supervision. Although almost all barracks are owned by the parents of one of the barracks' 
members, parental supervision is rarely present. Parents are relatively complicit in facilitating barracks in various ways (e.g., allowing the use of private property, donating old furniture for barracks use, helping purchase food and drinks, and providing electricity). Some barracks have rules and regulations, but most of the time during a barracks evening, youngsters keep an eye on each other.

A third perspective is the availability perspective. In the Netherlands, the legal age-limit for soft alcohol use (i.e., beer, wine, drinks under 15\% alcohol) is 16, while that for strong alcohol (i.e., distilled spirits, liquor) is 18. Although we know that alcohol retailers do not always comply with these age restrictions on alcohol sales (Gosselt, Van Hoof, De Jong, \& Prinsen, 2007), situations with no supervision and freely available alcohol for even very young teens are obviously of great concern. Aside from being freely available, alcohol prices in barracks are also very low. Most barracks use supermarket prices (sometimes with a small amount of overhead for barracks improvement), which is about a quarter of legal pub prices. Since, for adolescents, price discounts (and other financial incentives) are positively related to alcohol consumption (Holder, 1998; Van Hoof, Van Noordenburg, \& De Jong, 2008), it is hardly surprising that barracks visitors drink more alcohol in total, on more days, and are more often drunk as compared to non-visitors. Based on the field research, it turns out that alcohol consumption in barracks often greatly exceeds responsible consumption levels.

A fourth and final perspective is the social perspective. Aside from the aspects of barracks described above, these places clearly fulfill a social need of adolescents in rural areas. In places where youth services are not available and bars and pubs are relatively rare, barracks are a cheap and welcoming alternative, and more attractive than a parent's couch.

The aforementioned perspectives overlap to some extent. It may also be possible to think of other perspectives, but, in our view, these four perspectives constitute the primary areas on which policymakers should focus.

The increase in barracks in recent decades has become relevant for local health policymakers, as well as national politicians. Barracks visitors consume significantly more alcohol, and are more often drunk, than non-visitors. Barracks are isolated 'islands' in the 
countryside, and parental supervision is often limited or absent. The barracks phenomenon is a complex issue from a variety of perspectives, and tailor-made policies are rarely implemented. Local and national policymakers might still confront these issues, however, or confront related issues like binge drinking, illicit drug use, or public safety within barracks. A lack of extant policy and the inability of authorities to intervene emphasize the growing importance of the barracks phenomenon.

\subsection{ACKNOWLEDGMENTS}

The field research was supported was supported by STAP, the internet study was partly funded by VWA (Dutch Food and Consumer Product Safety Authority), and the questionnaire study was supported by Tactus Addiction Treatment and the University of Twente. 
"To refrain from evil and from strong drink and to be always, steadfast in virtue; this is the good luck"

Hindu Prince Gautama Siddharta (563 - 483 B.C.) - Buddha, founder of Buddhism. 


\section{Mystery Shopping and Alcohol Sales: Do Supermarkets and Liquor Stores Sell Alcohol to Underage Customers?}

Jordy F. Gosselt Joris J. van Hoof Menno D.T. de Jong Sander Prinsen Journal of Adolescent Health, 2007, 41, 302-308.

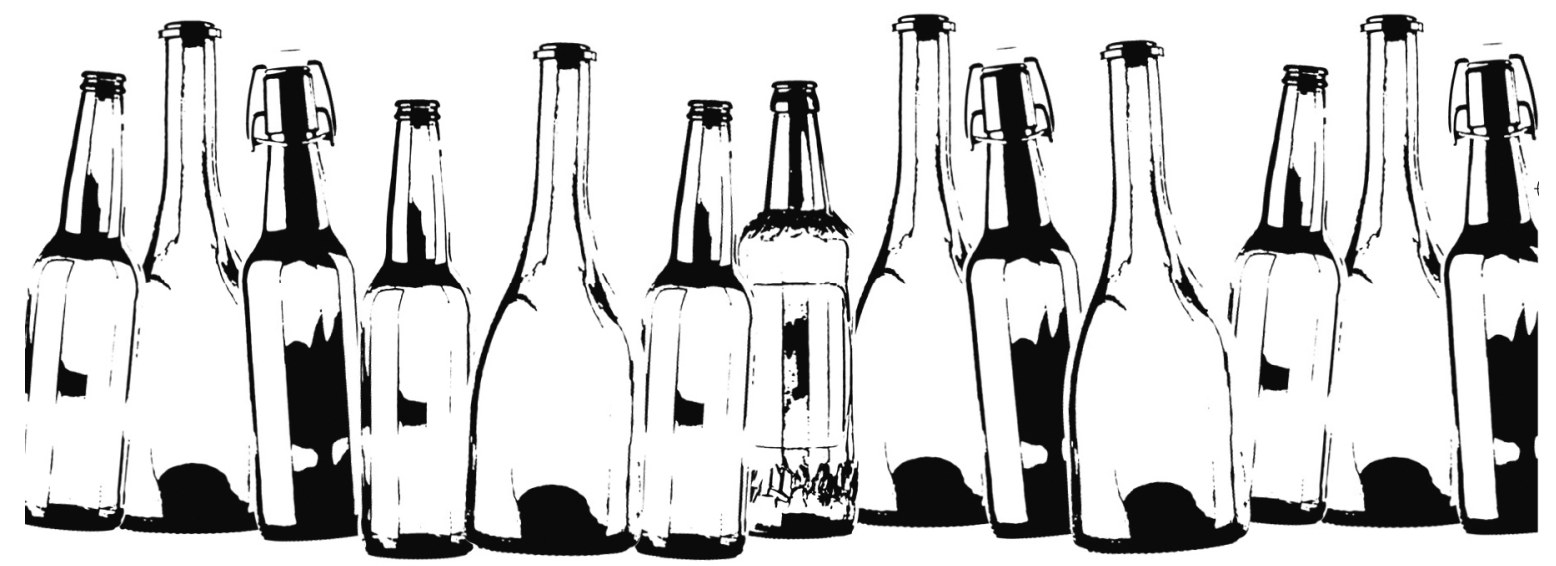




\subsection{ABSTRACT}

Purpose: The Dutch national policy regarding alcohol and youth relies on retailers' willingness to refuse to sell alcohol to underage customers. This study examined unobtrusively whether supermarkets and liquor stores do indeed comply with the legal age restrictions for alcohol sales.

Methods: A research protocol was developed based on the methodology of mystery shopping. Using the protocol, 150 supermarkets and 75 liquor stores were visited by 15year-old adolescents who tried to buy soft alcoholic beverages (legal age: 16), and 75 liquor stores were visited by 17-year-old adolescents who tried to buy strong alcoholic beverages (legal age: 18).

Results: Of all 300 buying attempts, 86\% were successful. In supermarkets, $88 \%$ of all attempts succeeded. In liquor stores, a difference was found between the purchase of strong alcohol by 17 -year-olds (89\%) and the purchase of soft alcoholic beverages by 15year-olds $(77 \%)$. In only 71 of all visits, mystery shoppers were asked for an ID. In $39 \%$ of these cases, they were still able to buy alcohol. Female adolescents were more successful in buying alcohol than male adolescents.

Conclusions: The results show that supermarkets and liquor stores generally fail to see the need for extra care when young customers try to buy alcohol. Legal age restrictions without enforcement and facilitation clearly do not suffice to protect adolescents from early exposure to alcohol. 


\subsection{INTRODUCTION}

Although the dangers of alcohol for adolescents are widely acknowledged, underage alcohol consumption is on the rise. Research in the Netherlands shows that $90 \%$ of the 15 year-old adolescents have had experience with drinking alcoholic beverages, and that $52 \%$ drink alcohol on a weekly basis (Monshouwer, Van Dorsselaer, Gorter, Verdurmen, \& Vollebergh, 2004; Van de Pol \& Duijser, 2003). Almost 20\% of the male and $10 \%$ of the female 15-year-old adolescents drink more than ten glasses of alcohol on an average weekend day, and $63 \%$ of the 15 -year-olds report to have been drunk at least once in their lives (Monshouwer et al., 2004).

Although many different factors may contribute to these high figures of underage alcohol consumption, easy access to alcohol is generally assumed to play a significant role (Forster et al., 1994; Wagenaar et al., 1993; Wagenaar et al., 1995). In the United States, alcohol use and alcohol-related problems among youngsters increased when the legal drinking age was lowered in the 1970s (Wagenaar, 1983). When the legal age was raised to 21 in the late 1970s and early 1980s, a reduction of alcohol problems among youngsters was established (Dumouchel, Williams, \& Zador, 1987; George, Crowe, Abwender, \& Skinner, 1989; O'Malley \& Wagenaar, 1991). Similar findings were reported in studies into youth and smoking, where supply variables (actual or perceived access to tobacco products) invariably appeared to be an important predictor of underage tobacco use (Boyle, Claxton, \& Forster, 1997; Flay, 1993; Robinson, Klesges, Zbikowski, \& Glaser, 1997; Swan, Creeser, \& Murray, 1990).

In the Netherlands, the Alcohol Licensing and Catering Act prohibits retailers to sell alcohol products to young customers. A distinction is made between soft alcoholic beverages $(<15 \%$ alcohol) and strong alcoholic drinks $(>15 \%$ alcohol). The legal age limits are 16 for soft alcoholic beverages and 18 for strong alcoholic drinks. Since 2000, retailers are obliged to ask for identification and verify the age when young people try to buy alcohol. Most Dutch stores carry signs or stickers about the age restrictions. 
To evaluate the effectiveness of these legal prescriptions, a Dutch research agency periodically conducts surveys among managers of supermarkets, liquor stores and the hotel and catering industry (Bieleman, Biesma, Kruize, \& Snippe, 2004). Of the supermarkets, $99 \%$ of the managers reported to instruct their personnel about the age restrictions, and 91\% actually checked whether their cashiers observed them. Of the liquor stores, all managers instructed their personnel, and 78\% performed compliance checks. Moreover, $91 \%$ of the supermarket managers and $94 \%$ of the managers of liquor stores stated that no single offense regarding the age restrictions had occurred in their stores. In a survey among 13- to 17-year-old adolescents, however, the same research agency found very different results: underage respondents claimed to be successful in $90 \%$ of their buying attempts (Bieleman et al., 2004).

According to store managers, the Alcohol Licensing and Catering Act offers sufficient protection against underage alcohol sales; according to adolescents, alcohol is more or less freely available in the Netherlands. Explanations may be searched in two directions. Adolescents may use tricks to mislead store personnel (ask older-looking friends to buy alcohol, use falsified IDs) or report exaggerated success rates. Managers, on the other hand, may report socially desirable estimations of the practice in their stores.

To shed more light on the problem of underage alcohol sales, unobtrusive research approaches such as mystery shopping are indispensable. A company or institution is then visited by a trained accomplice, who pretends to be a 'normal' customer, but acts according to a script. Immediately after the visit, a detailed form is completed about the mystery shopper's experiences. Mystery shopping is frequently used to investigate the service quality of stores (Finn \& Kayandé, 1999; Wilson, 2001) and the quality of medical care (Luck \& Peabody, 2002; Madden, Quick, Ross-Degnan, \& Kafle, 1997). In the United Kingdom and especially in the United States, this type of undercover research has also been used to investigate retailers' compliance with alcohol legislation. The success rates of US studies fluctuated between $26 \%$ and $97 \%$ and appeared to be strongly related to the degree of enforcement involved in the region (e.g., the use of fines or license suspensions) (Britt, Toomey, Dunsmuir, \& Wagenaar, 2006; Freisthler, Greunewald, Treno, \& Lee, 2003; Preusser \& Williams, 1992; Preusser, Williams, \& Weinstein, 1994; Wagenaar, Toomey, \& Erickson 2005; Wolfson et al., 1996). The success rate in the only UK study 
was $83 \%$ (Willner, Hart, Binmore, Cavendish, \& Dunphy, 2000). These studies also identified variables that may affect the buying success of underage purchasers: the buyer's age and gender, location and type of outlet, and in-store signage.

In this article, we report on the development and first use of a mystery shopping protocol to investigate underage alcohol sales in Dutch supermarkets and liquor stores. We did this to gauge the overall situation in the Netherlands, which is characterized by a policy of age restrictions without substantial enforcement efforts. Authorities may punish stores that are caught in the act of selling alcohol to a minor, but the chances of doing this are slim without a mystery shopping approach. In this situation, much depends on the willingness of store personnel to verify the age of young customers, and act upon it.

We also addressed three specific hypotheses. First, we hypothesized that liquor stores are less susceptible to underage alcohol sales than supermarkets. Liquor store vendors are more knowledgeable about alcohol regulations than cashiers in supermarkets (Bieleman et al., 2004), and are also more suspicious of the possibility that underage customers may try to buy alcoholic beverages (Wolfson et al., 1996). Furthermore, the buying situation in liquor stores is more personal and less hasty than that in supermarkets. We investigated whether it would help to remove all alcohol beverages from supermarkets, and only sell them in specialized liquor stores.

Second, we hypothesized that the number of other customers waiting affects the success rate of the mystery shoppers, since age verification would cause unwanted delay. Busyness in the store is one of the obvious excuses store personnel may use for not verifying the age of young people who try to buy alcohol.

Third, as was also found by Willner et al. (2000), we hypothesized that female mystery shoppers are more successful than male mystery shoppers. This hypothesis is supported by a study by Merrill, Stanford, Lindsay, and Neiger (2000), who found that store clerks have more trouble identifying underage female customers than underage male customers. 


\subsection{LEGAL AND ETHICAL CONSIDERATIONS}

Since this was, to our knowledge, the first time this type of mystery research was used in the Netherlands, we carefully considered the legal and ethical implications. Legally, there was one major issue. Stores that sell alcohol to underage purchasers commit an offense and are therefore liable to penalty. Although underage mystery shoppers who try to buy alcohol are in principle not punishable under the Dutch law, their buying attempt may be seen as a provocation of an offense. To solve this problem, we considered working with pseudounderage buyers (younger-looking mystery shoppers who have reached the legal age to buy alcohol), as some of the earlier undercover studies did (Britt et al., 2006; Freisthler et al., 2003; Wagenaar et al., 2005; Wolfson et al., 1996). However, we decided that this would weaken the persuasiveness of the results, as the stores would in fact act according to the law if they agreed to sell alcohol. We therefore chose to work with real underage mystery shoppers, but prescribed that they would abort their buying attempt after the cashier had recorded the amount at the cash register, which is an unambiguous sign of a selling intention.

Regarding the supermarkets and liquor stores involved, the main ethical issue was whether it would be justified to include them in the study without their prior consent. We found four important criteria in the literature to judge the appropriateness of undercover research approaches: (1) societal relevance of the research topic, (2) inadequacy of the more conventional research methods, (3) public nature of the events observed, and (4) avoidance of negative consequences for the research objects (Cassell, 1980; Dench, Iphofen, \& Huws, 2004; Denzin \& Erikson, 1982; ESOMAR, 2005; Hodges, 1988). Using these criteria, we concluded that a mystery shopping approach would be permissible here. First, underage drinking is seen as an important societal problem, and several studies confirm the high and increasing alcohol consumption among Dutch adolescents (Monshouwer et al., 2004; Van de Pol \& Duijser, 2003). Second, the contradictory self reports of store managers and adolescents underline the inadequacy of conventional research methods. Third, the interactions between customers and store personnel in supermarkets and liquor stores are public: other people may enter the stores whenever they want and are able to observe the transaction. Fourth, we avoided negative consequences for the stores and vendors included 
in two ways: (a) the mystery shoppers behaved like normal customers and did not demand too much time of the store personnel, and (b) we safeguarded the anonymity of all stores and vendors in the study.

Regarding the adolescents partaking in the research as mystery shoppers, two ethical considerations were relevant. First, we did not want our study to encourage them to use alcohol. We therefore only selected adolescents with some prior experience in buying and drinking alcohol, and also asked their parents for informed consent. Furthermore, the adolescents were personally debriefed about the dangers of alcohol. Second, we did not want the adolescents to be confronted with awkward situations, vendor aggression, or police interrogations during the store visits. The mystery shoppers therefore carried an official letter explaining the research purpose of the buying attempt, and one of the researchers was close by to intervene should any trouble arise. No such situations occurred.

\subsection{METHODS}

\section{Mystery shopping protocol}

The mystery shoppers were picked up at their homes and transported by car to a preselected list of supermarkets and/or liquor stores in their living area. They were accompanied by two research assistants: a driver and a navigator/facilitator/observer. They were first given instructions about the script they had to follow. After arriving at a target store, the mystery shopper received 50 eurocents and entered the store alone. One of the research assistants waited inconspicuously near the entrance of the store, to observe the purchase attempt and be able to interfere should any problem arise.

The 15-year-old adolescents chose one alcoholic beverage-beer for male and premix drinks for female mystery shoppers (both containing 5\% alcohol), in line with the preferences within this age group-and took it to the checkout. In the supermarkets, they also picked a small bag of potato chips; in the liquor stores, they only bought the drink. When approaching the checkout, the mystery shoppers memorized the number of paydesks that were open and chose the most left-hand pay-desk. The mystery shoppers 
counted the number of customers in the line before them, and, once the store vendors started serving them, the number of customers behind them. Upon actually encountering the vendors, the mystery shoppers greeted them ("Hello"), and estimated their age. If they were asked whether the alcohol was for personal use, the mystery shoppers would answer affirmatively. If they were asked about their age, they would lie and claim that they were 16 years old. If they were asked for an ID, they would show their real ID.

If the store personnel refused to sell the alcohol, the mystery shoppers would not further insist and leave the store. If the store personnel was willing to sell the alcohol, which they signaled by recording the amount and/or mentioning the price, the mystery shoppers would act surprised and say that they did not have enough money with them. In the supermarkets, they would then only buy the potato chips; in the liquor stores, they would buy nothing. No real purchases of alcohol took place, but the unambiguous selling intentions were used as indications of real alcohol sales, which is justified by a study of Cummings, SaundersMartin, Clarke, and Perla (1996). After the store visit, the mystery shoppers joined the research assistants and immediately filled out an extensive checklist (Table I).

The visits by the 17-year-old adolescents largely followed the protocol described above. The 17-year-olds only went to liquor stores, since strong alcoholic drinks are not available in Dutch supermarkets. One difference in the script involved the type alcohol: instead of soft alcoholic beverages, the mystery shoppers tried to buy a bottle of strong alcohol—rum for male and red vodka mix for female mystery shoppers (both containing approximately $40 \%$ alcohol). And, obviously, they lied that they were 18 instead of 17.

\section{Recruitment of mystery shoppers}

As mentioned before, we chose to work with adolescents who had not reached the legal age to buy alcohol. At the same time, we did not want the mystery shoppers to look older than their real age. Therefore, we contacted high school teachers in three Dutch regions (west, south, and north/east), and asked them to help us recruit mystery shoppers. We asked teachers because they have daily contact with adolescents, and thus must be able to select adolescents who look typical for their age groups. The teachers were also asked to judge whether the candidates could handle the task and had some prior experience with alcohol. A total of thirteen adolescents participated in the research; four for each region 
(one girl was replaced halfway because she turned 16 during the research period). The mystery shoppers received a compensation for partaking in the study.

\section{Sample of supermarkets and liquor stores}

The research was conducted in three regions, which were selected to represent the diversity of the Dutch society: the regions around Amsterdam (west), Enschede (north/east), and Eindhoven (south). For each region, we included both rural and urban areas in the sample, and we randomly selected 50 supermarkets and 50 liquor stores. All 150 supermarkets and 75 of the liquor stores were visited by 15 -year-old mystery shoppers; the other 75 liquor stores were visited by 17-year-old mystery shoppers. All visits took place between December 2005 and February 2006, on weekdays between 9 AM and 5 PM (Table I). The 15-year-old mystery shoppers performed 15 to 25 visits a day; the 17-year-old mystery shoppers 12 to 13.

\section{$9.5 \quad$ RESULTS}

\section{Success rates of the mystery shoppers}

A total of $86 \%$ of all purchase attempts proved to be successful. In the supermarkets, the success rate was $88 \%$. In the liquor stores, a significant difference $\left(\chi^{2}=3.89, N=150, p<\right.$ .05 ) was found between the 15-year-old mystery shoppers who tried to buy a soft alcoholic beverage $(77 \%)$ and the 17-year-old mystery shoppers who tried to buy strong alcohol (89\%). The results partly support our first hypothesis, which assumed that liquor stores would be more cautious with underage customers than supermarkets. This hypothesis is confirmed for the 15-year-old adolescents $\left(\chi^{2}=4.33, N=225, p<.05\right)$, although it must be noted that a success rate of $77 \%$ is still very high. The success rate of 17 -year-olds buying strong alcohol did not differ from the rate of 15-year-olds in supermarkets. Table I gives an overview of the various store and visit characteristics and the corresponding success rates.

\section{Vendor behaviours: asking for age and ID}

For a more detailed view on the alcohol sales to underage customers, we analyzed to what extent the mystery shoppers were asked for their age and/or ID (Table II) and how these 
vendor reactions affected the purchasers' success (Table III). In the majority of the visits (72\%), the vendors did not ask the mystery shoppers for their age or ID and sold the alcohol without any reservations. When vendors only asked for the mystery shoppers' age (4\% of the visits), all purchase attempts succeeded. When vendors asked for an ID (12\% of the visits), or first asked the mystery shoppers' age and then asked for their ID (12\% of the visits), the overall success rate dropped to 36 and $43 \%$ respectively. The effective prevention of underage alcohol sales thus starts with store personnel's readiness to systematically ask for an ID of all young customers who try to buy alcohol; first or only asking for a customer's age does not significantly contribute to the prevention of underage alcohol sales.

Table I: Characteristics of visits, stores, mystery shoppers, and vendors

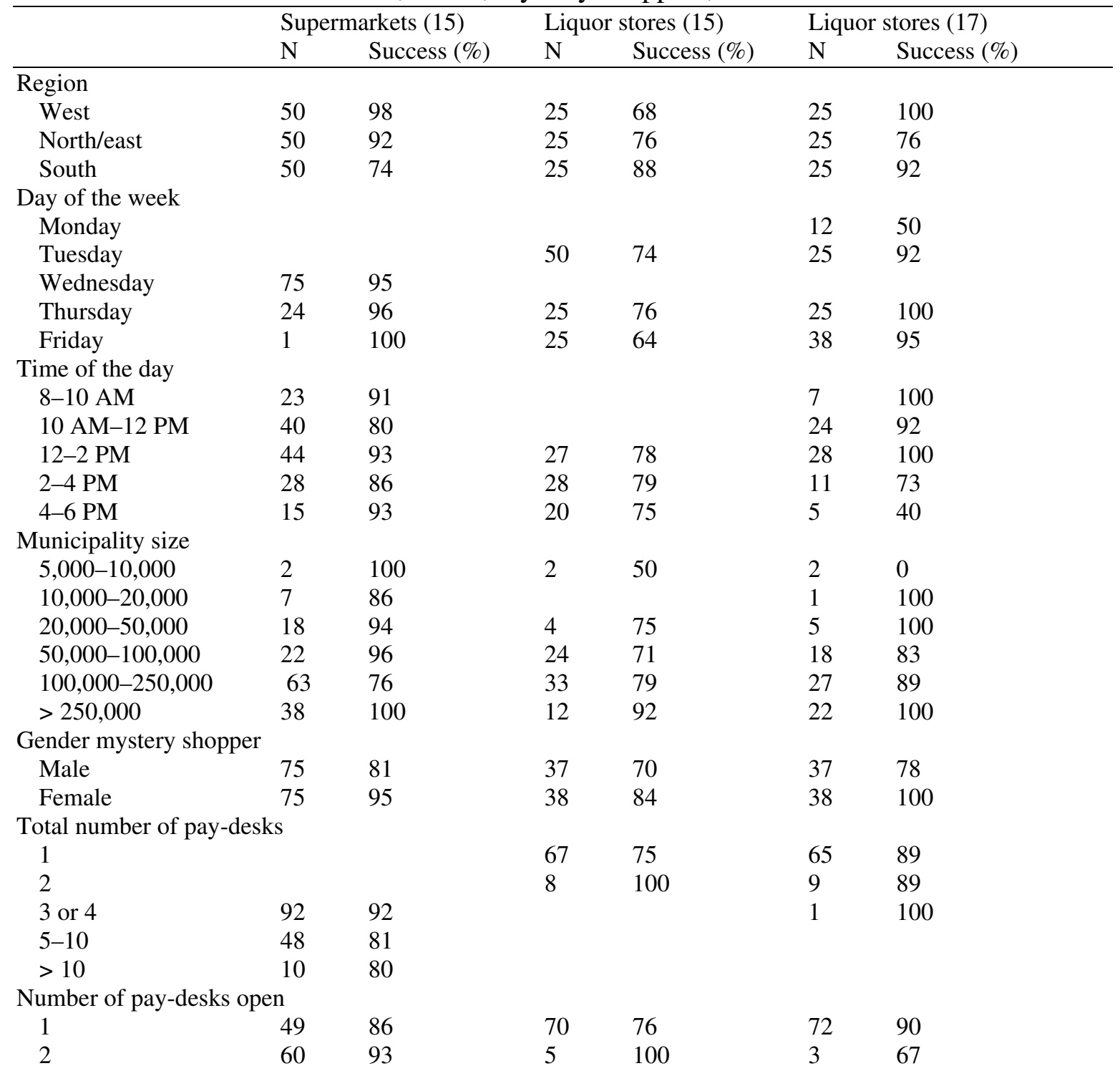




\begin{tabular}{|c|c|c|c|c|c|c|}
\hline 3 & 24 & 83 & & & & \\
\hline$>3$ & 17 & 82 & & & & \\
\hline \multicolumn{7}{|c|}{ Number of customers before } \\
\hline 0 & 26 & 89 & 47 & 79 & 53 & 89 \\
\hline 1 & 48 & 88 & 23 & 78 & 17 & 88 \\
\hline 2 & 45 & 89 & 3 & 33 & 4 & 100 \\
\hline$>2$ & 31 & 87 & 2 & 100 & 1 & 100 \\
\hline \multicolumn{7}{|c|}{ Number of customers behind } \\
\hline 0 & 34 & 79 & 63 & 78 & 60 & 90 \\
\hline 1 & 43 & 91 & 10 & 80 & 10 & 80 \\
\hline 2 & 35 & 89 & 2 & 50 & 3 & 100 \\
\hline$>2$ & 38 & 92 & & & 2 & 100 \\
\hline \multicolumn{7}{|c|}{ Gender of vendor } \\
\hline Male & 15 & 93 & 44 & 77 & 45 & 87 \\
\hline Female & 135 & 87 & 31 & 77 & 30 & 93 \\
\hline \multicolumn{7}{|c|}{ Estimated age $(y)$ of vendor } \\
\hline$<20$ & 45 & 87 & 1 & 100 & & \\
\hline $20-25$ & 27 & 96 & 7 & 86 & 7 & 100 \\
\hline $26-30$ & 78 & 86 & 9 & 67 & 2 & 100 \\
\hline $31-35$ & & & 8 & 50 & 4 & 100 \\
\hline $36-40$ & & & 12 & 92 & 10 & 70 \\
\hline $41-45$ & & & 9 & 78 & 24 & 92 \\
\hline $46-50$ & & & 5 & 100 & 13 & 85 \\
\hline$>50$ years & & & 24 & 75 & 15 & 93 \\
\hline
\end{tabular}

Although the ID checks had some preventive effect, it is remarkable that $39 \%$ of the buying attempts succeeded (= mean success rate for "ID check only" and "Age and ID check") even when an ID was shown. In those cases, the vendors were willing to sell the alcohol even though they were presented with unambiguous information that the mystery shopper was too young to buy the alcohol.

Table II: Vendor reactions to purchase attempts

\begin{tabular}{lllll}
\hline & $\begin{array}{l}\text { Supermarket } \\
15 \text {-year-old }\end{array}$ & $\begin{array}{l}\text { Liquor store } \\
15 \text {-year-old }\end{array}$ & $\begin{array}{l}\text { Liquor store } \\
17 \text {-year-old }\end{array}$ & Total \\
\cline { 2 - 5 } No intervention & $113(76 \%)$ & $43(58 \%)$ & $60(80 \%)$ & $216(72 \%)$ \\
Age check only & $5(3 \%)$ & $5(7 \%)$ & $3(4 \%)$ & $13(4 \%)$ \\
ID* check only & $22(15 \%)$ & $10(13 \%)$ & $4(5 \%)$ & $36(12 \%)$ \\
Age and ID check & $10(7 \%)$ & $17(23 \%)$ & $8(11 \%)$ & $35(12 \%)$ \\
\hline
\end{tabular}

*ID = identification. 
Table III: Success rate per type of vendor reaction

\begin{tabular}{lllll}
\hline & $\begin{array}{l}\text { Supermarket } \\
15 \text {-year-old }\end{array}$ & $\begin{array}{l}\text { Liquor store } \\
15 \text {-year-old }\end{array}$ & $\begin{array}{l}\text { Liquor store } \\
17 \text {-year-old }\end{array}$ & Total \\
\cline { 2 - 5 } No intervention & $100 \%$ & $100 \%$ & $100 \%$ & $100 \%$ \\
Age check only & $100 \%$ & $100 \%$ & $100 \%$ & $100 \%$ \\
ID* check only & $37 \%$ & $40 \%$ & $25 \%$ & $36 \%$ \\
Age and ID check & $60 \%$ & $35 \%$ & $38 \%$ & $43 \%$ \\
\hline
\end{tabular}

*ID = identification.

\section{Effects of busyness in the store and gender}

To test the second hypothesis, assuming that busy-ness in the store would positively affect the adolescents' buying success, we conducted a series of $\chi^{2}$ tests. Busy-ness in the store was measured as the number of customers in line before and behind the mystery shoppers. We distinguished four categories $(0,1-2,3-5$, and $>5$ customers). No significant relation was found between busy-ness in the store and buying success $\left(\chi^{2}=3.811, \mathrm{df}=3, \mathrm{p}=.283\right)$. We also did not find significant effects on vendors' tendency to ask for mystery shoppers' age $\left(\chi^{2}=1.103, \mathrm{df}=3, \mathrm{p}=.776\right)$ or ID $\left(\chi^{2}=1.733, \mathrm{df}=3, \mathrm{p}=.630\right)$. We therefore reject the second hypothesis.

Regarding the third hypothesis, we found that female mystery shoppers were significantly more successful than male mystery shoppers (93 vs. $78 \% ; \chi^{2}=14.722, \mathrm{df}=1, \mathrm{p}<.001$ ). This is also reflected in vendors' tendency to ask for the mystery shoppers' age or ID. Male adolescents were significantly more often asked for their age ( 26 vs. $7 \% ; \chi^{2}=14.722, \mathrm{df}=1$, $\mathrm{p}<.001)$ and their ID (38 vs. $\left.9 \% ; \chi^{2}=34.873, \mathrm{df}=1, \mathrm{p}<.001\right)$ than female adolescents. The third hypothesis is thus confirmed.

\subsection{DISCUSSION}

The results of our study show that Dutch supermarkets and liquor stores generally do not comply with legal age restrictions for alcohol sales. Underage adolescents can easily buy alcohol in supermarkets and liquor stores, and are rarely confronted with vendors asking for their age or ID. Female adolescents are more successful than male adolescents. If underage adolescents are asked how old they are, a simple lie suffices to be able to buy the 
alcohol; if they are asked for their ID, they still have a good chance to succeed. Busy-ness in the store is not of influence on vendors' nonchalance with age restrictions. These findings raise serious questions about youth alcohol policy in the Netherlands, and, more in generally, the use of age restrictions without sufficient attention for compliance.

A first issue concerns the measurement of compliance. Policymakers seem to rely on self report data to monitor the effectiveness of the age restrictions. The results of our study indicate that the self reports of store managers are by no means a valid indication of the degree to which stores observe the age restrictions. The self reports of adolescents, on the other hand, appear to strongly correspond with the findings in this study. We would suggest that a mystery shopping approach is the most valid way of measuring compliance, and that adolescents' self reports would be the second-best alternative. Self reports of store managers or vendors tend to provide misleading feedback on compliance with age restrictions.

A second issue concerns the way compliance can be improved. One month before the start of our data collection, the PVAD (a national partnership of alcohol-selling retailers) had started an information campaign to inform and instruct vendors about the legal age restrictions. Since our data were collected at the height of the campaign activities, our findings raise serious doubts about the effectiveness of such information campaigns.

In the United States, three studies have focused on the effectiveness of other possible interventions. Forster et al. (1998) showed that various kinds of enforcement are a fruitful way of reducing underage sales. Such an approach should not only focus on warnings and penalties in the case of an offense, but also on the actual and perceived chance of being caught (Montgomery, Long Foley, \& Wolfson, 2006). Toomey et al. (2001) successfully used a training program aimed at the owners and managers of alcohol establishments, which started with a risk assessment and gradually developed into the facilitation of underage sales prevention. Wagenaar et al. (2005) compared the effects of a management training and enforcement checks, and found the (periodic) enforcement checks to be more effective. These interventions all boil down to a combination of enforcement strategies and communication. Communication will only be effective if the store managers wholeheartedly endorse the necessity to comply with the legal age restrictions. 
Enforcement checks will only be effective when store managers are aware of them, and are periodically informed about their results and consequences.

Three ID-related problems appear to inhibit stores to effectively prevent underage alcohol sales. The first problem involves the prevailing interpretation of the legal age restrictions. A precondition for effective age restrictions is that vendors get accustomed to verifying the age of a broader range of young-looking customers. Merrill et al. (2000), for instance, concluded that, in order to effectively observe a 21 years age restriction, store clerks should ask the IDs of all customers estimated below 27 years. This awareness is currently lacking in the supermarkets and liquor stores. A second problem is that people are not used to being asked for an ID in a supermarket or liquor store. An information campaign focusing exclusively on store personnel will therefore not suffice; customers must also be prepared for such a change in store policy. A third problem concerns the Dutch ID documents themselves: we found evidence in the mystery shoppers' verbal accounts that vendors had trouble inferring customers' ages on the basis of birth dates on an ID.

In all, the results of our study suggest that legal age restrictions without facilitation of the vendors and without enforcement strategies will not suffice to prevent underage alcohol sales. Furthermore, our study demonstrates the usefulness of mystery shopping to monitor the effectiveness of alcohol restrictive policies. 
"A Gin \& Tonic a day keeps the doctor away"

After Elizabeth Bowes-Lyon (1900 - 2002) - 'Queen Mother' of England 


\title{
Improving Shop Floor Compliance with
}

\author{
Age Restrictions for Alcohol Sales: the
}

Effectiveness of a Feedback Letter

\section{Intervention.}

Joris J. van Hoof

Jordy F. Gosselt

Niels Baas

Menno D.T. de Jong

Submitted

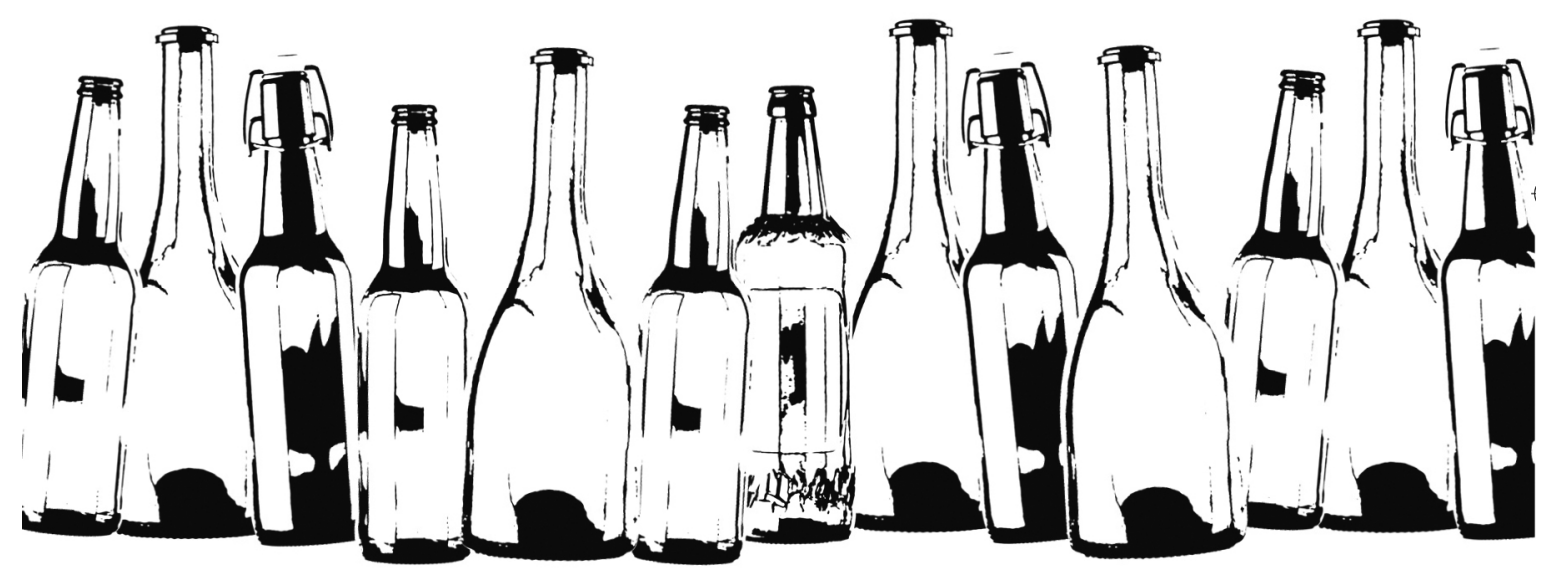




\subsection{ABSTRACT}

Purpose: In this study, we investigated the effects and handling of an intervention to increase compliance with the age limits on alcohol sales to minors. The intervention tested in this field experiment consisted of a letter addressed to shops including their personal compliance results based on a mystery shopping study.

Method: We measured compliance in 146 alcohol outlets (fast food restaurants, supermarkets, bars and night clubs, liquor stores, and youth centres) in one region in the Netherlands with 15-year-old mystery shoppers. About half $(n=72)$ of the outlets received the intervention (the experimental group), and after this intervention, we again measured compliance $(n=138)$. Then we sent the same intervention to the control group and interviewed all the outlets regarding their handling of the intervention $(n=106)$.

Results: After the experimental group received the intervention, compliance increased significantly (from $18.1 \%$ to $32.4 \%$ ). In the control group, compliance did not change. Of the outlets interviewed, $81 \%$ stated that they had received the intervention, and the action most commonly taken was to bring the intervention to the attention of their staff.

Conclusions: Compliance with respect to underage alcohol sales can be changed, but compliance levels remain low in the Netherlands. The more serious the intervention was treated by the alcohol outlet, the greater the change in compliance. 


\subsection{INTRODUCTION}

Alcohol consumption is associated with positive effects (such as leisure, relaxation, and partying), but predominantly, excessive alcohol use is connected with negative consequences. Alcohol use can cause health related problems, such as liver disease, heart disease, stroke, intoxication, and mental health issues, as well as societal problems, such as crime, rape, (traffic) accidents, and fighting (Brown, Tapert, Granholm, \& Delis, 2000; Ellickson, Tucker, \& Klein, 2003; Macdonald et al., 2005; Sindelar, Barnett, \& Spirito, 2004; Tapert et al., 2003; Warner \& White, 2003).

In many countries (including the Netherlands), alcohol is the most widely abused substance among youth and adolescents (Hibell et al., 2004; Johnston, O'Malley, Bachman, \& Schulenberg, 2006; Van der Laar, Cruts, Verdurmen, Van OoyenHouben, \& Meijer, 2008). In addition to the problems listed above, adolescents who consume alcohol may engage in unprotected sex; severe alcohol intoxication; perform poorly at school; and develop various physical diseases, permanent brain damage, and addiction later in life (Centres for Disease Control and Prevention, n.d.; Ellickson et al., 2003; Macdonald et al., 2005; Miller, Naimi, Brewer, \& Jones, 2007; Sen, 2002; Sindelar et al., 2004; Tapert et al., 2003; Van Hoof, Van der Lely, Rodrigues Pereira, \& Van Dalen, 2010).

Alcohol availability is considered the most important predictor of adolescent alcohol consumption, drinking patterns, and alcohol-related damage (Paschall, Grube, \& Kypri, 2009; Popova, Giesbrecht, Bekmuradov, \& Patra, 2009). Availability includes economic (pricing), physical (opening hours and outlet density), social (peer drinking and parenting), and legal (age limits) aspects.

Social availability issues arise mainly in the private domain (i.e., at home or at a friend's home), and are considered private (parental) responsibility in the Netherlands. There is, for instance, no regulation on providing alcohol to underage youth. Parenting style and social norms might be influenced by governmental health campaigns, societal norms in general, or specific educational programs. 
Economic, physical and legal availability, however, can be influenced by governmental laws and regulations. With respect to economic and physical availability, in the Netherlands, regulations exist regarding taxation, minimum sales prices, the use of discounts, opening hours for both on-premise and off-premise alcohol sales points, and the licensing of alcohol sales. These regulations influence alcohol consumption in general (including adolescent consumption), but regulations related to legal availability are theoretically most effective on reducing underage alcohol consumption.

As in many countries, the Netherlands has age limits for alcohol sales. This legislation states that it is not legal to sell beverages containing low alcohol levels $(<15 \%$, and including some distilled wines, such as port and sherry) to persons younger than 16 years or beverages containing high alcohol levels $(>15 \%)$ to persons younger than 18 years. Sales personnel in supermarkets, liquor stores, and the catering industry are obliged to verify the customer's age (by identification card) if there could be any doubt about the age of the potential customer. Of course, the role of the sales personnel is crucial for proper functioning of the age limit regulations.

In the study of Willner, Hart, Binmore, Cavendish, and Dunphy (2000), alcohol vendors were interviewed and asked about problems they experienced while restricting underage youth from purchasing alcohol beverages and following the legislation. In that study, only $12.5 \%$ of sales personnel admitted having problems with underage adolescents attempting to purchase alcohol. When young people are asked or when examining compliance using mystery shopper (decoy) research, a different result is obtained: purchasing alcohol turns out to be easy (Britt, Toomey, Dunsmuir, \& Wagenaar, 2006; Freisthler, Greunewald, Treno, \& Lee, 2003; Preusser \& Williams, 1992; Preusser, Williams, \& Weinstein, 1994; Wagenaar, Toomey, \& Erickson 2005; Willner et al., 2000; Wolfson et al., 1996). In the Netherlands, the difference between statements of alcohol sales personnel and experimental findings factual compliance is even greater. In a recent study, $100 \%$ of the sales personnel interviewed in supermarkets stated that they comply with the age limits on alcohol sales. For liquor stores, $99 \%$ of the personnel state that they comply, and in the catering industry, the figure is $93 \%$ (Bieleman, Kruize, \& Zimmerman, 2010). Many mystery shop studies, covering hundreds of underage alcohol purchases, show compliance levels varying from 0 to 50\% (Gosselt, Van Hoof, \& De Jong, 2007; Van Hoof, \& Baas, 
2009; Van Hoof, Mulder, Gosselt, Van Poppel, \& De Jong, 2008a; Van Hoof, Van Poppel, Mulder, \& Baas, 2008b).

Because compliance is important in reducing alcohol consumption in adolescents, and in underage youth in particular, and given the fact that compliance levels are low, it is important to experiment with interventions that increase compliance. Research shows that information interventions, such as information campaigns and training programs, can increase compliance (Wagenaar et al., 2005; Willner et al., 2000). In addition, more severe interventions, such as increased enforcement levels and police interventions, cause higher compliance rates (Lewis et al., 1996; Preusser et al., 1994; Scribner \& Cohen, 2001; Wagenaar et al., 2005).

In this study, we studied the effect of a combination of the abovementioned types of interventions. We measured compliance in alcohol outlets by conducting underage mystery shopping alcohol purchase attempts and subsequently informed the individual outlets about their performance by sending a feedback letter. In a second wave of mystery shopping alcohol purchase attempts, we measured the effects of the intervention. Furthermore (and to our knowledge this has not been done before), we contacted all the alcohol outlets that had been visited and interviewed the manager on how the intervention letter was handled within the organisation. Finally, we were able to analyse whether a positive letter (compliance) was treated differently than a negative letter (illegal sales), and to what extent any difference in internal treatment was related to compliance.

\subsection{METHODS}

\section{Procedure and research design}

The research consisted of three data collection rounds (two waves of underage mystery shopping to determine compliance rates, followed by an interview session), with an intervention between the two mystery shopping waves, see also figure 1 . In the first wave, zero-measurement mystery shopping study, 146 alcohol outlets were visited by 15 -year-old 
adolescents who attempted to purchase beverages containing low alcohol (the legal age for purchasing alcohol is 16 years in the Netherlands).

After analysing the level of compliance, we semi randomly split the group of outlets in two, based on type of alcohol outlet (fast food restaurants, supermarkets, bars and night clubs, liquor stores, and youth centres) and mystery shopping result (compliant versus noncompliant). We then took into account the specific address of each outlet, switching two stores to the other group because they were located in the same shopping area as nearby stores in the same group and might therefore be in close contact. We then sent half of all alcohol outlets visited $(n=72)$ an intervention letter containing a summary of our research, the result of the purchase attempt within the specific outlet (13 cases of compliance, and 59 cases of non-compliance), and an information brochure from the Dutch Food and Consumer Product Safety Authority (VWA) with tips for improving or maintaining compliance.

Approximately ten days after the intervention, we again visited the alcohol outlets (138 out of 146) to execute the second wave of underage mystery shopping purchase attempts (using exactly the same protocol and the same mystery shoppers as used in the wave 1 measurement) to investigate the effects of the intervention letter.

Directly after this second wave of mystery shopping visits, we sent the second half of the alcohol outlets $(n=74)$ the same research summary, their own result (14 in compliance, 60 non-compliant), and the VWA brochure.

The third stage of the research consisted of a qualitative round in which we interviewed (by phone) 106 of the 146 alcohol outlets to further investigate (a) the actions taken after receiving the intervention letter, (b) any communication with the personnel, and (c) the (perceived) effects of the intervention. The study was approved by the Ethical Commission of the Faculty of Behavioural Sciences of the University of Twente. The mystery shopping study (protocol, participating underage mystery shoppers, ethical and legal issues) was largely based on the Dutch standard, as addressed in Gosselt, Van Hoof, De Jong, and Prinssen (2007). All interviews were conducted by researchers of the University of Twente. 
Figure 1: Research design

\begin{tabular}{|c|c|c|c|c|c|}
\hline \multirow{2}{*}{ Experimental group } & $\mathrm{O}_{1}$ & $\mathrm{X}_{1 \mathrm{a}}(\mathrm{n}=13)$ & $\mathrm{O}_{2}$ & & $\mathrm{O}_{3}$ \\
\hline & $(\mathrm{n}=72)$ & $\mathrm{X}_{1 \mathrm{~b}}(\mathrm{n}=59)$ & $(\mathrm{n}=68)$ & & $(\mathrm{n}=55)$ \\
\hline \multirow{2}{*}{ Control group } & $\mathrm{O}_{1}$ & & $\mathrm{O}_{2}$ & $X_{1 a}(n=14)$ & $\mathrm{O}_{3}$ \\
\hline & $(\mathrm{n}=74)$ & & $(\mathrm{n}=70)$ & $\mathrm{X}_{1 \mathrm{~b}}(\mathrm{n}=60)$ & $(\mathrm{n}=51)$ \\
\hline \multicolumn{6}{|c|}{$\mathrm{O}_{1}=$ mystery shopping wave 1 (zero-measurement) } \\
\hline \multicolumn{6}{|c|}{$\mathrm{O}_{2}=$ mystery shopping wave 2 (effects intervention) } \\
\hline \multicolumn{6}{|c|}{$\mathrm{O}_{3}=$ interviews (by phone) } \\
\hline \multicolumn{6}{|c|}{$\mathrm{X}_{1 \mathrm{a}}=$ intervention positive letter (compliance $\mathrm{O}_{1}$ ) } \\
\hline $\mathrm{X}_{1 \mathrm{~b}}=$ intervention negati & complian & $\left.\mathrm{O}_{1}\right)$ & & & \\
\hline
\end{tabular}

\section{Selection of alcohol outlets}

Taking into account the influences of opening hours (e.g., night clubs) and seasons (e.g., the specific opening times for beach pavilions and sports clubs), as well as the fact that an outlet can be visited by a 15-year-old adolescent without being noticed, we randomly selected 146 alcohol outlets (out of approximately 350 outlets in total) within one region (consisting of nine municipalities, located in the central part of the Netherlands). The corpus consisted of five types of alcohol outlets (46 privately owned fast food restaurants, 37 supermarkets, 35 bars and night clubs, 26 liquor stores, and 2 youth centres), representatively spread over the nine municipalities (based on the number of inhabitants), varying from 6 to 48 alcohol outlets per municipality.

\section{Mystery shoppers}

Four 15-year-old adolescents participated as mystery shoppers in this research. To recruit the mystery shoppers, we contacted high school teachers in the region and asked them to bring the research to the attention of appropriate 15-year-old students (this was assessed by the teachers based on their physical appearance and suitability for the task). The students were invited to apply by e-mail. Based on national data (95\% confidence interval) on youth heights and weights, photographs, and availability, we selected four mystery shoppers (two boys and two girls). During the mystery shopping purchase attempts, the mystery shoppers were dressed in jeans, a sweater, and a coat, without visible brand logos. The girls were not allowed to wear heavy make-up. Parents whose children participated were asked for their consent. The mystery shoppers received financial compensation (equal to an average 15year-old holiday job) for their participation. 


\section{Mystery shopping protocol}

The 15-year-old mystery shoppers were trained to discover to what extent it was possible to purchase beverages containing alcohol. To do so, they visited 150 alcohol outlets in which they attempted, following a protocol, to purchase a beverage containing alcohol. In supermarkets, liquor stores, and fast food restaurants, the mystery shopper, randomly selected to the outlets) entered the outlet alone. In supermarkets and liquor stores, the mystery shoppers took a can of beer and went to the cashier. In fast food restaurants, the mystery shopper went to the clerk immediately and ordered a take-away beer. If the vendor asked about the age of the mystery shopper, he or she was instructed to lie and state that he or she was 16 years old. If the vendor (also) asked for identification, the mystery shopper would show his or her real ID (showing that the mystery shopper was too young to purchase alcohol, based on the listed date of birth of birth). In bars, night clubs and youth centres, two mystery shoppers (a boy and a girl) entered the location together and ordered two beers. The same protocol was then followed. After a purchase attempt, the mystery shoppers left the location inconspicuously. All beverages containing alcohol that were purchased were discarded after the research.

\section{Intervention}

After the first mystery shopping study, half of the alcohol outlets (the experimental group) were sent an intervention consisting of three parts: (i) a summary of the mystery shopping research, (ii) a letter with their own result, and (iii) an information brochure on age limits prepared by the Dutch Food and Consumer Product Safety Authority (VWA). The letter with the shops' mystery shopping results were labelled with the specific outlet address and printed on the stationary of the local youth alcohol prevention program. Two different letters were sent out: a positive letter to shops in compliance with the age limits (13 in the experimental group and 14 in the control group) containing the message that the research showed that an underage mystery shopper was not able to buy alcohol in their shop. A compliment was made, together with an expression of expectation and confidence that this behaviour would continue. A negative letter was sent to shops that sold alcohol to the underage mystery shoppers (59 in the experimental group and 60 in the control group), containing the message that a 15 -year-old had been able to purchase alcohol in their outlet. The letter also contained a warning that this behaviour may lead to the imposition of a fine 
or even closure of the shop. Finally, the letter expressed the hope that the behaviour of the personnel would change in the future and referred to the VWA brochure containing tips and tricks to improve compliance. In both letters, the time frame of the mystery shopping purchase attempt was not made specific, to avoid possible consequences for individual sales persons.

\section{Telephone interviews}

After telephoning the outlets, the interviewers first asked who they were talking to, and, if not already talking with the store owner or manager, they asked to be put through to them (or, in the event that failed, to make an appointment to call back at a more suitable time). The interviews started with a short introduction regarding the conducted mystery shopping research and the intervention letters that were sent. First, the interviewers verified whether the manager remembered receiving the intervention letter. If so, they asked (i) what the manager did with this letter (i.e., was the letter shared with the sales personnel, and if so, how?); (ii) were any actions undertaken with respect to the intervention and the VWA brochure; (iii) had the shop manager received any other communication with respect to the sale of alcohol to underage youth; and finally (iv), had the manager taken any steps in the past (i.e., before our intervention) to increase compliance with the law regarding the sale of alcohol to underage youth?

\section{Interview coding}

All answers were registered using semi-structured interview schemes. Ten interviews were coded separately by two coders, and inter-coder reliability was calculated. Cohen's Kappa (unweighted) varied from 0.71 to 1.00 . The differences between the coders were discussed in a meeting, and the coding scheme was further elaborated. One researcher coded the remaining 96 interviews (106 in total, minus ten that were double-coded), resulting in a total of approximately 750 codings. The researcher discussed thirteen answers with a second researcher. 


\subsection{RESULTS}

\section{Effect of the intervention letter on compliance}

First, we will present the second wave mystery shopping results for the experimental group and the effect of the intervention letter on (i) compliance and (ii) asking for identification. The compliance rate in the first mystery shopping wave was fairly equal between the two groups. The mean compliance rate for the experimental group was $18.1 \%$, and that of the control group was $18.9 \%$. These results are in line with the average compliance rate in the Netherlands (Gosselt, et al, 2007). In both groups, approximately $30 \%$ of the sales personnel asked for identification before selling or refusing the alcohol. After the intervention letter had been sent to the 72 shops in the experimental group (13 in compliance, 59 non-compliant), we performed the second mystery shopping wave in all 146 shops (minus eight shops, due to closure), to determine any changes in compliance.

Table I: Compliance rates and asking for ID in the two mystery shopping waves.

\begin{tabular}{lllllll}
\hline & $\#$ & & Compliance & \multicolumn{3}{c}{ Ask ID } \\
& Wave 1 & Wave 2 & Wave 1 & Wave 2 & Wave 1 & Wave 2 \\
\hline Control group & $\mathrm{n}=74$ & $\mathrm{n}=70$ & $18.9 \%(14)$ & $8.6 \%(6)$ & $28.4 \%(21)^{*}$ & $45.7 \%(32)^{*}$ \\
Exp. group & $\mathrm{n}=72$ & $\mathrm{n}=68$ & $18.1 \%(13) *$ & $32.4 \%(22)^{*}$ & $31.9 \%(23)^{*}$ & $54.4 \%(37)^{*}$ \\
\hline Total & $N=146 \mathrm{~N}=138$ & $18.5 \%(27)$ & $20.3 \%(28)$ & $30.1 \%(44)^{*}$ & $50.0 \%(69) *$ \\
\hline
\end{tabular}

* Significant Chi-Square test values $\mathrm{p}<.05$ between wave 1 and wave 2 compliance

In the experimental group, the compliance significantly increased from $18.1 \%$ to $32.4 \%$ $\left[\chi^{2}(1, N=140)=3.81, p=.04\right]$. In the control group, the compliance level did not change $\left[\chi^{2}(1, N=144)=3.22, p=.06\right]$. In both the experimental group $\left[\chi^{2}(1, N=140)=7.21, p=\right.$ $.01]$ and the control group $\left[\chi^{2}(1, N=144)=4.65, p=.02\right]$, sales personnel asked for identification cards more often in the second mystery shopping wave. For the experimental group we also compared compliance rates for the positive and negative letters in mystery shopping wave $2(n=68)$. For the negative letters $(n=56)$ compliance rates in wave 2 were $35.7 \%$ and for the positive letters $(n=12)$ compliance rate in wave 2 turned out to be $16.7 \%$, which does not differ significantly $\left[\chi^{2}(1, N=68)=1.64, p=.31\right]$. 


\section{Intervention handling (interview results)}

In total, 106 interviews were conducted, of which 24 were with personnel from outlets that received a positive intervention letter and 82 were with personnel from outlets that received a negative intervention letter. As also can be seen in Table II, $81 \%$ of the interviewees confirmed they received the intervention letter. Approximately $70 \%$ of the shop owners indicated they took some action after reading the letter. Most of these actions involved informing the (sales) personnel about the outcome, and when a positive letter was received, compliments were given from the management to the sales personnel. In $55 \%$ of the cases in which the vendors did sell alcohol to underage youth (negative letter), the results were discussed with the personnel and they were asked to become stricter and to ask for identification cards more often before sales.

Table II: Intervention handling, sorted by type of intervention: positive letter (compliance) versus negative letter (non-compliance)

\begin{tabular}{|c|c|c|c|}
\hline & $\begin{array}{l}\text { Total } \\
\mathrm{N}=106\end{array}$ & $\begin{array}{l}\text { Positive letter } \\
\mathrm{n}=24\end{array}$ & $\begin{array}{l}\text { Negative letter } \\
\mathrm{n}=82\end{array}$ \\
\hline \multicolumn{4}{|l|}{ Did you receive the letter? } \\
\hline Yes & $86(81 \%)$ & $20(83 \%)$ & $66(80 \%)$ \\
\hline No & $14(13 \%)$ & $3(13 \%)$ & $11(13 \%)$ \\
\hline Don't know & $6(6 \%)$ & $1(4 \%)$ & $5(6 \%)$ \\
\hline \multicolumn{4}{|l|}{ Actions taken after receiving letter } \\
\hline Read, but no further actions were taken & $10(9 \%)$ & $3(13 \%)$ & $7(9 \%)$ \\
\hline Read, informed (some) personnel & $62(58 \%)$ & $17(71 \%)$ & $45(55 \%)$ \\
\hline Read, actions taken in shop & $11(10 \%)$ & $0(0 \%)$ & $11(13 \%)$ \\
\hline Don’t know & $23(22 \%)$ & $4(17 \%)$ & $19(23 \%)$ \\
\hline \multicolumn{4}{|l|}{ Discussed letter with personnel } \\
\hline No & $9(8 \%)$ & $3(13 \%)$ & $6(7 \%)$ \\
\hline Yes, with all of them & $57(54 \%)$ & $14(58 \%)$ & $43(52 \%)$ \\
\hline Yes, sales personnel only & $12(11 \%)$ & $3(13 \%)$ & $9(11 \%)$ \\
\hline Yes, managers only & $5(5 \%)$ & $0(0 \%)$ & $5(6 \%)$ \\
\hline Don't know & $23(22 \%)$ & $4(17 \%)$ & $19(23 \%)$ \\
\hline \multicolumn{4}{|l|}{ Action with VWA brochure } \\
\hline No & $59(56 \%)$ & $18(75 \%)$ & $41(50 \%)$ \\
\hline Yes & $15(14 \%)$ & $2(8 \%)$ & $13(16 \%)$ \\
\hline Don't know & $32(30 \%)$ & $4(17 \%)$ & $28(34 \%)$ \\
\hline \multicolumn{4}{|c|}{ Information otherwise received regarding the sale of alcohol to minors } \\
\hline No & $65(61 \%)$ & $14(58 \%)$ & $51(62 \%)$ \\
\hline Yes, from our own organisation & $19(18 \%)$ & $7(30 \%)$ & $12(15 \%)$ \\
\hline Yes, from someone else & $17(16 \%)$ & $3(13 \%)$ & $14(17 \%)$ \\
\hline Don't know & $5(5 \%)$ & $0(0 \%)$ & $5(6 \%)$ \\
\hline
\end{tabular}


Eleven interviewees informed us that further actions were taken in their shops (usually in addition to conversations with the personnel). These actions involved the placement of signs communicating the age limits for purchasing alcohol in the shops and placing alcohol information brochures at the pay desks, and some interviewees indicated that the intervention letter is going to be used when training new sales personnel. One shop indicated that they had increased the age limit to 20 years. Fifteen shops used the VWA brochure to improve (13 instances) or continue ( 2 instances) compliance in their shop. Some supermarket owners told us they had communicated the results of the mystery shopping research, including their own results, to their brand chain headquarters. Other supermarket owners indicated they also had received information about the mystery shopping from their headquarters (via newsletter).

\section{Intervention handling effects}

As mentioned before, in the experimental group we performed 72 mystery shopping visits in the first wave and subsequently sent 72 intervention letters (13 of which were positive and 59 negative). In the second wave, we were able to re-visit 68 alcohol outlets using mystery shopping, after which we conducted interviews with 53 of the shop owners. To investigate the effect of different intervention handling on later mystery shop compliance (i.e., wave two) we sorted the results and presented them as in Table III.

Table III: Experimental group intervention handling, sorted on later compliance

\begin{tabular}{llll}
\hline & $\begin{array}{l}\text { Total } \\
\mathrm{N}=53\end{array}$ & $\begin{array}{l}\text { Compliance } \\
\mathrm{n}=21\end{array}$ & $\begin{array}{l}\text { Non-compliance } \\
\mathrm{n}=32\end{array}$ \\
\hline $\begin{array}{l}\text { Did you receive the letter? } \\
\text { Yes }\end{array}$ & $46(87 \%)$ & $20(95 \%)$ & $26(81 \%)$ \\
No & $5(9 \%)$ & $1(5 \%)$ & $4(13 \%)$ \\
Don't know & $2(4 \%)$ & $0(0 \%)$ & $2(6 \%)$ \\
Actions taken after receiving letter & & & \\
Read, but no further actions were taken & $5(9 \%)$ & $3(14 \%)$ & $2(6 \%)$ \\
Read, informed (some) personnel & $34(64 \%)$ & $15(71 \%)$ & $19(59 \%)$ \\
Read, actions taken in shop & $4(8 \%)$ & $1(5 \%)$ & $3(9 \%)$ \\
Don't know & $10(19 \%)$ & $2(10 \%)$ & $8(25 \%)$ \\
No & & & $3(9 \%)$ \\
Yes, with all of them & $5(9 \%)$ & $2(10 \%)$ & $18(56 \%)$ \\
Yes, sales personnel only & $31(58 \%)$ & $13(62 \%)$ & $2(6 \%)$ \\
Yes, managers only & $4(8 \%)$ & $2(10 \%)$ & $2(6 \%)$ \\
Don't know & $3(11 \%)$ & $1(5 \%)$ & $7(22 \%)$ \\
& $10(19 \%)$ & $3(14 \%)$ & \\
& & & \\
& & &
\end{tabular}


Action with VWA brochure

$\begin{array}{llll}\text { No } & 32(60 \%) & 13(62 \%) & 19(59 \%) \\ \text { Yes } & 5(9 \%) & 2(10 \%) & 3(9 \%) \\ \text { Don't know } & 16(30 \%) & 6(28 \%) & 10(31 \%)\end{array}$

Information otherwise received about alcohol sales to minors

$\begin{array}{llll}\text { No } & 31(58 \%) & 9(43 \%) & 22(69 \%) \\ \text { Yes, from our own organisation } & 7(13 \%) & 3(14 \%) & 4(13 \%) \\ \text { kn someone else } & 10(19 \%) & 6(29 \%) & 4(13 \%) \\ & 5(9 \%) & 3(14 \%) & 2(6 \%)\end{array}$

Within the 53 interviews, some differences between shops that complied versus those that did not are remarkable. Seven shop owners did not remember receiving the intervention letter. Out of those seven owners, six of their shops also sold alcohol to an underage adolescent after the intervention. In the group of shops that complied, the letter appears to have been discussed more intensively within their organisation than for the shops that sold alcohol afterwards. Also (but again the numbers are small), it appears that in the compliant group, a greater number of shops received other information on alcohol sales from without their organisation.

\subsection{DISCUSSION}

Because $81 \%$ of the 106 shop owners we interviewed indicated that they had received the intervention letter, it is fair to conclude that the compliance of their shop with age restrictions is interesting to shop owners. To remember a single letter when managing a shop involving many important issues occurs only if the specific topic has attracted particular interest. Both positive and negative intervention letters were reported to have been received four out of five times, but were handled differently. Positive letters were shared with the personnel more often than were negative letters. On the one hand, this makes sense because a positive letter is more pleasurable to share. On the other hand, a change in personnel behaviour may be desired when negative letters are received, and therefore the compliance findings may to be discussed. However, compliance measured after sending the letter did not differ between the specific content of the letter (positive versus negative). Also, some shop owners told us that they had been informed about the 
research and the use of underage mystery shoppers via colleagues. This occurred mainly in the social entertainment industry, in which different bars are in contact with each other. This also illustrates the level to which shop and bar owners are interested in the subject of alcohol sales to minors. To what extent this interest regards the importance of not selling alcohol to minors versus anger about the research method is not clear.

Despite the abovementioned interest in the subject, the rate compliance is approximately $20 \%$. This means that a 15-year-old adolescent is able to purchase an alcoholic beverage without any serious difficulty. When he or she walks into ten randomly selected shops, he or she walks out with eight beverages. Even after receiving the intervention letter and the announcement that a second mystery shopping research is going to be conducted within the near future, compliance increased to only $32 \%$. This means that in ten tries, an underage adolescent can buy seven beverages instead of eight.

One supermarket chain took the letter seriously after some of their (freelance) supermarket owners had communicated the details and results of the mystery shop research to their headquarters. Other shops were simply informed about the research and, presumably, about the importance of compliance with respect to age limits for the purchase of alcohol. Further, it is possible that supermarkets not only within the research region were informed, but that the research intervention reached a greater area (perhaps the whole country).

This study shows that compliance rates can be influenced as they stem from human behaviour, but, as said before, we only reached a maximum of $32 \%$ compliance. Obviously, this raises the question to what ultimate level compliance can be increased and what efforts are necessary to achieve this. In general, the more seriously the letter was treated and discussed within the organisation, the greater the compliance rates. Further research is needed to investigate to what level compliance can be influenced, for what period, and at what financial cost and to what effect on society.

In the Netherlands, we have a practice of mystery shopping in alcohol since 2006, and the highest compliance rate ever found has been 50\% (Gosselt et al., 2007; Van Hoof \& Baas, 2009; Van Hoof et al., 2008a; Van Hoof et al., 2008b). In a society with these levels of compliance, when a 15-year-old who wants to buy alcohol conducts two purchase 
attempts, their chance of purchasing alcohol increases to $75 \%$. This includes all types of alcohol outlets: supermarkets, sports canteens, fast food restaurants, bars, youth centres, and liquor stores. Youth alcohol consumption causes alcohol intoxication treatment in hospitals several times a week in the Netherlands. Research shows that underage intoxicated youth admitted in hospitals to treat alcohol intoxication, obtained alcohol in commercial places in about half of the cases, mainly in supermarkets and bars (Van Hoof et al., 2010). If compliance were higher, underage youth would be less able to consume alcohol (excessively), alcohol intoxication would decrease, and many related negative consequences would also disappear (i.e., costs, addiction, and disease).

\subsection{ACKNOWLEDGMENTS}

We would like to thank the youth alcohol prevention program 'Samen aan de slag, tegen riskant alcoholgebruik van jongeren in de Gooi en Vechtstreek' [Working together, against youth alcohol abuse in the Gooi and Vechtstreek region] (representing 9 municipalities) for facilitating this research. 
"Never accept a drink from a urologist."

Erma Louise Bombeck (1927 -1996) - American humorist 
General Discussion

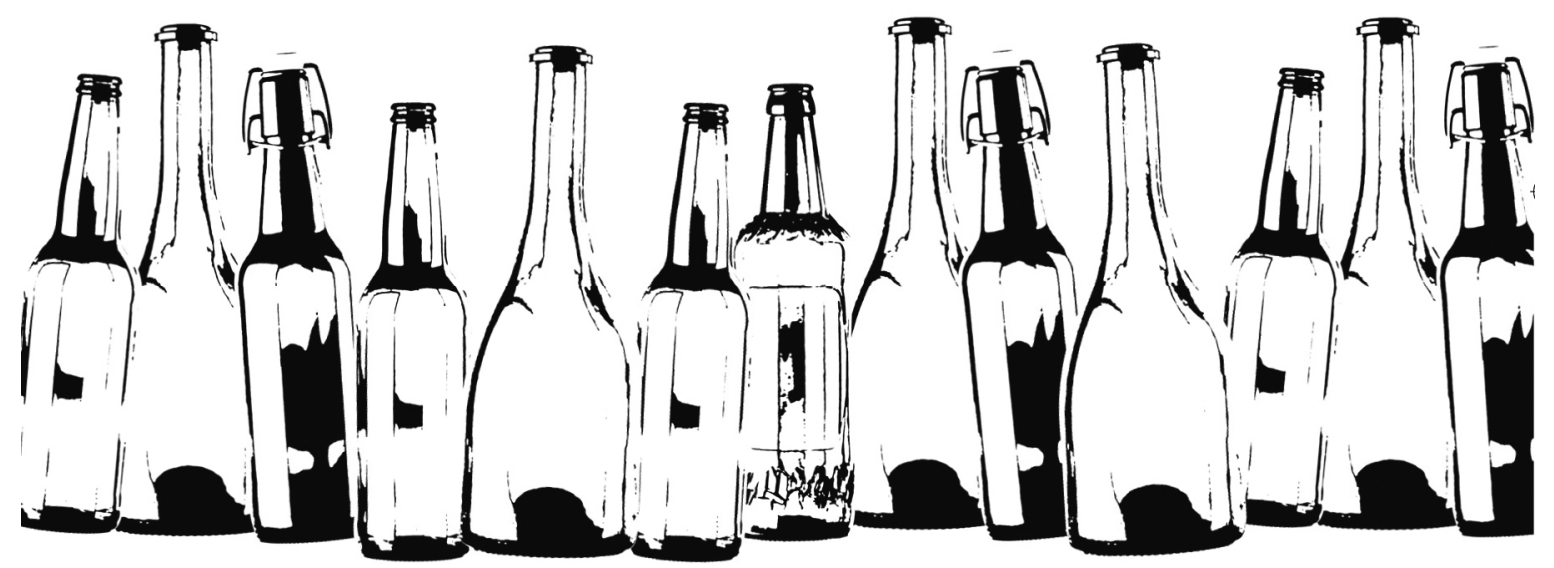




\subsection{MAIN FINDINGS PER STUDY}

Figure II: Outline of the studies in this dissertation

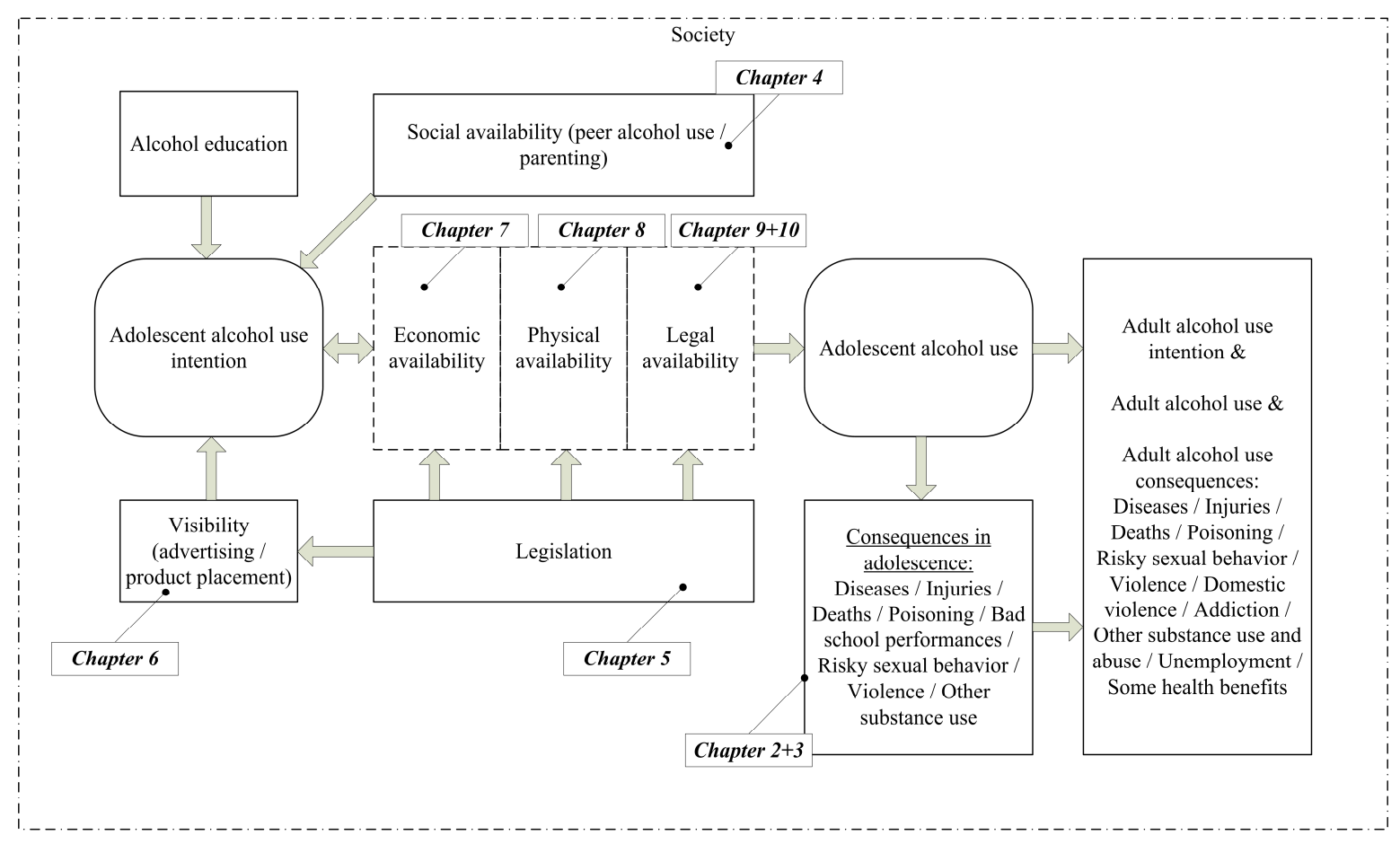

\section{Chapters 2 and 3}

In these chapters, the first two years of a study designed to monitor the prevalence and characteristics of adolescent alcohol intoxications treated in Dutch hospital Centers of Pediatrics is described. The study showed that the problem of alcohol intoxication in adolescents was evident in the Netherlands and that the numbers over 2007 and 2008 were worrisome. In total, a number of 634 adolescents were admitted to Centres of Paediatrics in Dutch hospitals for treatment of alcohol related incidents, especially alcohol intoxication. These intoxications are serious enough that hospital treatment is necessary. Within the study, a variety of factors on the specific adolescents, such as the level of intoxication, the treatment received, and their drinking patterns, were analysed. It was striking to see that the adolescents involved were not addicted or problematic adolescents, but rather average teens. Apparently, these teens got involved in a drinking event that degraded into excessive consumption and alcohol intoxication. These excesses were serious enough that these adolescents needed to stay at least one night at the hospital. Treatment with IV fluids was needed in almost all cases. Additionally, these teens had Blood Alcohol Concentrations 
(BACs) of approximately $1.8 \mathrm{~g} / \mathrm{L}$ (gram alcohol / litre blood), which meant they had an amount of alcohol in their blood equal to 10 to 15 glasses (depending on, among others, body fluids) of alcohol-containing beverages. Furthermore, these teens may have consumed more alcohol because the liver may have already processed the first couple of drinks, and the last couple of drinks were still in the stomach (not yet in the blood).

\section{Chapter 4}

This study was designed to highlight severe alcohol-related incidents (both positive and negative) in the lives of Dutch adolescents. In qualitative interviews, young adolescents were asked about alcohol-related incidents they either experienced or observed. Young people were found to have already experienced many serious events concerning alcohol use and abuse. The adolescents which were interviewed (average age: 15.4 years old) had experienced a total of 145 alcohol related incidents, which is 3.2 incidents per participant. In many cases, parents were not aware of the incidents, and if they were aware they often responded mildly. When adolescents tried to make sense of alcohol-related events, they appeared to have the tendency to interpret adverse affects of alcohol positively, and to be reluctant to translate negative experiences into lower drinking intentions. In all, the study shows that alcohol use and abuse is deeply rooted in the lives of 15- and 16-year-old adolescents.

\section{Chapter 5}

In this study, we questioned over 1,500 parents about their opinions on adolescent alcohol abuse, perceived negative consequences, norms on adolescent alcohol use, and their support of several alcohol control policies. It was discovered that these parents judged that the Dutch situation of adolescent alcohol use (i.e. young starting ages and high quantities of alcohol use) was indeed problematic. Parents also strongly supported the norm that youth under 16 years of age should not consume alcohol at all. Furthermore, parents strongly supported initiatives on both national and regional levels to further implement alcohol control policies. Examples of policies that were strongly supported include 'give higher fines to shops that sell alcohol to under-aged customers', 'make regional and local alcohol policies', and 'ban pre-mixed beverages from supermarkets, and only sell these drinks in liquor stores'. The support for these measures was explained by regression 
analyses that showed that the degree to which parents judged the adolescent drinking situation to be worrisome was the strongest predictor for policy support.

\section{Chapter 6}

In this chapter, a content analysis and an experiment concerning the depiction of alcohol in a popular Dutch soap opera were described. In the first study, 40 episodes of the soap serie were analyzed with special attention to alcohol cues, drinking situations, type and amount of alcohol consumed, as well as the time of the day in the series at which alcohol was consumed. A coding scheme was used for this content analysis and counted 177 alcoholic beverages in these 40 episodes, which represented 4.4 drinks per episode. About $35 \%$ of the drinks represented alcohol misuse, $4 \%$ of the drinks were consumed in the morning, and only 2 of the 20 (also young) characters did not drink in any of the 40 episodes.

In the second study, an experiment was conducted in order to explore the extent to which these alcohol depictions might influence young viewers. In this study alcohol 'product placement' was compared with traditional commercials in a $2 * 2$ post-test design (alcohol commercials / soda commercials * 'wet' soap series * 'dry' soap series). In a school, 248 pupils were randomly selected and shown one of the four tapes. With the full cooperation of the school, and using a complex scheme, it was possible to show whole classes the tapes at the same time. After the viewing, students filled in a questionnaire on alcohol use intentions. Students who were exposed to alcohol commercials turned out to be more positive about alcohol compared to students who saw soda commercials.

With the two versions of the soap series, significant differences were also found, contrary to what was expected. Students who were exposed to the high alcohol consumption soap series turned out to be more negative about alcohol and also have lower alcohol consumption intentions compared to student who saw a completely alcohol-free soap opera series. To further investigate this outcome, debriefing sessions were organised, and it was found that the young students judged a couple of scenes as exaggerated negative alcohol consumption events. This study demonstrated that alcohol depiction, besides traditional commercials, can influence alcohol consumption intention in young viewers but that the way specific scenes are judged needs further investigation. 


\section{Chapter 7}

In this chapter, a study consisting of three parts to investigate alcohol discounts in the Dutch catering industry and its effect on availability was presented. The first study was an observation study in which 209 cafes were visited in five cities across the Netherlands. Within these 209 cafes, in 65 cafes, a total of 122 price discounts on alcohol were discovered. About $45 \%$ of these discounts were offered on a weekly basis. The second study was a content analysis of 256 café websites. Price discounts were also available on the internet, and over half of the discounts were offered on a weekly basis. Most discounts (71\%) were visible both on the cafe websites and in the café itself.

To explore the effects of these types of price actions, 409 students were questioned. These young people reported using, on average, eight alcohol-discounts a year and up to one price discount every week for to some respondents. Respondents also reported they explicitly chose cafes that had alcohol price discounts when going out, and they also reported that they consumed more drinks in comparison to when they do not visit price discount places.

\section{Chapter 8}

In the Netherlands, so called 'barracks' are an increasingly popular phenomenon, especially in rural areas. Barracks are situated in an old trailer, caravan, container, shed, barn, basement, or factory building and serve as gathering places where youth, adolescents and sometimes adults hang out and share time. In this chapter, three studies designed to investigate the barracks phenomenon are described. In the first study, 51 barracks were visited in order to conduct a qualitative study. From this field study, it became clear that barracks were very diverse in the way they looked and operated. Some barracks were 'innocent' places, such as sheds in the backyard where adolescents were watching television, playing games, and drinking Coke. At the other end of the spectrum, some barracks turned out to be illegal pubs, with professional bar installations, paying systems, and security measures. In all barracks, alcohol was cheaper than in the catering industry because the (alcoholic) drinks were bought at the supermarket.

In the second study, the websites of 442 barracks were analyzed. One of the main findings from this analysis was that alcohol and alcohol use were undoubtedly connected with 
barracks and their websites. Both in the pictures and text of the websites, alcohol was dominantly visible. Almost 50 websites also depicted commercial signs from alcohol brands.

In a third study, over 1,400 students were questioned, aged 15 to 17 years old, in one region with a lot of barracks on their barrack-visiting behaviour and alcohol use. It was discovered that barracks visitors consume more alcohol and have consumed more alcohol in the past.

\section{Chapter 9}

In chapter 9, a study is presented on an aspect of the legal availability of alcohol; compliance levels on age limits in Dutch supermarkets and liquor stores. At the end of 2006, a method of mystery shopping to assess compliance in the Netherlands was developed. Teams of trained 15-year-old and 17-year-old so called mystery shoppers visited 150 supermarkets and 150 liquor stores across the Netherlands. In the supermarkets and in 75 liquor stores, the 15-year-old mystery shoppers tried to purchase a soft alcoholic beverage, and in the 75 remaining liquor stores the 17-year-olds tried to buy strong $(>15 \%$ alcohol) spirits. Of all 300 purchase attempts, compliance was found to be $14 \%$. In the liquor stores, a difference between the purchase of strong alcohol by 17 -year-olds $(11 \%$ compliance) and the purchase of soft alcoholic beverages by 15-year-olds (23\% compliance) was found. Supermarkets, on the other hand, complied in $12 \%$ of the cases. Out of the 300 purchase attempts, the vendor asked for age 13 times, identification 36 times or both 35 times. In the 13 cases where age was asked and the under-aged mystery shoppers lied that they had reached the legal age of 16 of age (as instructed), alcohol was always sold. In cases where ID was also verified, on which the date of birth showed that the mystery shoppers were too young to purchase alcohol, still $39 \%$ of the purchase attempts were authorised.

\section{Chapter 10}

To improve compliance levels, we started experimenting in 2009 with interventions to support sales personnel. In this study a field experiment was presented which explored an intervention used to improve compliance on alcohol sales to minors. In 146 alcohol outlets compliance levels were measured for a zero-measurement (again using mystery shopping 
based on the protocol developed in the study described in chapter 9). As an intervention, half of the shops (experimental group) were sent an intervention letter with the shop's individual result of the zero-measurement of the mystery shopping and with information on how to better estimate buyer's ages and comply more often. After this intervention, all shops ( $\mathrm{N}=138$, eight shops were closed) were again visited to establish compliance levels. In the experimental group (receiving the intervention), compliance significantly increased from $18.1 \%$ in the zero-measurement to $32.4 \%$ in the second wave of mystery shopping. In the control group, however, compliance did not change. These results showed that a rather simple intervention could change human behaviour and lead to better compliance.

After the second wave of mystery shopping the intervention letter was also sent to the shops in the control group. Finally, all shops $(\mathrm{N}=106,40$ shops did not want to participate or did not speak Dutch or English) were interviewed on how the intervention was handled within the organisation. In general, it was concluded that compliance and under-aged sales were paid serious attention and that the more intense the intervention was handled (in the experimental group), the higher the chance of compliance in the second wave of mystery shopping.

\subsection{GENERAL CONCLUSIONS}

In the past few decades, over 100,000 studies on alcohol use have been published in scientific journals. Studies on predictors were mainly designed on studying single relations or correlations (for instance, the effects of alcohol commercials on adolescent alcohol consumption). These findings are clearly important and help us to better understand the behaviour of adolescent alcohol consumption.

\section{Complex reality}

In practice, however, reality is more complex. In the previous example of adolescents exposed to and influenced by alcohol commercials, the effects are hard to predict in practice because other personality factors and external driving and restraining forces are playing a role in the behaviour. In the example, not only are the specific contents of the 
commercials and the frequency of exposure to the alcohol commercials factors, but the intelligence of the adolescents and the way they process information are also factors. Even when alcohol consumption intentions might increase, peer pressure and practical circumstances also play a role.

The factors are complex because they are all interconnected. If, for instance, the age limit for alcohol sales would be increased to 18 of age for all alcohol-containing beverages, this will have effects in the short term on alcohol sales within all age groups under 18 years of age (i.e. for 16- to 17-year-olds because it is now forbidden to sell them alcohol and for 14and 15-year-olds because they would be further away from the new age limit).

In addition, long-term effects will also appear. For instance, it is imaginable that parenting might be influenced by a new 18-year-old age limit, and parents might increase the 'first sip of alcohol at home' from 15 up to 17 years of age (both one year under the age limit). It is also possible that alcohol education programs in schools would shift one year up, or that alcohol commercials would change their target audiences. Perhaps an increase in the age limit would cause changes in the prices of alcohol because older (and richer) people are now the target audience. Finally, this example of an increase in the age limit on alcohol sales might influence other aspects of society and consumption. If youth are not allowed to go to bars under the age of 18 , more adolescents may choose to go to sport clubs or cinemas; soft drink companies may develop new drinks, and computer game designers might produce new games.

The diverse pallet of studies in this dissertation shows that predicting adolescent alcohol use is more complex than initially anticipated.

\section{Adolescent alcohol consumption consequences}

With respect to alcohol intoxication treatments in Dutch hospitals (chapters 2 and 3), the situation is worrisome. The year 2007 was not a year of many incidents because even more adolescents were treated in 2008. It is not plausible that this increase was only due to better registration in the data collection system by paediatric doctors because (a) we did not see 
an increase in admissions within the year 2007 and (b) for other diseases in the system, reliability checks showed good results.

In addition to the admissions numbers, some characteristics of adolescent admissions also shifted in 2008. Compared to 2007, the average age of the adolescents admitted was younger, the BAC was higher, and the time of reduced consciousness was longer in 2008. These three key indicators may not be statistically significant, but the direction of these indicators is troublesome. Adding to the worry, 500 alcohol intoxication cases were reported in Dutch hospitals for 2009 (Van Dalen, Van Hoof, Van der Lely, \& Rodrigues Pereira, 2009).

The number of adolescents treated in Dutch hospitals in this study was a serious underestimation of the real number of children becoming intoxicated from alcohol consumption. This is because (a) not all paediatricians participated in the NSCK observational system and were therefore not in the study, (b) not all children suffering from alcohol intoxication were treated by a paediatrician and (c) not all children suffering from alcohol intoxication were hospitalised but were treated at home or by another doctor. Therefore, the real number of children suffering from alcohol intoxication is expected to be much higher.

To help better establish the number of adolescents consuming alcohol leading to severe alcohol intoxication, our study in which we asked about alcohol incidents (chapter 4) might be useful. For each incident, we asked about the main consequences for the respondent. Getting sick and losing consciousness (or blacking out) were reported as the main consequences of the incidents. In our sample of 55 interviewees, losing consciousness or blacking out was reported to be the most important consequence 9 times. When one out of six adolescents suffers from blacking out once in the timeframe of 12 to 16 years of age, the number of 500 admitted adolescents a year admitted to Dutch Departments of Paediatrics in 2009 might even be an underestimation.

\section{Availability}

The studies in chapters $7,8,9$, and 10 clearly showed that availability might function as a barrier to, as well as a predictor for, adolescent alcohol use. The economic availability 
(price discounts) studied in chapter 7 demonstrated that adolescents were influenced by happy hours and other price discounts. In addition, adolescents reported that lower prices of alcoholic drinks triggered them to consume more alcohol.

From the barracks study reported in chapter 8, it became clear that physical availability in the barracks stimulated adolescents to consume alcohol. We did not focus on the low alcohol prices in the barracks (economic availability) or the lack of parental supervision (social availability), but these factors may also be relevant to adolescent alcohol use.

In the last two chapters, legal availability in the form of compliance with the legal age limit of the Netherlands was described. Adolescents who had not reached the legal age limit of 16 years-of-age (for low-alcohol-containing beverages) or 18 years-of-age (for strong alcoholic beverages) were not sufficiently rejected from commercial places when they tried to obtain alcohol. The studies reported in chapters 9 and 10 showed compliance rates with respect to under-age alcohol sales varying from $9 \%$ up to $32 \%$. In other studies we have conducted (Van Hoof, \& Baas, 2009; Van Hoof, Mulder, Gosselt, Van Poppel, \& De Jong, 2008a; Van Hoof, Van Poppel, Mulder, \& Baas, 2008b), compliance rates reached a maximum of $50 \%$ in small subsets of these studies (e.g. one specific supermarket brand or a small village). In general, sport canteens and the catering industry had the lowest compliance rates (up to $20 \%$ maximum), while fast food restaurants, liquor shops and supermarkets sometimes reached levels up to 50\%. Therefore, from a health promotion point of view, the different alcohol outlets should be looked at separately for intervention.

More research is needed to further investigate adolescent behaviour with respect to alcohol purchases. In sport canteens, for instance, adolescents are familiar with the sales personnel (often volunteer parents) who are not that strict about selling beer to under-age strangers, but they might be stricter with familiar under-age customers. Additionally, it was reported that sport canteen sales personnel sold alcohol to people under the legal age limit but that after one or two drinks, this service stopped. Another issue with respect to sport canteens is that adolescents were not reported to drink excessively in these locations. This observation is in line with the results discussed in chapters 2 and 3, as we did not observe intoxicated adolescents who had drunk themselves unconscious at a sports canteen. 
Unfortunately, we do not know how important fast food restaurants are in under-aged alcohol consumption, but in line with sports canteens, we did not observe intoxicated people coming from fast food restaurants in our hospital data reported in chapters 2 and 3. The catering industry, however, had a paradoxical role. On the one hand, the compliance rates were the worst in all our studies (Van Hoof, \& Baas, 2009; Van Hoof et al., 2008a; Van Hoof et al., 2008b), but on the other hand, alcohol was rather expensive (compared to supermarkets), and some sort of supervision was available. Nevertheless, about a third of the children admitted for alcohol intoxication drank their final alcoholic drink within the catering industry.

These data suggest that (a) compliance rates are indeed worrisome because the majority of the treated adolescents were under the age of 16 and that (b) supervision does not work efficiently. When the 2009 statistics on adolescent alcohol intoxication are included, about 300 adolescents could be saved by better catering industry compliance. Also identified from this study were two important off-premises sales points: liquor stores and supermarkets. Young people may buy alcohol at these locations for rather cheap prices and then consume it at separate public or private places. Despite compliance rates up to $50 \%$, these places should have full attention for the improvement of compliance.

\section{Alcohol attitudes}

An interesting question our critical incidents study (chapter 4) raised was that most of these incidents were evaluated as positive experiences by the adolescents despite the fact that rather serious consequences were experienced. In the Netherlands, hospitals are currently setting up special alcohol aftercare institutes in order to educate previously intoxicated adolescents and their parents to try to avoid future intoxications. When young people do not take this education seriously, however, these treatments are not effective and a waste of (public) money.

Public 'no to alcohol' initiatives are not very common in the Netherlands. As a result, youth in the Netherlands saying 'no' to alcohol and drugs is a small minority versus a bigger stream in, for instance, the U.S.A. This phenomenon might be due to the different alcohol cultures present in Europe. In the northern countries (Norway, Finland, Sweden, Denmark, and Iceland), the legislation is stricter, the prices are higher, and there is 
significant home brewing. The eastern countries (Poland, Romania, Bulgaria, Ukraine, Slovakia, Hungary, Serbia, and Czech Republic) have lower prices, less regulation, and also a lot of home brewing, but not as much adolescent drinking. The southern countries in Europe (Italy, Greece, Spain, Portugal, and France) are more laid back in their regulations, as they have an eating and drinking culture where they drink more wines and also earlier in the day. The western countries (Netherlands, United Kingdom, Ireland, Germany, and Belgium), by comparison, have a lot of designer drinks, and drinking is not always combined with meals. In these countries, adolescents go out to drink and, as described in chapter 7, they develop special places (barracks) to cheaply drink alcohol. These barracks are very common, are sometimes designed and used in a very professional way, and are often supported by parents.

The critical incident study, the barracks study, and the study in which we questioned parents about their opinions on alcohol control policies were a first hint of what could called the 'alcohol paradox'. In this paradox, both adolescents and parents seem to have two contradicting attitudes, strict and serious on the one hand and loose and light on the other hand. Parents do support governmental alcohol control policies, parents are strict with respect to age limits, parents state that current youth alcohol consumption is problematic, but on the other hand, parents support their children and other youth drinking in barracks. Adolescents are serious when they are questioned about their alcohol use, but when it comes to behaviour and behavioural changes, adolescents continue their risk behaviour. 


\subsection{FUTURE RESEARCH DIRECTIONS}

This dissertation explored a variety of factors influencing adolescent alcohol consumption behaviour, as well as one of the most serious direct consequences following from excessive alcohol consumption: alcohol intoxication treatments. For the future, the following directions seem interesting for further exploration.

\section{The 'real' alcohol world of adolescents}

Further research is needed in 'the adolescent world of alcohol'. A lot of research has clearly been done on drinking data, drinking locations, the purchase of alcoholic beverages, peer influence, and parenting styles among adolescents. However, more qualitative research methods are rarely used. The studies we conducted by having interviews with adolescents about alcohol experiences (chapter 4), as well as the observations in the barracks (chapter 8), give great insight into the 'real' world of adolescents and their (risk) behaviour.

In addition, we need further research to understand what motivates Dutch (as well as other western European) adolescents to have these 'drink to drink' and 'coma drinking' attitudes. From our point of view, qualitative research methods are preferred here.

\section{Parents}

It was striking to learn that parents seem to have two different attitudes. On the one hand, parents support stronger and stricter governmental alcohol control policies (as described in chapter 5), but on the other hand, parents are sometimes involved in adolescent alcohol incidents (chapter 4), and some actively support drinking in barracks (chapter 8). For example, in all three studies, parents were more or less involved. These attitudes may be in line with 'not in my backyard' principles. When you ask parents about problems (including alcohol misuse) with adolescents, they say 'these problems exists, and adolescents drink too much, but my kid is doing o.k.' This may explain why parents may support governmental regulations in general (on a national level), but when alcohol education comes in to their own family situation, parents ignore the problems or even increase them. Research shows that parents who are strict and do not allow their child to drink have fewer 
problem children. However, despite ongoing debates on this in the media, a lot of parents stick to the opinion that it is better to teach your child to drink to prevent them from becoming problem drinkers.

\section{Compliance}

Our studies demonstrated that compliance rates with alcohol sales regulations in youth are low. The study in chapter 10 illustrated that compliance rates can be improved but that this needs further study.

Despite the broad use of the term compliance rates, they are not a representative instrument to predict or monitor the factual availability of alcohol for under-aged youth. In the real world, youth who want to obtain alcohol do not stop trying after they are rejected once. This means that a compliance rate of $50 \%$ in a neighbourhood with four shops is not $50 \%$, but $50 \% * 50 \% * 50 \% * 50 \%=6.3 \%$. After four tries, if s/he still has not succeeded in buying alcohol, s/he starts again at another pay desk. After four more tries, the chance that alcohol has been purchased is now 99.99\%. In practice, youth who want to purchase alcohol likely know in which store it is easiest to obtain alcohol. If it is known which two shops out of those four sell alcohol to under-aged youth, the compliance rate then drops to $0 \%$.

As demonstrated in chapter 10, however, it is possible to increase compliance rates by interventions, such as an intervention letter. These increases are rather small, though, and will gradually disappear over time. Despite national campaigns and training by the Dutch Food Retail Association (CBL - Centraal Bureau Levensmiddelen), compliance rates are still under 50\% (Van Hoof, \& Baas, 2009; Van Hoof et al., 2008a; Van Hoof et al., 2008b). In March 2009 the CBL introduced a national campaign in which the consumers were also targeted and instructed to show their identification card if they were less than 20 years of age when they wanted to purchase alcoholic beverages in supermarkets.

To further combat poor compliance, only low-alcohol-containing drinks are sold in supermarkets, so there is only one age limit there; 16 years old. On a website designed and owned by the CBL (www.supermarkt.nl), the national campaign is explained to give supermarkets a better tool to avoid under-aged alcohol sales. The websites says: 'because it 
is difficult to estimate young people's ages, the age at which people are required to identify themselves will be increased to 20 years old.' On the same website, a training program is available and can be used by supermarket personnel. From an outsider's perspective, the two populations targeted are a strange combination.

The legislation in the Netherlands clearly states that the alcohol sales personnel are required to verify someone's age (by asking for an identity card) if it is not certain that the person has reached the legal age limit. Therefore, it is a good idea to communicate this legislation to the public to avoid people who are over 16, but look younger, from becoming angry that they are asked for identity cards when they want to purchase alcohol. This argument, in particular, is the one used by alcohol sales personnel and supermarkets represented by the CBL. However, the possible side effects of asking identity cards from people are not studied and therefore cannot analyse this argument. Because alcohol problems and youth drinking are such large issues in the Netherlands, a side effect that some younger looking people are unnecessarily asked for an identification card does not seem that important.

Another side effect this campaign might cause is that the public opinions on responsibility and alcohol sales might shift. Under this campaign (also broadcast on television), young people are clearly given the responsibility to show identity cards when under 20 years of age instead of the sellers having the responsibility to ask for identity cards. Another pitfall of the campaign is that only asking for identity cards is not enough. Our mystery shopping studies revealed that when potential customers are asked for an identification card, alcohol sales are still authorised in about half of the cases. This occurred despite the depicted day of birth stating that the mystery shoppers were too young. We need more research, for instance, on other ID card designs (e.g. with different colour cards or lay-out, as in some U.S. states) to investigate this strange outcome.

\section{Legislation}

As reported in chapter 6, happy hours and price discounts on alcohol are very common in the Dutch catering industry. About $31 \%$ of the 209 cafes visited offered some type of price discount. The websites of the cafés analysed also showed similar results. On $25 \%$ of the 256 websites analysed, price discounts on alcohol were dominantly displayed. This was 
surprising since the Dutch Advertising Code clearly states that commercial alcohol messages should be aimed at an adult audience. Despite the fact that the alcohol discounts in cafes and on café websites are not targeted at adolescents only, they still reach youth on a large scale. Additionally, the cafes we visited were places where youth congregated, and the adolescents we questioned here report that these discounts influenced them. From a social science researcher's point of view, it's hard to imagine that café owners don't know these discounts also affect young customers. In fact, it could be possible that some price discounts are aimed at young people. For the future, more research will be aimed at more in dept studies on investigating the sales and advertising of alcohol in relation to legislation and socially responsible entrepreneurship.

My research over the past few years also targeted my interest in the legislation on a national level. In the Netherlands, many organisations are involved in the alcohol debate, both in the public eye and behind the scenes. Within this alcohol debate, more and more interest has been grown in how legislation is formed and what different organisations, people and political parties contribute to the process, especially the role of individual persons and alcohol industry brands in lobbying and the influence they have will be explored. 


\section{References}

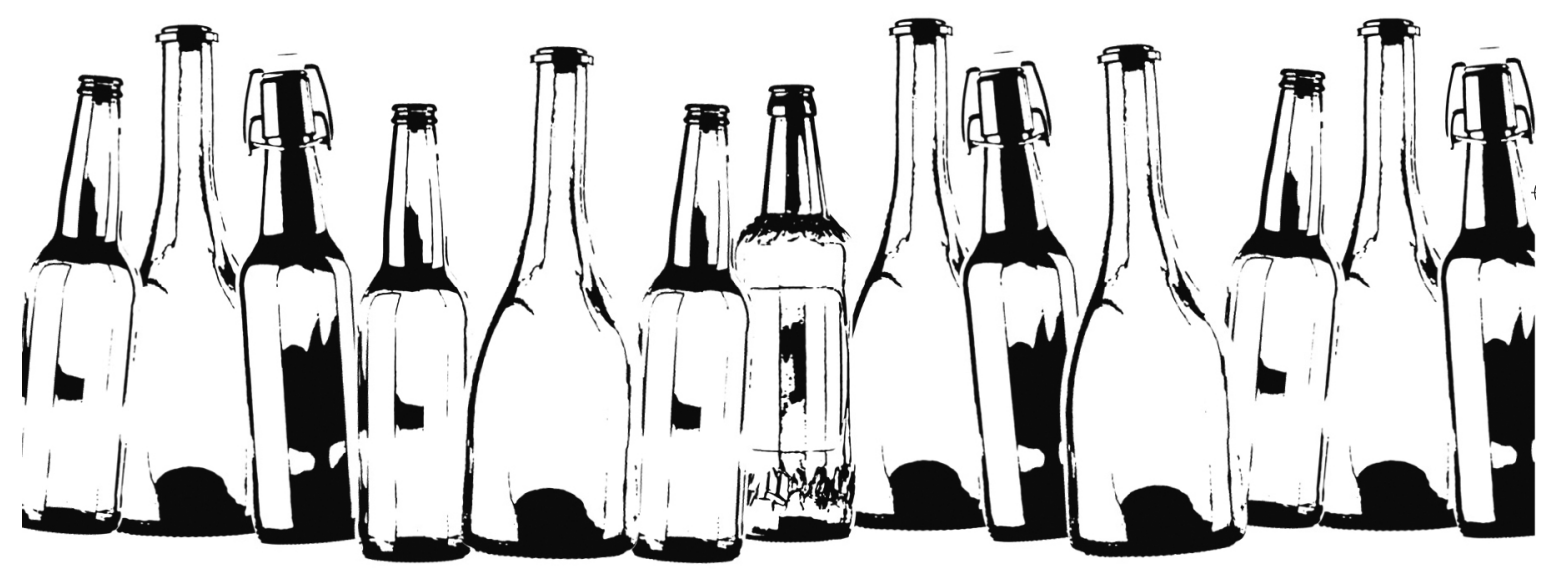


Abar, C., \& Turrisi, R. (2008). How important are parents during the college years? A longitudinal perspective of indirect influences parents yield on their college teens' alcohol use. Addictive Behaviors, 33, $1360-1368$.

Abbey, A. McAuslan, P., \& Ross, L. T. (1998). Sexual assault perpetration by college men: The role of alcohol, misperception of sexual intent, and sexual beliefs and experiences. Journal of Social and Clinical Psychology, 17,167-195.

Adlaf, E. M., \& Kohn, P. M. (1989). Alcohol advertising, consumption and abuse: A covariance-structural modelling look at Strickland's data. British Journal of Addiction, 84, 749-757.

Adrian, M. (1988). Social costs of alcohol. Canadian Journal of Public Health, 79, 316-322.

Ahlawat, S. K., \& Siwach, S. B. (1994). Alcohol and coronary artery disease. International Journal of Cardiology, 44, 157-162.

Aitken, P. P., Eadie, D. R., Leathar, D. S., McNeill, R. E. J., \& Scott, A. C. (1988a). Television advertisements for alcoholic drinks do reinforce under-age drinking. British Journal of Addiction, 83, 13991419.

Aitken, P. P., Leathar, D. S., \& Scott, A. C. (1988b). Ten- to sixteen-year-olds' perceptions of advertisements for alcoholic drinks. Alcohol and Alcoholism, 23, 491-500.

Ajani, U. A., Gaziano, J. M., Lotufo, P. A., Liu, S., Hennekens, C. H., Buring, J. E., \& Manson, J. E. (2000). Alcohol consumption and risk of coronary heart disease by diabetes status. Circulation, 102, 500-505.

Ajzen, I. (1991). The theory of planned behavior. Organizational Behavior and Human Decision Processes, 50, 179-211.

Akhter, M., Kuriyama, S., Nakaya, N., Shimazu, T., Ohmori, K., Nishino, Y., Tsubono, Y., Fukao, A., \& Tsuji, I. (2007). Alcohol consumption is associated with an increased risk of distal colon and rectal cancer in Japanese men: The Miyagi Cohort Study. European Journal of Cancer, 43, 383-390.

Amdur, M. A. (1975). Alcohol-related problems in a general hospital emergency room. Illinois Medical Journal, 148, 509-510.

Anderson, P., \& Baumberg, P. (2006). Alcohol in Europe. A public health perspective. London, UK: Institute of Alcohol studies. 
Applegate, B. K., Cullen, F. T., Barton, S. M., Richards, P. J., Lanza-Kaduce, L., \& Link, B. G. (1995). Public support for drunk-driving countermeasures: social policy for saving lives. Crime \& Delinquency, 41, 171-190.

Arico, S., Galatola, G., Tabone, M., \& Corrao, G. (1994). Amount and duration of alcohol intake in patients with chronic liver disease: An Italian multicentre study. Italian Journal of Gastroenterology, 26, 59-65.

Arthur, D. (2001). The effects of the problem-based alcohol early-intervention education package on the knowledge and attitudes of students of nursing. Journal of Nursing Education, 40, 63-72.

Ary, D. V., Tildesley, E., Hops, H., \& Andrews, J. (1993). The influence of parent sibling, and peer modelling and attitudes on adolescent use of alcohol. The International Journal of the Addictions, 28, 853880.

Athyros, V. G., Liberopoulos, E. N., Mikhailidis, D. P., Papageorgiou, A. A., Ganotakis, E. S., Tziomalos, K., Kakafika, A. I., Karagiannis, A., Lambropoulos, S., \& Elisaf, M. (2008). Association of drinking pattern and alcohol beverage type with the prevalence of metabolic syndrome, diabetes, coronary heart disease, stroke, and peripheral arterial disease in a Mediterranean cohort. Angiology, 58, 689-697.

Atkin, C. K. (1990). Effects of televised alcohol messages on teenage drinking patterns. Journal of Adolescent Health Care, 11, 10-24.

Atkin, C., Hocking, J., \& Block, M. (1984). Teenage drinking: Does advertising make a difference? Journal of Communication, 34, 157-167.

Austin, E. W., Chen, M. J., \& Grube, J. W. (2006). How does alcohol advertising influence underage drinking? The role of desirability, identification and scepticism. Journal of Adolescent Health, 38, 376-384.

Austin, E., \& Knaus, C. (2000). Predicting the potential for risky behavior among those `too young` to drink as the result of appealing advertising. Journal of Health Communication, 5, 13-27.

Babor, T. F., Caetano, R., Casswell, S., Edwards, G., Giesbrecht, N., Graham, K., Grube, J. W., Gruenewald, P. J., Hill, L., Holder, H. D., Homel, R., Österberg, E., Rehm, J., Room, R. \& Rossow, I. (2003). Alcohol: No Ordinary Commodity. Oxford, UK: Oxford University Press.

Bagnall, G. (1990). Alcohol education for 13 years old - does it work? Results from a controlled evaluation. British Journal of Addiction, 85, 89-96. 
Bagnardi, V., Blangiardo, M., La Vecchia, C.., \& Corrao, G. (2001). A meta-analysis of alcohol drinking and cancer risk. British Journal of Cancer, 85, 1700-1705.

Bagnardi, V., Zatonski, Scotti, L., La Vecchia, C., \& Corrao, G. (2008). Does drinking pattern modify the effect of alcohol on the risk of coronary heart disease? Evidence from a meta-analysis. Journal of Epidemiology and Community Health, 62, 615-619.

Baker, T. K., Johnson, M. B., Voas, R. B., \& Lange, J. E. (2000). To Reduce Youthful Binge Drinking: Call an Election in Mexico. Journal of Safety Research, 31, 61-69.

Bako, G., Mackenzie, W. C., \& Smith, E. S. (1976). The effect of legislated lowering of the drinking age on fatal highway accidents among young drivers in Alberta, 1970-1972. Canadian Journal of Public Health, 67, 161-163.

Bardou, M., Montembault, S., Giraud, V., Balian, A., Borotto, E., Houdayer, C., Capron, F., Chaput, J. C., \& Naveau, S. (2002). Excessive alcohol consumption favours high risk polyp or colorectal cancer occurrence among patients with adenomas: A case control study. Gut, 50, 38-42.

Bargh, J. A., Chen, M., \& Burrows, L. (1996). Automaticity of social behavior: Direct effects of trait construct and stereotype activation on action. Journal of Personality and Social Psychology, 71, 230-244.

Barnes, G. M., \& Welte, J. W. (1986). Patterns and predictors of alcohol use among 7-12th grade students in New York State. Journal of Studies on Alcohol, 47, 53-62.

Barnes, G. M., Hoffman, J. H., Welte, J. W., Farrell, M. P., \& Dintcheff, B. A. (2006). Effects of parental monitoring and peer deviance on substance use and delinquency. Journal of Marriage and Family, 68, 10841104.

Barnes, G. M., Reifman, A. S., Farrell, M. P., \& Dintcheff, B. A. (2000). The effects of parenting on the development of adolescent alcohol misuse: A six-wave latent growth model. Journal of Marriage and Family, 62, 175-186.

Barnett, N. P., Monti, P. M., Cherpitel, C., Bendtsen, P., Borges, G., Colby, S. M., Nordqvist, C., \& Johansson, K. (2003). Identification and brief treatment of alcohol problems with medical patients: An International perspective. Alcoholism, Clinical and Experimental Research, 27, 262-270.

Bar-on, M. E. (2000). The effects of television on child health: Implications and recommendations. Archive of Disease in Childhood, 83, 289-292. 
Beck, K. H., \& Treiman, K. A. (1996). The relationship of social context of drinking, perceived social norms, and parental influence to various drinking patterns of adolescents. Addictive Behaviours, 21, 633-644.

Bell, A. C., Ge, K., \& Popkin, B. M. (2001). Weight gain and its predictors in Chinese adults. International Journal of Obesity, 25, 1079-1086.

Bieleman, B., Biesma, S., Kruize, A., \& Snippe, J. (2004). Monitor Alcoholverstrekking Jongeren 2003. Naleving Leeftijdsgrenzen 16 en 18 Jaar: Metingen 1999, 2001 en 2003. [Monitor Alcohol Supply Adolescents. Compliance with Age Restrictions 16 and 18 Years: Measurements 1999, 2001, and 2003.] Groningen, The Netherlands: Intraval.

Bieleman, B., Kruize, A., \& Zimmerman, C. (2010). Monitor Alcoholverstrekking Jongeren 2009. Naleving leeftijdsgrenzen 16 en 18 jaar Drank- en Horecawet: tweejaarlijkse metingen 1999-2009. [Monitor Alcohol Supply Adolescents. Compliance with age restrictions 16 and 18 Years: two-year measurements 1999-2009.] Groningen, The Netherlands: Intraval.

Bloss, G. (2006). Measuring the health consequences of alcohol consumption: Current needs and methodological challenges. Digestive Diseases, 23, 162-169.

Bongaerts, B. W. C., Van Den Brandt, P. A., Goldbohm, R. A., De Goeij, A. F. P. M., Weijenberg, M. P. (2008). Alcohol consumption, type of alcoholic beverage and risk of colorectal cancer at specific subsites. International Journal of Cancer, 123, 2411-2417.

Bongers, I. M. B., Van de Goor, I. A. M., \& Garretsen, H. F. L. (1998). Social climate on alcohol in Rotterdam, the Netherlands: public opinions on drinking behaviour and alcohol control measures. Alcohol \& Alcoholism, 32, 141-150.

Bonomo, Y. A., Bowes, G., Coffey, C., Carlin, J. B., \& Patton, G. C. (2004). Teenage drinking and the onset of alcohol dependence: A cohort study over seven years. Addiction, 99, 1520-1528.

Borzekowski, D. L. G. (1996). Embedded anti-alcohol messages on commercial television: What teenagers perceive. Journal of Adolescent Health, 19, 345-352.

Borzekowski, D. L. G., \& Poussaint A. F. (1999). Public service announcement perceptions - A quantitative examination of anti-violence messages. American Journal of Preventive Medicine, 17, 181-188.

Bot, S. M., Engels, R. C. M. E., Knibbe, R. A., \& Meeus, W. H. J. (2007). Pastime in a pub: observations of young adults' activities and alcohol consumption. Addictive Behaviors, 32, 491-504. 
Boyle, R. G., Claxton, A. J., \& Forster, J. L. (1997). The role of social influences and tobacco availability on adolescent smokeless tobacco use. Journal of Adolescent Health, 20, 279-285.

Brewer, R. D., Morris, P. D., Cole, T. B., Watkins, S., Patetta, M. J., \& Popkin, C. (1994). The risk of dying in alcohol-related automobile crashes among habitual drunk drivers. New England Journal of Medicine, 331, 513-517.

Britt, H., Toomey, T. L., Dunsmuir, W., \& Wagenaar, A. C. (2006). Propensity for and correlates of alcohol sales to underage youth. Journal of Alcohol \& Drug Education, 50, 25-42.

Brown, J. D., \& Witherspoon, E. M. (2002). The mass media and American adolescents' health. Journal of Adolescent Health, 31, 153-170.

Brown, S. A., Tapert, S. F., Granholm, E., \& Delis, D. C. (2000). Neurocognitive functioning of adolescents: Effects of protracted alcohol use. Alcoholism: Clinical and Experimental Research, 24, 164-171.

Busselle, R. W. (2001). Television exposure, perceived realism, and exemplar accessibility in the social judgment process. Media Psychology, 3, 43-67.

Caspi, A., Moffitt, T. E., Newman, D. L., \& Silva, P. A. (1996). Behavioral observations at age 3 years predict adult psychiatric disorders: Longitudinal evidence from a birth cohort. Archives of General Psychiatry, 53, 1033-1039.

Cassell, J. (1980). Ethical principles for conducting fieldwork. American Anthropologist, 83, 28-41.

Casswell, S. (2004). Alcohol brands in young peoples' everyday lives: new developments in marketing. Alcohol \& Alcoholism, 39, 471-476.

Casswell, S., \& Maxwell, A. (2005). Regulation of alcohol marketing: A global view. Journal of Public Health Policy, 26, 343-358.

Casswell, S., \& Zhang, J. F. (1998). Impact of liking for advertising and brand allegiance on drinking and alcohol-related aggression: A longitudinal study. Addiction, 93, 1209-1217.

CBS (2005a) http://statline.cbs.nl/StatWeb/publication/?VW=T\&DM=SLNL\&PA=37312\&D1=a\&D2=a,!1$\underline{4, ! 6-7 \& H D=090218-1136 \& H D R=G 1 \& S T B=T}$

CBS (2005b) http://statline.cbs.nl/StatWeb/publication/?DM=SLNL\&PA=37312\&D1=0-32,35$69 \& \mathrm{D} 2=10 \& \mathrm{HDR}=\mathrm{G} 1 \& \mathrm{STB}=\mathrm{T} \& \mathrm{VW}=\mathrm{T}$ 
Centers for Disease Control and Prevention. (n.d.). Alcohol-Related Disease Impact 2008. Retreived November 10, 2009, from http://www.cdc.gov/alcohol/ardi.htm.

Centraal Bureau voor de Statistiek (2006) [Statistics Netherlands]. Reported Health and Lifestyle. Retrieved January 5, 2006, from http://statline.cbs.nl.

Chaiken, S., \& Bargh, J. A. (1993). Occurrence versus moderation of the automatic attitude activation effect: reply to Fazio. Journal of Personality and Social Psychology, 64, 759-765.

Chaloupka, F. J., \& Wechsler, H. (1996). Binge drinking in college: The impact of price, availability, and alcohol control policies. Contemporary Economic Policy, 14, 112-124.

Chaloupka, F. J., Saffer, H., \& Grossman, M. (1993). Alcohol-Control Policies and Motor-Vehicle Fatalities. Journal of Legal Studies, 22, 161-186.

Chatterji, P. (2006). Does alcohol use during high school affect educational attainment?: Evidence from the National Education Longitudinal Study. Economics of Education Review, 25, 482-497.

Chen, M. J., Gruenewald, P. J., \& Remer, L. G. (2009). Does Alcohol Outlet Density Affect Youth Access to Alcohol? Journal of Adolescent Health, 44, 582-589.

Cheng, K. K., Duffy, S. W., Day, N. E., Lam, T. H., Chung, S. F., \& Badrinath, P. (1995). Stopping drinking and risk of oesophageal cancer. British Medical Journal, 310, 1094-1097.

Cherpitel, C. J. (1993). Alcohol and injuries: A review of international emergency room studies. Addiction, $88,923-937$.

Cherpitel, C. J., Meyers, A. R., \& Perrine, M. W. (1998). Alcohol consumption, sensation seeking and ski injury: A case-control study. Journal of Studies on Alcohol, 59, 216-221.

Chikritzhs, T., \& Stockwell, T. (2002). The impact of later trading hours for Australian public houses (hotels) on levels of violence. Journal of Studies on Alcohol, 63, 591-599.

Cho, E., Smith-Warner, S. A., Ritz, J., Van Den Brandt, P. A., Colditz, G. A., Folsom, A. R., Freudenheim, J. L., Giovannucci, E., Goldbohm, R. A., Graham, S., Holmberg, L., Kim, D. H., Malila, N., Miller, A. B., Pietinen, P., Rohan, T. E., Sellers, T. A., Speizer, F. E., Willett, W. C., Wolk, A., \& Hunter, D. J. (2004). Alcohol Intake and Colorectal Cancer: A Pooled Analysis of 8 Cohort Studies. Annals of Internal Medicine, $140,603-613$. 
Chou, S. P., \& Pickering, R. P. (1992). Early onset of drinking as a risk factor for lifetime alcohol-related problems. British Journal of Addiction, 87, 1199-1204.

Christenson, P. G., Henriksen, L., \& Roberts, D. F. (2000). Substance use in popular prime time television. Office of National Drug Control Policy: Mediascope.

Christie, J., Fisher, D., Kozup, J. C., Smith, S., Burton, S., \& Creyer, E. H. (2001). The effects of barsponsored alcohol beverage promotions across binge and nonbinge drinkers. Journal of Public Policy \& Marketing, 20, 240-253.

Chung, W. J., Chun, H. J., \& Lee, S. M. (2006). Socioeconomic costs of alcohol drinking in Korea. Journal of preventive medicine and public health = Yebang Ǔihakhoe chi., 39, 21-29.

Clapper, R. L., Buka, S. L., Goldfield, E. C., Lipsitt, L. P., \& Tsuang, M. T. (1995). Adolescent problem behaviors as predictors of adult alcohol diagnoses. International Journal of the Addictions, 30, 507-523.

Cleophas, T. J. (1999). Wine, beer and spirits and the risk of myocardial infarction: A systematic review. Biomedicine and Pharmacotherapy, 53, 417-423.

Collins, D., \& Cellucci, T. (1991). Effects of a school-based alcohol education program with a media prevention component. Psychological Reports, 69, 191-197.

Collins, R. L., Ellickson, P. L., McCaffrey, D. F., \& Hambarsoomians, K. (2005). Saturated in beer: Awareness of beer advertising in late childhood and adolescence. Journal of Adolescent Health, 37, 29-36.

Collins, R. L., Ellickson, P. L., McCaffrey, D., \& Hambarsoomians, K. (2007). Early Adolescent Exposure to Alcohol Advertising and Its Relationship to Underage Drinking. Journal of Adolescent Health, 40, 527-534.

Comeau, N., Stewart, S. H., \& Loba, P. (2001). The relations of trait anxiety, anxiety sensitivity, and sensation seeking to adolescents' motivations for alcohol, cigarette, and marijuana use. Addictive Behaviors, $26,803-825$.

Commission for Distilled Spirits (n.d.). World Drink Trends 2005 Edition. Henley-on-Thames: World Advertising Research Center Ltd.

Conner, M., \& McMillan, B. (1999). Interaction effects in the theory of planned behaviour: Studying cannabis use. The British Journal of Social Psychology, 38, 195-222. 
Conner, M., Graham, S., \& Moore, B. (1999). Alcohol and intentions to use condoms: applying the theory of planned behaviour. Psychology \& Health, 14, 795-812.

Connolly, G. M., Casswell, S., Zhang, J. F., \& Silva, P. A. (1994). Alcohol in the mass media and drinking by adolescents: A longitudinal study. Addiction, 89, 1255-1263.

Conway, K. P., Compton, W., Stinson, F. S., \& Grant, B. F. (2006). Lifetime comorbidity of DSM-IV mood and anxiety disorders and specific drug use disorders: Results from the National Epidemiologic Survey on Alcohol and Related Conditions. Journal of Clinical Psychiatry, 67, 247-257.

Cook, P. J. (1993). Drinking and schooling. Journal of Health Economics, 12, 411-429.

Cook, P. J., \& Tauchen, G. (1982). The Effect of Liquor Taxes on Heavy Drinking. Bell Journal of Economics, 13, 379-390.

Corrao, G., Aricò, S., Zambon, A., Torchio, P., \& Di Orio, F. (1997). Female sex and the risk of liver cirrhosis. Scandinavian Journal of Gastroenterology, 32, 1174-1180.

Corrao, G., Bagnardi, V., Zambon, A., \& Arico, S. (1999). Exploring the dose-response relationship between alcohol consumption and the risk of several alcohol-related conditions: A meta-analysis. Addiction, 94, 15511573.

Corrao, G., Bagnardi, V., Zambon, A., \& La Vecchia, C. (2004). A meta-analysis of alcohol consumption and the risk of 15 diseases. Preventive Medicine, 38, 613-619.

Corrao, G., Bagnardi, V., Zambon, A., \& Torchio, P. (1998). Meta-analysis of alcohol intake in relation to risk of liver cirrhosis. Alcohol and Alcoholism, 33, 381-392.

Corrao, G., Rubbiati, L., Bagnardi, V., Zambon, A., \& Poikolainen, K. (2000). Alcohol and coronary heart disease: A meta-analysis. Addiction, 95, 1505-1523.

Cullen, F. T., Wright, J. P., Brown, S., Moon, M. M., Blankenship, M. B., \& Applegate, B. K. (1998). Public support for early intervention programs: implications for a progressive policy agenda. Crime \& Delinquency, 44, 187-204.

Cummings, K. M., Saunders-Martin, T., Clarke, H., \& Perla, J. (1996). Monitoring vendor compliance with tobacco sales laws: Payment vs. no payment approaches. American Journal of Public Health, 86, 750-751. 
Dal Cin, S., Worth, K. A., Dalton, M. A., \& Sargent, J. D. (2008). Youth exposure to alcohol use and brand appearances in popular contemporary movies. Addiction, 103, 1925-1932.

De Bellis, M. D., Clark, D. B., Beers, S. R., Soloff, P. H., Boring, A. M., Hall, J., Kersh, A., \& Keshavan, M. S. (2000). Hippocampal volume in adolescent-onset alcohol use disorders. American Journal of Psychiatry, 157, 737-744.

De Cuyper, N., Kiran, S., De Witte, H., \& Aygoglu, F. N. (2008). Associations between temporary employment, alcohol dependence and cigarette smoking among Turkish health care workers. Economic and Industrial Democracy, 29, 388-405.

De Lint, J., \& Schmidt, W. (1971). Consumption averages and alcoholism prevalence; a brief review of epidemiological investigations. British Journal of Addiction, 66, 97-107.

De Micheli, D., \& Formigoni, M. L. O. S. (2004). Drug use by Brazilian students: Associations with family, psychosocial, health, demographic and behavioral characteristics. Addiction, 99, 570-578.

Deakin, S., \& Cohen, E. (1986). Alcohol attitudes and behaviors of freshmen and their parents. Journal of College Student Personnel, 27, 490-495.

Degenhardt, L., Hall, W., \& Lynskey, M. (2001). Alcohol, cannabis and tobacco use among australians: A comparison of their associations with other drug use and use disorders, affective and anxiety disorders, and psychosis. Addiction, 96, 1603-1614.

Dench, S., Iphofen, R., \& Huws, U. (2004). An EU Code of Ethics for Socio-Economic Research. IES Report 412. Brighton, UK: Institute for Employment Studies.

Dent, C. W., Grube, J. W., \& Biglan, A. (2005). Community level alcohol availability and enforcement of possession laws as predictors of youth drinking. Preventive Medicine, 40, 355-362.

Denzin, N. K., \& Erikson, K. T. (1982). On the ethics of disguised observation: An exchange. In: M. Bulmer (Eds.), Social research ethics: An examination of the merits of covert participant observation (pp. 142-151). London, UK: MacMillan.

Devlin, N. J., Scuffham, P. A., \& Bunt, L. J. (1997). The social costs of alcohol abuse in New Zealand. Addiction, 92, 1491-1505.

DeVore, E. R., \& Ginsburg, K. R. (2005). The protective effects of good parenting on adolescents. Current Opinion in Pediatrics, 17, 460-465. 
DeWit, D. J., Adlaf, E. M., Offord, D. R., \& Ogborne, A. C. (2000). Age at first alcohol use: A risk factor for the development of alcohol disorders. American Journal of Psychiatry, 157, 745-750.

Deykin, E. Y., Levy, J. C., \& Wells, V. (1987). Adolescent depression, alcohol and drug abuse. American Journal of Public Health, 77, 178-182.

DiCicco, L., Biron, R., \& Carifio, J. (1984). Evaluation of the CASPAR alcohol education curriculum. Journal of Studies on Alcohol, 45, 160-169.

Dijck, D., \& Knibbe, R. A. (2005). De prevalentie van probleemdrinken in Nederland; een algemeen bevolkingsonderzoek [prevalence of problematic alcohol use in the Netherlands; a medical examination of the population]. Maastricht, The Netherlands: Maastricht University.

Discover Health (2010). How Alcohol Works. Retreived August 13, 2010, from: http://health.howstuffworks.com/wellness/drugs-alcohol/alcohol5.htm

Dishion, T. J., \& Loeber, R. (1985). Adolescent marijuana and alcohol use: The role of parents and peers revisited. American Journal of Drug and Alcohol Abuse, 11, 11-25.

Doll, R., Peto, R., Hall, E., Wheatley, K., \& Gray, R. (1994). Mortality in relation to consumption of alcohol: 13 years' observations on male British doctors. British Medical Journal, 309, 911-918.

Donohew, R. L., Hoyle, R. H., Clayton, R. R., Skinner, W. F., Colon, S. E., \& Rice, R. E. (1999). Sensation seeking and drug use by adolescents and their friends: Models for marijuana and alcohol. Journal of Studies on Alcohol, 60, 622-631.

Downs, C. W., \& Adrian, A. D. (2004). Assessing organizational communication; Strategic communication audits. London, UK: Guildford.

Duailibi, S. Ponicki, W., Grube, J., Pinsky, I., Laranjeira, R., \& Raw, M. (2007). The effect of restricting opening hours on alcohol-related violence. American Journal of Public Health, 97, 2276-2280.

Dumouchel, W., Williams, A. F., \& Zador, P. L. (1987). Raising the alcohol purchase age. The Journal of Legal Studies, 16, 249-266.

Dunn, C., Zatzick, D., Russo, J., Rivara, R., Roy-Byrne, P., Ries, R., Wisner, D., \& Genitello, L. (2003). Hazardous drinking by trauma patients during they ear after injury. The Journal of Trauma, 54, 707-712. 
Duryea, E. J., \& Okwumabua, J. O. (1988). Effects of a preventive alcohol education program after three years. Journal of Drug Education, 18, 23-31.

Duryea, E., Mohr, P., Newman, I. M., Martin, G. L., \& Egwaoje, E. (1984). Six-months follow-up results of a preventive alcohol education intervention. Journal of Drug Education, 14, 97-104.

Ebbert, J. O., Janney, C. A., Sellers, T. A., Folsom, A. R., \& Cerhan, J. R. (2005). The association of alcohol consumption with coronary heart disease mortality and cancer incidence varies by smoking history. Journal of General Internal Medicine, 20, 14-20.

Edwards, G. (1997). Alcohol policy and the public good. Addiction, 92, S73-S79.

Edwards, G., Anderson, P. L., Babor, T. F., Casswell, S., Ferrence, R., Giesbrecht, N., Godfrey, C., Holder, H. D., Lemmens, P., Mäkelä, K., Midanik, L. T., Norström, T., Österberg, E., Romelsjö, A., Room, R., Simpura, J., \& Skog, O. J. (1994). Alcohol Policy and the Public Good. Oxford, UK: University Press.

Ellickson, P. L., \& Bell, R. M. (1990). Drug prevention in junior high: A multi-site longitudinal test. Science, 247, 1299-1305.

Ellickson, P. L., Collins, R. L., Hambarsoomians, K., \& McCaffrey, D. F. (2005). Does alcohol advertising promote adolescent drinking? Results from a longitudinal assessment. Addiction, 100, 235-246.

Ellickson, P. L., Tucker, J. S., \& Klein, D. J. (2003). Ten-year prospective study of public health problems associated with early drinking. Pediatrics, 111, 949-955.

Ellickson, P. L., Tucker, J. S., Klein, D. J., \& McGuigan, K. A. (2001). Prospective risk factors for alcohol misuse in late adolescence. Journal of Studies on Alcohol, 62, 773-782.

Engels, R. C. M. E., Hermans, R., Van Baaren, R. B., Hollenstein, T., \& Bot, S. M. (2009). Special issue: The message and the media: Alcohol portrayal on television affects actual drinking behaviour. Alcohol and Alcoholism, 44, 244-249.

Engels, R. C. M. E., Knibbe, R. A., De Vries, H., Drop, M. J., \& Van Breukelen, G. J. P. (2006). Influences of Parental and Best Friends' Smoking and Drinking on Adolescent Use: A Longitudinal Study. Journal of Applied Social Psychology, 29, 337-361.

ESOMAR (2005). ESOMAR World Research Codes \& Guidelines: Mystery Shopping Studies. http://www.esomar.org/uploads/pdf/ESOMAR_Codes\&Guidelines_MysteryShopping.pdf (Accessed November 10, 2006). 
Everett, S. A., Schnuth, R. L., \& Tribble, J. L. (1998). Tobacco and alcohol use in topgrossing American films. Journal of Community Health, 23, 317-324.

Exum, M. L. (2006). Alcohol and aggression: An integration of findings from experimental studies. Journal of Criminal Justice, 34, 131-145.

Fabian, L. E. A., Toomey, T. L., Lenk, K. M., \& Erickson, D. J. (2008). Where do underage college students get alcohol? Journal of Drug Education, 38, 15-26.

Farrell, S., Manning, W. G., \& Finch, M. D. (2003). Alcohol dependence and the price of alcoholic beverages. Journal of Health Economics, 22, 117-147.

Fenoglio, P., Parel, V., \& Kopp, P. (2003). The social cost of alcohol, tobacco and illicit drugs in France, 1997. European Addiction Research, 9, 18-28.

Fergusson, D. M., Horwood, L. J., \& Lynskey, M. T. (1995). The prevalence and risk factors associated with abusive or hazardous alcohol consumption in 16-year-olds. Addiction, 90, 935-946.

Fergusson, D. M., Lynskey, M. T., \& Horwood, L. J. (1996). Alcohol misuse and juvenile offending in adolescence. Addiction, 91, 483-494.

Ferrari, P., Jenab, M., Norat, T., Moskal, A., Slimani, N., Olsen, A., Tjønneland, A., Overvad, K., Jensen, M. K., Boutron-Ruault, M. C., Clavel-Chapelon, F., Morois, S., Rohrmann, S., Linseisen, J., Boeing, H., Bergmann, M., Kontopoulou, D., Trichopoulou, A., Kassapa, C., Masala, G., Krogh, V., Vineis, P., Panico, S., Tumino, R., Van Gils, C. H., Peeters, P., Bueno-de-Mesquita, H. B., Ocké, M. C., Skeie, G., Lund, E., Agudo, A., Ardanaz, E., López, D. C., Sanchez, M. J., Quirós, J. R., Amiano, P., Berglund, G., Manjer, J., Palmqvist, R., Van Guelpen, B., Allen, N., Key, T., Bingham, S., Mazuir, M., Boffetta, P., Kaaks, R., \& Riboli, E. (2007). Lifetime and baseline alcohol intake and risk of colon and rectal cancers in the European Prospective Investigation into Cancer and Nutrition (EPIC). International Journal of Cancer, 121, 2065 2072.

Fillmore, K. M., Golding, J. M., Graves, K. L., Kniep, S., Leino, E. V., Romelsjö, A., Shoemaker, C., Ager, C. R., Allebeck, P., \& Wilsnack, S. (1998). Alcohol consumption and mortality. III. Studies of female populations. Addiction, 93, 219-229.

Finn, A., \& Kayandé, U. (1999). Unmasking a phantom: A psychometric assessment of mystery shopping. Journal of Retailing, 75, 195-217. 
Fishbein, M., \& Ajzen, I. (1975). Belief, Attitude, Intention, and Behavior: An Introduction to Theory and Research. Reading, MA: Addison-Wesley.

Fisher, L. B., Miles, I. W., Austin, S. B., Camargo Jr., C. A., \& Colditz, G. A. (2007). Predictors of initiation of alcohol use among US adolescents: Findings from a prospective cohort study. Archives of Pediatrics and Adolescent Medicine, 161, 959-966.

Flanagan, J. C. (1954). The critical incident technique. Psychological Bulletin, 51, 327-358.

Flay, B. R. (1993). Youth tobacco use: Risks, patterns, and control. In: J. Slade \& C. T. Orleans (Eds.), Nicotine addiction: Principles and management (pp. 365-384). New York, NY: Oxford University Press.

Flynn, B. S., Worden, J. K., Bunn, J. Y., Dorwaldt, A. L., Dana, G. S., \& Callas, P. W. (2006). Mass media and community interventions to reduce alcohol use by early adolescents. Journal of Studies on Alcohol, 67, 66-74.

Forster, J. L., McGovern, P. G., Wagenaar, A. C., Wolfson, M., Perry, C. L., \& Anstine, P. S. (1994). The ability of young people to purchase alcohol without age identification in northeastern Minnesota, USA. Addiction, 89, 699-705.

Forster, J. L., Murray, D. M., Wolfson, M., Blaine, T. M., Wagenaar, A. C., \& Hennrikus, D. J. (1998). The effect of community policies to reduce youth access to tobacco. American Journal of Public Health, 88, 1193-1198.

Foxcroft, D. R., Ireland, D., Lister-Sharp, D. J., Lowe, G., \& Breen, R. (2003). Longer-term primary prevention for alcohol misuse in young people: A systematic review. Addiction, 98, 397-411.

Foxcroft, D. R., Lister-Sharp, D., \& Lowe, G. (1997). Alcohol misuse prevention for young people: A systematic review reveals methodological concerns and lack of reliable evidence of effectiveness. Addiction, 92, 531-537.

Franceschi, S., Levi, F., Dal Maso, L., Talamini, R., Conti, E., Negri, E., \& La Vecchia, C. (2000). Cessation of alcohol drinking and risk of cancer of the oral cavity and pharynx. International Journal of Cancer, 85, 787-790.

Freisthler, B., Greunewald, P. J., Treno, A. J., \& Lee, J. (2003). Evaluating alcohol access and the alcohol environment in neighborhood areas. Alcoholism, Clinical and Experimental Research, 27, 477-484. 
Friedman, L. A., \& Kimball, A. W. (1986). Coronary heart disease mortality and alcohol consumption in Framingham. American Journal of Epidemiology, 124, 481-489.

Friese, B., \& Grube, J. (2008). Differences in drinking behavior and access to alcohol between native american and white adolescents. Journal of Drug Education, 38, 273-284.

Fromme, K., Alan Marlatt, G., Baer, J. S., \& Kivlahan, D. R. (1994). The alcohol skills training program: A group intervention for young adult drinkers. Journal of Substance Abuse Treatment, 11, 143-154.

Furnham, A., Ingle, H., Gunter, B., \& McClelland, A. (1997). A content analysis of alcohol portrayal and drinking in British television soap operas. Health Education Research, 12, 519-529.

Garfield, C. F., Chung, P. J., \& Rathouz, P. J. (2003). Alcohol Advertising in Magazines and Adolescent Readership. Journal of the American Medical Association, 289, 2424-2429.

George, W. H., Crowe, L. C., Abwender, D., \& Skinner, J. B. (1989). Effects of raising the drinking age to 21 years in New York State on self-reported consumption by college students. Journal of Applied Social Psychology, 19, 623-635.

Gerbner, G., Gross, L., Morgan, M., \& Signoreilli, N. (1986). Living with television: The dynamics of the cultivation process. In: J. Bryant \& D. Zillman (Eds.), Perspectives on Media Effects. Hillsdale, NJ: Lawrence Erlbaum.

Ghaeni, L. (2008). Alcohol consumption in patients with epilepsy - Completely off-limits? [Alkohol bei patienten mit epilepsie - Komplett verboten?]. PsychoNeuro, 34, 258-261.

Giancola, P. R. (2002). Alcohol-related aggression during the college years: Theories, risk factors and policy implications. Journal of Studies on Alcohol, Supplement, 14, 129-139.

Giesbrecht, N., \& Greenfield, T. K. (1999). Public opinions on alcohol policy issues: a comparison of American and Canadian surveys. Addiction, 94, 521 - 531.

Gigleux, I., Gagnon, J., St-Pierre, A., Cantin, B., Dagenais, G. R., Meyer, F., Després, J. P., \& Lamarche, B. (2006). Moderate alcohol consumption is more cardioprotective in men with the metabolic syndrome. Journal of Nutrition, 136, 3027-3032.

Gilman, S. E., \& Abraham, H. D. (2001). A longitudinal study of the order of onset of alcohol dependence and major depression. Drug and Alcohol Dependence, 63, 277-286. 
Ginzler, J. A., Cochran, B. N., Domenech-Rodríguez, M., Cauce, A. M., \& Whitbeck, L. B. (2003). Sequential progression of substance use among homeless youth: An empirical investigation of the gateway theory. Substance Use and Misuse, 38, 725-758.

Glynn, S. A., Albanes, D., Pietinen, P., Brown, C. C., Rautalahti, M., Tangrea, J. A., Taylor, P. R., Virtamo, J. (1996). Alcohol consumption and risk of colorectal cancer in a cohort of Finnish men. Cancer Causes and Control, 7, 214-223.

Golub, A., Labouvie, E., \& Johnson, B. D. (2000). Response reliability and the study of adolescent substance use progression. Journal of Drug Issues, 30, 103-118.

Goodstadt, M. S., Sheppard, M. A., \& Chan, G. C. (1982). An evaluation of two school-based alcohol education programs. Journal of Studies on Alcohol, 43, 352-369.

Gordon, E., \& Devinsky, O. (2001). Alcohol and marijuana: Effects on epilepsy and use by patients with epilepsy. Epilepsia, 42, 1266-1272.

Gordon, T., \& Doyle, J. T. (1986). Alcohol consumption and its relationship to smoking, weight, blood pressure, and blood lipids. The Albany Study. Archives of Internal Medicine, 146, 262-265.

Gosselt, J. F., Van Hoof, J. J., \& De Jong, M. D. T. (2007). Alcohol en jongeren in Zuidoost-Brabant. Nulmeting nalevingsonderzoek en draagvlakonderzoek. [Alcohol and youth in Zuidoost-Brabant: A baseline compliance and policy support study.] Enschede, The Netherlands: University of Twente.

Gosselt, J. F., Van Hoof, J. J., De Jong, M. D. T., \& Prinsen, S. (2007). Mystery Shopping and Alcohol Sales: Do Supermarkets and Liquor Stores Sell Alcohol to Underage Customers? Journal of Adolescent Health, 41, 302-308.

Graham, J. W., Marks, G., \& Hansen, W. B. (1991). Social Influence Processes Affecting Adolescent Substance Use. Journal of Applied Psychology, 76, 291-298.

Grant, B. F., \& Dawson, D. (1997). Age at Onset of Alcohol Use and its Association with DSM-IV Alcohol Abuse and Dependence: Results from the National Longitudinal Alcohol Epidemiologic Survey. Journal of Substance Abuse, 9, 103-110.

Grant, B. F., \& Harford, T. C. (1995). Comorbidity between DSM-IV alcohol use disorders and major depression: Results of a national survey. Drug and Alcohol Dependence, 39, 197-206. 
Grant, B. F., Stinson, F. S., \& Harford, T. C. (2001). Age at onset of alcohol use and DSM-IV alcohol abuse and dependence: A 12-year follow-up. Journal of Substance Abuse, 13, 493-504.

Grant, B. F., Stinson, F. S., Dawson, D. A., Chou, S. P., Dufour, M. C., Compton, W., Pickering, R. P., \& Kaplan, K. (2004). Prevalence and co-occurrence of substance use disorders and independent mood and anxiety disorders: Results from the national epidemiologic survey on alcohol and related conditions. Archives of General Psychiatry, 61, 807-816.

Grant, J. D., Scherrer, J. F., Lynskey, M. T., Lyons, M. J., Eisen, S. A., Tsuang, M. T., True, W. R., \& Bucholz, K. K. (2006). Adolescent alcohol use is a risk factor for adult alcohol and drug dependence: Evidence from a twin design. Psychological Medicine, 36, 109-118.

Greenfield, T. K. (1993). Reasons for abstaining or limiting drinking: U.S. national trends between 1984 and 1990. Paper presented at the annual meeting of the research society on alcoholism, San Antonio, Texas.

Gronbaek, M. (2004). Epidemiologic evidence for the cardioprotective effects associated with consumption of alcoholic beverages. Pathophysiology, 10, 83-92.

Grønbæk, M. N., Becker, P. U., Johansen, D., Tønnesen, H., Jensen, G., \& Sørensen, T. I. A. (1999). Alcohol and upper digestive tract cancer. Results from prospective populations studies I [Alkohol og øvre gastrointestinal cancer Resultater fra Hovedstadens Center for Prospektive Befolkningsstudier]. Ugeskrift for Laeger, 161, 6196-6199.

Gronbaek, M., Becker, U., Johansen, D., Gottschau, A., Schnohr, P., Hein, H. O., Jensen, G., \& Sorensen, T. I. A. (2000). Type of alcohol consumed and mortality from all causes, coronary heart disease, and cancer. Annals of Internal Medicine, 133, 411-419.

Grossman, M., Chaloupka, F. J., Saffer, H., \& Laixuthai, A. (1994). Effects of alcohol price policy on youth: A summary of economic research. Journal of Research on Adolescence, 4, 357-364.

Grube, J. W. (1997). Preventing sales of alcohol to miners: Results from a community trial. Addiction, 92, S251-S260.

Grube, J. W., \& Waiters, E. (2005). Alcohol in the media: Content and effects on drinking beliefs and behaviors among youth. Adolescents Medicine Clinics, 16, 327-343.

Grube, J. W., \& Wallack, L. (1994). Television beer advertising and drinking knowledge, beliefs, and intentions among schoolchildren. American Journal of Public Health, 84, 254-259. 
Gruber, E. L., Thau, H. M., Hill, D. L., Fisher, D. A., Grube, J. W. (2005). Alcohol, tobacco and illicit substances in music videos: A content analysis of prevalence and genre. Journal of Adolescent Health, 37, 81-83.

Gruchow, H. W., Sobocinski, K. A., Barboriak, J. J., \& Scheller, J. G. (1985). Alcohol consumption, nutrient intake and relative body weight among US adults. American Journal of Clinical Nutrition, 42, 289-295.

Gruenewald, P. J., Ponicki, W. R., \& Holder, H. D. (1993). The relationship of outlet densities to alcohol consumption: A time series cross-sectional analysis. Alcoholism: Clinical and Experimental Research, 17, $38-47$.

Hanewinkel, R., Tanski, S. E., \& Sargent, J. D. (2007). Exposure to alcohol use in motion pictures and teen drinking in Germany. International Journal of Epidemiology, 36, 1068-1077.

Hansagi, H., Romelsjo, A., De Verdier, M. G., Andreasson, S., \& Leifman, A. (1995). Alcohol consumption and stroke mortality: 20-year follow-up of 15077 men and women. Stroke, 26, 1768-1773.

Hansen, A. (2003). The portrayal of alcohol and alcohol consumption in television news and drama programmes. A research report for Alcohol Concern. Leicester: University of Leicester, Centre for Mass Communication Research.

Harford, T. C., \& Grand, B. F. (1987). Psychosocial factors in adolescent drinking contexts. Journal of Studies on Alcohol, 48, 551-557.

Harnett, R., Herring, R., Thom, B., \& Kelly, M. (1999). Exploring young men's drinking using the AUDIT questionnaire. Alcohol and Alcoholism, 34, 672-677.

Harwood, H. J., Fountain, D., \& Livermore, G. (1998). Economic costs of alcohol abuse and alcoholism. Recent developments in alcoholism : an official publication of the American Medical Society on Alcoholism, the Research Society on Alcoholism, and the National Council on Alcoholism, 14, 307-330.

Hastings, G., Anderson, S., Cooke, E., \& Gordon, R. (2005). Alcohol marketing and young people's drinking: A review of the research. Journal of Public Health Policy, 26, 296-311.

Hauge, R., \& Irgens-Jensen, O. (1986). The relationship between alcohol consumption, alcohol intoxication and negative consequences of drinking in four Scandinavian countries. British Journal of Addiction, 81, 513524. 
Hauser, W. A., Ng, S. K. C., \& Brust, J. C. M. (1988). Alcohol, seizures, and epilepsy. Epilepsia, 29, S66S78.

Hearst, M. O., Fulkerson, J. A., Maldonado-Molina, M. M., Perry, C. L., \& Komro, K. A. (2007). Who needs liquor stores when parents will do? The importance of social sources of alcohol among young urban teens. Preventive Medicine, 44, 471-476.

Hemphill, S. A., Munro, G., \& Oh, S. (2007). Adolescents' expenditure on alcohol: A pilot study. Australian Journal of Social Issues, 42, 623-636.

Hennekens, C. H., Rosner, B., \& Cole, D. S. (1978). Daily alcohol consumption and fatal coronary heart disease. American Journal of Epidemiology, 107, 196-200.

Hibell, B., Andersson, B., Bjarnason, T., Ahlström, S., Balakireva, O., Kokkeve, A., \& Morgan, M. (2004). The ESPAD Report 2003: Alcohol and other drug use among students in 35 European countries. Stockholm, Sweden: The Swedish Council for Information on Alcohol and Other Drugs and the Pompidou Group of the Council of Europe.

Hiller-Sturmhöfel, S., \& Scott Swartzwelder, H. (2005). Alcohol's effects on the adolescent brain: What can be learned from animal models. Alcohol Research and Health, 28, 213-221.

Hilton, M. E., \& Kaskutas, L. (1991). Public support for warning labels on alcoholic beverage containers. British Journal of Addiction, 86, 1323-1333.

Hingson, R. W., \& Howland, J. (1987). Alcohol as a risk factor for injury or death resulting from accidental falls: a review of the literature. Journal of Studies on Alcohol, 48, 212-219.

Hingson, R. W., \& Winter, M. R. (2003). Epidemiology and Consequences of Drinking and Driving. Alcohol Research and Health, 27, 63-78.

Hingson, R. W., Heeren, T., \& Winter, M. R. (2006). Age at Drinking Onset and Alcohol Dependence; Age at Onset, Duration, and Severity. Archive of Pediatrics \& Adolescent Medicine, 160, 739-746.

Hingson, R. W., Heeren, T., \& Zakocs, R. C. (2001). Age of drinking onset and involvement in physical fights after drinking. Pediatrics, 108, 872-877.

Hingson, R. W., Heeren, T., Jamanka, A., \& Howland, J. (2000). Age of drinking onset and unintentional injury involvement after drinking. Journal of the American Medical Association, 284, 1527-1533. 
Hingson, R. W., Heeren, T., Winter, M. R., \& Wechsler, H. (2003). Early age of first drunkenness as a factor in college students' unplanned and unprotected sex attributable to drinking. Pediatrics, 111, 34-41.

Hingson, R. W., Heeren, T., Zakocs, R. C., Kopstein, A., \& Wechsler, H. (2002). Magnitude of alcoholrelated mortality and morbidity among U.S. College students ages 18-24. Journal of Studies on Alcohol, 63, 136-144.

Hingson, R. W., Heeren, T., Zakocs, R. C., Winter, M. R., \& Wechsler, H. (2003a). Age of first intoxication, heavy drinking, driving after drinking and risk of unintentional injury among U.S. college students. Journal of Studies on Alcohol, 64, 23-31.

Hingson, R. W., Strunin, L., Berlin, B. M., \& Heeren, T. (1990). Beliefs about AIDS, use of alcohol and drugs, and unprotected sex among Massachusetts adolescents. American Journal of Public Health, 80, 295299.

Hodges, L. W. (1988). Undercover, masquerading, surreptitious taping. Journal of Mass Media Ethics, 3, 2636.

Holder, H. D. (1998). Alcohol and the community. A systems approach to prevention. Cambridge, UK: Cambridge University Press.

Holman, C. D., English, D. R., Milne, E., \& Winter, M. G. (1996). Meta-analysis of alcohol and all-cause mortality: A validation of NHMRC recommendations. Medical Journal of Australia, 164, 141-145.

Hong, Y. C., Lee, K. H., Kim, W. C., Choi, S. K., Woo, Z. H., Shin, S. K., \& Kim, H. (2005).

Polymorphisms of XRCC1 gene, alcohol consumption and colorectal cancer. International Journal of Cancer, 116, 428-432.

Hopkins, R. H., Mauss, A. L., Kearney, K. A., \& Weisheit, R. A. (1988). Comprehensive evaluation of a model alcohol education curriculum. Journal of Studies on Alcohol, 49, 38-50.

Ikehara, S., Iso, H., Toyoshima, H., Date, C., Yamamoto, A., Kikuchi, S., Kondo, T., Watanabe, Y., Koizumi, A., Wada, Y., Inaba, Y., \& Tamakoshi, A. (2008). Alcohol consumption and mortality from stroke and coronary heart disease among Japanese men and women: The Japan collaborative cohort study. Stroke, 39, 2936-2942.

Istvan, J., Murray, R., \& Voelker, H. (1995). The relationship between patterns of alcohol consumption and body weight. International Journal of Epidemiology, 24, 543-546. 
Jackson, K. M., Sher, K. J., Cooper, M. L., \& Wood, P. K. (2002). Adolescent alcohol and tobacco use: Onset, persistence and trajectories of use across two samples. Addiction, 97, 517-531.

Jackson, M. C., Hastings, G., Wheeler, C., Eadiel, D., Mackintosh, A. M. (2000). Marketing alcohol to young people: Implications for industry regulation and research policy. Addiction, 95, S597-S608.

Jackson, R., Scragg, R., \& Beaglehole, R. (1991). Alcohol consumption and risk of coronary heart disease. British Medical Journal, 303, 211-216.

Jernigan, D. H., Ostroff, J., \& Ross, C. (2005). Alcohol advertising and youth: A measured approach. Journal of Public Health Policy, 26, 312-325.

Jernigan, D. H., Ostroff, J., Ross, C., \& O'Hara III, J. A. (2004). Sex differences in adolescent exposure to alcohol advertising in magazines. Archives of Pediatrics and Adolescent Medicine, 158, 629-634.

Ji, B. T., Dai, Q., Gao, Y. T., Hsing, A. W., McLaughlin, J. K., Fraumeni Jr., J. F., \& Chow, W. H. (2002). Cigarette and alcohol consumption and the risk of colorectal cancer in Shanghai, China. European Journal of Cancer Prevention, 11, 237-244.

Johnson, P. B., Boles, S. M., \& Kleber, H. D. (2000). The relationship between adolescent smoking and drinking and likelihood estimates of illicit drug use. Journal of Addictive Diseases, 19, 75-81.

Johnston, L., O’Malley, P. M., Bachman, J. G., \& Schulenberg, J. E. (2006). Monitoring the Future national results on adolescent drug use: Overview of key findings, 2005. Bethesda, MD: National Institute on Drug Abuse.

Jones, N. E., Pieper, C. F., \& Robertson, L. S. (1992). The effect of legal drinking age on fatal injuries of adolescents and young adults. American Journal of Public Health, 82, 112-115.

Jones, S., Casswell, S., \& Zhang, J. F. (1995). The economic costs of alcohol-related absenteeism and reduced productivity among the working population of New Zealand. Addiction, 90, 1455-1461.

Jones-Webb, R., Fabian, L. E. A., Harwood, E. M., Toomey, T. L., \& Wagenaar, A. C. (2004). Fatal injuries associated with alcohol use among youth and adults: 1990-1998. Journal of Child and Adolescent Substance Abuse, 14, 41-60.

Jones-Webb, R., Toomey, T., Miner, K., Wagenaar, A. C., Wolfson, M., \& Poon, R. (1997). Why and in what context adolescents obtain alcohol from adults: A pilot study. Substance Use and Misuse, 32, 219-228. 
Jones-Webb, R., Wagenaar, A., \& Finnegan, J. (1997). Designing a survey of public opinions regarding alcohol control policies among African American and white adults. Journal of Health Care for the Poor and Underserved, 8, 18-24.

Kaiser Family Foundation and Children Now (1997). Talking with kids about tough issues: A national survey. Palo Alto, CA: Henry J. Kaiser Family Foundation.

Kalichman, S. C., Cain, D., Zweben, A., \& Swain, G. (2003). Sensation seeking, alcohol use and sexual risk behaviors among men receiving services at a clinic for sexually transmitted infections. Journal of Studies on Alcohol, 64, 564-569.

Kalichman, S. C., Weinhardt, L., DiFonzo, K., Austin, J., \& Luke, W. (2002). Sensation seeking and alcohol use as markers of sexual transmission risk behavior in HIV-positive men. Annals of Behavioral Medicine, 24, 229-235.

Kaminer, Y., Burleson, J. A., \& Goldberger, R. (2002). Cognitive-behavioral coping skills and psychoeducation therapies for adolescent substance abuse. Journal of Nervous and Mental Disease, 190, 737745.

Kandel, D. B., Yamaguchi, K., \& Chen, K. (1992). Stages of progression in drug involvement from adolescence to adulthood: Further evidence for the gateway theory. Journal of Studies on Alcohol, 53, 447457.

Kannel, W. B., \& Ellison, R. C. (1996). Alcohol and coronary heart disease: The evidence for a protective effect. Clinica Chimica Acta, 246, 59-76.

Kato, I., Nomura, A. M. Y., Stemmermann, G. N., \& Chyou, P. H. (1992). Prospective study of the association of alcohol with cancer of the upper aerodigestive tract and other sites. Cancer Causes and Control, 3, 145-151.

Keil, U., Chambless, L. E., Döring, A., Filipiak, B., \& Stieber, J. (1997). The relation of alcohol intake to coronary heart disease and all-cause mortality in a beer-drinking population. Epidemiology, 8, 150-156.

Kenkel, D. S. (1993). Do Drunk Drivers Pay Their Way? A Note on Optimal Penalties for Drunk Driving. Journal of Health Economics, 36, 877-913.

Kim, D. H. (2007). The interactive effect of methyl-group diet and polymorphism of methylenetetrahydrofolate reductase on the risk of colorectal cancer. Mutation Research - Fundamental and Molecular Mechanisms of Mutagenesis, 622, 14-18. 
Kim, D. H., Ahn, Y. O., Lee, B. H., Tsuji, E., Kiyohara, C., \& Kono, S. (2004). Methylenetetrahydrofolate reductase polymorphism, alcohol intake, and risks of colon and rectal cancers in Korea. Cancer Letters, 216, $199-205$

King III, C., Siegel, M., Jernigan, D. H., Wulach, L., Ross, C., Dixon, K., \& Ostroff, J. (2009). Adolescent Exposure to Alcohol Advertising in Magazines: An Evaluation of Advertising Placement in Relation to Underage Youth Readership. Journal of Adolescent Health, 45, 626-633.

Kitamura, A., Iso, H., Sankai, T., Naito, Y., Sato, S., Kiyama, M., Okamura, T., Nakagawa, Y., Iida, M., Shimamoto, T., \& Komachi, Y. (1998). Alcohol intake and premature coronary heart disease in urban Japanese men. American Journal of Epidemiology, 147, 59-65.

Kittner, S. J., Garcia Palmieri, M. R., \& Costas Jr., R. (1983). Alcohol and coronary heart disease in Puerto Rico. American Journal of Epidemiology, 117, 538-550.

Klatsky, A. L. (1996). Alcohol, coronary disease, and hypertension. Annual Review of Medicine, 47, 149160.

Klatsky, A. L., Armstrong, M. A., \& Friedman, G. D. (1992). Alcohol and mortality. Annals of Internal Medicine, 117, 646-654.

Knibbe, R. A., Oostveen, T., \& Van de Goor, I. (1991). Young people's alcohol consumption in public drinking places: reasoned behaviour or related to the situation? British Journal of Addiction, 86, 1425-1433.

Komro, K. A., \& Toomey, T. L. (2002). Strategies to prevent underage drinking. Journal of Alcohol Research \& Health, 26, 5-14.

Komro, K. A., Flay, B. R., Hu, F. B., Zelli, A., Rashid, J., Amuwo, S. (1998). Urban pre-adolescents report perceptions of easy access to drugs and weapons. Journal of Child and Adolescent Substance Abuse, 8, 7790.

Komro, K. A., Maldonado-Molina, M. M., Tobler, A. L., Bonds, J. R., \& Muller, K. E. (2007). Effects of home access and availability of alcohol on young adolescents' alcohol use. Addiction, 102, 1597-1608.

Konnopka, A., \& König, H. H. (2007). Direct and indirect costs attributable to alcohol consumption in Germany. PharmacoEconomics, 25, 605-618. 
Koppes, L. L. J., Dekker, J. M., Hendriks, H. F. J., Bouter, L. M., \& Heine, R. J. (2006). Meta-analysis of the relationship between alcohol consumption and coronary heart disease and mortality in type 2 diabetic patients. Diabetologia, 49, 648-652.

Koppes, L. L. J., Dekker, J. M., Hendriks, H. F. J., Bouter, L. M., \& Heine, R. J. (2005). Moderate alcohol consumption lowers the risk of type 2 diabetes: A meta-analysis of prospective observational studies.

Diabetes Care, 28, 719-725.

Korte, J., Postel, M. G., Van Hoof, J. J., \& Pieterse, M. E. (n.d.). Young People's Alcohol Use in "Private Peer Group Settings". Submitted

Kotecki, J. E., Fowler, J. B., German, T. C., Stephenson, S. L., \& Warnick, T. (2000). Kentucky pharmacists' opinions and practices related to the sale of cigarettes and alcohol in pharmacies. Journal of Community Health, 25, 343-355.

Kotecki, J. E., Torabi, M. R., \& Elenijan, S. I. (1997). Pharmacists' opinions and practices related to the sale of cigarettes and alcohol - a follow-up study. Journal of Community Health, 22, 469-479.

KPMG (2001). Kosten en baten van alcoholzorg en -preventie: eindrapport. Hoofddorp, The Netherlands: KPMG Bureau voor Economische Argumentatie.

Krishnan, H. S., \& Chakravarti, D. (1999). Memory measures for pretesting advertisements: an integrative conceptual framework and a diagnostic template. Journal of Consumer Psychology, 8, 1-37.

Kuntsche, E., Kuendig, H., \& Gmel, G. (2008). Alcohol outlet density, perceived availability and adolescent alcohol use: A multilevel structural equation model. Journal of Epidemiology and Community Health, 62, 811-816.

Kuntsche, E., Kuendig, H., \& Gmel, G. (2008). Alcohol outlet density, perceived availability and adolescent alcohol use: A multilevel structural equation model. Journal of Epidemiology and Community Health, 62, 811-816.

Kuo, M., Wechsler, H., Greenberg, P., \& Lee, H. (2003). The marketing of alcohol to college students: The role of low prices and special promotions. American Journal of Preventive Medicine, 25, 204-211.

Kushner, M. G., Abrams, K., \& Borchardt, C. (2000). The relationship between anxiety disorders and alcohol use disorders: A review of major perspectives and findings. Clinical Psychology Review, 20, 149-171. 
Kushner, M. G., Sher, K. J., \& Beitman, B. D. (1990). The relation between alcohol problems and the anxiety disorders. American Journal of Psychiatry, 147, 685-695.

KWF (2004). Signaleringscommissie Kanker van KWF Kankerbestrijding. De rol van voeding bij het ontstaan van kanker. [The Dutch Cancer Association: The role of food which comes into existence of cancer.] The Hague, The Netherlands: KWF Kankerbestrijding.

LaBrie, J. W., Hummer, J. F., Neighbors, C., \& Larimer, M. E. (2010). Whose opinion matters? The relationship between injunctive norms and alcohol consequences in college students. Addictive Behaviors, 35, 343-349.

LaBrie, J. W., Hummer, J. F., Neighbors, C., \& Larimer, M. E. (2010). Whose opinion matters? The relationship between injunctive norms and alcohol consequences in college students. Addictive Behaviors, 35, 343-349.

Lamble, D., Rajalin, S., \& Summala, H. (2002). Mobile phone use while driving; public opinions on restrictions. Transportation, 29, 223-236.

Lang, E., \& Stockwell, T. (1991). Drinking locations of drink-drivers: A comparative analysis of accident and nonaccident cases. Accident Analysis and Prevention, 23, 573-584.

Langer, R. D., Criqui, M. H., \& Reed, D. M. (1992). Lipoproteins and blood pressure as biological pathways for effect of moderate alcohol consumption on coronary heart disease. Circulation, 85, 910-915.

Larimer, M. E., Turner, A. P., Mallett, K. A., \& Geisner, I. M. (2004). Predicting drinking behavior and alcohol-related problems among fraternity and sorority members: Examining the role of descriptive and injunctive norms. Psychology of Addictive Behaviors, 18, 203-212.

Latimer, W. W., Harwood, E. M., Newcomb, M. D., \& Wagenaar, A. C. (2001). Sociodemographic and individual predictors of alcohol policy attitudes: results from a US probability sample. Alcoholism: Clinical \& Experimental Research, 25, 549-556.

Lau, M. A., Pihl, R. O., \& Peterson, J. B. (1995). Provocation, acute alcohol intoxication, cognitive performance, and aggression. Journal of Abnormal Psychology, 104, 150-155.

Launoy, G., Milan, C. H., Faivre, J., Pienkowski, P., Milan, C. I., \& Gignoux, M. (1997). Alcohol, tobacco and oesophageal cancer: Effects of the duration of consumption, mean intake and current and former consumption. British Journal of Cancer, 75, 1389-1396. 
Lee, J. A., Jones-Webb, R. J., Short, B. J., \& Wagenaar, A. C. (1997). Drinking location and risk of alcoholimpaired driving among high school seniors. Addictive Behaviors, 22, 387-393.

Leigh, B. C. (1990). The relationship of substance use during sex to high-risk sexual behaviour. Journal of Sex Research, 27, 199-213.

Leino, E. V., Romelsjö, A., Shoemaker, C., Ager, C. R., Allebeck, P., Ferrer, H. P., Fillmore, K. M., Golding, J. M., Graves, K. L., \& Kniep, S. (1998). Alcohol consumption and mortality. II. Studies of male populations. Addiction, 93, 205-218.

Lewis, N. O., Lapham, S. C., \& Skipper, B. J. (1998). Drive-up liquor windows and convicted drunk drivers: A comparative analysis of place of purchase. Accident Analysis and Prevention, 30, 763-772.

Lewis, R. K., Paine-Andrews, A., Fawcett, S. B., Francisco, V. T., Richter, K. P., Copple, B., \& Copple, J. E. (1996). Evaluating the effects of a community coalition's efforts to reduce illegal sales of alcohol and tobacco products to minors. Journal of Community Health, 21, 429-436.

Licciardone, J. C. (2003). Outcomes of a Federally Funded Program for Alcohol and Other Drug Prevention in Higher Education. American Journal of Drug and Alcohol Abuse, 29, 803-827.

Lieber, C. S. (1994). Susceptibility to alcohol-related liver injury. Alcohol and alcoholism (Oxford, Oxfordshire). Supplement, 2, 315-326.

Ligon, J., Thyer, B. A., \& Lund, R. (1996). Drinking, eating, and driving: Evaluating the effects of partially removing a sunday liquor sales ban. Journal of Alcohol and Drug Education, 42, 15-24.

Lin, O. S. (2009). Acquired risk factors for colorectal cancer. Methods in Molecular Biology, 472, 361-372.

Lindeman, R. D., Romero, L. J., Allen, A. S., Liang, H. C., Baumgartner, R. N., Koehler, K. M., \& Garry, P. J. (1999). Alcohol consumption is negatively associated with the prevalence of coronary heart disease in the New Mexico elder health survey. Journal of the American Geriatrics Society, 47, 396-401.

Long, J. A., O’Connor, P. G., Gerbner, G., \& Concato, J. (2002). Use of alcohol, illicit drugs, and tobacco among characters on prime-time television. Substance Abuse, 23, 95-103.

Longnecker, M. P. (1994). Alcoholic beverage consumption in relation to risk of breast cancer: Meta-analysis and review. Cancer Causes and Control, 5, 73-82. 
Longnecker, M. P., \& Enger, S. M. (1996). Epidemiologic data on alcoholic beverage consumption and risk of cancer. Clinica Chimica Acta, 246, 121-141.

Longnecker, M. P., Orza, M. J., Adams, M. E., Vioque, J., \& Chalmers, T. C. (1990). A meta-analysis of alcoholic beverage consumption in relation to risk of colorectal cancer. Cancer Causes and Control, 1, 5968.

López-Frías, M., De la Fe Fernández, M., Planells, E., Miranda, M. T., Mataix, J., \& Llopis, J. (2001). Alcohol consumption and academic performance in a population of high school students. Journal of Studies on Alcohol and Drugs, 62, 741-744.

Luck, J., \& Peabody, J. W. (2002). Using standardised patients to measure physicians' practice: Validation study using audio recordings. British Medical Journal, 325, 679-682.

Macdonald, S., Cherpitel, C. J., Borges, G., DeSouza, A., Giesbrecht, N., \& Stockwell, T. (2005). The criteria for causation of alcohol in violent injuries based on emergency room data from six countries. Addictive Behaviors, 30, 103-113.

Madden, J., Quick, J. D., Ross-Degnan, D., \& Kafle K. K. (1997). Undercover careseekers: Simulated clients to study the health provider behavior in developing countries. Social Science and Medicine, 45, 1465-1482.

Maekawa, S. J., Aoyama, N., Shirasaka, D., Kuroda, K., Tamura, T., Kuroda, Y., \& Kasuga, M. (2004). Excessive alcohol intake enhances the development of synchronous cancerous lesion in colorectal cancer patients. International Journal of Colorectal Disease, 19, 171-175.

Mäkelä, K., \& Mustonen, H. (2002). Relationships of drinking behaviour, gender and age with reported negative and positive experiences related to drinking. Addiction, 95, 727-736.

Mäkelä, P., Valkonen, T., \& Poikolainen, K. (1997). Estimated numbers of deaths from coronary heart disease 'caused' and 'prevented' by alcohol: An example from Finland. Journal of Studies on Alcohol, 58, 455-463.

Mallet, K. A., Lee, C., Neighbors, C., Larimer, M. A., \& Turrisi, R. J. (2006). Do we learn from our mistakes? An examination of the impact of negative alcohol-related consequences on college students' drinking patterns and perceptions. Journal of Studies on Alcohol, 67, 269-276.

Mann, L. B., \& Folts, J. D. (2004). Effects of ethanol and other constituents of alcoholic beverages on coronary heart disease: A review. Pathophysiology, 10, 105-112. 
Marchi, A. G., Lamminpää, A., Azeredo, P., Williamson, L. M., Cabecadas, M., \& Renier, S. (2003). Acute alcohol intoxication in adolescents: A multicentre study. Italian Journal of Pediatrics, 29, 211-216.

Marcus, R. F., \& Reio Jr., T. G. (2002). Severity of injury resulting from violence among college students: Proximal and distal influences. Journal of Interpersonal Violence, 17, 888-908.

Markowitz, S., \& Grossman, M. (1998). Alcohol regulation and domestic violence towards children.

Contemporary Economic Policy, 16, 309-320.

Markowitz, S., \& Grossman, M. (2000). The effects of beer taxes on physical child abuse. Journal of Health Economics, 19, 271-282.

Marmota, M. G. (2001). Alcohol and coronary heart disease. International Journal of Epidemiology, 30, 724729.

Martin, C. A., Kelly, T. H., Rayens, M. K., Brogli, B. R., Brenzel, A., Smith, W. J., \& Omar, H. A. (2002). Sensation seeking, puberty, and nicotine, alcohol, and marijuana use in adolescence. Journal of the American Academy of Child and Adolescent Psychiatry, 41, 1495-1502.

Martinez, J. A., Rutledge, P. C., \& Sher, K. J. (2007). Fake ID Ownership and Heavy Drinking in Underage College Students: Prospective Findings. Psychology of Addictive Behaviors, 21, 226-232.

Mathews, J. D. (1976). Alcohol use, hypertension and coronary heart disease. Clinical Science and Molecular Medicine, 51, 661-663.

Mathios, A., Avery, R., Bisogni, C., \& Shanahan, J. (1998). Alcohol portrayal on prime-time television: Manifest and latent messages. Journal of Studies on Alcohol, 59, 305-310.

Mauss, A. L., Hopkins, R. H., Weisheit, R. A., \& Kearney, K. A. (1988). The problematic prospects for prevention in the classroom: Should alcohol education programs be expected to reduce drinking by youth? Journal of Studies on Alcohol, 49, 51-61.

Mayer, R. R., Forster, J. L., Murray, D. M., \& Wagenaar, A. C. (1998). Social settings and situations of underage drinking . Journal of Studies on Alcohol, 59, 207-215.

Mays, D., Thompson, N., Kushner, H. I., Mays II, D. F., Farmer, D., \& Windle, M. (2010). Sports-specific factors, perceived peer drinking, and alcohol-related behaviors among adolescents participating in schoolbased sports in Southwest Georgia. Addictive Behaviors, 35, 235-241. 
McDonnell, R., \& Maynard, A. (1985). The costs of alcohol misuse. British Journal of Addiction, 80, 27-35.

McEwan, R. T., McCallum, A., Bhopal, R. S., \& Madhok, R. (1992). Sex and the risk of HIV infection: The role of alcohol. British Journal of Addiction, 87, 577-584.

McGinnis, J. M., \& Foege, W. H. (1993). Actual causes of death in the United States. Journal of the American Medical Association, 270, 2207-2212.

McMillan, B., \& Connor, M. (2003). Using the theory of planned behaviour to understand alcohol and tobacco use in students. Psychology, Health \& Medicine, 8, 317-328.

Measham, F., \& Brain, K. (2005). 'Binge' drinking, British alcohol policy and the new culture of intoxication. Crime, Media, Culture, 1, 262-283.

Medina, K. L., Schweinsburg, A. D., Cohen-Zion, M., Nagel, B. J., \& Tapert, S. F. (2007). Effects of alcohol and combined marijuana and alcohol use during adolescence on hippocampal volume and asymmetry. Neurotoxicology and Teratology, 29, 141-152.

Meister, K. A., Whelan, E. M., \& Kava, R. (2000). The health effects of moderate alcohol uptake in humans: An epidemiologic review. Critical Reviews in Clinical Laboratory Sciences, 37, 261-296.

Meropol, S. B., Moscati, R. M., Lillis, K. A., Ballow, S., \& Janicke, D. M. (1995). Alcohol-related injuries among adolescents in the emergency department. Annals of Emergency Medicine, 26, 180-186.

Merrill, R. M., Stanford, E. J., Lindsay, G. B., \& Neiger B. L. (2000). The relationship of perceived age and sales of tobacco and alcohol to underage customers. Journal of Community Health, 25, 401-410.

Mignogna, M. D., Fedele, S., Lo Russo, L., \& Lo Muzio, L. (2001). Lack op public awaress toward alcohol consumption as risk factor for oral and pharyngeal cancers. Preventive Medicine, 33, 137-139.

Miller, G. J., Beckles, G. L. A., Maude, G. H., \& Carson, D. C. (1990). Alcohol consumption: Protection against coronary heart disease and risks to health. International Journal of Epidemiology, 19, 923-930.

Miller, J. W., Naimi, T. S., Brewer, R. D., \& Jones, S. E. (2007). Binge drinking and associated health risk behaviors among high school students. Pediatrics, 119, 76-85.

Miller, T. R., \& Blincoe, L. J. (1994). Incidence and cost of alcohol-involved crashes in the United States. Accident Analysis and Prevention, 26, 583-591. 
MOgroep (2008). Brancherapport Bureaus Jeugdzorg 2007, Utrecht, The Netherlands: MOgroep.

Mohler-Kuo, M., Dowdall, G. W., Koss, M. P., \& Wechsler, H. (2004). Correlates of rape while Intoxicated in a National Sample of College Women. Journal of Studies on Alcohol, 65, 37-45.

Monshouwer, K., Van Dorsselaer, S., Gorter, A., Verdurmen, J., \& Vollebergh, W. (2008). Jeugd en Riskant Gedrag. Kerngegevens uit het Peilstationsonderzoek 2007. [Youth and Risky Behavior: Core Figures from Monitoring Study 2007.] Utrecht, The Netherlands: Trimbos Institute.

Monshouwer, K., Van Dorsselaer, S., Gorter, A., Verdurmen, J., \& Vollebergh, W. (2004). Jeugd en riskant gedrag. Kerngegevens uit het peilstationsonderzoek 2003. [Youth and Risky Behavior: Core Figures from Monitoring Study 2003.] Utrecht, The Netherlands: Trimbos Institute.

Montgomery, J. M., Long Foley, K., \& Wolfson, M. (2006). Enforcing the minimum drinking age: State, local and agency characteristics associated with compliance checks and Cops in Shops programs. Addiction, $101,223-231$.

Montgomery, R. L., \& Haemmerlie, F. M. (1993). Undergraduate adjustment to college, drinking behavior, and fraternity membership. Psychological Reports, 73, 801-802.

Moore, R. D., \& Pearson, T. A. (1986). Moderate alcohol consumption and coronary artery disease. A review. Medicine, 65, 242-267.

Moskal, A., Norat, T., Ferrari, P., \& Riboli, E. (2007). Alcohol intake and colorectal cancer risk: A doseresponse meta-analysis of published cohort studies. International Journal of Cancer, 120, 664-671.

Mukamal, K. J., Chiuve, S. E., \& Rimm, E. B. (2006). Alcohol consumption and risk for coronary heart disease in men with healthy lifestyles. Archives of Internal Medicine, 166, 2145-2150.

Mukamal, K. J., Chung, H., Jenny, N. S., Kuller, L. H., Longstreth Jr., W. T., Mittleman, M. A., Burke, G. L., Cushman, M., Psaty, B. M., \& Siscovick, D. S. (2006). Alcohol consumption and risk of coronary heart disease in older adults: The cardiovascular health study. Journal of the American Geriatrics Society, 54, 3037.

Mullahy, J., \& Sindelar, J. (1989). Life cycle effects of alcoholism on education, earnings, and occupation. Inquiry, 26, 272-282.

Mullahy, J., \& Sindelar, J. (1996). Employment, unemployment, and problem drinking. Journal of Health Economics, 15, 409-434. 
Muñoz, S. E., Navarro, A., Lantieri, M. J., Fabro, M. E., Peyrano, M. G., Ferraroni, M., Decarli, A., La Vecchia, C., \& Eynard, A. R. (1998). Alcohol, methylxanthine-containing beverages, and colorectal cancer in Cordoba, Argentina. European Journal of Cancer Prevention, 7, 207-213.

Mustonen, H., \& Mäkelä, K. (1999). Relationships between characteristics of drinking occasions and negative and positive experiences related to drinking. Drug and Alcohol Dependence, 56, 79-84.

Nagoshi, C. T., Wilson, J. R., \& Rodriguez, L. A. (1991). Impulsivity, sensation seeking, and behavioral and emotional responses to alcohol. Alcoholism: Clinical and Experimental Research, 15, 661-667.

Nakamura, K., Tanaka, A., \& Takano, T. (1993). The social cost of alcohol abuse in Japan. Journal of Studies on Alcohol, 54, 618-625.

National Center for Chronic Disease Prevention and Health Promotion, Division of Adult and Community Health. (n.d). Alcohol-related disease impact 2008. Atlanta, GA: Centers for Disease Control and Prevention. Retrieved from http://www.cdc.gov/alcohol/ardi.htm

National Highway Traffic Safety Administration (2003). Traffic safety facts 2002: alcohol. DOT HS-809606. Washington, DC: NHTSA, National Center for Statistics and Analysis.

National Public Health Compass (2007). Bevolking: Verleden, heden, toekomst, 2007 [Population: past, present, future, 2007]. Retrieved from http://www.rivm.nl/vtv/object_document/o1169n16911.html

Newman, I. M., Anderson, C. S., \& Farrell, K. A. (1992). Role rehearsal and efficacy: two 15-month evaluations of a ninth-grade alcohol education program. Journal of Drug Education, 22, 55-67.

NIAAA (2004-2005a). The effects of alcohol on physiological processes and biological development. Alcohol Research \& Health, 28, 125-131.

NIAAA (2004-2005b). Genetics, pharmacokinetics, and neurobiology of adolescent alcohol use. Alcohol Research \& Health, 28, 133-142.

Norström, T. (1987). The impact of per capita consumption on Swedish cirrhosis mortality. British Journal of Addiction, 82, 67-75.

Norström, T., \& Skog, O. J. (2001). Alcohol and mortality: Methodological and analytical issues in aggregate analyses. Addiction, 96, S5-S17. 
Nyström, M. (1992). Positive and negative consequences of alcohol drinking among young university students in Finland. British Journal of Addiction, 87, 715-722.

O'Donnell, M. A. (1985). Research on drinking locations of alcohol-impaired drivers: Implications for prevention policies. Journal of Public Health Policy, 6, 510-525.

Ólafsdóttir, H. (1997). The dynamics of shifts in alcoholic beverage preference: Effects of the legalization of beer in Iceland. Journal of Studies on Alcohol, 59, 107-114.

O'Malley, P., \& Wagenaar, A. C. (1991). Effects of minimum age laws on alcohol use, related behaviors, and traffic crash involvement among American youth 1976-1987. Journal of Studies on Alcohol, 52, 478-491.

Oostveen, T., Knibbe, R. A., \& De Vries, H. (1996). Social influences on young adults' alcohol consumption: Norms, modeling, pressure, socializing, and conformity. Addictive Behaviors, 21, 187-197.

Osterberg, E. (1995). Do Alcohol Prices Affect Consumption and Related Problems? In H. D. Holder and G. Edwards (Eds.), Alcohol and Public Policy: Evidence and Issues (pp. 145-163). Oxford, UK: University Press.

Otani, T., Iwasaki, M., Yamamoto, S., Sobue, T., Hanaoka, T., Inoue, M., \& Tsugane, S. (2003). Alcohol Consumption, Smoking, and Subsequent Risk of Colorectal Cancer in Middle-Aged and Elderly Japanese Men and Women: Japan Public Health Center-based Prospective Study. Cancer Epidemiology Biomarkers and Prevention, 12, 1492-1500.

Papadakis, J. A., Ganotakis, E. S., \& Mikhailidis, D. P. (2000). Beneficial effect of moderate alcohol consumption on vascular disease: Myth or reality? Journal of The Royal Society for the Promotion of Health, $120,11-15$.

Parker, D. L., Shultz, J. M., \& Gertz, L. (1987). The social and economic costs of alcohol abuse in Minnesota, 1983. American Journal of Public Health, 77, 982-986.

Paschall, M. J., Grube, J. W., \& Kypri, K. (2009). Alcohol control policies and alcohol consumption by youth: a multi-national study. Addiction, 104, 1849-1855.

Paschall, M. J., Grube, J. W., Black, C., Flewelling, R. L., Ringwalt, C. L., Biglan, A. (2007a). Alcohol outlet characteristics and alcohol sales to youth: Results of alcohol purchase surveys in 45 oregon communities. Prevention Science, 8, 153-159. 
Paschall, M. J., Grube, J. W., Black, C., Ringwalt, C. L. (2007b). Is Commercial Alcohol Availability Related to Adolescent Alcohol Sources and Alcohol Use? Findings from a Multi-Level Study. Journal of Adolescent Health, 41, 168-174.

Pedersen, A., Johansen, C., \& Grønbæk, M. (2003). Relations between amount and type of alcohol and colon and rectal cancer in a Danish population based cohort study. Gut, 52, 861-867.

Pedersen, W., \& Skrondal, A. (1998). Alcohol consumption debut: Predictors and consequences. Journal of Studies on Alcohol, 59, 32-42.

Peele, S., \& Brodsky, A. (1997). Gateway to nowhere: How alcohol came to be scapegoated for drug abuse. Addiction Research and Theory, 5, 419-426.

Pendleton, L. L., Smith, C., \& Roberts, J. L. (1990). Public opinions on alcohol policies. British Journal of Addiction, 85, 125-130.

Perreira, K. M., \& Sloan, F. A. (2001). Life events and alcohol consumption among mature adults: A longitudinal analysis. Journal of Studies on Alcohol, 62, 501-508.

Perry, C. L., Williams, C. L., Komro, K. A., Veblen-Mortenson, S., Stigler, M. H., Munson, K. A., Farbakhsh, K., Jones, R. M., \& Forster, J. L. (2002). Project Northland: Long-term outcomes of community action to reduce adolescent alcohol use. Health Education Research, 17, 117-132.

Peterson, J. B., Rothfleisch, J., Zelazo, P. D., Pihl, R. O. (1990). Acute alcohol intoxication and cognitive functioning. Journal of Studies on Alcohol, 51, 114-122.

Pinsky, I., \& El Jundi, S. A. R. J. (2008). Alcohol advertising and alcohol consumption among youngsters: Review of the international literature I [O impacto da publicidade de bebidas alcoólicas sobre o consumo entre jovens: Revisão da literatura internacional]. Revista Brasileira de Psiquiatria, 30, 362-374.

Pitkänen, T., Lyyra, A. L., \& Pulkkinen, L. (2005). Age of onset of drinking and the use of alcohol in adulthood: a follow-up study from age 8-42 for females and males. Addiction, 100, 652-661.

Poelen, E. A. P., Scholte, R. H. J., Willemsen, G., Boomsma, D. I., \& Engels, R. C. M. E. (2007). Drinking by parents, siblings, and friends as predictors of regular alcohol use in adolescents and young adults: A longitudinal twin-family study. Alcohol and Alcoholism, 42, 362-369. 
Popelka, M. M., Cruickshanks, K. J., Wiley, T. L., Tweed, T. S., Klein, B. E. K., Klein, R., \& Nondahl, D. M. (2000). Moderate alcohol consumption and hearing loss: A protective effect. Journal of the American Geriatrics Society, 48, 1273-1278.

Popova, S., Giesbrecht, N., Bekmuradov, D., \& Patra, J. (2009). Hours and days of sale and density of alcohol outlets: impacts on alcohol consumption and damage: a systematic review. Alcohol and Alcoholism, 44, 500-516.

Prescott, C. A., \& Kendler, K. S. (1999). Age at first drink and risk for alcoholism: A noncausal association. Alcoholism: Clinical and Experimental Research, 23, 101-107.

Presley, C. A., Meilman, P. W., \& Cashin, J. R. (1996). Alcohol and drugs on American college campuses: use, consequences, and perceptions of the campus environment, Volume IV: 1992-94. Carbondale, IL: The Core Institute, Southern Illinois University.

Preusser D. F., \& Williams A. F. (1992). Sales of alcohol to underage purchasers in three New York counties and Washington, D.C. Journal of Public Health Policy, 13, 306-317.

Preusser D. F., Williams A. F., \& Weinstein H. B. (1994). Policing underage alcohol sales. Journal of Safety Research, 25, 127-133.

Radenkova-Saeve, J. (2007). Epidemiological profile of acute alcohol poisoning in toxicology clinic, emergency hospital “N. I. Pirogov.” Acta Medica Bulgarica, 34, 41-46.

Ramstedt, M. (2001). Per capita alcohol consumption and liver cirrhosis mortality in 14 European countries. Addiction, 96, S19-S34.

Rehm, J. T., Bondy, S. J., Sempos, C. T., \& Vuong, C. V. (1997). Alcohol consumption and coronary heart disease morbidity and mortality. American Journal of Epidemiology, 146, 495-501.

Rehm, J., Mathers, C., Popova, S., Thavorncharoensap, M., Teerawattananon, Y., \& Patra, J. (2009). Global burden of disease and injury and economic cost attributable to alcohol use and alcohol-use disorders. The Lancet, 373, 2223-2233.

Rehm, J., Room, R., Graham, K., Monteiro, M., Gmel, G., \& Sempos, C. T. (2003a). The relationship of average volume of alcohol consumption and patterns of drinking to burden of disease: An overview, Addiction, 98, 1209-1228. 
Rehm, J., Sempos, C. T., \& Trevisan, M. (2003b). Average volume of alcohol consumption, patterns of drinking and risk of coronary heart disease - A review. Journal of Cardiovascular Risk, 10, 15-20.

Reifman, A., Barnes, G. M., Dintcheff, B. A., Farrell, M. P., \& Uhteg, L. (1998). Parental and peer influences on the onset of heavier drinking among adolescents. Journal of Studies on Alcohol, 59, 311-317.

Reis, J., \& Riley, W. L. (2000). Predictors of college students' alcohol consumption: Implications for student education. Journal of Genetic Psychology, 161, 282-291.

Reis, J., Riley, W., Lokman, L., \& Baer, J. (2000). Interactive multimedia preventive alcohol education: A technology application in higher education. Journal of Drug Education, 30, 399-421.

Reynolds, K., Lewis, L. B., Nolen, J. D. L., Kinney, G. L., Sathya, B., \& He, J. (2003). Alcohol Consumption and Risk of Stroke: A Meta-analysis. Journal of the American Medical Association, 289, 579-588.

Rice, D. P., Kelman, S., \& Miller, L. S. (1991). Estimates of economic costs of alcohol and drug abuse and mental illness, 1985 and 1988. Public Health Reports, 106, 280-292.

Richter, L., Vaughnan, R. D., \& Foster, S. E. (2004). Public attributes about underage drinking policies: results from a national survey. Journal of Public Health Policy, 25, 58-77.

Rigaud, D. (2000). Protective effects following alcohol drinking. [Effets protecteurs des boissons alcooliques]. Cahiers de Nutrition et de Dietetique, 35, 85-91.

Rimal, R. N. (2008). Modeling the relationship between descriptive norms and behaviors: A test and extension of the theory of normative social behavior (TNSB). Health Communication, 23, 103-116.

Rimm, E. B., \& Moats, C. (2007). Alcohol and Coronary Heart Disease: Drinking Patterns and Mediators of Effect. Annals of Epidemiology, 17, S3-S7.

Rimm, E. B., Giovannucci, E. L., Willett, W. C., Colditz, G. A., Ascherio, A., Rosner, B., \& Stampfer, M. J. (1991). Prospective study of alcohol consumption and risk of coronary disease in men. Lancet, 338, 464-468.

Rimm, E. B., Klatsky, A., Grobbee, D., \& Stampfer, M. J. (1996). Review of moderate alcohol consumption and reduced risk of coronary heart disease: Is the effect due to beer, wine, or spirits? British Medical Journal, $312,731-736$. 
Rimm, E. B., Williams, P., Fosher, K., Criqui, M., \& Stampfer, M. J. (1999). Moderate alcohol intake and lower risk of coronary heart disease: Meta-analysis of effects on lipids and haemostatic factors. British Medical Journal, 319, 1523-1528.

Rissanen, A. M., Heliovaara, M., Knekt, P., Reunanen, A., \& Aromaa, A. (1991). Determinants of weight gain and overweight in adult Finns. European Journal of Clinical Nutrition, 45, 419-430.

Robertson, J. A., \& Plant, M. A. (1988). Alcohol, sex and risks of HIV infection. Drug and Alcohol Dependence, 22, 75-78.

Robinson, L. A., Klesges, R. C., Zbikowski, S. M., \& Glaser, R. (1997). Predictors of risk for different stages of adolescent smoking in a biracial sample. Journal of Consulting and Clinical Psychology, 65, 653-662.

Rodriguez, E., Lasch, K. E., Chandra, P., Lee, J. (2001a). The relation of family violence, employment status, welfare benefits, and alcohol drinking in the United States. Western Journal of Medicine, 174, 317-323.

Rodriguez, E., Lasch, K. E., Chandra, P., Lee, J. (2001b). Family violence, employment status, welfare benefits, and alcohol drinking in the United States: What is the relation? Journal of Epidemiology and Community Health, 55, 172-178.

Romano, M., Duailibi, S. M., Pinsky, I., \& Laranjeira, R. (2007). Alcohol purchase survey by adolescents in two cities of State of São Paulo, Southeastern Brazil. [Pesquisa de compra de bebidas alcoólicas por adolescentes em duas cidades do Estado de São Paulo]. Revista de Saude Publica, 41, 495-501.

Rossow, I. (1996). Alcohol-related violence: The impact of drinking pattern and drinking context. Addiction, 91, 1651-1661.

Rossow, I., Pape, H., \& Storvoll, E. E. (2005). Sources of intoxication: How do under-aged adolescents procure alcohol? [Beruselsens kilder - Hvordan ungdom skaffer seg alkohol]. Tidsskrift for den Norske Laegeforening, 125, 1160-1162.

Rossow, I., Pape, H., \& Wichstrøm, L. (1999). Young, wet and wild? Associations between alcohol intoxication and violent behaviour in adolescence. Addiction, 94, 1017-1031.

Rossow, I., Storvoll, E. E., \& Pape, H. (2007). Enforcement of the mimimum legal age for purchase of alcohol. [Håndheves aldersgrensen for a få kjøpt alkohol?]. Tidsskrift for den Norske Laegeforening, 127, 1510-1512. 
Rowland, N., \& Maynard, A. K. (1993). Standardized alcohol education: A hit or miss affair? Health Promotion International, 8, 5-12.

Russell, D. W., \& Russell, C. A. (2008). Embedded alcohol messages in television series: The interactive effect of warnings and audience connectedness on viewers' alcohol beliefs. Journal of Studies on Alcohol and Drugs, 69, 459-467.

Sacco, R. L., Elkind, M., Boden-Albala, B., Lin, I. F., Kargman, D. E., Hauser, W. A., Shea, S., \& Paik, M. A. (1999). The protective effect of moderate alcohol consumption on ischemic stroke. Journal of the American Medical Association, 281, 53-60.

Saffer, H. (1991). Alcohol advertising bans and alcohol abuse: An international perspective. Journal of Health Economics, 10, 65-79.

Saffer, H. (1997). Alcohol advertising and motor vehicle fatalities. Review of Economics and Statistics, 79, 431-442.

Saffer, H. (2002). Alcohol advertising and youth. Journal of Studies on Alcohol, 63, 173-181.

Saffer, H., \& Dave, D. (2002). Alcohol consumption and alcohol advertising bans. Applied Economics, 34, 1325-1334.

Saffer, H., \& Dave, D. (2006). Alcohol advertising and alcohol consumption by adolescents. Health Economics, 15, 617-637.

Sakuta, H., Suzuki, T., Ito, T., \& Yasuda, H. (2007). Beer ethanol consumption and plasma homocysteine among patients with type 2 diabetes. Diabetes Research and Clinical Practice, 78, 202-207.

Salaspuro, M. P. (2003). Alcohol consumption and cancer of the gastrointestinal tract. Bailliere's Best Practice and Research in Clinical Gastroenterology, 17, 679-694.

Sargent, J. D., Beach, M. L., Dalton, M. A., Mott, L. A., Tickle, J. J., Ahrens, M. B., \& Heatherton, T. F. (2001a). Effect of seeing tobacco use in films on trying smoking among adolescents: Cross sectional study. British Medical Journal, 323, 1394-1397.

Sargent, J. D., Tickle, J. J., Beach, M. L., Dalton, M. A., Ahrens, M. B., \& Heatherton, T. F. (2001b). Brand appearences in contemporary cinema films and contribution to global marketing of cigarettes. The Lancet, 357, 29-32. 
Sargent, J. D., Wills, T. A., Stoolmiller, M., Gibson, J., \& Gibbons, F. X. (2006). Alcohol use in motion pictures and its relation with early-onset teen drinking. Journal of Studies on Alcohol, 67, 54-65.

Schatzkin, A., \& Longnecker, M. P. (1994). Alcohol and breast cancer: Where are we now and where do we go from here? Cancer, 74, 1101-1110.

Schechter, E. J. (1986). Alcohol Rationing and Control Systems in Greenland. Contemporary Drug Problems, 13, 587-620.

Schmid, T. L., Jeffery, R. W., Forster, J. L., Rooney, B., Klepp, K., \& McBride, C. (1990). Public support for policy initiatives regulating alcohol use in Minnesota: a multi-community survey. Journal of Studies on Alcohol, 51, 438-442.

Schuckit, M. A., \& Hesselbrock, V. (1994). Alcohol dependence and anxiety disorders: What is the relationship? American Journal of Psychiatry, 151, 1723-1734.

Schutten, M., Van den Eijnden, J. J. M.,\& Knibbe, R. A. (2003). Alcohol en werk. Een onderzoek naar alcoholgebruik onder de werkende Beroepsbevolking. [Alcohol and Work. A research on alcohol use by the working population]. Rotterdam, The Netherlands: Instituut voor Onderzoek naar Leefwijzen \& Verslaving (IVO)

Schwartz, R. H., Farrow, J. A., Banks, B., \& Giesel, A. E. (1998). Use of false ID cards and other deceptive methods to purchase alcoholic beverages during high school. Journal of Addictive Diseases, 17, 25-33.

Scorza, C. A., Cysneiros, R. M., Arida, R. M., Terra, V. C., Machado, H. R., De Almeida, A. C. G., Cavalheiro, E. A., \& Scorza, F. A. (2009). Alcohol consumption and sudden unexpected death in epilepsy: Experimental approach. Arquivos de Neuro-Psiquiatria, 67, 1003-1006.

Scribner, R. A., \& Cohen, D. A., The effect of enforcement on merchant compliance with the minimum legal drinking age law. Journal of Drug Issues, 31, 857-866.

Scribner, R. A., Cohen, D. A., \& Fisher, W. (2000). Evidence of a structural effect for alcohol outlet density: A multilevel analysis. Alcoholism: Clinical and Experimental Research, 24, 188-195.

Scrull, T. K., \& Wyer, R. S. (1979). The role of category accessibility in the interaction of information about persons: some determinants and implications. Journal of Personality and Social Psychology, 37, 1660-1672.

Sen, G. (2002). Does alcohol use increase the risk of sexual intercourse among adolescents? Evidence from the NLSY97. Journal of Health Economics, 21, 1085-1093. 
Shaper, A. G., \& Wannamethee, S. G. (2000). Alcohol intake and mortality in middle aged men with diagnosed coronary heart disease. Heart, 83, 394-399.

Shaper, A. G., Wannamethee, G., \& Walker, M. (1994). Alcohol and coronary heart disease: A perspective from the British Regional Heart Study. International Journal of Epidemiology, 23, 482-494.

Sharmer, L. (2001). Evaluation of alcohol education programs on attitude, knowledge, and self-reported behavior of college students. Evaluation and the Health Professions, 24, 336-357.

Sharpe, C. R., Siemiatycki, J., \& Rachet, B. (2002). Effects of alcohol consumption on the risk of colorectal cancer among men by anatomical subsite (Canada). Cancer Causes and Control, 13, 483-491.

Sheehan, M., Schonfeld, C., Ballard, R., Schofield, F., Najman, J., \& Siskind, V. (1996). A three year outcome evaluation of a theory based drink driving education program. Journal of Drug Education, 26, 295312 .

Shimizu, N., Nagata, C., Shimizu, H., Kametani, M., Takeyama, N., Ohnuma, T., \& Matsushita, S. (2003). Height, weight, and alcohol consumption in relation to the risk of colorectal cancer in Japan: A prospective study. British Journal of Cancer, 88, 1038-1043.

Shope, J. T., Copeland, L. A., Maharg, R., \& Dielman, T. E. (1996). Effectiveness of a high school alcohol misuse prevention program. Alcoholism: Clinical and Experimental Research, 20, 791-798.

Shope, J. T., Copeland, L. A., Marcoux, B. C., \& Kamp, M .E. (1996). Effectiveness of a school-based substance abuse prevention program. Journal of Drug Education, 26, 323-337.

Shults, R. A., Elder, R. W., Sleet, D. A., Nichols, J. L., Alao, M. O., Carande-Kulis, V. G., Zaza, S., Sosin, D. M., \& Thompson, R. S. (2001). Reviews of evidence regarding interventions to reduce alcohol-impaired driving. American Journal of Preventive Medicine, 21, 66-88.

Signorielli, N. (1990). Television and health: Images and impact. In: C. Atkin \& L. Wallack (Eds.), Mass communication and public health: Complexities and conflicts. Beverly Hills, CA: Sage.

Sindelar, H. A., Barnett, N. P., \& Spirito, A. (2004). Adolescent alcohol use and injury. A summary and critical review of the literature. Minerva Pediatrica, 56, 291-309.

Singer, D. G. (1985). Alcohol, television, and teenagers. Pediatrics, 76, 668-674. 
Single, E., Robson, L., Rehm, J., \& Xie, X. (1999). Morbidity and mortality attributable to alcohol, tobacco, and illicit drug use in Canada. American Journal of Public Health, 89, 385-390.

Single, E., Robson, L., Xie, X., \& Rehm, J. (1998). The economic costs of alcohol, tobacco and illicit drugs in Canada, 1992. Addiction, 93, 991-1006.

Singletary, K. W., \& Gapstur, S. M. (2001). Alcohol and breast cancer: Review of epidemiologic and experimental evidence and potential mechanisms. Journal of the American Medical Association, 286, $2143-$ 2151.

Sise, C. B., Sack, D. I., Sise, M. J., Riccoboni, S. T., Osler, T. M., Swanson, S. M., \& Martinez, M. D. (2009). Alcohol and high-risk behavior among young first-time offenders. Journal of Trauma - Injury, Infection and Critical Care, 67, 498-502.

Slater, M. D., \& Rouner, D. (2002). Entertainment-education and Elaboration Likelihood: Understanding the processing of narrative persuasion. Communication Theory, 12, 173-191.

Smart, R. G. (1988). Does alcohol advertising affect overall consumption? A review of empirical studies. Journal of Studies on Alcohol, 49, 314-323.

Smith, D. I. (1988). Effect on traffic accidents of introducing Sunday alcohol sales in Brisbane, Australia. International Journal of the Addictions, 23, 1091-1099.

Smith, L. A., \& Foxcroft, D. R. (2009). The effect of alcohol advertising, marketing and portrayal on drinking behaviour in young people: Systematic review of prospective cohort studies. BMC Public Health, 9 , art. no. 51 .

Smith, R. C., \& Geller, E. S. (2009). Marketing and alcohol-related traffic fatalities: Impact of alcohol advertising targeting minors. Journal of Safety Research, 40, 359-364.

Smith-Warner, S. A., Spiegelman, D., Yaun, S. S., Van Den Brandt, P. A., Folsom, A. R., Goldbohm, R. A., Graham, S., Holmberg, L., Howe, G. R., Marshall, J. R., Miller, A. B., Potter, J. D., Speizer, F. E., Willett, W. C., Wolk, A., \& Hunter, D. J. (1998). Alcohol and breast cancer in women: A pooled analysis of cohort studies. Journal of the American Medical Association, 279, 535-540.

Snyder, L. B., Milici, F. F., Slater, M., Sun, H., \& Strizhakova, Y. (2006). Effects of alcohol advertising exposure on drinking among youth. Archives of Pediatrics and Adolescent Medicine, 160, 18-24. 
Solomon, C. G., Hu, F. B., Stampfer, M. J., Colditz, G. A., Speizer, F. E., Rimm, E. B., Willett, W. C., \& Manson, J. E. (2000). Moderate alcohol consumption and risk of coronary heart disease among women with type 2 diabetes mellitus. Circulation, 102, 494-499.

Sood, S. (2002). Audience involvement and entertainment-education. Communication Theory, 12, 153-172.

Spear, L. (2002). Adolescent brain and the college drinker: Biological basis of propensity to use and misuse alcohol. Journal of Studies on Alcohol, 14, 71-81.

Stacy, A. W., Zogg, J. B., Unger, J. B., \& Dent, C. W. (2004). Exposure to televised alcohol ads and subsequent adolescent alcohol use. American Journal of Health Behavior, 28, 498-509.

Stall, R., McKusick, L., Wiley, J., Coates, T. J., \& Ostrow, D. G. (1986). Alcohol and drug use during sexual activity and compliance with safe sex guidelines for AIDS: the AIDS Behavioral Research Project. Health Education Quarterly, 13, 359-371.

Statistics Netherlands (2007a). Bevolking: Kerncijfers naar diverse kenmerken, 2007 [Population, various indicators, 2007]. Retrieved from

http://statline.cbs.nl/StatWeb/publication/?VW=T\&DM=SLNL\&PA=37296ned\&D1=a\&D2=0,10,20,30,40,5 0,(1-1)-1\&HD=090122-1014\&HDR=G1\&STB=T

Statistics Netherlands (2007b). Huishoudens: Grootte, samenstelling 2007 [Households: size, composition 2007]. Retreived from

http://statline.cbs.nl/StatWeb/publication/?VW=T\&DM=SLNL\&PA=37312\&D1=a\&D2=a,!1-4,!6-

$7 \& \mathrm{HD}=090121-1731 \& \mathrm{HDR}=\mathrm{G} 1 \& \mathrm{STB}=\mathrm{T}$

Statistics Netherlands (2007c). Jaarboek onderwijs in cijfers 2007 [Yearbook eduacation in figures 2007]. Voorburg, The Netherlands.

Stern, S. R. (2005). Messages from teens on the big screen: Smoking, drinking, and drug use in teen-centered films. Journal of Health Communication, 10, 331-346.

STIVA (2006). The advertising code for alcoholic beverages with guidelines. Den Haag, The Netherlands: STIVA.

Stockwell, T., Lang, E., \& Rydon, P. (1993). High risk drinking settings: The association of serving and promotional practices with harmful drinking. Addiction, 88, 1519-1526.

Storvoll, E. E., Pape, H., \& Rossow, I. (2008). Use of commercial and social sources of alcohol by underage drinkers: The role of pubertal timing. Addictive Behaviors, 33, 161-166. 
Strasburger, V. C. (2002). Alcohol advertising and adolescents. Pediatric Clinics of North America, 49, 353376.

Su, L. J., \& Arab, L. (2004). Alcohol consumption and risk of colon cancer: Evidence from the national health and nutrition examination survey I epidemiologic follow-up study. Nutrition and Cancer, 50, 111-119.

Suh, I., Shaten, B. J., Cutler, J. A., \& Kuller, L. H. (1992). Alcohol use and mortality from coronary heart disease: The role of high- density lipoprotein cholesterol. Annals of Internal Medicine, 116, 881-887.

Suter, P. M., Häsler, E., \& Vetter, W. (1997). Effects of alcohol on energy metabolism and body weight regulation: Is alcohol a risk factor for obesity? Nutrition Reviews, 55, 157-171.

Sutherland, I., \& Willner, P. (1998). Patterns of alcohol, cigarette and illicit drug use in English adolescents. Addiction, 93, 1199-1208.

Swahn, M. H., Hammig, B. J., \& Ikeda, R. M. (2002). Prevalence of youth access to alcohol or a gun in the home. Injury prevention: journal of the International Society for Child and Adolescent Injury Prevention, 8, 227-230.

Swan, A. V., Creeser, R., \& Murray, M. (1990). When and why children first start to smoke. International Journal of Epidemiology, 19, 323-330.

Tanasescu, M., Hu, F. B., Willett, W. C., Stampfer, M. J., \& Rimm, E. B. (2001). Alcohol consumption and risk of coronary heart disease among men with type 2 diabetes mellitus. Journal of the American College of Cardiology, 38, 1836-1842.

Tannen, T. (2003). Media giant and foundation team up to fight HIV/AIDS. The Lancet, 361, 1440-1441.

Tapert, S. F. (2005). Alcohol and the adolescent brain. Alcohol Research Health, 28, 205-213.

Tapert, S. F., Aarons, G. A., Sedlar, G. R., \& Brown, S. A. (2001). Adolescent substance use and sexual risktaking behaviour. Journal of Adolescent Health, 28, 181-189.

Tapert, S. F., Brown, G. G., Kinderman, S. S., Cheung, E. H., Frank, L. R., \& Brown, S. A. (2001). fMRI measurement of brain dysfunction in alcohol-dependent young women. Alcoholism, Clinical and Experimental Research, 25, 236-245. 
Tapert, S. F., Brown, G. G., Kindermann, S. S., \& Cheung, E. H. (2001). fMRI Measurement of brain dysfunction in alcohol-dependent young women. Alcoholism: Clinical \& Experimental Research, 25, 236245.

Tapert, S. F., Caldwell, L., \& Burke, C. (2005). Alcohol and the adolescent brain: Human studies. Alcohol Research and Health, 28, 205-212.

Tapert, S. F., Cheung, E. H., Brown, G. G., Frank, L. R., Paulus, M. P., Schweinsburg, A. D., Meloy, M. J., \& Brown, S. A. (2003). Neural Response to Alcohol Stimuli in Adolescents With Alcohol Use Disorder. Archives of General Psychiatry, 60, 727-735.

Terza, J. V. (2002). Alcohol abuse and employment: A second look. Journal of Applied Econometrics, 17, 393-404.

Theobald, H., Johansson, S. E., Bygren, L. O., \& Engfeldt, P. (2001). The effects of alcohol consumption on mortality and morbidity: A 26-year follow-up study. Journal of Studies on Alcohol, 62, 783-789.

Thompson, K. M., \& Yokota, F. (2001). Depiction of alcohol, tobacco, and other substances in G-rated animated feature films. Pediatrics, 107, 1369-1374.

Thun, M. J., Peto, R., Lopez, A. D., Monaco, J. H., Henley, S. J., Heath Jr., C. W., \& Doll, R. (1997). Alcohol consumption and mortality among middle-aged and elderly U.S. adults. New England Journal of Medicine, 337, 1705-1714.

Thygesen, L. C., Keiding, N., Johansen, C., \& Grønbæk, M. (2007). Changes in alcohol intake and risk of upper digestive tract cancer. Acta Oncologica, 46, 1085-1089.

Thygesen, L. C., Wu, K., Grønbæk, M., Fuchs, C. S., Willett, W. C., \& Giovannucci, E. (2008). Alcohol intake and colorectal cancer: A comparison of approaches for including repeated measures of alcohol consumption. Epidemiology, 19, 258-264.

Tolstrup, J., Jensen, M. K., Tjønneland, A., Overvad, K., Mukamal, K. J., \& Grønbaek, M. (2006).

Prospective study of alcohol drinking patterns and coronary heart disease in women and men. British Medical Journal, 332, 1244-1247.

Toomey, T. L., \& Wagenaar, A. C. (1999). Policy options for prevention: The case of alcohol. Journal of Public Health Policy, 20, 192-213. 
Toomey, T. L., Erickson, D. J., Patrek, W., Fletcher, L. A., \& Wagenaar, A. C. (2005). Illegal alcohol sales and use of alcohol control policies at community festivals. Public Health Reports, 120, 165-173.

Toomey, T. L., Wagenaar, A. C., Erickson, D. J., Fletcher, L. A., Patrek, W., \& Lenk, K. M. (2004). Illegal alcohol sales to obviously intoxicated patrons at licensed establishments. Alcoholism: Clinical and Experimental Research, 28, 769-774.

Toomey, T. L., Wagenaar, A. C., Gehan, J. P., Killian, G., Murray, D. M., \& Perry, C. L. (2001). Project ARM: Alcohol Risk Management to prevent sales to underage and intoxicated patrons. Health Education \& Behavior, 28, 186-199.

Toriola, A. T., Kurl, S., Laukanen, J. A., Mazengo, C., \& Kauhanen, J. (2008). Alcohol consumption and risk of colorectal cancer: The Findrink study. European Journal of Epidemiology, 23, 395-401.

Townsend, L., Flisher, A. J., \& King, G. (2007). A systematic review of the relationship between high school dropout and substance use. Clinical Child and Family Psychology Review, 10, 295-317.

Treno, A. J., Parker, R. N., \& Holder, H. D. (1993). Understanding U.S. alcohol consumption with social and economic factors: A multivariate time series analysis, 1950-1986. Journal of Studies on Alcohol, 54, 146156.

Trockel, M., Williams, S. S., \& Reis, J. (2003). Considerations for more effective social norms based alcohol education on campus: An analysis of different theoretical conceptualizations in predicting drinking among fraternity men. Journal of Studies on Alcohol, 64, 50-59.

Tsong, W. H., Koh, W. P., Yuan, J. M., Wang, R., Sun, C. L., \& Yu, M. C. (2007). Cigarettes and alcohol in relation to colorectal cancer: The Singapore Chinese Health Study. British Journal of Cancer, 96, 821-827.

Umeh, K., \& Patel, R. (2004). Theory of planned behaviour and ecstasy use: An analysis of moderatorinteractions. The British Journal of Social Psychology, 9, 25-38.

Valmadrid, C. T., Klein, R., Moss, S. E., Klein, B. E. K., \& Cruickshanks, K. J. (1999). Alcohol intake and the risk of coronary heart disease mortality in persons with older-onset diabetes mellitus. Journal of the American Medical Association, 282, 239-246.

Van Dalen, W. E., Van Hoof, J. J., Van der Lely, N., \& Rodrigues Pereira, R. (2009). Alcoholintoxicaties bij jongeren in Nederland. Een onderzoek bij kinderafdelingen in Nederlandse ziekenhuizen. Cijfers van 2007, 2008 en 2009 ( $\mathrm{t} / \mathrm{m}$ juni). [Alcohol intoxications in Dutch youth. A research on the Dutch hospital Centers of Pediatrics. Data of 2007, 2008 and 2009 (till June).] Utrecht / Enschede / Delft / Leiden, The Netherlands: 
STAP / University of Twente / Reinier de Graag Groep / Nederlands Signaleringscentrum Kindergeneeskunde (NSCK).

Van de Pol, M., \& Duijser, E. (2003). Meting alcoholgebruik jongeren. Onderzoek onder Nederlandse jongeren $10 \mathrm{t} / \mathrm{m} 15$ jaar. [Measurement of adolescent alcohol use. Investigation among Dutch adolescents between 10 and 15 years old.] Amsterdam, The Netherlands: NIPO.

Van den Berg, M., Van Baal, P. H. M., Tariq, L., Schuit, A. J., De Wit, G., \& Hoogenveen, R. T. (2008). The cost-effectiveness of increasing alcohol taxes: A modelling study. BMC Medicine, 6, art. no. 36.

Van der Laar, M. W., Cruts, A. A. N., Verdurmen, J. E. E., Van Ooyen-Houben, M. M. J., \& Meijer, R. F. (Eds.) (2008). Annual Report NDM 2007 [Netherlands National Drug Monitor]. Utecht, The Netherlands: Trimbos Institute, Netherlands Institute of Mental Health and Addiction.

Van der Vorst, H., Engels, R. C. M. E., Deković, M., Meeus, W., \& Vermulst, A. A. (2007). Alcohol-specific rules, personality and adolescents' alcohol use: A longitudinal person-environment study. Addiction, 102, 1064-1075

Van der Vorst, H., Engels, R. C. M. E., Meeus, W., Deković, M. (2006). The impact of alcohol-specific rules, parental norms about early drinking and parental alcohol use on adolescents' drinking behaviour. Journal of Child Psychology and Psychiatry and Allied Disciplines, 47, 1299-1306.

Van Hoof, J. J., \& Baas, N. (2009). Alcoholverstrekking aan jongeren onder de 16 jaar in de Gooi \& Vechtstreek. Nalevingsonderzoek Gooi \& Vechtstreek. [Alcohol sales to youth under 16 years of age in the Gooi \& Vechtstreek. Compliance study region Gooi \& Vechtstreek.] Enschede, The Netherlands: University of Twente, Department of Technical and Professional Communication.

Van Hoof, J. J., De Jong, M. D. T., \& Van Noordenburg, M. (2008). Prevalence happy hours and its effects. Journal of Public Health Policy, 29, 340-352.

Van Hoof, J. J., Mulder, J., Gosselt, J. F., Van Poppel, D., \& De Jong, M. D. T. (2008a). Alcoholverstrekking aan jongeren onder de 16 jaar in Katwijk. Nalevingsonderzoek + Beleidsadvies [Alcohol sales to youth under 16 years of age in Katwijk. Compliance study + policy advice.] Enschede / Utrecht, The Netherlands: University of Twente, Department of Technical and Professional Communication / STAP.

Van Hoof, J. J., Mulder, J., Gosselt, J. F., Van Poppel, D., \& De Jong, M. D. T. (2008a). Alcoholverstrekking aan jongeren onder de 16 jaar in Katwijk. Nalevingsonderzoek + Beleidsadvies [Alcohol sales to youth under 16 years of age in Katwijk. Compliance study + policy advice.] Enschede / Utrecht, The Netherlands:

University of Twente, Department of Technical and Professional Communication / STAP. 
Van Hoof, J. J., Van der Lely, N., Van Dalen, W. E., \& Rodrigues Pereira, R. (2010). Adolescent alcohol intoxication in the Dutch hospital departments of pediatrics. Journal of Studies on Alcohol and Drugs, 71, 366-372.

Van Hoof, J. J., Van Noordenburg, M., \& De Jong, M. D. T. (2007). Happy hours and other alcohol discounts in cafés: prevalence and effects on underage adolescents. Journal of Public Health Policy, 29, 340352 .

Van Hoof, J. J., Van Poppel, D., Mulder, J., \& Baas, N. (2008b). Alcohol en jongeren in Amersfoort: Beleidsinventarisatie gemeente Amersfoort. [Alcohol and youth in Amersfoort: Local alcohol policy in the municipality of Amersfoort.] Enschede / Utrecht, The Netherlands: University of Twente, Department of Technical and Professional Communication / STAP.

Van Laar, M. W., Cruts, A. A. N., Van Ooyen-Houben, A. A. M., Meijer, R. F., \& Brunt, T. (2010). Nationale Drug Monitor, Jaarbericht 2009. [The Netherlands National Drug Monitor, Anual report 2009]. Utrecht, The Netherlands: WODC, Trimbos-Institute.

Van Laar, M. W., Cruts, A. A. N., Verdurmen, J. E. E., Van Ooyen-Houben, M. M. J., \& Meijer, R. F. (2007). Nationale Drug Monitor, Jaarbericht 2006 [National Illicit Drug Monitor, Annual Report 2006]. Utrecht, The Netherlands: Trimbos Institute.

Van Zundert, R. M. P., Van Der Vorst, H., Vermulst, A. A., \& Engels, R. C. M. E. (2006). Pathways to alcohol use among Dutch students in regular education and education for adolescents with behavioral problems: The role of parental alcohol use, general parenting practices, and alcohol-specific parenting practices. Journal of Family Psychology, 20, 456-467.

Vanable, P. A., Buchbinder, S. P., Douglas Jr., J. M., Judson, F. N., McKirnan, D. J., Bartholow, B. N., \& MacQueen, K. M. (2004). Alcohol use and high-risk sexual behavior among men who have sex with men: The effects of consumption level and partner type. Health Psychology, 23, 525-532.

Varney, S. J., \& Guest, J. F. (2002). The annual societal cost of alcohol misuse in Scotland. PharmacoEconomics, 20, 891-907.

Velleman, R. D. B., Templeton, L. J., \& Copello, A. G. (2005). The role of the family in preventing and intervening with substance use and misuse: A comprehensive review of family interventions, with a focus on young people. Drug and Alcohol Review, 24, 93-109. 
Verdurmen, J., Smit, E., Van Dorsselaer, S., \& Schulten, I. (2008). Ouders over alcohol-, roken-, en drugsspecifieke opvoeding 2007. Utrecht, The Netherlands: Trimbos Institute, Netherlands Institute of Mental Health and Addiction.

Villani, S. (2001). Impact of media on children and adolescents: A 10-year review of the research. Journal of the American Academy of Child and Adolescent Psychiatry, 40, 392-401.

Vitale, S. (2007). A trip to the emergency room. Substance use among emergency room patients in the Netherlands: Prevalence rates and methodological considerations (Unpublished doctoral thesis). Erasmus University, Rotterdam, The Netherlands.

Vogel, R. A. (2002). Alcohol, heart disease, and mortality: A review. Reviews in Cardiovascular Medicine, 3, 7-13.

Wagenaar, A. C. (1983). Alcohol, Young Drivers, and Traffic Accidents: Effects of Minimum Age Laws. Lexington, Mass: Lexington Books.

Wagenaar, A. C., \& Perry, C. L. (1994). Community strategies for the reduction of youth drinking: Theory and application. Journal of Research on Adolescence, 4, 319-345.

Wagenaar, A. C., \& Toomey, T. L. (2002). Effects of minimum drinking age laws: Review and analyses of the literature from 1960 to 2000. Journal of Studies on Alcohol, 63, 206-225.

Wagenaar, A. C., Finnegan, J. R., Wolfson, M., Anstine, P. S., Williams, C. L., \& Perry, C. L. (1993). Where and how adolescents obtain alcohol beverages. Public Health Reports, 108, 459-464.

Wagenaar, A. C., Murray, D. M., \& Toomey, T. L. (2000b). Communities mobilizing for change on alcohol (CMCA): Effects of a randomized trial on arrests and traffic crashes, Addiction, 95, 209-217.

Wagenaar, A. C., Murray, D. M., Gehan, J. P., Wolfson, M., Forster, J. L., Toomey, T. L., Perry, C. L., \& Jones-Webb, R. (2000a). Communities mobilizing for change on alcohol: Outcomes from a randomized community trial. Journal of Studies on Alcohol, 61, 85-94.

Wagenaar, A. C., Toomey, T. L., \& Erickson, D. J. (2005). Preventing youth access to alcohol: Outcomes from a multi-community time series trial. Addiction, 100, 335-345.

Wagenaar, A. C., Toomey, T.L., Murray, D. M., Short, B. J., Wolfson, M., \& Jones-Webb, R. (1995). Sources of alcohol for underage drinkers. Journal of Studies on Alcohol, 57, 325-333. 
Wald, I., Morawski, J., \& Moskalewicz, J. (1986). Alcohol and alcohol problems research 12. Poland. British Journal of Addiction, 81, 729-734.

Wallack, L., Grube, J. W., Madden, P. A., \& Breed, W. (1990). Portrayals of alcohol on prime-time television. Journal of Studies on Alcohol, 51, 428-437.

Wannamethee, S. G., \& Shaper, A. G. (2003). Alcohol, body weight, and weight gain in middle-aged men. American Journal of Clinical Nutrition, 77, 1312-1317.

Wannamethee, S. G., Field, A. E., Colditz, G. A., \& Rimm, E. B. (2004). Alcohol intake and 8-year weight gain in women: A prospective study. Obesity Research, 12, 1386-1396.

Warner, L. A., \& White, H. R. (2003). Longitudinal effects of age at onset and first drinking situations on problem drinking. Substance Use \& Misuse, 38, 1983-2016.

Wechsler, H., Davenport, A., Dowdall, G., Moeykens, B., \& Castillo, S. (1994). Health and behavioral consequences of binge drinking in college: A national survey of students at 140 campuses. Journal of the American Medical Association, 272, 1672-1677.

Wechsler, H., Kuo, M., Lee, H., Dowdall, G. W. (2000). Environmental correlates of underage alcohol use and related problems of college students. American Journal of Preventive Medicine, 19, 24-29.

Wechsler, H., Lee, J. E., Hall, J., Wagenaar, A. C., Lee, H. (2002). Secondhand effects of student alcohol use reported by neighbors of colleges: The role of alcohol outlets. Social Science and Medicine, 55, 425-435.

Wechsler, H., Lee, J. E., Kuo, M., \& Lee, H. (2000). College binge drinking in the 1990s: A continuing problem. Results of the Harvard School of Public Health 1999 College Alcohol Study. Journal of American College Health, 48, 199-210.

Weinberg, L., \& Wyatt, J. P. (2006). Children presenting to hospital with acute alcohol intoxication. Emergency Medicine Journal, 23, 774-776.

Weintraub Austin, E., Chen, M. J., \& Grube, J. W. (2006). How does alcohol advertising influence underage drinking? The role of desirability, identification and scepticism. Journal of Adolescent Health, 38, 376-384.

Wells, J. E., Horwood, L. J., \& Fergusson, B. M. (2004). Drinking patterns in mid-adolescence and outcomes in late adolescence and early adulthood. Addiction, 99, 1529-1541. 
Welte, J. W., \& Barnes, G. M. (1985). Alcohol: The gateway to other drug use among secondary-school students. Journal of Youth and Adolescence, 14, 487-498.

Werch, C. E., Pappas, D. M., Carlson, J. M., Edgemon, P., Sinder, J. A., \& DiClemente, C. C. (2000). Evaluation of a brief alcohol prevention program for urban school youth. American Journal of Health Behavior, 24, 120-131.

White, A. M., \& Swartzwelder, H. S. (2005). Age-related effects of alcohol on memory and memory-related brain function in adolescents and adults. Recent developments in alcoholism: an official publication of the American Medical Society on Alcoholism, the Research Society on Alcoholism, and the National Council on Alcoholism, 17, 161-176.

Whitehead, P. C., Craig, J., Langford, N., MacArthur, C., Stanton, B., \& Ferrence, R. G. (1975). The Legal Minimum Drinking Age and Fatal Motor Vehicle Crashes. The Journal of Legal Studies, 4, 219-239.

Wichstrøm, L. (1998). Alcohol intoxication and school dropout. Drug and Alcohol Review, 17, 413-421.

Wikipedia (2010a). Alcohol. Retreived August 13, 2010, from: http://en.wikipedia.org/wiki/Alcohol

Wikipedia (2010b). Short-term effects of alcohol. Retreived August 13, 2010, from:

http://en.wikipedia.org/wiki/Short-term_effects_of_alcohol

Wilks, J., \& Callan, V. (1984). Similarity of university students' and their parents' attitudes toward alcohol. Journal of Studies on Alcohol, 45, 326-333.

Williams, A. F., Rich, R. F., Zador, P. L., \& Robertson, L. S. (1975). The Legal Minimum Drinking Age and Fatal Motor Vehicle Crashes. The Journal of Legal Studies, 4, 219-239.

Williams, S. S., \& Mulhall, P. F (2005). Where public school students in Illinois get cigarettes and alcohol: Characteristics of minors who use different sources. Prevention Science, 6, 47-57.

Willner, P., Hart, K., Binmore, J., Cavendish, M., \& Dunphy, E. (2000). Alcohol sales to underage adolescents: An unobtrusive observational field study and evaluation of a police intervention. Addiction, 95, $1373-1388$.

Wilson, A. M. (2001). Mystery shopping: Using deception to measure service performance. Psychology and Marketing, 18, 721-734. 
Wilsterman, M. E. F., Dors, N., Sprij, A. J., \& Wit, J. M. (2004). Kliniek en beleid bij jongeren met alcoholintoxicatie op de afdelingen spoedeisende hulp in de regio Den Haag, 1999-2000 [Treatment and policy on youth alcohol intoxication in first aid departments.in the Den Haag region, 1999-2000.] Nederlands Tijdschrift voor de Geneeskunde, 148, 1496-1500.

Windle, M., Spear, L. P., Fuligni, A. J., Angold, A., Brown, J. D., Pine, D., Smith, G. T., Giedd, J., \& Dahl, R. E. (2008). Transitions into underage and problem drinking: Developmental processes and mechanisms between 10 and 15 years of age. Pediatrics, 121 (Suppl. No. 4), S273-S289.

Wolaver, A. M. (2002). Effects of heavy drinking in college on study effort, grade point average, and major choice. Contemporary Economic Policy, 20, 415-428.

Wolfson, M., Toomey, T. L., Murray, D. M., Forster, J. L., Short, B. J., \& Wagenaar, A. C. (1996). Alcohol outlet policies and practices concerning sales to underage people. Addiction, 9, 598-602.

Wood, M. D., Mitchell, R. E., Read, J. P., \& Brand, N. H. (2004). Do Parents Still Matter? Parent and Peer Influences on Alcohol Involvement among Recent High School Graduates. Psychology of Addictive Behaviors, 18, 19-30.

Wood, M. D., Read, J. P., Palfai, T. P., \& Stevenson, J. F. (2001). Social influence processes and college student drinking: The mediational role of alcohol outcome expectancies. Journal of Studies on Alcohol, 62, $32-43$.

Wood, M. D., Sher, K .J., \& Strathman, A. (1996). Alcohol outcome expectancies and alcohol use and problems. Journal of Studies on Alcohol, 57, 283-288.

Wood, M. D., Sher, K. J. \& McGowan, A. K. (2000). Collegiate alcohol involvement and role attainment in early adulthood: Findings from a prospective high-risk study. Journal of Studies on Alcohol, 61, 278-289.

World Health Organization (2004). Global Status Report on Alcohol 2004. Geneva, Switzerland: Department of Mental Health and Substance Abuse.

World Health Organization (n.d.). Retreived from

http://www.who.int/substance_abuse/facts/alcohol/en/index.html

Wyer, R. S., \& Scrull, T. K. (1981). Category accessibility: Some Theoretical and empirical issues concerning the processing of social stimulus information. In: E. T. Higgins, C. P. Herman, \& M. P. Zanna (Eds.), Social cognition: The Ontario symposium. Hillsdale, NJ: Erlbaum. 
Wyllie, A., Zhang, J. F., \& Casswell, S. (1998a). Positive responses to televised beer advertisements associated with drinking and problems reported by 18 to 29-year-olds. Addiction, 93, 749-760.

Wyllie, A., Zhang, J. F., \& Casswell, S. (1998b). Responses to televised alcohol advertisements associated with drinking behaviour of 10-17-year-olds. Addiction, 93, 361-371.

Xie, X., Rehm, J., Single, E., Robson, L., \& Paul, J. (1998). The economic costs of alcohol abuse in Ontario. Pharmacological Research, 37, 241-249.

Yamada, K., Araki, S., Tamura, M., Sakai, I., Takahashi, Y., Kashihara, H., \& Kono, S. (1997). Case-control study of colorectal carcinoma in situ and cancer in relation to cigarette smoking and alcohol use (Japan). Cancer Causes and Control, 8, 780-785.

Yamada, T., Kendix, M., \& Yamada, T. (1996). The impact of alcohol consumption and marijuana use on high school graduation. Health Economics, 5, 77-92.

Yano, K., Rhoads, G. G., \& Kagan, A. (1977). Coffee, alcohol and risk of coronary heart disease among Japanese men living in Hawaii. New England Journal of Medicine, 297, 405-409.

Younis, J., Cooper, J. A., Miller, G. J., Humphries, S. E., \& Talmud, P. J. (2005). Genetic variation in alcohol dehydrogenase $1 \mathrm{C}$ and the beneficial effect of alcohol intake on coronary heart disease risk in the Second Northwick Park Heart Study. Atherosclerosis, 180, 225-232.

Yu, J., \& Williford, W. R. (1992). The age of alcohol onset and alcohol, cigarette, and marijuana use patterns: An analysis of drug use progression of young adults in New York State. International Journal of the Addictions, 27, 1313-1323.

Zador, P. L., Krawchuk, S. A., \& Voas, R. B. (2000). Alcohol-related relative risk of driver fatalities and driver involvement in fatal crashes in relation to driver age and gender: an update using 1996 data. Journal of Studies on Alcohol, 61, 387-395.

Zhu, L., Gorman, D. M., \& Horel, S. (2004). Alcohol outlet density and violence: A geospatial analysis. Alcohol and Alcoholism, 39, 369-375. 


\section{Samenvatting (Summary in Dutch)}

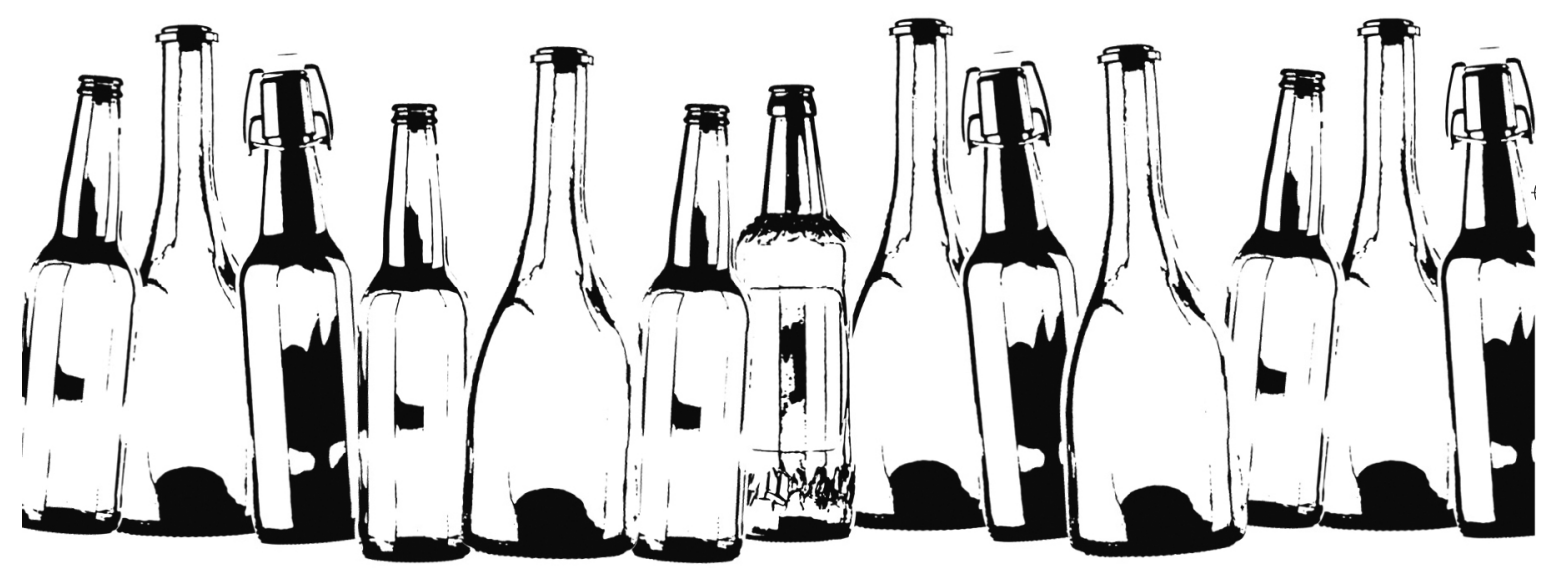


Zestien jaar en nog nooit dronken geweest?

Jongeren en alcoholgebruik, voorspellers en consequenties.

De laatste jaren is er in Nederland veel discussie over het onderwerp 'alcohol en jongeren'. Binnen dit thema heb ik de afgelopen jaren uiteenlopend onderzoek uitgevoerd. De studies maken de omvang en de gevolgen van de alcoholproblematiek inzichtelijker en dragen bij aan een beter begrip van het alcoholgerelateerde gedrag van jongeren. In dit proefschrift is een selectie opgenomen van negen wetenschappelijke artikelen, waarvan er op het moment van drukken zes in wetenschappelijke, peer-reviewed, tijdschriften zijn gepubliceerd.

\section{HOOFDSTUK 1: INLEIDING}

Alcohol is, na koffie en thee, de meest gebruikte drug ter wereld, ook in Nederland. Veel mensen drinken alcohol omdat ze zich daar prettig van gaan voelen, maar het gebruik van alcohol is niet zonder gevaar. Uit wetenschappelijk onderzoek blijkt dat alcohol nadelige gevolgen kan hebben voor de volwassen gebruiker en voor de maatschappij als geheel. Op individueel niveau toont onderzoek aan dat alcoholgebruik kan leiden tot leverziektes zoals levercirrose en leverkanker. Ook in het hele traject dat de alcohol in het lichaam aflegt, kan kanker ontstaan als gevolg van, of versneld groeien door, alcoholgebruik. Dit zijn tumoren aan de lippen, mond, keel, strottenhoofd, slokdarm, maag, dunne darm, dikke darm en endeldarm. Tevens zijn er studies die relaties aantonen tussen alcoholgebruik en overgewicht, borstkanker, bloedziektes en hartproblemen. Er zijn overigens ook studies die laten zien dat matig alcoholgebruik juist goed is voor hart en bloedvaten. Op maatschappelijk niveau is alcoholgebruik gerelateerd aan huiselijk geweld, geweldsincidenten en crimineel gedrag, werkloosheid, ziekenhuisopnames, verkeersongelukken en sterfte. Alcoholgebruik kost de maatschappij op deze manier veel geld. KPMG heeft in 2001 uitgerekend dat alcoholgebruik de Nederlandse maatschappij jaarlijks 2,6 miljard euro kost.

Voor jongeren heeft alcoholgebruik mogelijk nog ernstiger gevolgen. De kans dat iemand naar aanleiding van alcoholgebruik de hierboven beschreven aandoeningen krijgt, neemt toe naarmate iemand langer alcohol drinkt. Wie op jongere leeftijd begint met drinken, heeft meer kans om de genoemde aandoeningen te krijgen. Een ander belangrijk probleem 
is dat alcoholgebruik op jonge leeftijd de ontwikkeling van de hersenen verstoort. In de puberteit verandert het brein van een jongerenbrein naar volwassen hersenen. Uit onderzoek blijkt dat de hersenen van jongeren die alcohol drinken zich niet optimaal ontwikkelen. Onderzoek laat ook zien dat alcoholgebruik op jonge leeftijd een voorspeller is van verslavingen op latere leeftijd. Jongeren die vroeg drinken, drinken later meer en vormen een grotere risicogroep om vroeg of laat drugs te gaan gebruiken. Alcoholgebruik op jonge leeftijd is ook gerelateerd aan onveilig seksueel gedrag, slechtere schoolprestaties en alcoholvergiftiging. Hoofdstukken $\boldsymbol{2}$ en $\mathbf{3}$ van het proefschrift brengen alcoholvergiftigingen onder Nederlandse jongeren in kaart.

Om alcoholgebruik te voorspellen is een conceptueel model opgesteld, gebaseerd op wetenschappelijke theorieën om menselijk gedrag te verklaren. Daadwerkelijk alcoholgebruik door jongeren wordt voorafgegaan door de intentie om alcohol te gebruiken. Deze intentie is gerelateerd aan een aantal psychologische kenmerken en wordt gestimuleerd door de zichtbaarheid van alcohol in de communicatie in de maatschappij. Educatie en voorlichting over alcohol kunnen de intentie juist afremmen. Opvoeding en het alcoholgebruik van vrienden zijn eveneens van invloed op de intentie die een jongere heeft om alcohol te willen gebruiken. Dit aspect noem ik de 'sociale beschikbaarheid van alcohol'. In hoofdstuk 4 wordt een studie besproken die dieper ingaat op alcoholgerelateerde incidenten die jongeren hebben meegemaakt en de betekenis van die incidenten voor hen. In hoofdstuk 5 bespreek ik een onderzoek naar de meningen van ouders over overheidsmaatregelen met betrekking tot alcohol en jongeren. In hoofdstuk 6 komt een onderzoek aan bod naar de invloed van alcoholreclame en de zichtbaarheid van alcohol in soapseries op de intentie om alcohol te gebruiken.

De intentie om alcohol te gaan gebruiken is nog geen daadwerkelijk alcoholgebruik. Tussen de intentie en het daadwerkelijk gebruik zitten drie mogelijke barrières, die ik de 'economische, fysieke en juridische beschikbaarheid van alcohol' noem. Onderzoek toont aan dat lagere prijzen van alcohol leiden tot meer alcoholgebruik en dat hogere prijzen, vaak versleuteld in belasting op alcohol, juist leiden tot een afname van alcoholgebruik. In hoofdstuk 7 bespreek ik een onderzoek dat de Nederlandse praktijk van kortingen op alcohol in de horeca in kaart heeft gebracht en waarin aan jongeren is gevraagd welke invloed deze kortingen hebben op hun alcoholgebruik. Uit wetenschappelijk onderzoek 
blijkt ook een correlatie tussen de fysieke beschikbaarheid van alcohol (het aantal verkooppunten en de openingstijden) en alcoholgebruik. Hieraan verwant is het onderzoek in hoofdstuk 8 gericht op drinken in 'hokken en keten' en de invloed van fysieke beschikbaarheid aldaar op alcoholgebruik. De laatste twee studies gaan over juridische beschikbaarheid. Wetgeving is ook een barrière voor alcoholgebruik door jongeren. Zo zijn in Nederland leeftijdsgrenzen in de wet opgenomen die verbieden om alcohol te verkopen aan jongeren onder de 16 jaar. Sterke drank (meer dan 15\% alcohol) mag niet verkocht worden aan mensen jonger dan 18 jaar. In hoofdstuk 9 laat ik zien in hoeverre deze leeftijdsgrenzen door verkopers van alcohol worden nageleefd en in hoofdstuk 10 wordt een onderzoek besproken dat erop is gericht deze naleving te verbeteren.

\section{HOOFDSTUK 2}

Dit onderzoek heeft tot doel in kaart te brengen hoeveel jongeren met een alcoholvergiftiging (ook alcoholcoma genoemd) worden opgenomen op kinderafdelingen van Nederlandse ziekenhuizen. Ook is in dit onderzoek ingegaan op de kenmerken van deze jongeren, de aard en omstandigheden die hebben geleid tot deze alcoholvergiftiging en de behandeling die de jongeren hebben ontvangen. Om dit in kaart te brengen zijn gegevens verzameld met het systeem van het Nederlands Signalerings Centrum Kindergeneeskunde (NSCK), waarbij de meeste kinderartsen in Nederland zijn aangesloten. Vanaf 1 januari 2007 geldt alcoholvergiftiging als een aandoening die gemeld moet worden in het systeem. Indien kinderartsen een kind behandelen en vaststellen dat er sprake is van in het bloed, volgt een melding en vullen de kinderartsen een vragenlijst in. In 2007 hebben de Nederlandse kinderartsen 297 keer een jongere gemeld met alcohol in het bloed. Het onderzoek laat zien (gebaseerd op 231 ingevulde vragenlijsten) dat verreweg het grootste aandeel $(92 \%)$ van deze jongeren is opgenomen met als voornaamste reden een alcoholvergiftiging. Daarnaast zijn de redenen van opname verkeersongelukken, geweld en zelfmoordpogingen waarbij alcohol is geconsumeerd. Gemiddeld zijn de jongeren net 15 jaar oud en vormen ze een representatieve afspiegeling van de Nederlandse jeugd (evenveel jongens als meisjes, opleidingsniveau, gezinssituatie en achtergrond gelijk aan het Nederlands gemiddelde). Gemiddeld zijn de jongeren meer dan 2 uur (van enkele minuten tot 16 uur coma) buiten bewustzijn en is de bloed-alcohol-concentratie (BAC) $1,84(0,05-4,30)$ wat betekent dat er tussen de 10 en 15 drankjes zijn geconsumeerd. Bijna altijd is alcohol gedronken samen met vrienden en vaak hebben deze vrienden de alcohol 
ook geregeld. Ongeveer een derde van de jongeren geeft aan dat ze zelf de alcohol hadden gekocht in de horeca of supermarkt.

\section{HOOFDSTUK 3}

In dit hoofdstuk wordt een kort artikel gepresenteerd dat de prevalentie van jongeren met een alcoholvergiftiging in 2008 analyseert en vergelijkt met de cijfers uit 2007. Het onderzoek is een voortzetting van het NSCK systeem zoals beschreven in hoofdstuk 2. In 2008 blijkt het aantal jongeren opgenomen in Nederlandse ziekenhuizen met een alcoholgerelateerde reden gestegen te zijn met $13 \%$ ten opzichte van 2007 . Wederom zijn het 'gemiddelde' Nederlandse jongeren die een alcoholvergiftiging krijgen. In 2008 echter is de gemiddelde leeftijd iets lager dan in 2007 (15,0 versus 15,3), is men langer buiten bewustzijn (2,9 uur versus 2,2 uur) en is de BAC iets hoger (1,88 versus 1,84). In 2008 blijkt maar liefst $45 \%$ van de jongeren zelf alcohol gekocht te hebben: 51 jongeren die dit deden waren onder de 16 jaar en hadden dus helemaal geen alcohol verkocht mogen krijgen.

\section{HOOFDSTUK 4}

Om meer zicht te krijgen op de 'sociale beschikbaarheid' van alcohol is een onderzoek opgezet en uitgevoerd waarin interviews zijn gehouden met 45 jongeren van 15 en 16 jaar oud. Deze jongeren is gevraagd naar alcoholgerelateerde incidenten (zowel positief als negatief) die zij hebben meegemaakt. In totaal werden 145 incidenten beschreven, wat neerkomt op gemiddeld 3,2 incidenten per jongere. Vervolgens zijn alle incidenten gecodeerd en zijn de uiteenlopende primaire en secundaire gevolgen in kaart gebracht. Deze gevolgen waren ziek worden (het belangrijkste gevolg bij 19\% van de incidenten), het krijgen van een ongeluk (11\%), flauwvallen (6\%), geheugenverlies (4\%), rare dingen doen (16\%), makkelijker contact maken (10\%), plezier maken $(7 \%)$, ruzie $(12 \%)$, vandalisme (2\%), problemen met slapen (3\%), problemen op werk of school (3\%), problemen met de politie (1\%), zorgen of zelfkritiek (3\%) en kritiek door anderen (2\%). Bij ongeveer de helft van de incidenten waren de ouders niet op de hoogte en als ze wel op de hoogte waren, reageerden ouders meestal niet of niet adequaat. Hoewel veel van de gevolgen negatief waren, beoordeelden de jongeren het beleefde incident als geheel 
positief en leidden negatieve incidenten over het algemeen niet tot een intentie om minder alcohol te gaan drinken.

\section{HOOFDSTUK 5}

Dit hoofdstuk beschrijft een enquête waarin 1550 ouders is gevraagd naar hun steun voor overheidsmaatregelen gericht op een afname van het alcoholgebruik door jongeren. Ouders bleken het in meerderheid eens te zijn met de stelling dat jongeren onder de 16 jaar helemaal niet zouden moeten drinken. Gemiddeld stelden ouders een startleeftijd voor van 15,2 jaar voor een eerste slokje alcohol, 16,3 voor een eerste glas alcohol en 18,0 jaar voor regelmatig alcoholgebruik. Moeders bleken hierin wat strenger te zijn dan vaders. Verder waren ouders ook de mening toegedaan dat het huidige alcoholgebruik door jongeren problematisch is en dat alcoholgebruik door jongeren serieuze gevolgen heeft. Ouders steunden ook de voorgestelde beleidsmaatregelen zoals hogere boetes voor winkels die alcohol verkopen aan jongeren onder de 16 jaar, regionaal en nationaal alcoholbeleid en mixdrankjes uit de supermarkt halen en deze alleen nog verkopen bij slijters. Hoe meer ouders overtuigd waren van het problematische karakter van het huidige alcoholgebruik onder jongeren, hoe sterker zij de genoemde beleidsmaatregelen steunden.

\section{HOOFDSTUK 6}

In dit hoofdstuk wordt een inhoudsanalytisch onderzoek gevolgd door een veldexperiment beschreven. In de inhoudsanalyse zijn 40 afleveringen van de soapserie 'Goede Tijden, Slechte Tijden' geanalyseerd op aanwezigheid van alcohol, waarbij ook gelet is op soort en hoeveelheid alcohol die door de personages gedronken werd, het tijdstip van de dag waarop gedronken werd en de context van het drinken. In totaal zijn 177 alcoholische dranken voorbijgekomen in de 40 afleveringen. Dit komt neer op gemiddeld 4,4 drankjes per aflevering. Bij ongeveer 35\% van de keren dat alcohol werd geconsumeerd betrof het onverantwoord alcoholgebruik, ofwel alcoholmisbruik. Zo werd bijvoorbeeld $4 \%$ van alle drankjes in de ochtend gedronken. Slechts 2 van de 20 personages hebben in de 40 afleveringen niet gedronken, waarmee de proportie geheelonthouders in de serie kleiner was dan in de Nederlandse samenleving. De conclusie kon getrokken worden dat de serie veel (onverantwoord) alcoholgebruik bevatte en de negatieve gevolgen van alcoholgebruik niet in beeld bracht. In een tweede deelstudie, het veldexperiment, is gekeken wat de 
eventuele effecten van deze zichtbaarheid van alcohol kunnen zijn. Hierbij is het onderzoek zo opgezet dat het alcoholgebruik in de serie vergeleken kon worden met de effecten van reguliere alcoholreclame ( $2 * 2$ post-test design). In een school hebben 248 leerlingen van 12 tot en met 18 jaar een van de vier varianten van een video bekeken die bestonden uit drie delen; reclame, soapserie, reclame. In de reclameblokken zaten alcoholreclames of frisdrankreclames en ook van de soapserie waren er twee varianten: met alcoholgebruik (in de helft van de scènes) of zonder alcoholgebruik. Na het zien van de video vulden de leerlingen een vragenlijst in waarin ze onder andere moesten aangeven hoeveel alcohol ze het komend weekend wilden gaan drinken (drinkintentie) en hoe positief ze over alcohol dachten. Jongeren die de alcoholreclames hadden gezien waren positiever over alcohol dan de jongeren die frisdrankreclames hadden gezien. Een verrassend effect werd gevonden met betrekking tot de soapserie. Jongeren die de serie met veel alcoholscènes hadden gezien, bleken negatiever over alcoholgebruik te oordelen dan jongeren die de controleversie zonder alcohol hadden gezien. Dit effect werkte ook door in drinkintenties. Jongeren die een soapserie hadden gezien met veel alcohol gaven aan komend weekend minder te gaan drinken dan jongeren uit de controlegroep. Deze effecten waren zo verrassend dat ik ben teruggegaan naar de jongeren om het onderzoek te evalueren. Uit deze evaluatie bleek dat de jongeren de soapserie wat overdreven 'dronken' vonden en daarom zo negatief reageerden. Dit onderzoek laat zien dat alcoholgebruik in televisieprogramma's effecten kan hebben op jongeren, maar de exacte boodschap bepaalt de richting en de grootte van het effect.

\section{HOOFDSTUK 7}

In dit hoofdstuk is gekeken naar een aspect van de 'economische beschikbaarheid' van alcohol, namelijk prijsacties in de Nederlandse horeca en de effecten daarvan op drinkintenties bij jongeren. Deze studie bestaat uit drie deelstudies. In de eerste deelstudie zijn in vijf grote steden, 209 cafés bezocht en is geobserveerd of er prijsacties waren en wat de kenmerken van die acties waren. In totaal zijn 122 prijsacties aangetroffen in 65 verschillende cafés. Ongeveer $45 \%$ van de prijsacties waren wekelijks terugkerende acties, vaak kortingen op bier (58 keer), cocktails (12 keer), shotjes ( 8 keer), mixjes ( 7 keer) of sterke drank (7 keer). Ook werd 13 keer een happy hour aangetroffen, waarin de klant in dat uur telkens de dubbele hoeveelheid drank krijgt voor de normale prijs (bestel één bier en krijg er één bier gratis bij). In een tweede deelstudie is onderzocht in hoeverre de 
prijsacties ook op het internet aangekondigd werden. Dat bleek vaak het geval. In een derde deelstudie is gekeken wat het effect van dit soort acties zou kunnen zijn op jongeren. Ik heb hiervoor 409 jongeren (van 14 tot en met 17 jaar) in een vragenlijst gevraagd in hoeverre zij zich bij het uitgaan laten leiden door dit soort prijsacties. Van de 409 jongeren gingen er 248 uit naar discotheken, cafés, hokken en keten en andere plaatsen, zoals bioscopen of hangplekken. Van deze jongeren dronken er 172 alcohol. Deze jongeren bezochten gemiddeld acht plaatsen per jaar waar kortingen op alcohol werden gegeven. De reclame hiervoor ging meestal van mond-tot-mond, maar ook $20 \%$ van de jongeren gaf aan via het internet te weten waar deze acties gehouden worden. Jongeren zeiden hun specifieke keuze voor een café of disco niet af te stemmen op een prijskorting. Jongeren gaven naar eigen zeggen evenveel geld uit als er kortingen waren, maar ze dronken dan wel meer. Uit dit onderzoek blijkt dat er - ook voor de eigenaar van een horecagelegenheid - niet veel positieve gevolgen zitten aan prijskortingen. Jongeren komen niet speciaal naar de gelegenheid toe. Ze geven ook niet meer geld uit. Ze drinken wel meer, maar dat heeft alleen negatieve gevolgen voor de jongeren zelf, alsmede voor de eigenaar van de horecagelegenheid.

\section{HOOFDSTUK 8}

Dit hoofdstuk beschrijft een driedelig onderzoek naar de zogenaamde 'hokken en keten' (vanaf nu 'keten' genoemd). In het eerste deelonderzoek zijn 51 keten bezocht en zijn de kenmerken ervan in kaart gebracht. Uit dit onderzoek blijkt dat er niet echt een generieke omschrijving van keten te maken is. In sommige keten zitten jongeren spelletjes te doen en wordt frisdrank gedronken. Andere keten lijken bijna professionele cafés, compleet met bar en tap waar betaald wordt met muntjes. Met betrekking tot alcohol is er wel een overeenkomstig element, alcohol is goedkoper dan in de reguliere horeca. Dat komt omdat de alcohol in de supermarkt wordt gekocht (soms met hulp van ouders). In een tweede studie zijn 442 keet websites bezocht en zijn 390 werkende websites inhoudsanalytisch onderzocht. Hieruit komt een duidelijker beeld naar voren van de karakteristieken van deze keten en van de bezoekers. Ongeveer de helft van de keten is open in het weekend, een kwart alleen op vrijdag, de overige keten zowel in het weekend als op weekdagen. Activiteiten die ondernomen worden, zijn spelletjes doen, televisie kijken, films kijken, verzamelen en indrinken voor het uitgaan en feestjes organiseren. Veelal zijn de ouders van een keetbezoeker eigenaar van de keet (oude caravan, schuur, fabriekshal) en/of de 
grond waarop deze staat. Uit de studie van de websites blijkt dat alcohol ook op de websites expliciet aanwezig is. Op bijna 50 websites staan logo's van alcoholmerken en op veel foto's is alcoholgebruik te zien. Ook staan er teksten van feestjes op de website om 'jezelf van de planeet te drinken' en worden er statistieken bijgehouden wie er hoe vaak heeft gekotst. Eén keet noemt zichzelf 'de beste plek om jezelf in coma te drinken'. In een laatste deel van dit hoofdstuk beschrijf ik een derde studie waarin 1400 jongeren van 15 tot en met 17 jaar zijn bevraagd over drinkgedrag en keetbezoek. Uit dit onderzoek blijkt dat keetbezoekers meer drinken dan jongeren die geen keten bezoeken.

\section{HOOFDSTUK 9}

In dit hoofdstuk komt de naleving van de leeftijdsgrenzen voor alcoholhoudende drank aan bod. Deze naleving maakt deel uit van de 'juridische beschikbaarheid' van alcohol. Voor het eerst is een grootschalig mysteryshop onderzoek opgezet en uitgevoerd in Nederland. Omdat er grote verschillen blijken te zitten tussen verklaringen van alcoholverkopers ("wij verkopen niet of zelfden alcohol aan jongeren onder de 16') en jongeren zelf ('het is buitengewoon makkelijk om alcohol te kopen') is een nieuwe methode ontwikkeld. In dit onderzoek zijn 15-jarige en 17-jarige jongeren getraind om alcohol te kopen, precies zoals jongeren van die leeftijd dat in de praktijk ook zouden doen. De 15-jarigen hebben 150 supermarkten en 75 slijterijen bezocht in drie regio's in Nederland en hebben geprobeerd om daar zwakalcoholische drank te kopen (leeftijdsgrens 16). De 17-jarigen hebben 75 slijterijen bezocht en hebben geprobeerd om daar sterke drank te kopen (leeftijdsgrens 18). Voor de bezoeken zijn de jongeren getraind en tijdens de bezoeken hielden de jongeren zich aan een script. In de supermarkten kregen de jongeren in $88 \%$ van de pogingen alcohol mee. In slijterijen kregen de 15-jarigen in 77\% van de pogingen zwakalcoholische drank mee. De 17-jarigen die sterkte drank probeerden te kopen slaagden in $89 \%$ van de gevallen. In slechts 71 van de 300 gevallen werd aan de té jonge klant gevraagd om zich te legitimeren. Nadat de jongere zijn / haar echte identiteitskaart had laten zien (waaraan is af te leiden dat iemand te jong is) kregen ze in 39\% toch nog alcohol verkocht. Dit onderzoek laat zien dat de rationale achter dit aspect van juridische beschikbaarheid goed kan zijn., maar dat de praktijk de effectiviteit van dit soort maatregelen bepaalt. Tijdens dit onderzoek (uitgevoerd in 2006) functioneerde die dagelijkse praktijk van correcte naleving slechts in $14 \%$ van de gevallen. 


\section{HOOFDSTUK 10}

Dit laatste onderzoek is opgezet en uitgevoerd om na te gaan of naleving met betrekking tot alcoholverkoop aan minderjarigen verbeterd kan worden. In dit onderzoek is een veldexperiment ontworpen met twee rondes van mysteryshoppen van alcohol met daar tussenin een interventie. Op dezelfde manier als beschreven in hoofdstuk 9 zijn in de eerste ronde van het mysteryshoponderzoek 146 verkooppunten bezocht waar door 15-jarige jongeren is geprobeerd om alcohol te kopen. De naleving bij deze bezoeken bleek 18,5\% te zijn (27 keer kregen de jongeren geen alcohol mee). Voor de interventie is de groep van 146 verkooppunten gesplitst in een experimentele groep $(n=72)$ en in een controlegroep $(n=74)$, beide met nagenoeg gelijk nalevingsniveau $(18,1 \%$ en $18,9 \%)$. De verkooppunten in de experimentele groep hebben allemaal een brief gekregen waarin het resultaat van het mysteryshop onderzoek werd gecommuniceerd (13 keer een positieve brief bij correcte naleving en 59 keer een negatieve brief bij alcoholverkoop). Na de brief hebben we alle 146 verkooppunten opnieuw bezocht en konden we bij 138 verkooppunten een tweede aankooppoging doen (8 verkooppunten waren gesloten). In de experimentele groep bleek de naleving na de brief significant gestegen naar 32,4\%. In de controlegroep (die dus geen interventie hadden ontvangen) bleef de naleving onveranderd. $\mathrm{Na}$ deze tweede ronde van mysteryshoppen is de brief ook gestuurd aan de verkooppunten in de controlegroep. Hierna zijn alle verkooppunten gebeld en is met 106 eigenaars een interview afgenomen. In dat interview is onderzocht hoe de interventiebrief behandeld is in de organisatie. In het algemeen geven de winkeliers aan dat ze de brief hebben ontvangen en dat ze de inhoud hebben gedeeld met de verkopers op de winkelvloer. Hoe serieuzer met de brief (en dus met het onderwerp) is omgegaan hoe groter de kans op naleving (alleen de experimentele groep).

\section{ALGEMENE CONCLUSIES EN TOEKOMSTIG ONDERZOEK}

Wanneer de studies in dit proefschrift als geheel worden beschouwd, kan een aantal algemene conclusies worden getrokken.

- Complexe werkelijkheid: veel onderzoeken die ik heb gelezen (en zelf heb uitgevoerd) onderzoeken een specifiek element van de werkelijkheid, bijvoorbeeld 'Wat is de relatie tussen alcoholreclames bekijken en drinkgedrag door jongeren?'. Onderzoek kan aantonen dat er bepaalde effecten zijn of dat bepaalde effecten 
uitblijven. De vertaling naar de praktijk is echter weerbarstig. Stel dat zou worden aangetoond dat alcoholreclame de intentie om alcohol te consumeren verhoogt, dan blijven er nog allerlei barrières zitten tussen intentie en consumptie. Als de overheid bijvoorbeeld alcoholreclames zou verbieden dan neemt niet per definitie de alcoholconsumptie af. De vraag is - en dat geldt voor alle elementen in de complexe realiteit - wat de bijdrage is van één element. Als alcoholproducenten als reactie op een reclameverbod bijvoorbeeld de prijzen van alcohol lager maken (om zo mensen te stimuleren het product te kopen), dan zou een reclameverbod wel eens averechts kunnen werken omdat een prijsprikkel ook van invloed op jongeren is. In toekomstig onderzoek zullen we ons ook moeten richten op het onderlinge gewicht van bepaalde factoren.

- Gevolgen van alcoholgebruik: in hoofdstuk 2 en 3 worden onderzoeken gepresenteerd die inventariseren hoeveel jongeren met de alcoholvergiftiging belanden op de kinderafdeling van de Nederlandse ziekenhuizen. De aantallen die deze onderzoeken laten zien zijn een onderschatting van het daadwerkelijke aantal jongeren dat per jaar een alcoholvergiftiging oploopt. In de eerste plaats omdat niet alle jongeren met een vergiftiging in het ziekenhuis komen, maar ook omdat niet alle jongeren worden doorgestuurd naar een kinderarts. Het kan ook zijn dat de kinderarts de reden van opname niet herkent als alcoholgerelateerd en ten slotte doen niet alle kinderartsen in Nederland mee met het systeem. Als wordt gekeken naar de alcoholincidenten die de jongeren hebben verteld in hoofdstuk 4 dan zou het aantal alcohol intoxicaties jaarlijks wel eens veel groter kunnen zijn. In dat onderzoek namelijk was een aanzienlijk deel van de gevolgen van de incidenten een alcoholvergiftiging of ziekte.

- Beschikbaarheid: zoals ik heb laten zien in hoofdstuk 7 is economische beschikbaarheid (prijsacties) een voorspeller voor (de intentie) tot alcoholgebruik. Ook de fysieke beschikbaarheid in hokken en keten (hoofdstuk 8) is van belang. In mijn opinie valt er op het terrein van de juridische beschikbaarheid (naleving leeftijdsgrenzen) het makkelijkst veel winst te boeken. De afgelopen jaren heeft de Universiteit Twente voor meer dan 100 Nederlandse gemeenten nalevingsonderzoeken uitgevoerd. De hoogste naleving die we hebben vastgesteld is $50 \%$. Ondanks allerlei interventies en acties vanuit de branche lukt het niet om meer dan 1 van de 2 jongeren geen alcohol te verkopen. Het is des te schrijnender 
dat ongeveer een derde van de jongeren die met een alcoholvergiftiging in het ziekenhuis is behandeld de alcohol zelf heeft gekocht in supermarkten of horeca. Een horecamedewerker zou geen alcohol moeten verkopen aan jongeren die al behoorlijk gedronken hebben. In 2008 hebben bovendien 51 jongeren van onder de 16 zelf alcohol gekocht. Het wordt, mijns inziens, tijd dat er in Nederland beter wordt nageleefd.

- Houding: in Nederland heerst een dubbele houding jegens alcohol en alcoholgebruik. Het onderzoek in hoofdstuk 4 roept de vraag op hoe het kan dat jongeren die ernstige alcohol incidenten hebben meegemaakt deze incidenten veelal positief duiden en zelden minder gaan drinken. Ook de houding van ouders is soms niet uniform; ouders steunen in grote mate een overheid die met striktere maatregelen komt, terwijl diezelfde ouders hokken en keten inrichten waar hun kinderen en vriendjes alcohol consumeren, ook op jonge leeftijd.

In toekomstig onderzoek zal ik dieper ingaan op de 'wereld van jongeren' en op de 'wereld van ouders'. Wat drijft jongeren nu echt om zich zo te gedragen? En hoe kan het dat ouders zulke uiteenlopende houdingen lijken te hebben? Ouders steunen allerlei maatregelen om de problematiek van jongeren en alcoholgebruik in te perken, maar op zaterdag worden aanhangers vol bier gekocht voor in de keet. Ook zal ik mij onverminderd blijven richten op de naleving van de leeftijdsgrenzen. Hierbij ga ik ook dieper in op het perspectief van de jongeren. De zwakste winkel in de keten bepaalt immers de naleving, als jongeren daarvan op de hoogte zijn. Tot slot zal ik me richten op de totstandkoming van alcoholbeleid op Nederlandse en Europese schaal. Hierbij ben ik met name geïnteresseerd in de invloed van (politieke) personen en organisaties. 

